\title{
Collaborative Governance and Unemployment in New Zealand: Two Case Studies
}

\author{
by \\ Greta Anne Gordon \\ 300062933 \\ A thesis submitted to Victoria University of Wellington in fulfilment of the \\ requirements for the degree of Doctor of Government (DGov)
}

School of Government

Victoria University of Wellington

Supervisors: Dr Chris Eichbaum \& Professor Michael Macaulay 


\section{Abstract}

Long-term unemployment is a significant problem for Governments and communities. It demands innovative and agile policy responses, including those that involve community partners. However, research has shown that for the New Zealand Government to achieve collaboration, deep change in institutional arrangements is required. This thesis investigates collaborative governance as an alternative paradigm, drawing on the Community Employment Group and Mayors Taskforce for Jobs initiatives as case studies. It explores the leadership styles and behaviours, participatory processes and accountability mechanisms that enabled ongoing and iterative community solving to address long-term unemployment.

Analysis of the case studies found that: the leaders wrote their own rulebooks, and as such, accountability and participatory mechanisms were inextricably intertwined with the personality, skills, competencies and preferences of the leader; the transparency of accountability arrangements were critical to the survival of the initiatives, and the informal mechanisms were at least as important as formal mechanisms; and that participation can be a much looser arrangement than that suggested in the collaborative governance literature. These cases showed that there is little room for complacency in collaborative governance. Tenacious and visionary leadership, formal and informal accountability mechanisms that give legitimacy to the initiative and frequent, genuine and open communication by all parties combine as key factors to sustain ongoing and iterative problem solving to address long-term unemployment. 


\section{Attestation of authorship}

I hereby declare that this submission:

- is my own work

- has been prepared specifically for the Doctorate of Government degree while under supervision at Victoria University of Wellington

- does not duplicate work from a thesis, dissertation or research paper that I have previously presented for another degree or diploma at this university

- clearly references and acknowledges the ideas and work of others, whether published or unpublished

- clearly acknowledges all assistance I have received in my research.

\section{Ethics approval}

The research study addressed within this thesis was approved by the Human Ethics Committee (Pipitea) of Victoria University of Wellington on 6 April 2014.

\section{Length of thesis}

I hereby certify that the length of this thesis, including footnotes, endnotes, essential appendices and bibliography, falls within the limit of 100,000 words. The word count for this thesis is: 71,128 . 


\section{Acknowledgments}

My heartfelt thanks to Dr Chris Eichbaum who guided me firstly to the Community Employment Group and Mayors Taskforce for Jobs, and then through the research and writing. Chris, without your patience and belief in me, I would never have made it this far.

To Professor Michael Macaulay, for your attention to detail, endless questions and enthusiasm for my research, thank you.

To Associate Professor Valentina Dinica, for your support as I began my journey into independent research, thank you.

My thanks to the Ministry of Social Development and Housing New Zealand Corporation (now Kāinga Ora), for paying fees in my first years and for allowing me time off to attend classes.

To all the people who gave their time to me, to talk about the wonderful initiatives that were the Mayors Taskforce for Jobs and the Community Employment Group. Your passion for the work came through in every interview: you inspired and sustained me along this long journey. And for that I thank you.

To Rosalie Chamberlain, editor extraordinaire and friend, thank you for your feedback, questions and comments.

And finally, to Liliane, Dad, Moira, Nina and Barbara. Your encouragement and pride in my endeavours meant I never gave up. This one's for us all. 


\section{Contents}

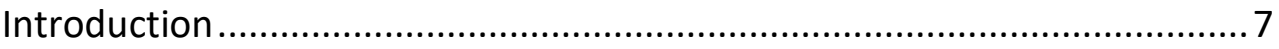

Chapter 1: Unemployment: the problem, consequences and solutions .... 14

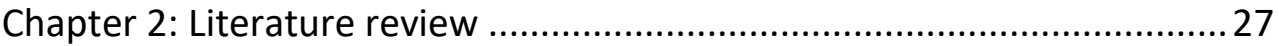

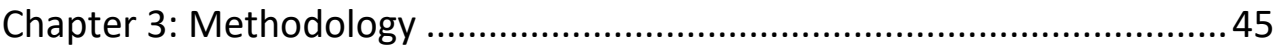

Chapter 4: The Community Employment Group Case Study - Part 1........ 59

Chapter 5: The Community Employment Group Case Study - Part 2.........93

Chapter 6: The Mayors Taskforce for Jobs Case Study - Part 1 ............... 123

Chapter 7: The Mayors Taskforce for Jobs Case Study - Part 2 ...............154

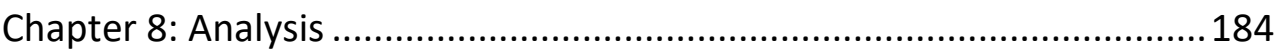

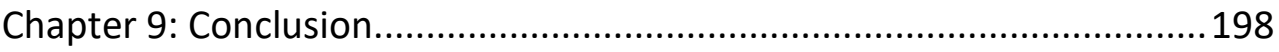

Appendix 1: Mayors Taskforce for Jobs / Central Government MOU ...... 212

Appendix 2: Mayors Taskforce for Jobs - Other Agreements.................. 246

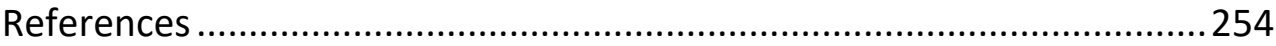




\section{Figures}

Figure 1: Unemployment in New Zealand 1986-2018

Figure 2: Unemployment in New Zealand by ethnic group

Figure 3: Youth unemployment in New Zealand

Figure 4: Regional unemployment rates 17

Figure 5: The self-perpetuating cycle of unemployment .18

Figure 6: Wellbeing Indicators by Labour Force Status 19

Figure 7: Health status by labour force status 19

Figure 8: Exacerbation of the self-perpetuating cycle .21

Figure 9: Collaborative governance continuum 32

Figure 10: Ansell and Gash model of collaborative governance .34

Figure 11: Case studies compared 50

Figure 12: Analytical framework .52

Figure 13: Community Employment Group structure. .65

Figure 14: Community Employment Group Funding ..............................66

Figure 16: Structure for the Mayors Taskforce for Jobs: 2003. .137

Figure 17: Local Government at the Cabinet Table. 142

Figure 18: NZ Government press releases: Mayors Taskforce for Jobs ....170

Figure 19: Signing of the Taskforce 2018 MOU 180

Figure 20: Four Dimensions of Accountability .185 


\section{Introduction}

\section{Context for the research}

Unemployment is one of the most significant problems governments face. Economists identify three general types of unemployment: structural, cyclical and frictional. When unemployment is structural (rather than cyclical or frictional) and the potential labour force does not have the capability to participate, a major risk for governments is that a proportion of the community will become unemployed for a long time. Left unchecked, long-term unemployment can become generational, with the children and grandchildren understanding unemployment as a way of life and having limited expectations of employment.

In New Zealand, unemployment and long-term unemployment affects people differently - Māori and Pacific people are more likely than New Zealand Europeans to be unemployed, young people are more likely to be unemployed than older people and people in some regions are more likely to be unemployed than those living in other regions. Long-term unemployment affects a significant proportion of the population and is prevalent in some communities.

The effects of long-term unemployment reach far wider than the individual or the need for government to provide income support. The symptoms of unemployment can combine into a self-perpetuating cycle of low income, substandard housing, health and behavioural problems, which lead to judicial problems and back to joblessness and low income. These problems cost government in financial terms and undermine the potential of individuals, communities and the New Zealand society.

As such, the complex and wicked problem of long-term unemployment is resistant to easy solutions. A macro-solution (such as monetary and fiscal policy adjustments) can only be partial at best, as it will fail to consider the influence of social factors and the irrationality of human behaviour. 
In the 2020s, the global pandemic is likely to result in higher unemployment in New Zealand than has been seen for some time. This indicates a case for policy solutions that are grounded in local labour markets, enable communities to participate in their design and implementation, and are able to be sustained over a period of time.

In New Zealand, the underlying paradigm for the public sector is based on agency theory, an economic theory that lends itself to markets and hierarchies. However, the systems, processes and practices that arise in hierarchies preclude effective collaboration and Dovey (2003, p. 87) found that to achieve collaboration in the New Zealand public sector, deep change in accountability and institutional arrangements, as well as in the culture was required. If markets and hierarchies are unable to enable collaboration, an answer may be found in different institutional arrangements.

\section{Research questions}

The over-arching research question is: What institutional arrangements enable iterative and ongoing community problem solving to address longterm unemployment?

A review of the literature identified collaborative governance as an alternative to agency theory. In this paradigm, collaboration is integral to the way of working. Collaboration responds to the need for partnerships in governing and managing public programmes, especially those designed to address wicked problems. Collaborative governance is a growing field and has been used by governments throughout the world to address a wide range of problems.

My definition of governance draws from Pierre and Peters (2005, pp. 3-5), where governance is represented as the combination of four activities:

- articulating a common set of priorities for society;

- achieving coherence, where the goals are consistent and coordinated;

- steering, where society is steered to achieve the goals; and 
- establishing accountability, or finding some means of holding actors accountable for their actions.

Collectively, these activities set the environment in which collaboration and partnerships might exist. When seeking the institutional arrangements that enable ongoing and iterative problem solving, two components are evident: the leader that will articulate common priorities, ensure coherence and steer towards goals, and articulate the accountability arrangements necessary when actors are not arranged in hierarchical order.

A third component emerges through the fact that actors will come from a diverse range of state and civil society organisations to participate. The research questions for this thesis are:

- What accountability arrangements, tools or methods can allow the Government to partner meaningfully and well with New Zealand communities to address long-term unemployment?

- What public sector leadership behaviours and competencies will facilitate collaboration between government and communities to address long-term unemployment?

- What types of participatory processes will enable communities and government organisations to engage in partnerships that address longterm unemployment?

Ansell \& Gash (2008, p. 544) have developed a definition and model of collaborative governance, which provides a useful theoretical framework and starting point for the research. The definition is:

'A governing arrangement where one or more public agencies directly engage non-state stakeholders in a collective decision-making process that is formal, consensus-oriented, and deliberative and that aims to make or implement public policy or manage public programmes or assets.'

This definition formalised the need for non-state stakeholders as actors in collaborative governance and focused on decision-making as the core 
process. The definition includes forums for public deliberation and multistakeholder dispute resolution in one-off cases alongside community problem solving. I have adopted the Ansell \& Gash definition for the purpose of this thesis but take a narrower view and exclude those interactions that do not involve ongoing or sustained engagement.

The Ansell \& Gash model is also useful for this thesis, as it places accountability arrangements, leadership behaviours and competencies, and participatory processes in context as important components of collaborative governance. However, as a contingency model, the Ansell \& Gash model does not provide guidance on the nature and requirements of those components to be successful.

Literature on collaborative governance, while wide-ranging, leaves room to add nuance on:

- the accountability mechanisms that might be viewed as legitimate and can stand alongside the traditional, hierarchical systems

- the types of leadership behaviours and competencies that will ensure sustainable engagement with communities so as to address the wicked problem of long-term unemployment

- how practically to engage with stakeholders, especially when groups are resident in far-flung communities or have limited ability to participate, as is likely when the problem is long-term unemployment.

\section{Research methodology and contribution to knowledge}

Assessment of the New Zealand Government's attempts to address longterm unemployment from 1991 identified two initiatives where the Government worked in partnership with communities. These initiatives, the Community Employment Group and Mayors Taskforce for Jobs were sustained over long periods of time, through successive Governments and had some success in addressing long-term unemployment within communities. 
A case study approach enabled the collection of a rich dataset that allowed analysis of the complex interplay between context and case, leadership behaviours and accountability arrangements, and the structural challenges of collaborative governance.

This result of this research has significance in three areas:

- It includes richly detailed stories of the life cycles of two initiatives where communities worked in collaboration with the New Zealand Government. This enables an understanding of not only what happened throughout their times, but also why it happened. These two stories have not been told before and contribute to the academic discourse on how public sector initiatives work in practice.

- It adds nuance to the literature on collaborative governance in areas where it is light: accountability mechanisms, leadership behaviours and competencies, and participatory processes. It has also identified some areas worthy of further research, including the use of the narrative in accountability, and whether there is a relationship between the scale and scope of a collaborative governance initiative and its longevity.

- It provides guidance that might help the New Zealand Government (and others) to work more closely with communities over the following years, to address the coming wave of unemployment and potential reformation of economies in the wake of COVID-19.

\section{Organisation of the research}

This thesis has nine chapters.

Chapter 1 discusses the real-world problem. It establishes unemployment as a wicked problem that affects different people differently, with no easy solution. While solutions to unemployment have traditionally been the focus of economists, such solutions can struggle to address a problem as wide-ranging and multi-faceted as long-term unemployment in New Zealand communities. The chapter ends with a discussion of collaboration and partnerships as an alternative to the economic lens and identifies the main research question for this thesis. 
Chapter 2 focuses on the research problem and provides a review of the literature. It notes that collaborative governance has implications for accountability and accountability arrangements; it relies on leaders within the Government to engage and on processes that enable community engagement. This chapter identifies the space in the literature for the significant contribution that this research brings.

Chapter 3 explains the rationale for selecting case study methodology and for selecting the two initiatives as the cases to be studied. It details the units of analysis, data collection procedures, data management and how the case studies were developed. The final section in this chapter describes how the analytical frame was applied, the results of which are found in Chapter 8.

Chapters 4-7 set out the case studies in rich detail. These case studies are expressed in separate chronological accounts, enabling the reader to obtain a comprehensive understanding of how the initiatives operated in practice. Each case study is presented in two chapters: the first detailing the origins, commencement and consolidation of the initiative; then the second chapter describing a downward trajectory. In the first case, the Community Employment Group (Chapters 4-5) - the story ends with the cancellation of the initiative. In the second case, the Mayors Taskforce for Jobs (Chapters 6-7) - while the group still exists in 2021, the initiative has morphed into something quite different.

Chapter 8 addresses the research questions, using the analytical frame described in Chapter 3, the results of the literature review and the case studies themselves. The three sections in Chapter 8 focus on accountability, leadership and participation. Each section starts with a recap of the relevant literature, a summary of the applicable material in each case study, then a concluding section that brings the analysis together. Chapter 8 forms the basis of the conclusions, which are presented in Chapter 9. 
Chapter 9 is the final chapter in this thesis. It concludes that collaborative governance has been a useful lens through which to consider the case studies. It provides answers to each of the research questions and recommendations to practitioners and academics on:

- the arrangements, tools and mechanisms for accountability

- the leadership behaviours and competencies required

- the participatory processes needed to deliver a successful collaborative governance initiative.

As such, Chapter 9 provides guidance to government and contributes materially to scholarship in the collaborative governance arena, by highlighting gaps in existing literature and the scope for further development. 


\section{Chapter 1: Unemployment: the problem, consequences}

\section{and solutions}

\section{Introduction to Chapter 1}

The employment rate is a vital measure of a nation's health as it denotes how well its economy is working. While a high employment rate is viewed as a positive indicator, a high unemployment rate can indicate the economy is failing and that hardship will follow for the members of that nation. Economists identify three general types of unemployment - some more harmful than others:

- Structural unemployment, where the potential labour force does not have the capability to participate. This is the most concerning type of unemployment, as it can lead to long-term unemployment and has multiple negative implications for individuals, their families, communities and society.

- Cyclical unemployment, reflecting the ups and downs of the market and where there is more capacity than jobs. This type of unemployment can be challenging for short periods of time. However, if it persists, it can become embedded as skills, knowledge and confidence are lost. The result of these lost skills, knowledge and confidence is a mismatch between the potential labour force and the available jobs and structural unemployment.

- Frictional unemployment, the gap between one job and another. This type of unemployment is the least harmful, as it represents the short period of unemployment that occurs after one job has finished, and another one starts.

This chapter focuses on long-term unemployment, describing the challenges it brings and the consequences on individuals, families, communities and societies. As a wicked problem, there is no one solution and no nation has been able to ensure an absence of long-term unemployment. The final part of this chapter considers the solutions for 
regional unemployment problems, noting the scarcity of comprehensive policy solutions that operate at a regional or local level and the corresponding scarcity of academic literature.

\section{Long term unemployment as a wicked problem}

In September 1991, New Zealand's unemployment rate reached 11.4 per cent, the highest measured by Statistics New Zealand's Household Labour Force survey up until that date (see

http://archive.stats.govt.nz/infoshare/). The phenomenon was global: around the world, governments were faced with high rates of unemployment and struggling economies. By May 1993, 100,000 New Zealanders had been out of work for six months or more (Harris, 1993). In 1992, the number of people unemployed for more than one year had reached 54,100 (Figure 1).

Figure 1: Unemployment in New Zealand 1986-2018

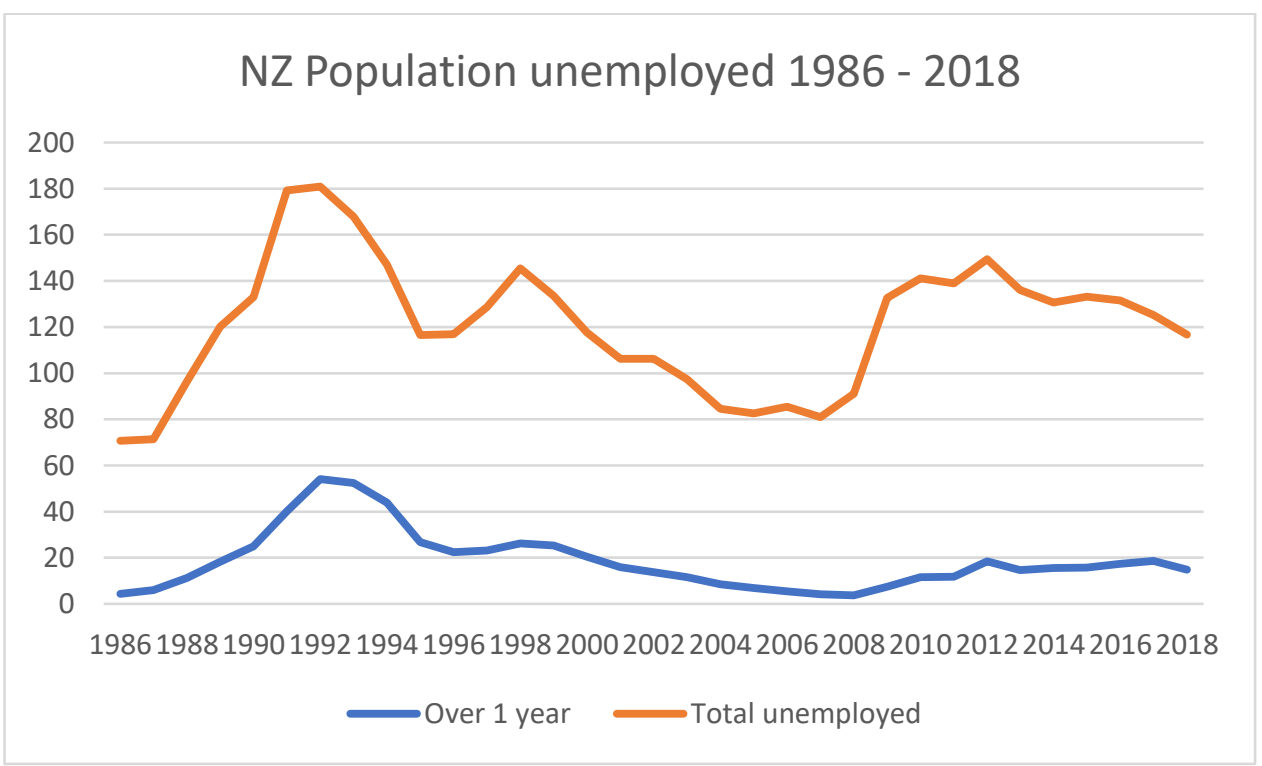

Source: Infoshare (http://archive.stats.govt.nz/infoshare/) Statistics New Zealand

While the unemployment rate in September 1991 has not been reached since, some groups of people in the New Zealand population continue to be more likely to be unemployed than others. Unemployment affects Māori and Pacific people more than people of other ethnicities, some regions more than others and young people more than older people. 
Where groups of people are more likely to be unemployed (and this problem persists), the risk is that the problem is structural rather than cyclical. Indeed, in 2005, half of New Zealand's business owners identified a lack of skilled labour as their most significant barrier to growth (Spoonley, 2008, p. 21), and this remains the case.

Figure 2 sets out the unemployment rates between 2008 and $2018^{1}$, by main ethnic group. For the last decade, Māori and Pacific people have seen significantly higher unemployment rates than Asian or European people: in 2013, the rate for Pacific peoples was 15 per cent of the labour force unemployed; for Māori it was closer to 13 per cent, Asian around 6 per cent and European around 5 per cent. This indicates a persistent and significant gap based on ethnicity.

Figure 2: Unemployment in New Zealand by ethnic group

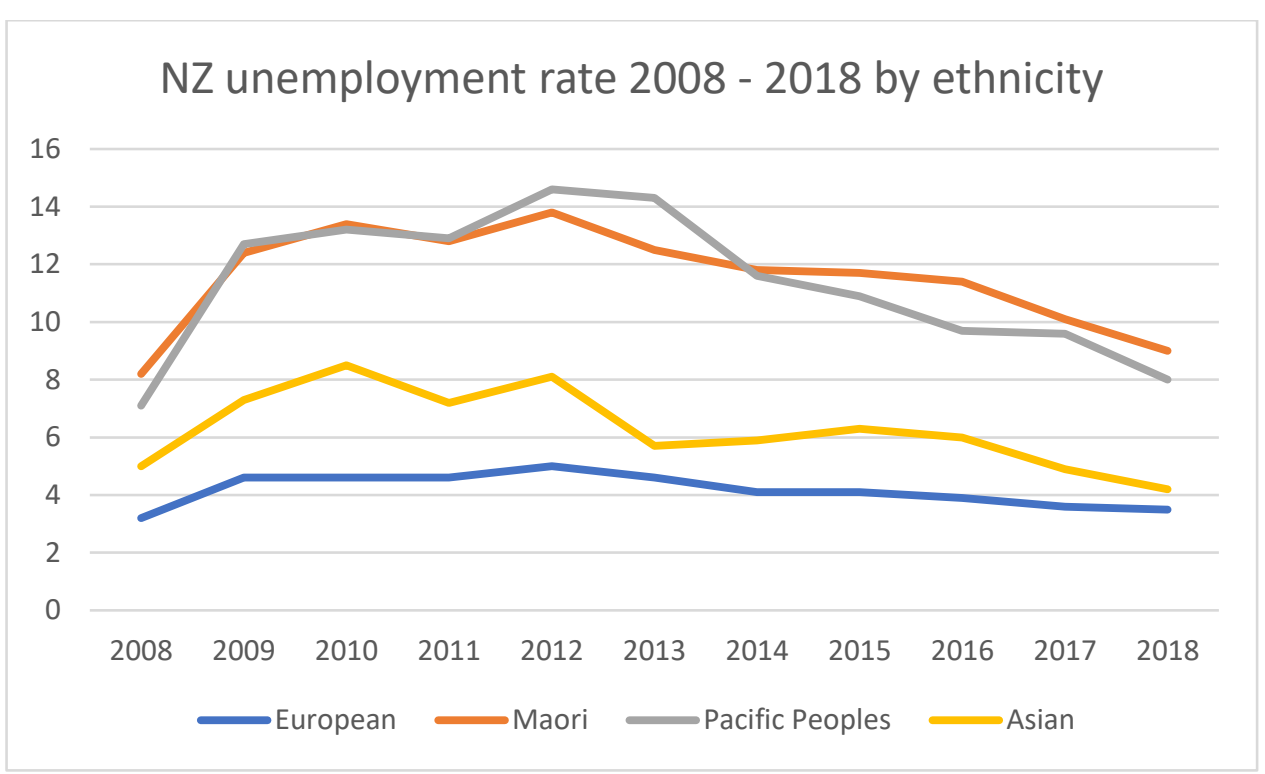

Source: Infoshare (http://archive.stats.govt.nz/infoshare/) Statistics New Zealand Unemployment is not evenly distributed across age groups and young people tend to have higher unemployment rates than older people (Figure 3). From 2008 until 2018, although a downward trend is evident, more than 10 per cent of young people aged between 15 and 24 years were not in employment, education or training.

\footnotetext{
${ }^{1}$ Unemployment rates by ethnicity are not available prior to 2008
} 


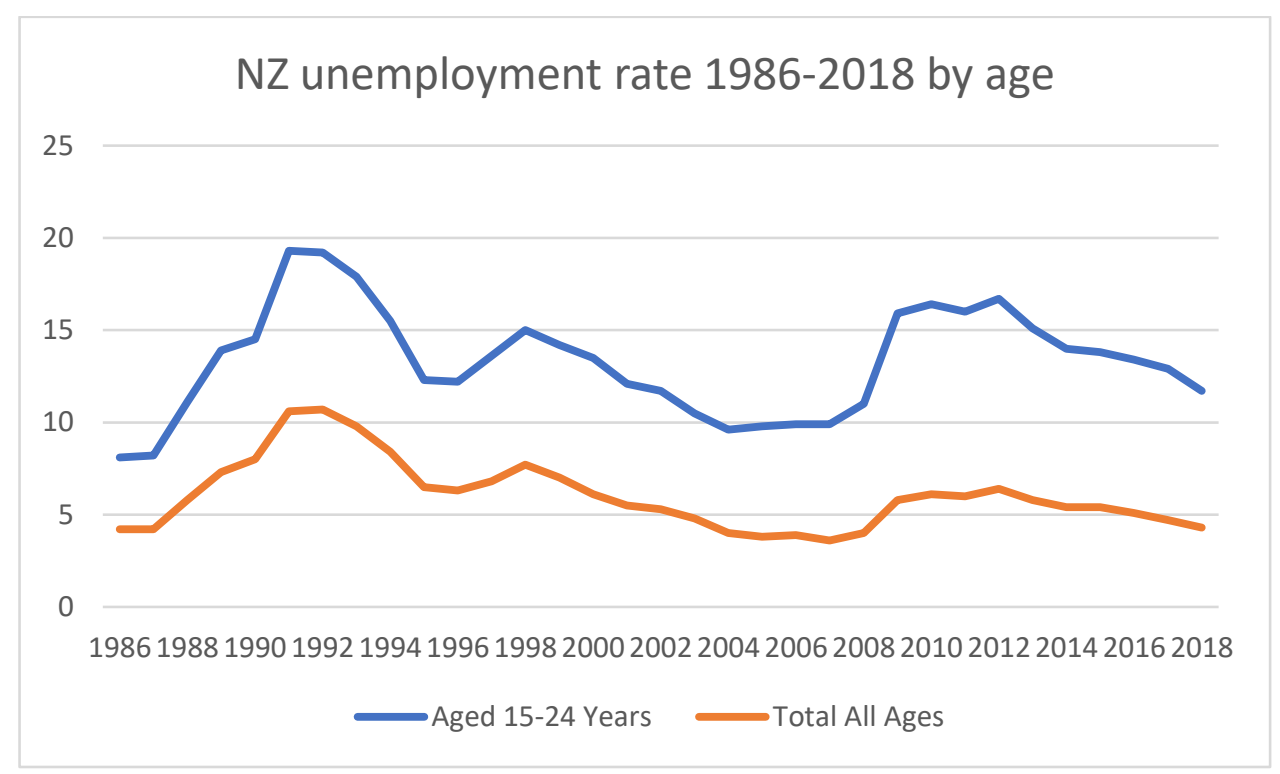

Source: Infoshare (http://archive.stats.govt.nz/infoshare/) Statistics New Zealand

Regions are not exempt from an inequitable distribution of unemployment rates, with the Northland region seeing rates of nearly 50 per cent unemployment in 1992. Gisborne/Hawke's Bay rates were also high when compared with the national rate, with over 20 per cent unemployment between 1988 and 2002, and again between 2008 and 2018 (Figure 4).

Figure 4: Regional unemployment rates

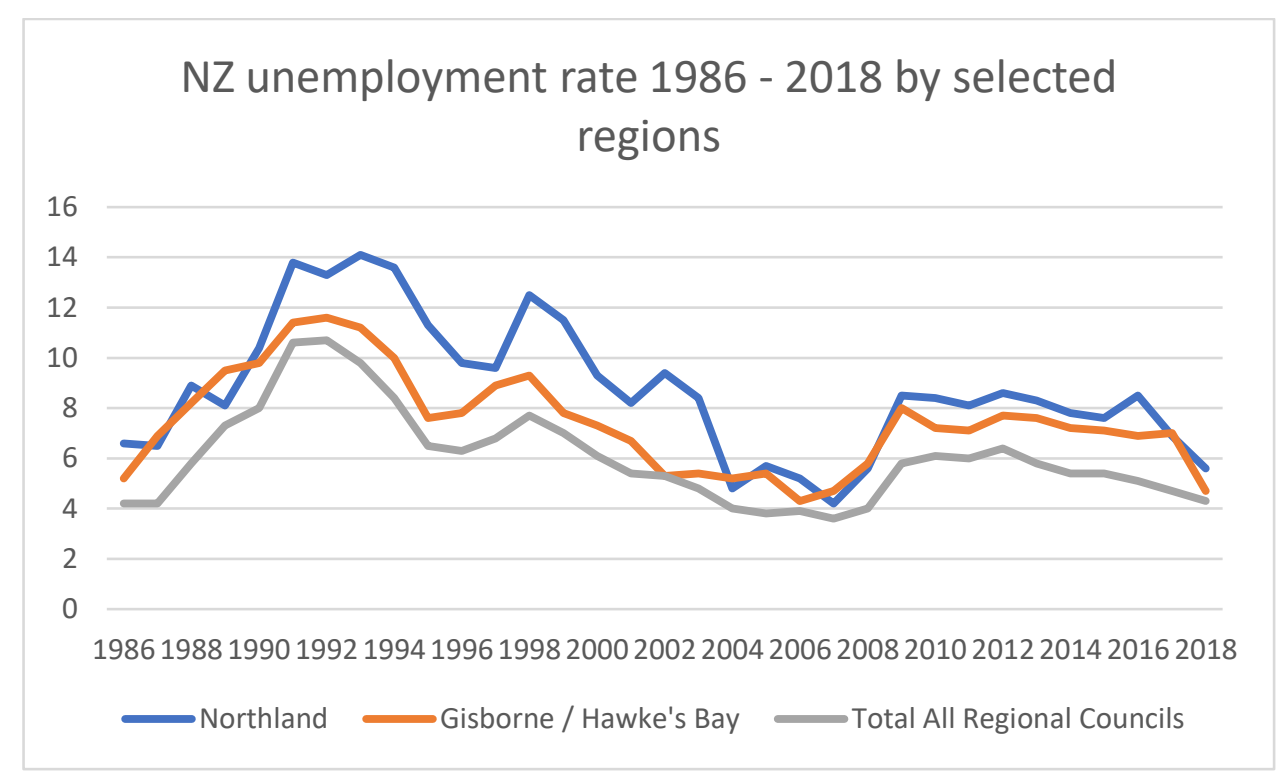

Source: Infoshare (http://archive.stats.govt.nz/infoshare/) Statistics New Zealand 
High rates of unemployment result in significantly reduced Government income from tax and correspondingly high welfare payments. However, a reduced Governmental income for a period is not the only negative consequence of long-term unemployment, as long-term unemployment is a wicked problem with a self-perpetuating cycle. Wicked problems are defined as those that are unstructured and complex, cross multiple boundaries of government and are resistant to solutions (Weber \& Khademian, 2008, p. 336). Long-term unemployment which affects communities and occurs across generations is a problem that is difficult to solve. At the individual level, the symptoms of unemployment may combine into a self-perpetuating cycle, making it difficult for people to move into employment - I capture this in Figure 5.

Figure 5: The self-perpetuating cycle of unemployment

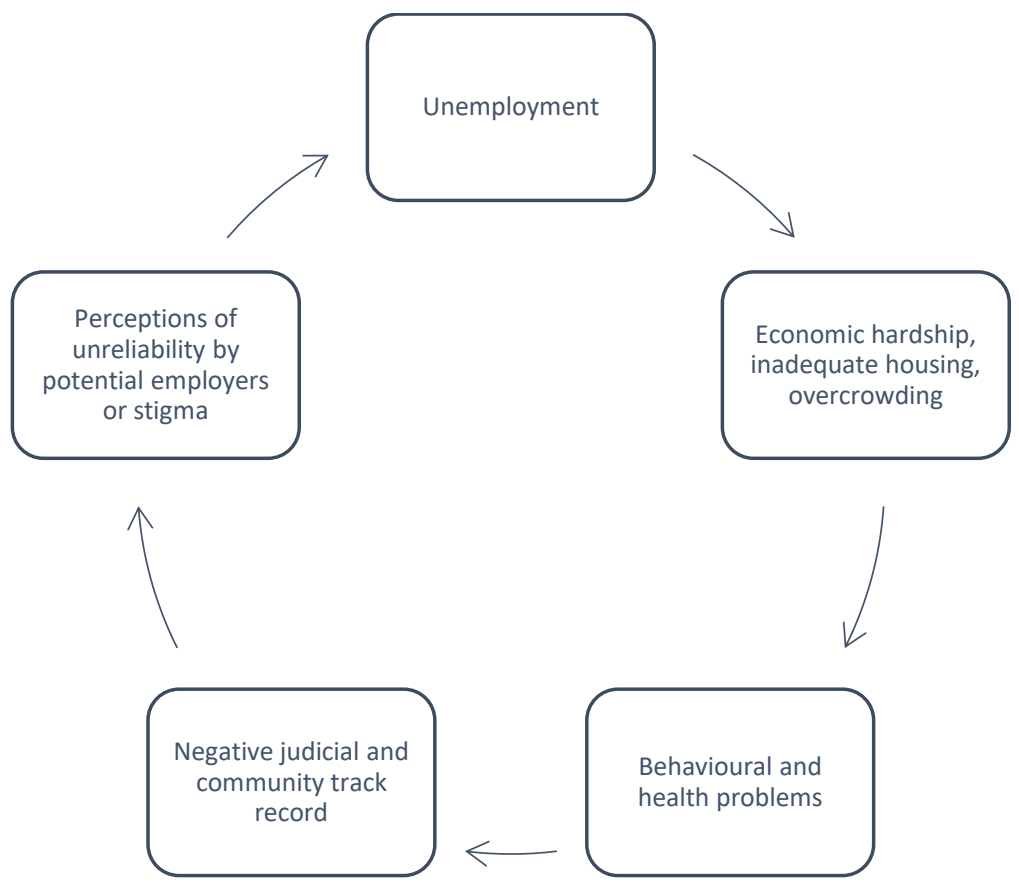

The symptoms of long-term unemployment include economic hardship, violence, criminality and poor mental and physical health. In New Zealand, people who were unemployed reported lower levels of wellbeing across a range of indicators, when compared with employed people (Figure 6) 


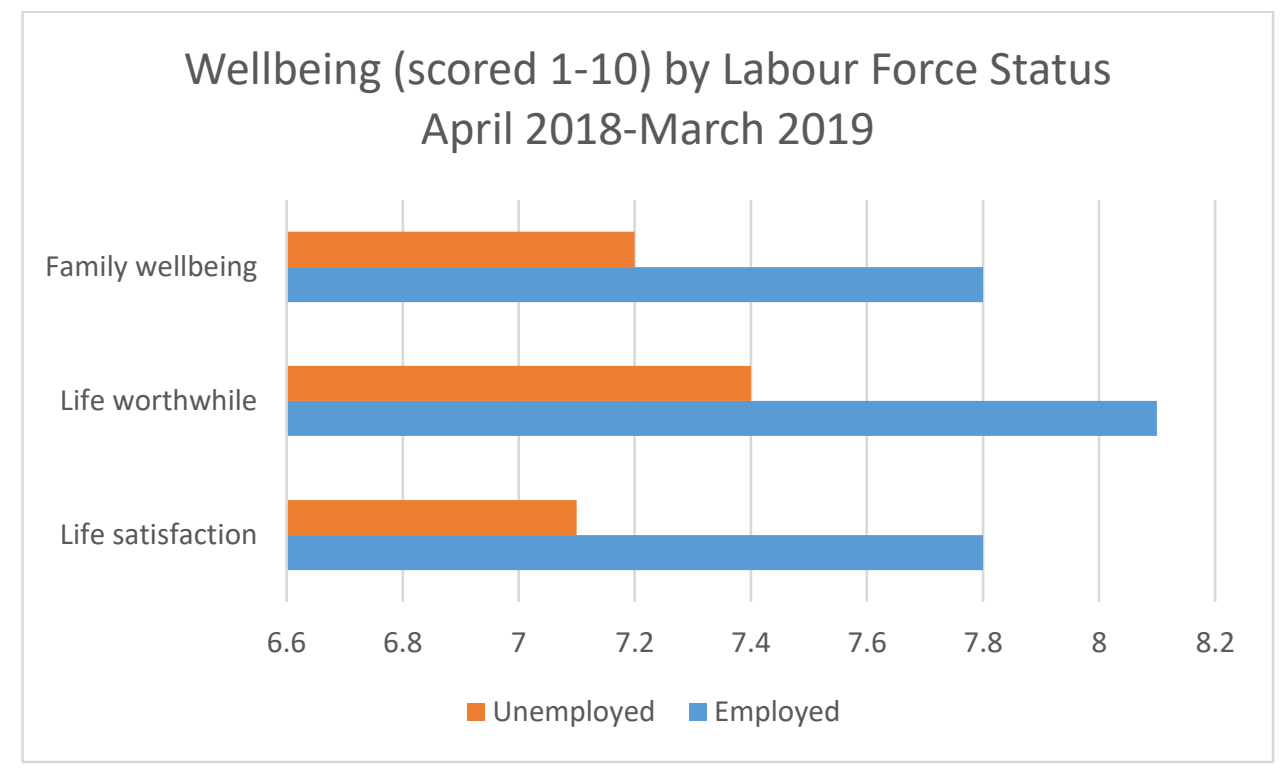

Source: General Social Survey 2018-9, Statistics New Zealand

Figure 7 shows the difference between the self-reported health status in employed and unemployed people in New Zealand between April 2018 and March 2019, with 50 per cent of unemployed people reporting their health status as 'very good' or 'excellent', compared with 60 per cent of employed people.

Figure 7: Health status by labour force status

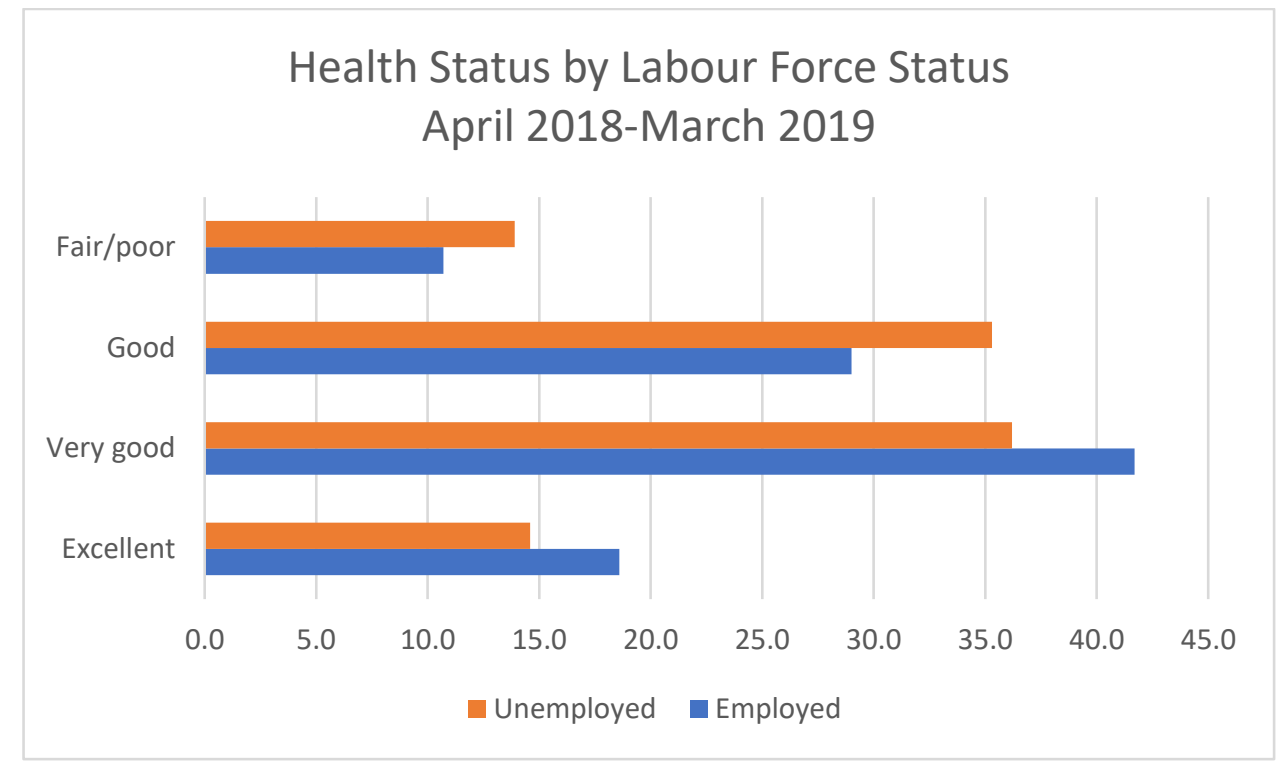

Source: General Social Survey (2019) Statistics New Zealand

The negative effects of unemployment begin early in the period of unemployment and are more difficult to address the longer a person is 
unemployed (Darling, 1992, p. 45). Social exclusion is a real risk for the long-term unemployed because it reduces their self-esteem and selfefficacy perceptions, making them quite sceptical that they are able to participate in the job market (Kieselbach, 2003, p. 73). Along with the individuals' perceptions that they are unable to work, the legislative and operational practices of the New Zealand public management system can unintentionally reinforce the unemployment cycle, for example by making it difficult to obtain or continue to receive an unemployment benefit and by keeping benefit rates low. In New Zealand, the benefit system is 'based on conditionality, including sanctions and is tightly targeted, with inadequate support to meet even basic needs' (Kia Piki Ake Welfare Expert Advisory Group, 2019, p. 7).

When the judicial system is involved, meeting commitments such as court appearances or being detained on remand; fulfilling sentences such as home detention or prison; or paying fines can exacerbate a negative track record and reinforce economic hardship. Where employers might be willing to give opportunities to people in the criminal justice system, the system itself can prevent the opportunities coming to fruition. In New Zealand, willing employers described the workload pressures faced (and therefore disincentive to support former prisoners into employment) because of the long process it takes to recruit someone from prison. (Te Uepu Hapai i te Ora, 2019, p. 59). I have developed Figure 8 to show how the actions of government can exacerbate the unemployment problem. 
Figure 8: Exacerbation of the self-perpetuating cycle

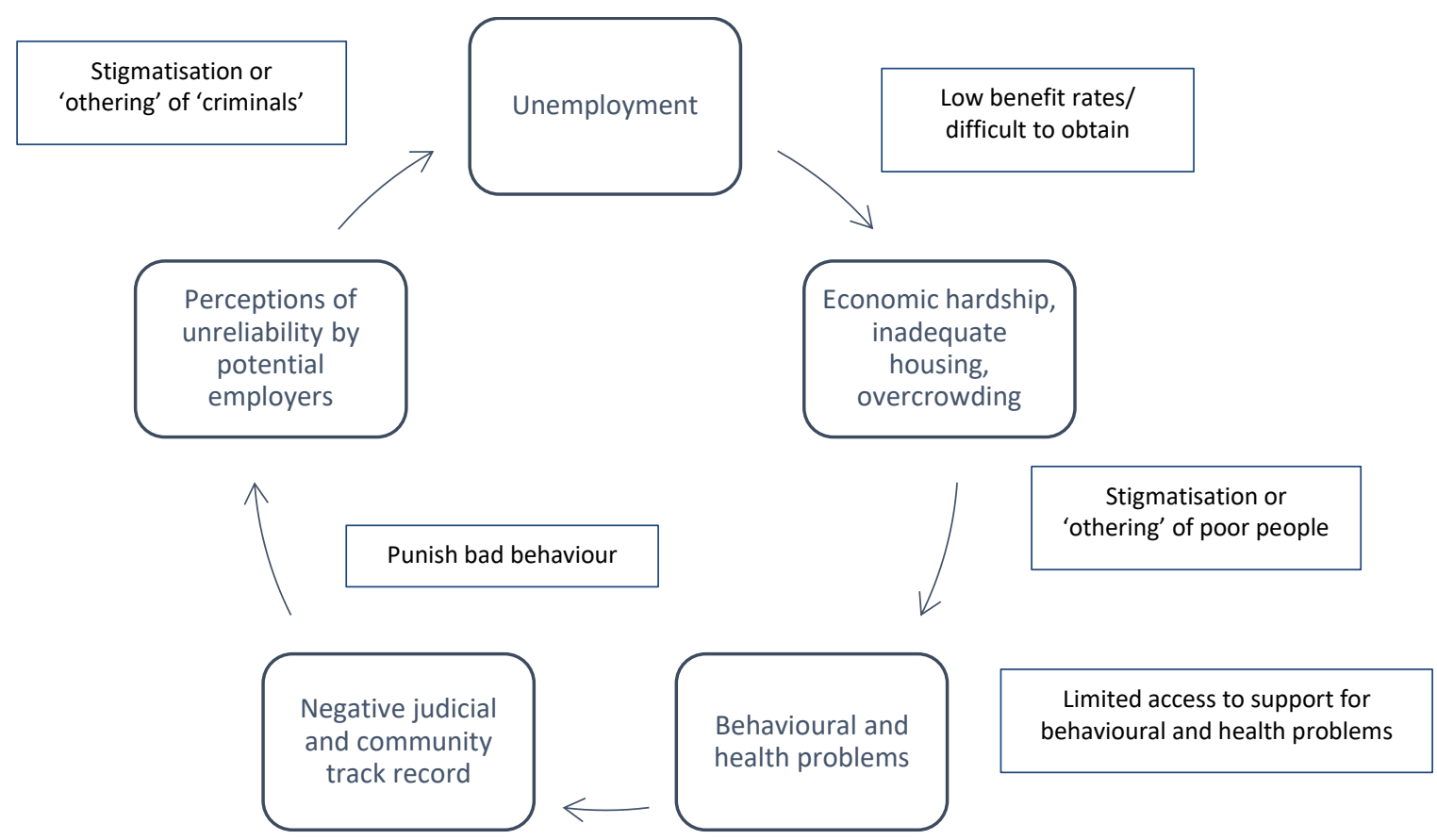

One case of long-term unemployment - with the associated symptoms of poverty, violence, criminality and lost opportunities through limited education and poor health - can result in hardship for an individual and their family. If not addressed, the impact of long-term unemployment can be felt across generations, especially when wider families and communities are involved.

Communities can be a positive or negative influence on the unemployed individual, creating or restricting access to the job market (Lindsay, 2009, p. 34). When a high proportion of individuals in a community are unemployed, the community is deprived of income and can become a harmful environment, resulting in a negative effect on individuals' experiences and perceptions of themselves (Bond et al., 2012, p. 5). Individuals who live in deprived communities are more likely to experience poorer health than the general population and are more likely to die younger (Chan et al, 2011, p. 1); and more likely to be a victim of crime (Ministry of Justice, 2014, p. 95).

When unemployment rates differ by ethnicity, as they do in New Zealand, there is risk of stereotyping, unconscious bias and racism; as people of 
non-dominant ethnicities can be characterised as lazy and unemployable, thus perpetuating the cycle.

While the impacts of unemployment are deeply felt at an individual and community level, typically employment, and more to the point unemployment, is a salient political and public policy issue. However, a macro-solution to the employment problem (such as monetary and fiscal policy adjustments) will be partial at best: there are too many differences between groups of people, based on their age, ethnicity or where they live and governments struggle to find effective interventions that address the problem of long-term unemployment. The next section discusses the challenges involved in finding such interventions.

\section{Solutions to long-term unemployment}

The problem of, and potential solutions for, unemployment have been the subject of debate by economists for the last thirty years (Chapman, 1993; Darling, 1992; Kieselbach, 2003; Krugman, 1994; Lindsay, 2009; Theodore, 2007). Many economists view the problem as an unintended by-product of the redistributionist policies of a welfare state (Krugman, 1994). More recently, economists note the impact of job availability and job quality as important demand-side concerns (Theodore, 2007). Solutions suggested by proponents of this viewpoint include further investment in human capital, pruning the welfare state and subsidising employment (Chapman, 1993).

However, there is no easy solution to long-term unemployment, as any solution needs to work for individuals and communities, and the pathway of progress will differ from individual to individual. Interim steps such as increased motivation, attitudes of potential employees and employers and the availability of employment opportunities do not lend themselves to easy measurement. This means that progress toward the goal can be ambiguous and characterised by long periods of seemingly fruitless effort, followed by unforeseeable opportunities, actions or conditions that lead to progress. Long-term unemployment requires interventions that target the: 
- absence of jobs

- absence of individuals who might be considered 'work ready' - that is, have the skills, experience and attitude necessary to fill the job

- attitudes of employers, who might prefer to bring in migrant labour, as people who might be controllable and reliable.

Breaking the cycle and enabling people to leap across the chasm that separates the employed from the long-term unemployed involves building self-belief in individuals, potential employers and the community along with the creation of jobs. Where there are local variations in labour supply and demand, macro-economic solutions can be of limited use and examining the problem from an economic lens has the drawback of failing to consider:

- the influence of social factors described in the previous section, the irrationality of human behaviour and the socio-behavioural complexity of the problem

- the difficulties of implementation when the problem is wide-ranging and multi-factorial.

Local or regional variations in unemployment rates over time reflect local conditions or changes in local economies and regional labour markets. For example, in Hawke's Bay in the 1990s, much of the high unemployment rate could be attributed to the closure of several large local employers. (Barrett \& Spoonley, 2001, p. 177).

While empirical work on regional unemployment disparities has been reported (Al-Ayouty \& Hassaballa), 2020; Theodore, 2017; Lambert et al, 2017; Best \& Burke, 2019), effective policy solutions to this localised problem remain elusive (Groenewold \& Hagger, 2008, p. 371) and measures to address regional unemployment include very few types of initiatives. Those that exist tend to fall into one of three categories:

- Profiling - statistical modelling of the unemployed population with a view to targeting services 
- Outreach - where case workers engage with individuals close to where they live

- Self-employment grants - which allocate funding to individuals wanting to start a business.

Outreach is often carried out by community organisations. Outreach differs from traditional forms of intervention by the lack of requirement to participate (and therefore lack of sanctions if individuals choose not to participate). Throughout the European Union, most outreach services target young people, rather than other hard-to-reach groups (Scoppetta \& Buckenleib, 2018, p. 20). Outreach approaches, while predominantly focused on creating a case management relationship, are also used to address skill deficits in the long-term unemployed. (Cedefop, 2018, p. 48). Another form of policy response to unemployment that is relevant to local economies or regions, is a 'new enterprise allowance' scheme, which allocates funding to individuals who wish to start a business. In Great Britain, such a scheme is considered successful in moving people off benefits and into self-employment (Cameron, 2015, p. 482).

A common theme across these policy responses to unemployment is the targeting of individuals, ensuring they are job-ready or supported into creating their own employment. These do not reflect a collaborative approach to solutions for regional unemployment problems.

Dean (2013), in a review of the range of initiatives to address long-term unemployment across the OECD found that 'a partnership approach can better tackle entrenched barriers, create a more integrated service for young people and providers...' (Dean, 2013, p. 25). Further, there are 'clear advantages in effective community engagement [including] trust, access, cost saving, understanding, a more joined up approach, local intelligence and local delivery' (Dean, 2013, p. 37). 


\section{The New Zealand context}

In the New Zealand public sector, agency theory provided a base for widesweeping public sector reforms in New Zealand in the late 1980s and early 1990s (Schick, 1998, p. 124). Agency theory is closely related to the governance modes of markets, with a focus on contractual relationships, price mechanisms and hierarchies; with a bureaucratic approach (Lowndes \& Skelcher, 1998, p. 318). However, this mode of governance does not support collaboration and deep changes in accountability and institutional arrangements, as well as culture, were found to be needed if collaborative arrangements were to succeed for the New Zealand public sector. (Dovey, 2003; Walker, 2006, p. 32). This indicates:

- governance is an important consideration for collaboration and partnerships

- an alternative form of governance might better enable collaboration and partnerships between governments and communities; rather than a form of governance based on agency theory, hierarchies and markets.

Agency theory sits within new public management, one of three major types of governance:

- new public management or market governance, where agencies deliver on government priorities at arms-length, using performance indicators and market mechanisms to secure outputs (drawing on agency theory)

- governance as multilevel or inter-governmental, focusing mainly on public actors working together across boundaries; and

- network governance, which involves networks of public and non-public actors (Klijn, 2008, pp. 507-508).

Over the last 15 years, the New Zealand public sector has seen a gradual shift away from the strict hierarchies of agency theory, to more collaborative ways of working, especially across government agencies. 
However, hierarchical approaches still dominate relationships between government agencies and community organisations, and there are few mature, collaborative arrangements in place.

As partnership approaches are seen to be more effective and have clear advantages in addressing long-term unemployment at a local level, and effective community engagement has clear advantages, this raises the main research question for this thesis:

What institutional arrangements enable iterative and ongoing community problem solving to address long-term unemployment?

The following chapter explores the literature on forms of governance that provide an alternative to the market-based approach, with a particular focus on collaborative governance. 


\section{Chapter 2: Literature review}

\section{Unpacking governance}

The previous chapter identified that long-term unemployment is a wicked problem, and that an alternative form of governance, such as network governance might better enable collaboration and partnerships within the New Zealand context. I note that the field of governance covers a multitude of different definitions of governance. One of the most used definitions is that of Pierre and Peters (2005, pp. 3-5), where governance is represented as the combination of four activities:

- articulating a common set of priorities for society;

- achieving coherence, where the goals are consistent and coordinated;

- steering, where society is steered to achieve the goals; and

- establishing accountability, or finding some means of holding actors accountable for their actions.

This definition highlights the importance of leaders in governance, as leaders will be responsible for the activities described. This indicates a need to understand the leadership behaviours and competencies that will articulate priorities, ensure coherence and steer towards goals, and raises the first sub-question for this research:

What leadership behaviours and competencies might facilitate collaboration between government and communities to address long-term unemployment?

The second sub-question for this research relates to the need for accountability arrangements where actors are not arranged in a hierarchical structure. Former New Zealand Minister of Finance, Sir Michael Cullen describes 'the thorny issue of ... accountability' in partnership arrangements as bringing its own set of challenges, including having tensions between trust on one hand, and certainty on the other. (Cullen , 2017, p. 351). The second research sub-question is therefore: 
What accountability arrangements, tools or methods can allow the Government to partner meaningfully and well with New Zealand communities to address long-term unemployment?

The final research sub-question moves to the more practical level of governance when working in a collaborative arrangement and asks:

What types of participatory processes enable communities and government organisations to engage in partnerships that address longterm unemployment?

This chapter considers collaborative governance as an alternative form of governance that might support collaboration between government and communities and the next section provides an overview of literature in the collaborative governance field.

\section{The emergence of collaborative governance}

As a contrast to hierarchy, markets and formal relationships, Ouchi (1980, p. 132) focused on interpersonal relationships and used the term 'clan' to describe a network or collaborative option. In this option, goal congruence and 'strong sense of community' were key factors in the collaborative space. In the clan structure, standard requirements were reciprocity, legitimate authority and common values and beliefs. Informational requirements focus on traditions rather than rules or prices. This work led the way for organisations to suggest new forms of governance and management and alternatives to agency theory that draw on collaboration have been debated since at least 1996:

- Huxham (1996, p. 15) identifies the idea of collaborative advantage as a direct alternative to competitive advantage, an underlying theme of markets.

- Lowndes and Skelcher (1998, pp. 314-316) describe the need for partnerships in governing and managing public programmes, especially to address wicked problems. 
- Huxham (2000, p. 338) frames partnerships as the result of government directives for collaborative initiatives and emphasis on participation of the community. Huxham's work determines that collaboration has many drivers including the need for efficiency, the transfer of good practice from one partner organisation to another, or as a means of sharing financial risk (Huxham, 2000, p. 340). These somewhat uninspiring and potentially unrealisable reasons for collaboration are contrasted with more ideological reasoning: that collaboration enables participation and empowerment of the community groups affected by the problem.

More generally, networks have 'assumed a place of prominence in the literature on public and private governing structures... to address complex problems.' (Weber \& Khademian, 2008, p. 334). Lowndes and Skelcher $(1998$, p. 331) note that 'sustaining collaboration seems to involve the underlying presence of a network mode of governance even when market or bureaucracy predominate.' For example, Ostrom (1996) in her treatise on coproduction describes two cases where public officials aimed to work with residents of poor neighbourhoods to improve specific infrastructure and services. However, one of those case studies failed due to top-down bureaucracy and stifling governance arrangements.

Two forms of governance have emerged based on collaboration and networks: collaborative governance and network governance.

- Collaborative governance focuses on government and non-government actors working together to make public policy or implement public programmes (Ansell \& Gash, 2008, p. 544).

- Similarly, network governance involves actors from different organisations participating in decision making. However, network governance is more concerned with the creation of goods or services so as to service a market (Jones, Hesterly, \& Borgatti, 1997, p. 914), rather than addressing social or political problems. 
Collaborative governance has emerged as a way to enable collaboration in relation to public policy and programmes (Scott \& Thomas, 2017, p. 192) and so I have selected this type of governance to provide an alternative lens on addressing the wicked problem of long-term unemployment. Of interest in this thesis have been the attempts to define collaborative governance and to develop models or frameworks that determine the components of collaborative governance, with a particular focus on those that include accountability mechanisms, leadership and participation.

The next section reviews the collaborative governance literature in relation to leadership, accountability and participation in ongoing and iterative community problem solving, to address long-term unemployment.

\section{Definitions of collaborative governance}

Definitions of collaborative governance arise from early studies of collaborative management arrangements within hospitals (Jacoby \& Terpstra, 1990; Loomer et al, 1993; Ronk, 1993). These authors focused on describing the implementation of collaborative management arrangements to replace strictly hierarchal processes, describing a permanent shift in the way of working, where better clinical outcomes were achieved. While these studies did not describe collaboration between different entities, it is worth noting that the origins of collaborative governance described a system that drew on trust, negotiation and collaboration. By 1998, the literature on collaborative governance was extending beyond hospital management and towards public management and public policy ${ }^{2}$, and beyond single organisational arrangements to multi-organisational partnerships. At this stage of the academic discourse, collaborative governance remained a term that was undefined, with Huxham (2000, p. 339) noting that it included 'all forms of,

\footnotetext{
${ }^{2}$ While nursing appears to have started the academic discourse on collaborative governance, the 27 articles published in health and nursing academic journals between 1990 and 2019 have been overtaken by the 269 articles published in public management academic literature over the same period.
} 
and labels for, governance that involves people in working relationships with those in other organisations.' The slightly more focused Henton et al $(2005$, p. 29$)$ noted that collaboration can take two paths: with the public (participatory) or without the public. The key notion at this stage of the discourse was collaboration; actors involved were secondary.

At that time, research had focused on the structures needed for collaboration, the skills needed for collaborative management, and the benefits of collaboration. A growing number of case studies was evident, with practice moving ahead of the academic literature (McGuire , 2006, p. 35).

An important step forward in the collaborative governance discourse was when Ansell and Gash (2008, p. 544) introduced a formal definition of collaborative governance that explicitly required non-state stakeholders to participate. The definition is:

'A governing arrangement where one or more public agencies directly engage non-state stakeholders in a collective decision-making process that is formal, consensus-oriented, and deliberative and that aims to make or implement public policy or manage public programmes or assets.'

These decision-making processes typically include three types of interaction: forums for public deliberation; community problem solving and multi-stakeholder dispute resolution. Often, forums for public deliberation are one-off cases of collaborative governance, with government officials using the results in future planning activities. Multistakeholder dispute resolution also tends to be a one-off process, with relationships and communication ceasing once agreement has been reached.

Subsequent work by Batory \& Swensson (2019) considered the state of the collaborative governance literature and found that while the Ansell \& Gash (2008) definition was in the most cited article, researchers across the United States and Europe continued to offer definitions which differed along five different continuums. The five continuums identified by Batory 
and Swensson (2019) are the degree to which: non-state actors are involved; the collaborative initiative is controlled by the state; whether organisations or citizens are engaged; whether the collaboration is permanent or task-based and whether the collaboration is purposeful or lacking purpose. These dimensions are described in Figure 9.

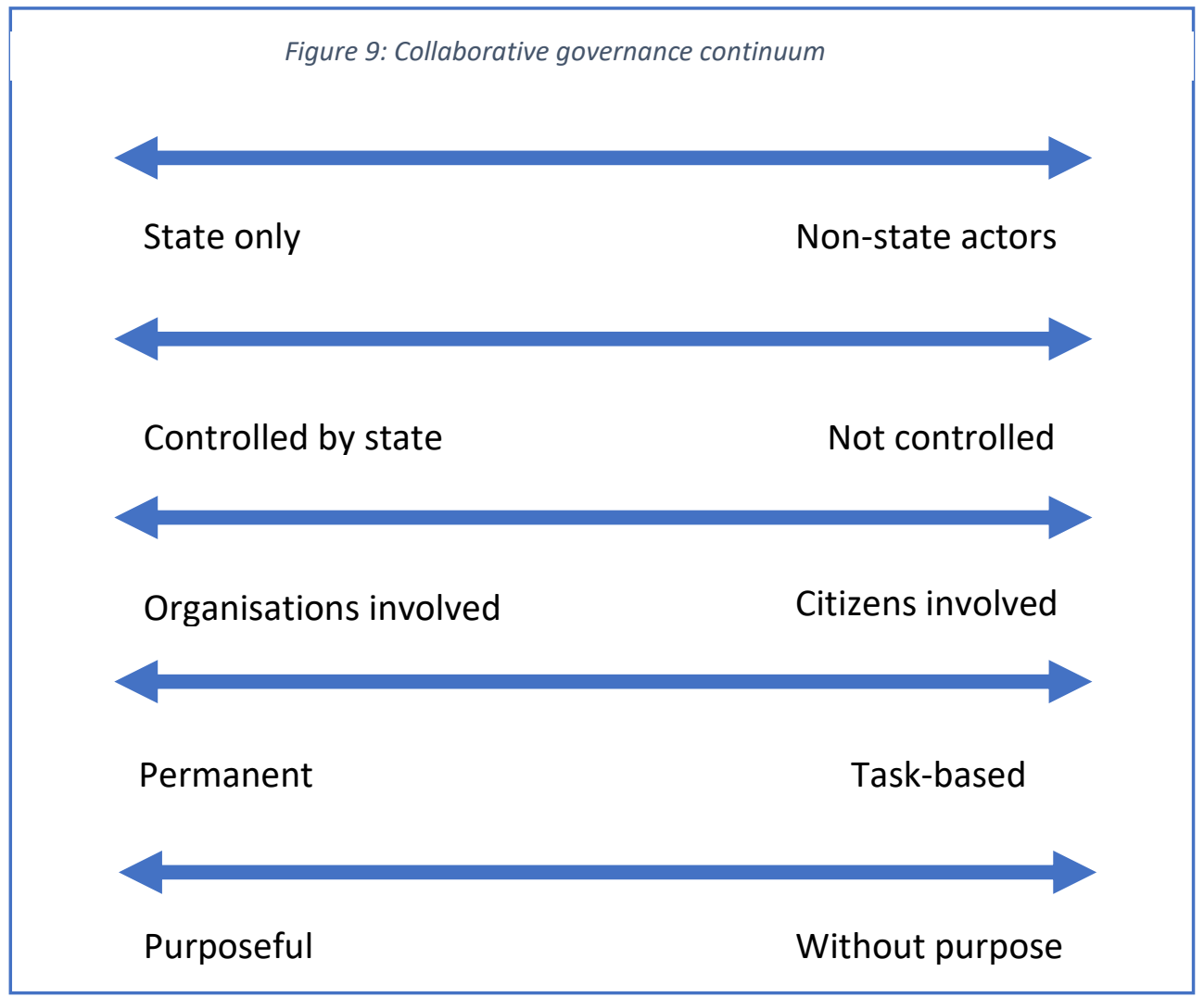

This work is consistent with the Ansell and Gash definition of 2008, allowing refinements of the definition so that collaborative governance initiatives can be readily categorised and compared with one another.

\section{Modelling collaborative governance}

Huxham (2000, p. 338) drew on O'Toole (1997) in defining the public arena as 'rife with both rhetoric about the potential of collaborative governance and complaints about the difficulty of achieving in practice'. To assist with understanding practice, Huxham (2000) sketched out the dimensions of structural complexity inherent in collaborative governance. The challenges these dimensions present (as discussed by Huxham) are set out below: 
- Working relationships: can be characterised by layers (eg, policy-level to policy-level; street-level to street-level; senior to senior) OR dominated by one organisation with the other brought in for advice/consultation from time to time.

- Organisational membership: can be based on an individual's expertise and relationships but may not represent the whole organisation.

- Governance and task structures: often become complex and characterised by multiple layers of governance, both existing and bespoke.

- Pluralism: there may be multiple collaborative partnerships demanding time from the same pool of people at a local level.

- Ambiguity: it may be unclear who is involved in the collaboration, in what capacity.

- Dynamics: over time, organisations involved in collaboration come and go; people may leave organisations and not transfer collaboration responsibilities onward; managers may not value collaborative activities.

These structural complexities focus on both the collaborative process (working relationships, governance and task structures, ambiguity) along with the conditions that might affect the process (organisational membership, pluralism and dynamics), identifying that collaborative governance is an area fraught with challenges that have implications for accountability and leadership. In particular, Huxham recommended that those who take leadership of collaborative initiatives should be 'serious reflective practitioners' (Huxham, 2000, p. 353) with leadership behaviours that might not be as anticipated (discussed in more detail below). Huxham (2000) also references the problems of accountability, sketching out the numerous ways in which actors inside a collaboration can struggle to identify to whom they are accountable - to the collaboration or to their parent organisation. However, there are many more dimensions to accountability in collaborative governance, including the nature and type of tools and mechanisms used and whether systems of accountability are 
formal or informal, internal or external, functional or strategic. I discuss these dimensions later in this chapter.

Collaborative governance initiatives were widespread by 2008 , but ways to measure its success were lacking. In response, Ansell and Gash conducted a wide-ranging literature review of collaborative governance case studies, finding 137 that fit their definition. From these, a contingency model was developed to identify the critical variables that will influence whether or not this mode of governance will produce successful collaboration' (Ansell \& Gash, 2008, p. 571). This model is described below in Figure 10.

Figure 10: Ansell and Gash model of collaborative governance

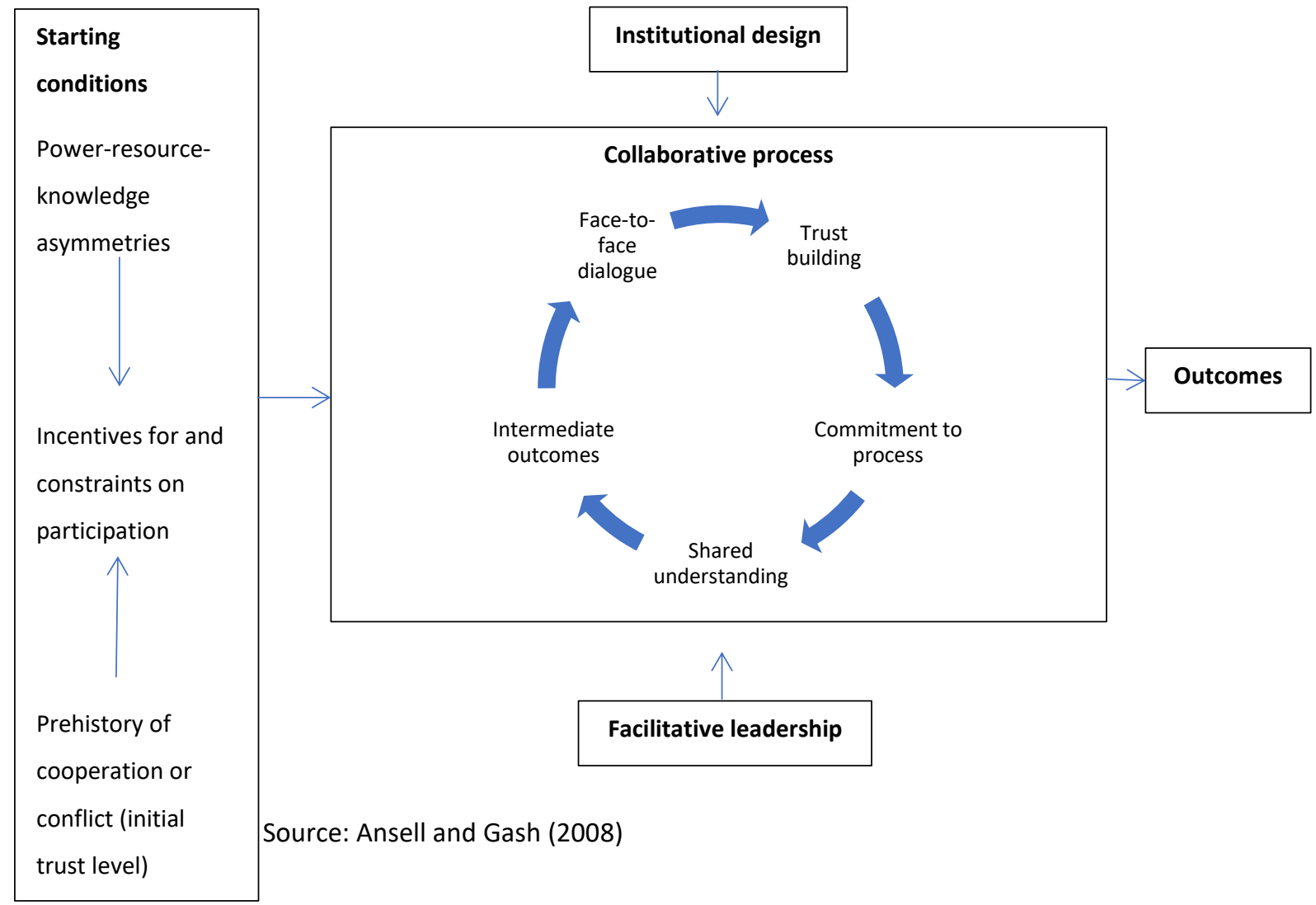

In this model, starting conditions, facilitative leadership and institutional design are either context for, or critical to, the process of collaboration, which in turn relies on communication, commitment and coordination. In 2011, Emerson et al defined an 'integrative framework for collaborative governance' that draws on and expands the Ansell \& Gash 2008 model. In this framework, the Collaborative Governance Regime is at the centre of 
the system and represents both the collaborative dynamics and collaborative actions (Emerson et al, 2011, p. 6). Sitting outside the Collaborative Governance Regime are drivers, impacts and the system context. Each of these components is supported by an exhaustive list of dimensions and components, which expands on the Ansell \& Gash model. For example, Emerson et al define political dynamics, power relations and levels of conflict/trust as three drivers in the system context - which are very similar to the power/resource/knowledge asymmetries and prehistory of cooperation or conflict/trust level set as starting conditions in the Ansell \& Gash model. Both models identify leadership as an underpinning component (Ansell \& Gash, p. 558) or as an essential driver and component of capacity for joint action (Emerson et al, p. 7). However, Emerson does not identify accountability as a key component of governance.

Huxham (2000), Ansell and Gash (2008) and Emerson et al (2011) all identify components of collaborative governance (albeit using different definitions) that impact on the success of collaborative processes and partnerships. Governance and task structures (Huxham, 2000) or institutional design (Ansell \& Gash, 2008) encompass the tricky area of accountability, or how people working collaboratively can account for the investment in their time and resources. Facilitative leadership underpins the Ansell \& Gash model, while Huxham highlights the personal aspect with his membership, ambiguity and dynamics challenges, and Emerson et al see leadership appearing in two places - as an essential driver of collaboration and as an indicator of capacity for joint action. Finally, all three approaches refer to the process of collaboration or the participatory processes that describe interactions between the parties involved in collaborative governance.

The Ansell \& Gash model provides a useful starting point for this thesis, as it places in context the components identified earlier: leadership, accountability and participatory processes. However, as a contingency model, the Ansell \& Gash model does not provide guidance on the types of 
accountability arrangements or participatory processes that will address the challenges of collaborative governance - the model merely suggests these components are important. The model also does not seek to forecast whether a collaborative governance approach is more effective than other potential approaches. ${ }^{3}$

The next section considers the collaborative governance literature on accountability, leadership and participatory mechanisms in more detail.

\section{Accountability in collaborative governance}

Edwards and Hulme (1996, p. 967) defined accountability as the means by which individuals and organisations report to a recognised authority (or authorities) and are held responsible for their actions'. This description includes short-term functional accountability for resource use, and strategic accountability for results. When partnerships are made between government and communities, an additional complexity is created: accountability to whom? (Stone \& Ostrower, 2007, p. 423). Edwards and Hulme (1996, p. 967) note that non-government organisations often must account upwards to government and downwards to trustees, staff or beneficiaries. In collaboration, a further aspect is the accountability each member of the group holds towards their fellow collaborators.

Ebrahim (2003) examined five broad mechanisms for non-government organisation accountability (reports and disclosure statements, performance assessments and evaluations, participation, self-regulation, social audits) and found that upward, short-term accountability dominated; while downward, internally focused and strategic mechanisms were underdeveloped (Ebrahim, 2003, p. 826). Later studies confirmed the predominance of upward accountability and noted that trustworthiness,

\footnotetext{
${ }^{3}$ I note Emerson \& Nabatchi (2015) draw on the Emerson et al framework of 2011 to suggest a performance matrix that allows different initiatives to be evaluated by evaluating each component of the framework through the lens of the participant organisations, the collaborative governance regime and target goals. Repeated application of this matrix may allow for different initiatives to be compared over time, leading to identification of the arrangements that may forecast success.
} 
shared norms and information all influence upward accountability. However, Masdar (2015, p. 153) found the practice of either formal or informal upward accountability alone can weaken effectiveness.

Henton et al. (2005, p. 23) note that decision-making processes are important, with clear links necessary between discussions, decisions and implementation vital for the legitimacy of the process, indicating one area of accountability. Booher and Innes $(2006$, p. 12) drew on a single case study to identify that a decision-making process and record of decisions were created to support the partnership. Donahue et al (2011, p. 213) outline the challenges of monitoring the private-sector agent involved in a collaborative enterprise, noting that monitoring must be an 'integral, instinctive, incessant aspect of its management process.' Donahue et al. (2011, p. 213) suggest that monitoring mechanisms fall away over time, leading to close attention only when catastrophe strikes. They suggest a continuing cycle of analysis, assignation, design and assessment to ensure the enduring success of the collaborative process. However, these authors do not address the seminal question of accountability to whom, simply that accountability in the form of monitoring must exist. In Donahue et al. (2011, p. 466) the authors argue that investment in government and a strong analytical and oversight capacity are the sine qua non of collaborative governance' - without this oversight, collaborative governance will not be effective but they do not answer the question of what oversight capacity is necessary.

Smith et al (2006) review 14 partnerships between government and communities, noting that there was strong upward accountability for spending and targets, but public oversight, or the ability of the community to hold the partnership to account, was missing. Smith et al (2006) argue that partnership governance should be fit-for-purpose, reflecting both the type and stage of development of the partnership.

In practice, collaborative governance accountability arrangements appear to have become a hybrid of traditional systems and collaborative systems, 
with leaders straddling the line between the two systems (Booher \& Innes, 2006). Empirical research on one successful collaborative governance arrangement, the CALFED process, emphasised that the process operated in the shadow of existing institutions, that is, within the existing legal framework and without setting up a separate decision-making agency (Booher \& Innes, 2006).

This review of the literature indicates that, while accountability is a necessary condition for partnerships between government and communities, the collaborative governance literature lacks a thorough and detailed description of accountability as a systemic response that is viewed as legitimate and can stand alongside the more bureaucratic, hierarchical and untrusting systems, rather than in their shadow.

\section{Leadership in collaborative governance}

Huxham (2000) identifies three dimensions of diversity that present even more challenges to collaboration: resources and aims (especially when these are different to each other); language and culture (which can often form barriers to relationships) and power relationships (and the problems inherent when these clash). While the focus of Huxham (2000) is on identifying the challenges of collaborative governance, these challenges suggest that leadership is an important component that will enable success. Huxham (2000, p. 353) saw that 'thuggery' or the single-minded dedication to collaboration along with perseverance and dominance of the governance arena, is seen as a way of ensuring progress in a collaborative environment. In contrast, Ansell and Gash (2008, p. 554) 'found that facilitative leadership is important for bringing stakeholders together and getting them to engage each other in a collaborative spirit'. Susskind \& Cruikshank (1987) suggest three escalating modes of operation for the leader when stakeholders are unable to collaborate, starting with facilitation (ensuring the integrity of the process), moving to mediation (increasing the role of the leader in finding solutions) and finally moving to 
arbitration (directly crafting a solution). In this conceptualisation, a major focus of the leader is on ensuring that collaboration takes place.

Emerson et al $(2012$, p. 9) take a wider view of the role of the leader in collaborative governance and suggest that the leader is also responsible for initiating and securing resources for a collaborative governance process. Crosby \& Bryson (2010, p. 219) suggest these roles can be split into the champion (responsible for the day-to-day management of the collaborative process) and the sponsor (responsible for ensuring the authority and resources are available to support the process).

So, while Huxham identifies 'thuggery' as a legitimate leadership style for collaborative success, Ansell \& Gash; Emerson et al; Crosby \& Bryson; and Susskind \& Cruikshank all suggest that a more facilitative leadership style is necessary. This suggestion harks back to the earlier literature, where collaborative governance is described as needing the more feminine 'softer skills' and best operated on a win-win basis.

The plethora of descriptions of the leader involved in collaborative governance indicates space to:

- add nuance to the literature

- focus on what leadership behaviours and competencies might facilitate effective collaboration between government and communities to address long-term unemployment.

\section{Participation in collaborative governance}

Leadership and leaders are merely one facet of the players involved in collaborative governance. In determining what collaborative governance required from people, Innes \& Booher (2003, p. 58) identified that 'collaborative governance is more than a set of guidelines created for the existing environment: rather, it requires a change in the way people think, act and behave and in the way society views government'.

In Huxham's challenges, working relationships and organisational membership presents the first two structural challenges to collaboration. 
In this facet, he has the agreement of many later academics, agreeing that the participation of stakeholders is critical to collaborative governance success or failure (Ansell \& Gash, 2008; Baker, 2009; Henton et al., 2005; O'Brien, 2010; Steurer, 2009). Collaborative governance, in any definition, includes public and private stakeholders in governance arrangements (Ansell \& Gash, 2008; Bingham, 2011; Bryan, 2004; Kapucu et al, 2009; O'Leary \& Vij, 2012). Ensuring the right stakeholders are engaged in the process of collaborative governance is perhaps the most fundamental design issue (Ansell \& Gash, 2008; Henton et al., 2005; O'Brien, 2010). Weak or non-inclusive participation can threaten to undermine the legitimacy of collaborative outcomes (Ansell \& Gash, 2008; Henton et al., 2005; O'Brien, 2010). Engagement, however, comes at a cost. Researchers interested in the value of participatory processes have identified the high cost and heavy time commitment on the part of both citizens and government officials as reasons to fully consider both positive and negative aspects of participatory processes (Lawrence \& Deagen, 2001, p. 866).

Irvin \& Stansbury (2004, p. 58) note that the potential loss of control by government agencies, possibility of poor decisions or possibility of decisions that would have been made without these processes as further reasons why government agencies may choose to not facilitate participatory processes. ${ }^{4}$ Costs, time commitments and motivation to facilitate or participate in processes all reflect the capacity of people in government agencies, non-government organisations and communities to participate. Capacity problems include, for example, organised stakeholder groups do not exist; some stakeholders may not have the skill or expertise to engage; stakeholders lack the time, energy or liberty to engage.

\footnotetext{
${ }^{4}$ This is borne out in the aim to engage in collaborative decision-making to name public assets, such as the 2016 poll to determine the name of a $£ 200 \mathrm{~m}$ research vessel owned by the Natural Environment Research Council, and operated by the British Antarctic Survey. The name 'Boaty McBoatface' was the most popular choice, with over 124,000 votes. The next most popular name received just over 34,000 votes (BBC News, 2016).
} 
Capacity to collaborate can be measured in different ways, for example, size and homogeneity of the group (Ostrom, 1990); willingness and ability to participate (Irvin \& Stansbury, 2004); and resource accessibility (Rowe \& Frewer, 2000). These analyses indicate that capacity can be categorised by two major groups: motivation and ability. These categories apply across all participants, whether government, non-government and community based. Capacity to participate will change over time and different types of processes may be relevant for different capacities. In addition, the process itself of engaging in collaborative governance should develop further capability to participate.

Other issues of stakeholder engagement include power imbalances (Huxham's final structural complexity and identified in Ansell \& Gash's model of collaborative governance) and a past history of conflict. Power imbalances between actors can reduce participation of key stakeholders (Ansell \& Gash, 2008; Walker \& Shannon, 2011) by reducing their motivation to engage. A history of conflict may express itself in low levels of trust, creating a vicious cycle of suspicion, distrust and stereotyping (Ansell \& Gash, 2008). ${ }^{5}$

Linked to the problem of participation is Huxham's governance and rules, or the institutional design of the initiative, which dictates how stakeholders engage and has a major impact on the success or failure of collaborative governance (Ansell \& Gash, 2008, p. 555; Bingham, 2011, p. 398; Freeman, 1997, p. 40; Glasbergen \& Driessen, 2005, p. 276; Henton et al., 2005, p. 28). Described as 'setting ground rules and processes for collaboration' (Ansell \& Gash, 2008, p. 555), clear ground rules and transparent processes contribute to building trust between actors. Literature on participatory processes mainly focuses on the type of process (budgeting, planning) or the type of engagement mechanism (surveys, ad hoc forums, advisory groups, governance groups). Researchers have

${ }^{5}$ This is especially relevant for the New Zealand Government when attempting to develop partnerships with Māori. 
identified a range of engagement mechanisms that enable citizen participation, including referenda; public hearings/inquiries/public opinion surveys; negotiated rule making; consensus conference; citizens jury/panel; citizen/public advisory committee; focus groups (Rowe \& Frewer, 2000). Of these, only a few (consensus conference, citizens jury/panel and citizen/public advisory committee) enable decision-making by citizens: the remaining mechanisms allow input only. Technologyenabled participatory mechanisms are less relevant in collaborative governance, as while it supports the sharing of information, technology is not always available to communities and cannot replace the advantages of face-to-face communication (English et al, 2002).

So, while the literature highlights the importance of engagement with the right stakeholders, there is little advice on the types of participatory mechanisms that would enable ongoing engagement between government and communities to address long-term unemployment. The literature is particularly scarce on engagement with indigenous peoples or far-flung communities, as exist in New Zealand.

\section{Addressing gaps in the literature}

While collaborative governance remains a somewhat elusive concept, the challenges of collaboration between government and communities are real and relevant to the question as to what institutional arrangements enable iterative and ongoing community problem solving to address longterm unemployment?

In this situation, the focus is on government partnerships with communities. However, the early literature, based as it was inside single organisations is still relevant. In particular, while the literature on single organisations highlighted the need for cultural change and to move from a situation of mistrust to trust, the early literature on collaboration with the public sector identified that mistrust was an inherent part of the way government deals with communities, especially when it comes to community organisations delivering services on government's behalf. 
As the literature on collaborative governance suggests that accountability arrangements tend to sit within the shadow of existing institutions, it does not provide for a systemic response that is viewed as legitimate and can stand alongside the more bureaucratic, hierarchical and untrusting systems. Accordingly, a detailed description of accountability mechanisms inside a collaborative governance process would add to the understanding of what accountability arrangements, tools or methods can allow government to partner meaningfully and well with New Zealand communities to address long-term unemployment.

While early literature focused on the soft skills of leaders in carrying out collaborative governance, Huxham (2000) noted that 'thuggery' as leadership was necessary. Later research focused on facilitative leadership, engaging and empowering people to collaborate. However, the adversarial system of government, the need to fight for and secure resources and to push through accountability arrangements that are different to the norm suggests that the facilitative leader with superb soft skills may not be able to deliver long-term success. The literature creates a new puzzle for this research: how a leader balances the facilitative role where collaboration is embedded into a programme, with the more traditional role in an adversarial system, where there is competition for authority and resources, and often the decisions are not the sole mandate of the leader of the collaborative governance initiative.

Finally, while an understanding of the leadership attributes is critical to identifying the institutional arrangements that support ongoing and iterative problem solving, collaborative governance arrangements by their very nature involve a range of stakeholders, and the nature of stakeholder engagement is identified by researchers as critical to the success of collaboration. While the literature identifies a range of mechanisms to enable participation, it does not provide guidance for collaboration in a widely dispersed and diverse population such as New Zealand, nor how to solve the problems of capacity and motivation to engage. 
The following chapter describes the methodology used to address the research questions in this thesis. The approach chosen was the development of two case studies, both New Zealand-based, and both representing a collaborative governance approach to addressing long-term unemployment. Such cases are rare in New Zealand and provide a way to address gaps not only in the collaborative governance literature, but also gaps in the literature on partnership initiatives focused on long-term unemployment. 


\section{Chapter 3: Methodology}

The previous chapter identified the potential for research with a focus on leadership, accountability and participation in collaborative governance to address current gaps in the literature. This chapter now focuses on the methodology. The first part of this chapter establishes the ontological position and epistemological standpoint for this research, then shows why case studies have been selected. The second part of the chapter details the research undertaken, including data collection procedures, data management, case study development and how the analytical framework was applied. Immediately following this chapter is the first of the two case studies.

\section{The selection of case study methodology}

Selection of the methodology for this research requires clarity about the ontological and epistemological position of the researcher. Ontology requires that the researcher be clear about the nature of reality - whether it exists independently of the researcher or can only be viewed through a subjective lens (Blaikie, 2007), while epistemology seeks to define how knowledge should be acquired and interpreted. In this case, the ontological position is interpretivism. The notion of collaborative governance is reflected in a series of actions carried out by actors; there are no independently-existing rules or roles and each rule and role is created by an actor, for the specific set of actors involved. Knowledge in this case is constructed and includes social relationships and interactions and so the epistemological stance is constructivism.

As researcher, construction of knowledge in this realm requires a range of different sources of data and information, indicating a qualitative approach to the research is appropriate - developing ideas through induction from evidence, viewing the problem as a whole rather than a series of elements and developing theories from understanding (Holden \& Lynch, 2004). The selected research questions predominantly focus on 'what works', or 'what might work' in an environment rich with contextual 
variables. Cresswell (2009) confirms that qualitative research is best suited to responding to topics that need to be explored or understood such as those posed for this research.

One method of qualitative research is the case study method, which aims to deliver intensive, holistic descriptions and analysis of phenomena (Merriam, 1998). Case studies are not representative of a population but they illuminate and extend relationships between constructs (Eisenhardt \& Graebner, 2007). While one case study can provide a basis for theorybuilding, multiple case studies enable comparisons and yield more robust, generalizable and testable theory (Eisenhardt \& Graebner, 2007).

Case studies are widely used when the context relates to organisations, or groups within organisations (Meyer, 2001). They allow for a holistic understanding of the case and for the research design to adapt as more information and insights come to light. This freedom of design contrasts with an approach such as a survey or other quantitative approach, where the scope of the research must be much more clearly defined at the outset. Case studies are common in the collaborative governance literature (Douglas et al., 2020), with Ansell and Gash (2008) relying on 137 case studies to develop their model of collaborative governance described in the previous chapter. In 2020 Douglas et al built a collaborative governance case databank to draw on the plethora of individual case studies and enable more generalisation across the field (Douglas et al, 2020). Within the case studies, focus has tended to be on collaborative governance structures, the skills public servants need for collaboration and the benefits of collaboration (McGuire, 2006). A growing grey literature is also evident, with the focus on emphasising the need to cooperate, the importance of developing partnerships and on how government can restructure to enhance participation (Batory \& Swensson, 2019, p. 33). The research questions could have been addressed through surveying government agencies and community organisations and eliciting the opinions of a wide range of people involved in different types of 
collaborative initiatives. However, surveying would not necessarily have provided the richness, depth and nuances of data indicated as necessary through the review of the literature, especially the:

- complex interplay between context and case

- leadership behaviours and accountability arrangements

- structural challenges of collaborative governance that Huxham (2000) indicates must be addressed.

To respond to the need for rich data, I sought case studies that had longevity and were large enough to involve a wide range of actors, that existed beyond the whim of a Minister and an electoral cycle, and through a succession of leaders. By necessity, most of the case studies' lifecycles had to have passed, to enable comparisons over time and throughout the life of the case. The focus of this research was also on the New Zealand public sector, with its peculiar and particular landscape the setting for understanding.

\section{The selection of two case studies}

In making the decision to pursue two case studies, I drew on Eisenhardt \& Graebner (2007), who noted that the problem of single cases is limitations in generalisability. Findings in one case, while inherently interesting, would be subject to observer bias and a lack of ability to look outside the case. The first mitigation against the limitations of generalisability was the use of two case studies that focused on the same problem and had each completed a lifecycle. This decision allowed for a nuanced and granular level of analysis when comparing and contrasting between the two case studies and would be more likely to generate 'good theory' - that according to Pfeffer (1982) is parsimonious, testable and logically coherent (Eisenhardt's first criteria to evaluate theory-building research using case studies). A review of the literature indicated that the assessment of related case studies is unusual - indeed, Eisenhardt \& Graebner (2007, p. 25) note that in applying case study methodology, 'each case serves as a distinct experiment that stands on its own as an analytic unit'. 
Therefore, the decision to use two case studies came from:

- the need for a rich (rather than broad) dataset, with the availability of two case studies that had not been studied before

- the fact that the case studies traversed a long period of time with different leaders and completed a life cycle.

The two case studies I selected for this research are the Community Employment Group and the Mayors Taskforce for Jobs. These case studies focused on long-term unemployment and were initiated from different starting points:

- The Community Employment Group was a central government initiative.

- The Mayors' Taskforce for Jobs was a local government initiative.

The Community Employment Group and the Mayors Taskforce for Jobs provided for research on national (rather than local) initiatives and were examples of how New Zealand Governments involved communities in problem-solving. These two initiatives were seen as world-leading in their time, with international delegations coming to New Zealand to observe and advancing proposals for similar approaches in their own jurisdictions. Both initiatives:

- enjoyed times of high support and engagement from New Zealand Governments, and suffered when that support was withdrawn

- traversed the challenging line of collaboration between government and communities

- enjoyed success in addressing long-term unemployment, in communities as diverse as Kaikoura ${ }^{6}$ and Ōtorohanga ${ }^{7}$.

\footnotetext{
${ }^{6}$ A town of around 2,000 people on the East Coast of the South Island, now famous for its whale watching tourism activities, which were set up under a forerunner to the Community Employment Group.

${ }^{7}$ A town of around 2,500 people in the heart of the King Country in the North Island, with an economy based mainly on agriculture, noted for reaching a youth unemployment rate of $0 \%$.
} 
These initiatives involved a different way of working for New Zealand Governments, with a collaborative rather than adversarial approach. The initiatives rejected managerialism, with its focus on hierarchy, control, accountability, measurement and the importance of tightly-managed organisations. Instead, both initiatives appeared to function more as a network. As the New Zealand public sector is moving toward a more collaborative approach the lessons learned from these relatively long-lived initiatives might be able to support the desired partnerships between government and communities.

Each case study traversed a long time period and direct observation of operations was not possible. This led to use of the historical method, using multiple sources of data, including drawing on contemporary accounts of the time. The following sections describe the units of analysis (the collaborative initiatives) in more detail.

\section{Community Employment Group}

The Community Employment Group was a team established in the Department of Labour in 1991 with the aim 'to encourage and assist communities and organisations in the development and establishment of new employment initiatives through information dissemination, brokerage, facilitation, networking and transferring the benefits of previous successful initiatives to other communities and organisations.' This team included an extensive network of fieldworkers who were based within communities and engaged in ongoing problem-solving to address unemployment. The fieldworkers were supported by a Wellington-based, national office team, which created and enforced the accountability mechanisms that gave the initiative legitimacy and enabled its sustained focus through multiple changes in government.

By 1998, the Community Employment Group was seen by the National/New Zealand First Coalition Government to be a mature group with good accountability mechanisms, achieving good outcomes and managing risk well. However, by 2004, the Community Employment Group 
had been shifted to the Department of Work and Income and back to the Department of Labour and had received significant criticism in the media for its lack of accountability and risk management. The Community Employment Group was disestablished on 31 March 2005.

\section{Mayors Taskforce for Jobs}

In 2000, the Mayors Taskforce for Jobs was formed to achieve 'zero waste of New Zealanders'. This initiative was a collaboration within a collaboration - Mayors of New Zealand came together with this common goal and they partnered with the Government and a range of other organisations to achieve it. Like the Community Employment Group, this initiative promoted local solutions to local problems, enabling a sharing of ideas throughout New Zealand and access to resources to turn ideas into reality.

By 2008, the initiative included all Mayors in New Zealand and a history of strong partnership with Ministers of the Crown, including the Prime Minister. The Mayors Taskforce for Jobs was responsible for allocating several hundred thousand dollars each year and was a strong influencer of employment policy. Since that time, the partnership has been in decline. While the Mayors Taskforce for Jobs still exists today, it has become a network for communication between Mayors, rather than a driving force for change.

The differences between the case studies are described in Figure 11.

Figure 11: Case studies compared

\begin{tabular}{|l|l|l|}
\hline & $\begin{array}{l}\text { Community Employment } \\
\text { Group }\end{array}$ & Mayors Taskforce for Jobs \\
\hline Led by & Central government & Local government \\
\hline Target population & Disadvantaged communities & Youth \\
\hline Dates of operation & $1991-2005$ & 2000 -current \\
\hline Funding level & $\sim \$ 20 m$ per annum & $\sim \$ 10 m$ per annum \\
\hline Partners & $\begin{array}{l}\text { Central government } \\
\text { employees/communities }\end{array}$ & $\begin{array}{l}\text { Government } \\
\text { Ministers/Mayors }\end{array}$ \\
\hline
\end{tabular}

While both case studies represent government and communities working in partnership to address long-term unemployment, the institutional 
structures, method of operations and nature of leadership for each case was different. However, there was some overlap in timeframe and in personnel, with a fieldworker in the Community Employment Group becoming the Mayor who started the Mayors Taskforce for Jobs.

\section{The analytical framework}

Drawing on the Ansell \& Gash (2008) model of collaborative governance, this research started with slightly modified definition, to reflect the notion of ongoing engagement rather than one-off exercises of collaboration. The next step was to construct the cases, focusing on three main perspectives:

- that of the media as viewed through media reports of the time

- that of the people involved in the cases, drawing on their reflections and perspectives through semi-structured interviews

- that of the policy-makers, as recorded in Ministers' archives, policy papers, Hansard: the official record of Parliament and speeches from Ministers of the time.

This approach (Figure 10) led to multiple layers of coding and the creation of two datasets, each reflecting the entirety of collected data about one case study. Interview transcripts, media reports and documents were uploaded to NVIVO and coded according to the year and their place in the initiative's lifecycle. This information was then mined for themes relating to leadership, accountability and participation. Starting with a wide pass, each theme was then reviewed in turn and sub-themes uncovered, which were then coded. This enabled the construction of two narrative case studies that paid specific attention to leadership, accountability and participation throughout. 


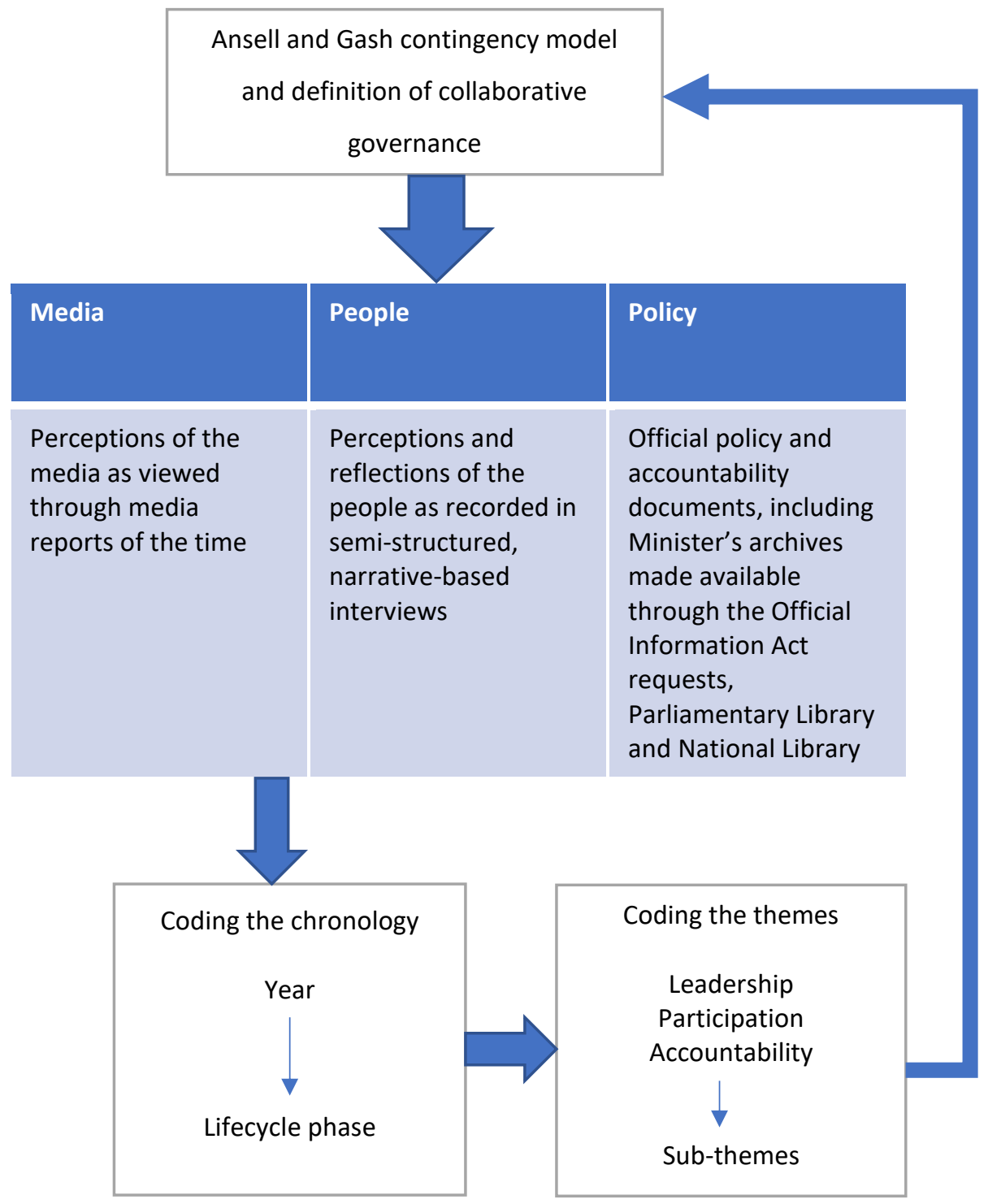

\section{Data collection procedures}

Yin (1989) notes that the case study approach typically uses a range of data collection methods such as archives, interviews, questionnaires and observations. This methodology allows for triangulation of data and strengthens the basis for conclusions. Observations were not possible as most of the initiatives' lifecycles existed outside the time period available for research. However, rich contemporary data sources existed in Parliament's verbatim record (Hansard), media releases and reports of the 
day and speeches from Ministers of the Crown recorded on the Beehive website from 1993.

\section{Documentary evidence}

Hansard and media files were created by a download from the Parliament and Newztext websites, where a search by keywork elicited all mentions of the Community Employment Group or Mayors' Taskforce for Jobs and created a chronological record of these mentions in the context of the relevant debate (Hansard) or article (media). These files were then mined for quantitative information (such as how often the Community Employment Group appeared in a Minister's media release in a particular year) and for content relevant to the case study.

In addition, accountability documents for the initiatives, reviews of the initiatives and records of meetings provided for a rich source of 'as it happened' information. The 'wayback machine ${ }^{8 \prime}$ website also allowed for access to contemporary documents and marketing material. Soft copies of documents were uploaded into NVIVO and coded according to the date created and topics covered.

While requests for information from New Zealand Government Agencies were made under the Official Information Act 1982, these elicited mainly publicly available information and in one case, an invitation for the researcher to discuss the case with a key informant rather than provide documentary information. The publicly available information was coded in the same way as the accountability documents, reviews and records of meetings. Verbatim notes were made during the discussion with the key informant and used, with their permission, as part of the evidence for this thesis. These notes were uploaded to NVIVO and coded in the same way as formal interviews (see below).

\footnotetext{
${ }^{8} \mathrm{~A}$ website that provides access to previous versions of websites as cached by web crawlers. For example, a search on a particular web address will deliver a calendar of when web crawlers cached information on that website. Clicking on the appropriate date will deliver a copy of the website from that date.
} 
While several hundred documents provided for a chronological history for each initiative, concepts such as leadership and accountability (beyond the written reports) would have proven difficult to understand without the reflections of the people who participated in the initiatives. Interviews also provided for understanding the particular (unwritten) settings of the time, the personalities at play and the politics that set the context.

Potential interviewees were identified through the documentary evidence, and in each case, they were asked who else could provide insights into the initiatives (reflecting a snowball approach to interviews). An initial approach was made via email and once contact had been established, an interview schedule, information note and consent form were emailed to participants. All but one interview was conducted face to face, and the interviewer checked at the beginning of each interview that the information note had been read. All participants then signed the consent form in the interviewer's presence. The interview conducted via Skype included the participant signing the consent form and scanning it, then emailing it back to the interviewer.

The interview format included a combination of open questions and probing. Open questions were used to invite the interviewee to relay their full involvement in the initiative, from start to finish. For example, the open questions included questions 'when did you first hear of the initiative, when did you first get involved, how did you get involved?' In some cases, few prompts were necessary as the interviewee provided a rich and detailed story of their experience.

The interview format also enabled a coherent, chronological narrative to be developed from each interview, reducing confusion about events and their timing, or individual's involvement in the initiative. Probing was used in two ways. First, in preparation for interviews, the researcher identified any puzzles from the documentary evidence that the interviewee might be able to shed light on and probed for interviewee recollections at relevant 
points in the narrative. Second, probing was used when the interviewee raised an interesting or unique point, which warranted further exploration. As interviewees were asked to recall events that had happened some time ago, retrospection was used. Retrospection is a method used, in particular, in social psychology, second language acquisition studies and reading research (Mann, 1986). Retrospection involves the recollection of an event, activity or task that the interviewee had been engaged in, and in reporting what they can recall of the mental states and actions they experienced at the time.

In one case, the interviewee brought along two people he had worked alongside, leading to an unintentional focus group, where perspectives and reflections were challenged on the spot. This situation led to:

- a greater understanding by all present of not only what took place, but what else was happening behind the scenes that explained why the events took place

- a much richer understanding of the events that took place, as each person was able to explain their understanding and motivations behind their actions across a series of events.

Interviews were supplemented with the biography of one key stakeholder who had died before any research could take place. The biography included interviews with people involved in the initiatives, leading to a wider range of perspectives on the cases. The researcher read through the biography, noting any mention of the Community Employment Group, Parekura Horomia's leadership style and how he interacted with people; and any mention of ways people were held to account. All relevant sections were then used to create an annotated index, with page numbers and paragraphs or sections from the biography typed out in full. The resulting document was uploaded to NVIVO and coding carried out as described below.

Overall, nine interviews were conducted with people involved in the Community Employment Group and four with people involved in the 
Mayors Taskforce for Jobs. These people were key actors in each of the cases.

\section{Data management}

All but one interview was recorded, then transcribed and stored in NVIVO. Verbatim notes from the remaining interview were also stored in NVIVO along with verbatim notes from personal communications with parties involved in the Mayors Taskforce for Jobs and Community Employment Group. Copies of documents were uploaded to a directory of files named and sorted by date and type.

Media files were created by using downloads, which delivered a soft copy document with all content ordered by date. These media files included every article that mentioned the Community Employment Group or Mayors Taskforce for Jobs published in a New Zealand newspaper between 1991 and 2017. Similarly, files were downloaded from Hansard, resulting in a complete record of Parliamentary debates that referenced the Community Employment Group or Mayors Taskforce for Jobs.

Coding initially focused on the major topics of leadership, accountability and participation as well as a timestamp. A second, third and fourth pass of coding was made as information emerged about different types of leadership, accountability and participation, providing for comparison at a more granular level.

\section{Case study development}

Each case study followed the same process of development. First, the documentary evidence was used to build a chronological history for each initiative, to identify:

- when major decisions were made

- changes over time in how the success of initiatives were reported

- facts such as the unemployment rate to be added at the appropriate points, based on Statistics New Zealand's historical collection of data and publication of time series. 
The chronological history included a 'legacy' section for the Community Employment Group. This was at the request of key informants and reflected that the influence of the Community Employment Group did not stop on the day it was disestablished.

The interviews then allowed perspectives and reflections to be added to the chronological account. The results were sent out to the interviewees for review and additional information received was then added into the chronological account. Three key informants who had not been able to take part in an interview were also provided with a draft of the relevant case study and they provided comments that were then incorporated. Sending out the draft case study allowed for any missing or misinterpreted information to be identified and corrected. It further prompted the recollections of key stakeholders, enabling an even richer understanding of the initiatives to be included. Comments received from stakeholders indicated that the case studies were 'accurate' and 'fair'. Many commented on how the case studies had 'brought back memories.' Flyvbjerg (2006) posits that case studies cannot be summarised. The dense case study is more useful for the practitioner and interesting for social theory and can be different things for different people. The case studies in this research are the main analytical units, necessarily dense and set within the context of their time. This approach satisfies Eisenhardt's (2007) second criteria for theory-building research, that the reporting of information should be thorough to give confidence that any resulting theory is valid. The result is a comprehensive historical narrative for each initiative, that includes not only what took place, but as far as possible, why events took place, according to the people who were involved. This is, after all, their story.

\section{Contribution to scholarship}

As noted in Chapter 2, while collaborative governance remains a somewhat elusive concept, the challenges of collaboration between government and communities are real and relevant to the question as to 
what institutional arrangements enable iterative and ongoing community problem solving to address long-term unemployment? While the tone of this question is normative, the methodology described in this chapter allowed for the drawing of lessons from two major initiatives from the New Zealand public sector, both of which involved collaboration between government and communities, and both of which focused on the wicked problem of long-term unemployment.

The presentation of the case studies in the following chapters allows for analysis of three key components of collaborative governance: leadership competencies and behaviours, accountability arrangements - both formal and informal, and the nature of the participatory process. This testing of the three defining elements of collaborative governance against the reality of two major initiatives in itself forms a significant contribution to scholarship. An additional contribution to scholarship is from the case studies themselves, with the delivery of two historical narratives at a level of detail that has not previously been the subject of any kind of exposition, let alone analysis. 


\section{Study - Part 1}

The Community Employment Group case study is covered in two parts:

- Part 1 (this chapter) details the origins, commencement and consolidation of the Community Employment Group initiative.

- Part 2 (Chapter 5) describes a downward trajectory of the initiative.

This chapter:

- describes the Community Employment Group from 1991 to 1996, the time when it was considered at its most successful

- includes the origins of the Community Employment Group, highlighting the challenges faced by its leader, Parekura Horomia in bringing together three disparate groups of people into one cohesive unit; and setting up the unit to lead in an environment that was not necessarily welcoming of this approach.

\section{Uneasy beginnings}

This section begins with a description of the origins of the Community Employment Group, including the type of people involved, the sponsorship from Government and the types of initiatives that were delivered. The people involved formed the initial cohort inside the Community Employment Group and came with different expectations of leadership and different ways of working.

The origins of the group

The Community Employment Group was established as a separate business unit within the Department of Labour in 1991. The Community Employment Group brought together three existing teams from the Departments of Internal Affairs and Labour:

- Alternative Employment Programme.

- Group Employment Liaison Scheme.

- Community Employment Development Unit. 
The Alternative Employment Programme was based in the Department of Internal Affairs. The programme focused on local economic development, with a major goal being self-employment (Interviewee F).

The Group Employment Liaison Scheme was based in the Department of Labour, with a mandate to work with gangs (Department of Labour, 1999; Interviewee F) through a network of fieldworkers in communities. A key feature of the Group Employment Liaison Scheme was the personnel; who came from or were closely linked with gangs; and the perceived independence of these people (Department of Labour, 1999). Known to 'defuse nasty gang situations' for the National Government, people working in the Group Employment Liaison Scheme had important links with Ministers of the Crown and government support to do what it took to resolve situations (Interviewee B). Closely related to the Group Employment Liaison Scheme was the Group Development Assistance pilot. The target group was 'people with or at risk of gang association, criminal records, and drug and alcohol abuse problems' (Department of Labour, 1999). Run by 'one person based in Timaru', the Group Development Assistance Pilot was also brought into the Community Employment Group (Interviewee C).

The Community Employment Development Unit was set up in 1989-1990, as a result of lobbying by people who worked in the Small Cooperative Enterprises programme (Interviewee A; Interviewee C). The Community Employment Development Unit was purposely configured to operate outside usual bureaucracy and focus on job creation and communitybased economic development (Gardner, 2014). It was to be 'nimble, working with people, getting their ideas, developing them, small seed grants to make things happen...' (Interviewee F). The philosophy of the Community Employment Development Unit was built on the recognition that 'the uniqueness of locality matters when it comes to implementing employment projects' (Scott, 1995). Within the Community Employment Development Unit, the workers were 'community corporate warriors' (Interviewee D) with a focus on meeting community needs through 
innovative means. New ideas and projects were developed every few weeks and community meetings were used by the fieldworkers to get people excited about possibilities (Interviewee F).

Just prior to the 1990 election, Parekura Horomia was appointed as the head of the Community Employment Development Unit with a brief to close it down (Gardner, 2014); (Interviewee B; Interviewee C; Interviewee D). Parekura Horomia's subsequent actions to secure support for the continued existence of the team identify a leader who was not willing to blindly follow instructions.

\section{Securing the Community Employment Group's existence}

On 27 October 1990, the National Party won the General Election in a landslide, winning 67 of the 97 seats in Parliament (Electoral Commission, 2016). The new National Government had an agenda of rationalisation (Interviewee B; Interviewee C) and the future of groups such as the Community Employment Development Unit was uncertain. In early 1991, Roger Maxwell, the Minister of Regional Development ordered a review of enterprise assistance programmes with the aim to ensure efficacy and to reduce the potential for duplication. The review was completed in June 1991 (Maxwell, 1991b) and Cabinet decisions followed shortly after (Maxwell, 1991a). Decisions included that the Department of Labour would be responsible for employment programmes (Horomia, 1991a). Jas McKenzie, the head of the Department of Labour, was a 'reluctant owner' of the Community Employment Development Unit (Interviewee D) who gave Parekura Horomia the mandate to close the unit down (Gardner, 2014); (Interviewee B; Interviewee C; Interviewee D). Instead, Parekura Horomia saw an opportunity to bring together the Group Employment Liaison Scheme, Small Cooperative Enterprises programme and Community Employment Development Unit to deliver on social, economic and employment outcomes and include a focus on Māori. Parekura Horomia persuaded Jas McKenzie to establish the Community Employment Group as a new unit (Interviewee D). This approach met the rationalisation 
requirements of the National Government while enabling the teams to continue (Interviewee D) with an official aim of improving coordination and effectiveness while retaining the teams' unique approach, networks and outcomes (Department of Labour, 1999). This early vision of Parekura Horomia was carried throughout Horomia's leadership of the Community Employment Group.

\section{First steps}

The Community Employment Group began operating on 3 October 1991, coinciding with the public announcement of Parekura Horomia's appointment as General Manager. An early mission was:

'To encourage and assist communities and organisations in the development and establishment of new employment initiatives through information dissemination, brokerage, facilitation, networking and transferring the benefits of previous successful initiatives to other communities and organisations.' (Office of the Chief Executive, Department of Labour, 1991).

Roger Maxwell became Minister of Business Development, Associate Minister of Employment and the Associate Minister of Immigration. Bill Birch, Minister of Employment, delegated Roger Maxwell responsibility for the Community Employment Group. At the time, this caused some concern as 'everyone thought what that meant was that basically community employment was going to be subsumed into business development...' (Interviewee E). However, Roger Maxwell saw the two portfolios as complementary and supported both. 'So, the two roles were quite well aligned... they were complementary. There was real base stuff in the community, kick starting the community or individuals in the community and then if they did start to get a bit successful, they had other levels of support that could be brought in through the Business Development Programme ${ }^{9 \prime}$ (Interviewee K). 'He became an advocate [for

\footnotetext{
${ }^{9}$ The Business Development Programme was established by the National Government in 1990, under the control of the Ministry of Commerce (Mazzarol \&
} 
the Community Employment Group]' (Interviewee E). 'I used to take him around quite a bit and he just loved this community, these community initiatives that were doing stuff that engaged people, instead of just a benefit and nothing else and a job that might not be there. He loved it' (Interviewee A). This support was attributed to the high unemployment of the time and the need for the government to be seen to be doing something. 'I found the government interestingly receptive to [the work of the Community Employment Group]' (Interviewee E). 'A lot of politicians would like to say that this was happening in their patch' (Interviewee A).

By 1 November 1991, the structure for the Community Employment Group had been approved by the Chief Executive; negotiations with the Public Sector Association (the union for public servants) completed; and advertisements for management and other key positions drafted for placement in newspapers on the following day. A transition team was in place, drawn from all three teams. In addition:

- the self-employment assistance component of the Local Employment and Enterprise Development Fund had been refined and renamed as Be Your Own Boss

- a transitional Business Skills Training package had been approved and allocated

- the criteria for the Community Employment Assistance Project Fund had been finalised and grants made as opportunity arose.

The most urgent task was seen as filling the management positions so that 'decisions could be taken by the people who would implement them' (Horomia, 1991b). The explicit intention to delegate decision making was

Clark, 2016). The Business Development Programme was delivered by Business Development Boards and comprised four components: 1 ) a preliminary business assessment; 2 ) business training (as identified by the assessment); 3 ) access to grants in three areas (innovation, strategy, implementation); and 4) best practice education and recognition, including business development quality awards. The emphasis was on the benefit to the individual client and the programme was predominantly delivered by private sector consultants. The programme was ceased in December 1999 (Massey, 2003). 
one part of Parekura Horomia's approach to accountability - the other part was that he held these managers to account for their decisions often, and in front of their colleagues.

Staffing in November 1991 comprised 11 Community Employment Advisors transferred from the Community Employment Development Unit, 15 Group Employment Liaison Scheme staff transferred from the New Zealand Employment Service and 16 Alternative Employment Programme Advisors transferred from the Department of Internal Affairs (Department of Labour, 1992). The intention to build on existing strengths was clear. In November 1991, Parekura Horomia submitted a structure diagram to Bill Birch, the Minister of Employment. This structure introduced the range of clientele expected to be targeted by the Community Employment Group and the notion of field staff, with the head office role supporting these staff (Figure 12). An unusual feature of this diagram is that communities are explicitly identified as a part of the structure. 


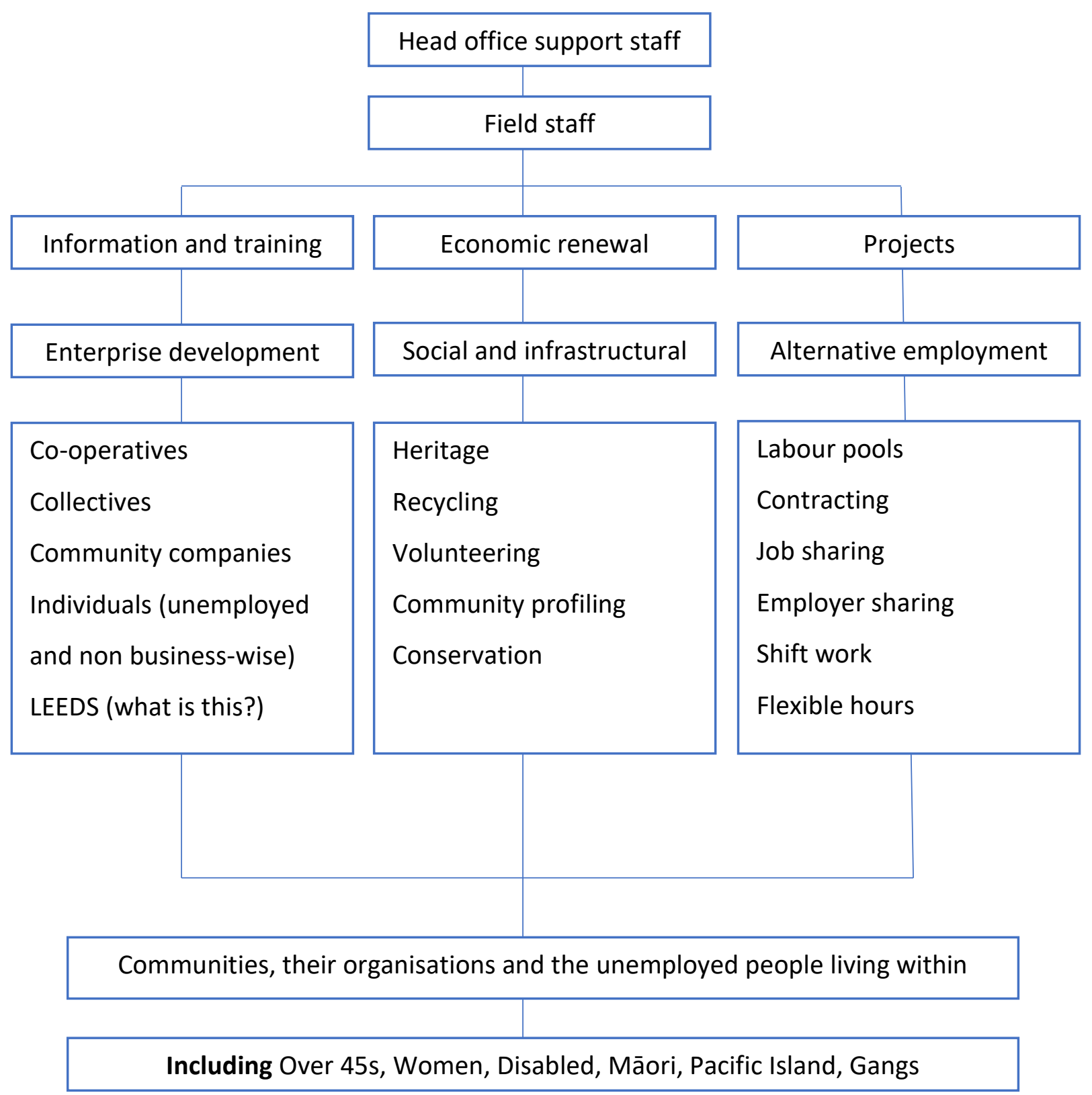


By 14 November 1991, funding was transferred to the Community Employment Group (Maxwell, 1991c). The budget in 1991/92 was approximately $\$ 5.7 \mathrm{~m}$ in operating costs and $\$ 11.557 \mathrm{~m}$ for payments on behalf of the Crown. Out of this budget, two funds were established, although of the funding in the 1991/92 budget, 70 per cent had already been committed or spent and only 30 per cent was available for use (Figure 14).

Figure 14: Community Employment Group Funding

\begin{tabular}{|l|c|}
\hline LOCAL EMPLOYMENT AND ENTERPRISE DEVELOPMENT FUND & \$m \\
\hline $\begin{array}{l}\text { Local Employment and Enterprise Development Scheme wind down costs } \\
\text { (committed) }\end{array}$ & 1.678 \\
\hline $\begin{array}{l}\text { Work Development Scheme and Small Cooperative Enterprises } \\
\text { programme wind down costs (committed) }\end{array}$ & 1.005 \\
\hline & \\
\hline Self-Employment Assistance Programme & 0.456 \\
\hline Business Skills Training (spent) & 3.829 \\
\hline Be Your Own Boss (committed) & 0.100 \\
\hline Company Rebuilders (committed) & 0.900 \\
\hline Agency-Based Projects & $\mathbf{7 . 9 7 7}$ \\
\hline TOTAL & \\
\hline & 0.308 \\
\hline COMMUNITY EMPLOYMENT ASSISTANCE PROJECTS FUND & 2.521 \\
\hline Community Employment Projects (spent) & 0.654 \\
\hline Community Employment Projects (unspent) & 0.096 \\
\hline Group Development Assistance (spent) & $\mathbf{3 . 5 7 9}$ \\
\hline Group Development Assistance (unspent) & $\mathbf{8 . 0 3 0}$ \\
\hline & $\mathbf{3 . 5 1 7}$ \\
\hline
\end{tabular}

A major focus for Parekura Horomia and his team in November 1991 was the immediate and compressed tender process for Be Your Own Boss Funding. The tender opened on 14 November 1991, with registrations of interest due on 20 November 1991. Tenders closed at 4pm on 6 December 1991 and funding allocated in January 1992 for an initial contract period of nine months (Maxwell, 1991c). Over 300 organisations registered their interest, with 80 submitting full tenders. Strict criteria were applied to the selection of tenders, with approximately 40 receiving funding (Maxwell, 1991d). 
At the same time, Parekura Horomia and his team undertook a range of regional visits and prepared for the official launch of the Community Employment Group (planned for March 1992) with:

- a new structure

- policy guidelines

- integration of the Group Employment Liaison Scheme, Group Development Assistance and Alternative Employment Programme staff into the Community Employment Group

- objectives for all fieldworkers

- monitoring and reporting systems (Maxwell, 1991c).

By 4 December 1991, a structure had been agreed for the Community Employment Group, including the division of fieldworkers into five regional teams: Northern, Central and Southern North Island and Northern and Southern South Island. Most field positions were filled by existing field staff from the Group Employment Liaison Scheme, Community Employment Development Unit and the Alternative Education Programme (Maxwell, 1991d).

The joining of three staff cultures into one was reasonably smooth considering the different types of people and cultures that had arisen in the teams. Each team had a very strong identity and way of working. 'CEDU [the Community Employment Development Unit] probably operated at a higher level... were probably better dressed than the rest, while SCOPE [Small Cooperative Enterprises programme] and GELS [Group Employment Liaison Scheme], a lot looked like unemployed people.' (Interviewee A). A few people had 'feathers fluffed up and some left' (Interviewee A) and '[some] people that... worked for CEDU [the Community Employment Development Unit] didn't really fit and slowly people fell out' (Interviewee F). However, the 'commonality was strong. And that commonality was about community development, practices and working. We all worked in the same way with groups.' (Interviewee A). ... fieldworkers were set up with a 'car, cell phone and laptop' (Interviewee 
D) and this way of working persisted through the early days of the Community Employment Group.

The Community Employment Group was quick to be seen as a cohesive group, albeit one unusual in the public service. 'Community Employment Group staff were not your usual public servants. They reflected the communities they worked in - Māori communities, rural communities, women, gang affiliates, activists and others.' (Gardner, 2014).

At times, it was difficult to determine where loyalties lay: to the community or to the public service. Gardner (2014, p. 113) noted 'they were a team of innovators spread right across the country, only meeting with their regional manager once a month, and quite often in conflict over whether their primary allegiance was to their community or to the public service.' Interviewee A explained 'because for many workers they can identify with the community too deeply that it is a risk in its not a professional approach. At the end of the day you have got to be clear about who pays your wage.' Interviewee K added that 'They were a small team but they tended to be the right people. They believed in what they were trying to do, but they were also worldly enough to know there had to be accountability and they needed some success at the end of the day. Otherwise, all the effort would be for nought. And by and large, they had those people' (Interviewee K). In this case study, accountability to whom was a live and continuing debate for many of those involved throughout the existence of the Community Employment Group.

In some cases, fieldworkers were seen to be acting outside normal structures. Interviewee C explained that 'what was driving all of us was a passion to actually empower communities. So, if the bureaucracy got in the way then we just went (a)round it... but bureaucracies hate outfits like that. They can't control them.'

Parekura Horomia, as General Manager, was also seen to act outside the normal rules at times. 'In the nicest possible way, he was prepared to take risks. He had a good gut feel, while he was a senior bureaucrat, I think 
probably, the state services didn't see him as their ideal, follow the doctrine. And that's why he was so effective. He was prepared to go out on a limb about an issue and say my gut feeling is this is going to work and that, I suppose was reflected in the personnel he hired to head up the teams in the various parts of the country' (Interviewee K). This preparedness to go outside the normal rules is unusual in the public sector.

The frenetic pace of establishment in 1991 was continued into 1992. On 15 January 1992, 47 successful tenderers were announced for the delivery of the Be Your Own Boss programme. All agencies that received an offer accepted and, by 4 February 1992, contracts were with the agencies for signing. (Maxwell, 1992a). By 21 January 1992, six administrative support positions had been confirmed and duties commenced; the five regional teams had met and briefings taken place; and appointments to the two senior management positions of Community Operations Manager and Manager Operations Support had been made (Horomia, 1991b). The pace of establishment was likely part of Parekura Horomia's plans to secure the future of the unit.

Senior appointees made at that time were to remain with the Community Employment Group for quite some time, representing a stable leadership team. The 1997/98 Community Employment Group Annual Report listed Meka Whaitiri, Marie France, Margaret Crozier, Richard Brooking, John Bishara, Jay Sepie and Hilary Allison in key management positions (Community Employment Group, 1997). All had been with the Community Employment Group from the beginning (Interviewee A; Interviewee B; Interviewee C; Interviewee D; Interviewee E).

The official launch of the Community Employment Group appeared to be the only casualty of compressed timeframes, being moved from 14 February 1992 to 25 March 1992 (Maxwell, 1992a). Ongoing focus was on the remaining personnel appointments; office refurbishments in Wellington and the establishment of permanent field offices; 
implementation of monitoring and filing systems; and development of national strategies (Horomia, 1991b).

By the end of February 1992, the mission of the Community Employment Group had changed slightly: 'to help communities identify their own resources and to use those resources to increase their employment potential' (Robinson, 1992).

In April 1992, the Community Employment Group facilitated an 'Employment Taskforce', with politicians and senior officials ${ }^{10}$ visiting the small towns of Murupara, Whakatāne and Ōpōtiki on the East Cape. Community members were able to discuss a range of proposals directly with the politicians and senior officials, including the types of programmes delivered by the Community Employment Group. The direct discussion of community concerns with high-ranking Ministers was an effective form of participation by communities, outside of that facilitated by fieldworkers.

Of particular concern to those taking part in the Employment Taskforce was the high levels of youth unemployment and no available jobs. Roger Maxwell, the Associate Minister of Employment, felt that the reorganisation of the Community Employment Group and establishment of Business Development Boards would respond to the concerns raised, but that further investigation was warranted over the next month (Maxwell, 1992c). Further rationalisation of the Community Employment Group and Business Development Boards was raised by April 1992 but resoundingly rebuffed as 'the Business Development and Community Employment programmes now have a clear focus and are distinct as to outcomes' (Maxwell, 1992b), reflecting the tactics of Parekura Horomia in not just establishing the Community Employment Group, but establishing its relationship with other, like initiatives.

\footnotetext{
${ }^{10}$ The Associate Minister of Employment, Secretary of Labour, Secretary of Commerce, General Manager of the Community Employment Group, an advisor from the Department of Prime Minister and Cabinet, the Chairman of the Employment Caucus Committee and Member of Parliament for East Cape
} 
On 19 February 1992, Parekura Horomia put forward a proposal to rearrange the funding for 1992/93, going from the two funds (Local Employment and Enterprise Development Fund and Community Employment Assistance Fund) to one Project Fund. Community Employment Services and Policy Advice were the outputs proposed for inclusion in the 1992/93 budget (Horomia, 1992a). This would allow for more flexibility within the Group of how finances were applied, managed and accounted for.

The Community Employment Group output plan described as the role of the Group as 'the provision of a range of services to assist communities, groups and individuals to identify their local resources, to overcome barriers to employment and enterprise development and to generate sustainable employment opportunities at a local and national level. It included:

- providing information, advice and brokerage services, through a nationwide network of fieldworkers, to the Community Employment Group's clients within the community

- identifying innovative local strategies and initiatives which may have national employment-generating potential and facilitating development of these strategies

- promoting and disseminating information on successful employment and enterprise-related strategies through publications both formal and informal links with community organisations

- liaising with the New Zealand Employment Service and other agencies to ensure that clients are aware of the most appropriate sources of advice and assistance, and to facilitate the availability of labour market opportunities (eg, Enterprise Allowance, Community Taskforce and Taskforce Green) to the Community Employment Group's clients

- liaising and working in partnership with central and local government, community agencies and the private sector to encourage alternative sources of funds for employment-related initiatives 
- bringing community partners together to work in partnership to address the needs of alienated groups and those not served by existing agencies or programmes

- administering POBOCs [Payments on Behalf of the Crown], including approving proposals, negotiating contracts, and monitoring and evaluating expenditure and results' (Horomia, 1992a).

All of these ways of working (apart from the last) involved extensive use of fieldworkers to coordinate.

At that stage, performance standards had not been developed, although commitment was made to 'facilitate a quantifiable level of services and activities'. Measures were intended for the development of national community employment strategies, the number of community planning days, the number of local economic renewal strategies and the number of business skills training places, among others (Horomia, 1992a).

The Policy Advice output included the 'provision of advice to the Minister of Employment on community employment issues, including the most appropriate design and mix of Government assistance to the community sector and the social and economic impact of policies in this sector.' (Horomia, 1992a).

Projects were categorised as either 'enterprise development' or 'employment development'.

- Enterprise development included Women in Enterprise; Cooperatives; Company Rebuilding; Community Companies; Individuals (unemployed and non-business wise); Small Business; Local Employment and Enterprise Development Scheme and Be Your Own Boss.

- Employment Development included Heritage; Recycling; Volunteering; Community Profiling; School Leavers; Labour Pools; Contracting; Job Sharing; Employer Sharing; Marae Projects and Work Programmes. 
Clientele was wide-ranging and included Over 45s, Women, Disabled, Māori, Pacific Island, Gangs, Local Authorities, Government and Community Agencies and the private sector (Horomia, 1992a).

The predominant way of working was through its national network of fieldworkers, providing advice and grants to organisations that would deliver appropriate assistance to target client groups. (Horomia, 1992a). Of the total $\$ 11.557 \mathrm{~m}$ in the Community Employment Group budget (excluding operating costs), $\$ 1.52 \mathrm{~m}$ had been committed into the 1992/93 year. (Horomia, 1992a).

\section{Consolidation}

The 1993 election resulted in a return of the National Party to power and changes for the Community Employment Group. Alongside a new Minister of Employment, Wyatt Creech, multi-party talks about employment resulted in a Task Force with an ambitious goal: to give every New Zealander an opportunity to be in paid work (Bray \& Strang, 1996). The Task Force comprised 11 members including chief executives of private businesses, polytechnic principals, mayors and representatives from the Council of Trade Unions, the Employers' Federation and Government organisations (McKenzie, 2016).

In November 1994, the Task Force presented a wide-ranging final report to the Prime Minister, Jim Bolger. The report included 120 proposals centred around three areas:

- growth and employment

- education, training and employment for youth

- employment and training policies for adults.

The report also proposed greater community involvement in employment initiatives and a pro-active strategy to overcome disadvantage faced by Māori and Pacific Island people (Bray \& Strang, 1996). In response, the National Government announced (inter alia) the provision of additional resources to the Community Employment Group over the next three years. 
(Bray \& Strang, 1996). The assistance was to be targeted to Māori, disadvantaged rural and urban communities, Pacific Islands people and women. The Focus on Employment package resulted in the Vote Employment Non-Departmental Output Class 01: Community Employment Projects increasing by $\$ 0.850 \mathrm{~m}$ from $1996 / 97$ to fund new Community Employment Mobile Information Service projects, additional Specialist Advice projects and Key Worker projects (Troup, 1995). To support the increase, additional funding of $\$ 1.246 \mathrm{~m}$ was provided in each year to employ an additional four field and four head office staff (Troup, 1995). At this time, the Government described the Community Employment Group as 'the primary agency responsible for facilitating local employment initiatives' (New Zealand Government, 1995). By 9 August 1996, Parekura Horomia was able to report to Wyatt Creech, the Minister of Employment that 'a number of organisations which CEG [the Community Employment Group] has worked with are now showing the benefits of broadening existing skills and there is a consequent reduction in the problems these organisations encounter in implementing ideas (Horomia, 1996b). This capability building within communities was a long-lasting feature of the Community Employment Group and became a core part of its legacy. The associated Cabinet Minute also identified a refocusing of Community Employment Group business, including disengagement from national strategies by 30 June 1999. Government's reason given for exiting programmes was that it would shift the Community Employment Group back to being a 'seeding funding agency rather than a permanent funder of programmes... in line with the original intent of the Community Employment Group' (Creech, 1996). This included progressively redirecting all funding spent on the Mature Employment Service, Mainstreet and Business Grow to other initiatives. Be Your Own Boss Funding was also reduced from $\$ 3.8 \mathrm{~m}$ to $\$ 1.5 \mathrm{~m}$. Further increases of $\$ 2.381 \mathrm{~m}$ in $1996 / 97$ and $\$ 1.190 \mathrm{~m}$ in $1997 / 98$ were provided to enable implementation before redirected funding became available (Troup, 1995). The Government considered these initiatives were valuable but did not fit with the 
Community Employment Group's core business and so the Community Employment Group was directed to identify alternative agencies to take responsibility for the initiatives (Horomia, 1997c). The assumption of Government was that accountability for the initiatives could be shifted easily to another (unidentified) government department.

Once Cabinet decisions were known, the Community Employment Group moved quickly to implement the requirements and to determine a new strategy. This ability to redirect focus in light of shifting government priorities, and to take staff with him, was a skill practiced consistently throughout Parekura Horomia's leadership of the Community Employment Group.

Overall, projects targeted to one or more of the priority groups increased from 45 per cent in 1994/95 to 80 per cent in 1995/96 (Horomia, 1996c). This change was eventually seen as fundamental by the staff of the Community Employment Group and it took months of 'debate, discussion and testing the concept' to shift from a programme delivery to target group approach (Gardner, 2014). 'We had to be focused on the disadvantaged, so people had to be disadvantaged. The Dunedin people were how do you define disadvantaged and they kept asking us questions. And the answer was of course you could work it out for yourself. [Parekura Horomia] got frustrated. For God's sake, he said. If I look out the window and I see there's shit on the ducks' backs, then the ducks are disadvantaged' (Interviewee C).

In each of the strategies, emphasis was given to skill development. Parekura Horomia noted that many communities had an existing skill base but that the skills lacked an employment focus. For example, communities had the organisational and planning skills needed to plan a tangi but did not realise these could translate into an employment context (Horomia, 1996c). The deep knowledge Parekura Horomia had of communities was evident in this approach. 


\section{Māori strategy}

The Māori strategy was supported by:

- specific programmes such as Mahi a Iwi, He Oranga Poutama, Wahine Tukaha and the Māori Women's Development Fund

- partnerships with organisations such as the National Māori Congress, Māori Women's Welfare League, Te Puni Kōkiri, the Health Sponsorship Council and the Hillary Commission (Horomia, 1996c). Mahi a Iwi was a programme designed to support marae to enhance skills and develop assets. A staircasing model was used, with marae entering the staircase at the relevant step. Community Employment Group support was delivered according to the needs of the marae and the level of maturity in community strategic planning the marae had reached. This was an approach highly responsive to the needs of the government's community partners.

He Oranga Poutama was established through partnership between Te Puni Kōkiri, the Health Sponsorship Council, the Hillary Commission and Community Employment Group in 1995. Initially having a timespan of three years, the aim was to promote health, sports and fitness along with employment opportunities. Kaiwhakahaere (manager) positions were established in Northland, Auckland, Tainui, Bay of Plenty, East Coast, Hawkes' Bay and Taranaki (Horomia, 1996c). This programme evolved over time and was a part of the Sport New Zealand portfolio in 2013 (McKegg, et al, 2013). In this example, partnerships were made across government to deliver a multi-outcomes focused programme in communities.

\section{Rural/urban disadvantaged communities}

The focus of the rural/urban disadvantaged communities was to provide a safety net for those people not covered by other strategies. A key focus of the rural strategies was to deal with the unique effects of geographical isolation. In these programmes, partnerships with agencies such as Regional Councils and local development trusts were important (Horomia, 
1996c) to develop and support programmes of relevance to the local community.

\section{Pacific Island peoples' strategy}

The Pacific Island peoples' strategy reflected the population's relative youth, strength of cultural and church ties and diversity, reflecting another example of tailoring to the needs and reality of the specific community. For this strategy, links were formed with the Ministry of Pacific Island Affairs. Support from the Community Employment Group in 1995/96 focused on opening up access to opportunities for Pacific people, including raising awareness of the information and advice available (Horomia, 1996c)

\section{Women's strategy}

The Women's strategy had three elements: training, positive activity and networking. Within this strategy, a particular focus was on Pacific, Māori and young women, and self-employment (Horomia, 1996c). This was one of few strategies that did not use tailoring to a great extent, perhaps because the target group was so diverse.

\section{Other projects and roles}

Key workers were people appointed to roles in community organisations to carry out a range of roles, for example management, promotion, marketing, coordination, plan development and service development (Horomia, 1996c). These roles closely mirrored the fieldworker roles, although more specialist advice was available through Specialist Advice Projects, which involved consultants giving advice on specialist areas such as forestry management, strategic planning and marketing (Horomia, 1996c).

In $1995 / 96, \$ 300,000$ was allocated to four Community Employment Mobile Information Services units based in Invercargill, Paihia, Auckland and Wellington. Each Community Employment Mobile Information Services unit was responsible for targeting one or more of the target 
populations outlined in the Government's Focus on Employment strategy: Māori, Pacific Island, rural/urban disadvantaged or women. In 1996/97 a further Community Employment Mobile Information Services unit was commissioned to target the needs of women in remote communities in the upper South Island (Horomia, 1996c). The mobile units provided a different way to engage directly with communities.

Fresh Start commenced in June 1995. Fresh Start was a community initiative supported by the Prisoners Aid and Rehabilitation Society (PARS), the New Zealand Employers Federation, the New Zealand Council of Trade Unions, the Department of Corrections, New Zealand Employment Service, Community Employment Group and other organisations. The aim was to reduce reoffending by setting up a register of employers willing to employ people with criminal convictions (where the convictions were unrelated to the job under consideration). Modelled on a similar scheme in Australia, normal employment practices were followed but all job applicants were assessed on merit without prejudice to a criminal record. This scheme sought to avoid the (lawful) discrimination toward job seekers with a criminal record (Horomia, 1997d). This initiative represented a further enhancement to the Community Employment Group, where it partnered with a range of government and community-based groups to target a particularly vulnerable group of people in an innovative way.

In 1995/96, a project team was established to review the funded projects process and the results of a client satisfaction survey. Overall, 70 per cent of those surveyed were satisfied with the Community Employment Group's service delivery. As a result of the comments received in the survey, improvements were made to accountability documents, including the Funding Application Form, Letters of Agreement, Reports and communication with organisations as funding applications were processed (Horomia, 1996c). A report to Bill Birch, the Minister of Employment stated, 'The Community Employment Group distributed grants on a caseby-case basis, balancing an openness to innovation with managing the 
risks that come from working with a succession of new groups. Risk management included:

- evaluating the Mahi a Iwi strategy and Pacific Islands projects

- overhauling the existing database and management information systems

- developing further specialist advice projects that give funded groups the opportunity for management training' (Horomia, 1996b).

The overhaul of the existing database and management information systems was necessary because Prism, a software system that collated reports together, was starting to fail. This was due to 'real life [being] so messy that the software had so many clip-ons that it basically gave way, became dysfunctional' (Interviewee B).

While the Community Employment Group was focused on national strategies, it continued to support local initiatives. For example, in December 1996, a hailstorm in the Hawkes' Bay disrupted the fruit growing season. In response, the Community Employment Group reactivated mechanisms created in 1994 in a similar situation. A grant was provided to enable a help line to provide initial advice and referrals and the local fieldworker worked with the Rural Support Trust to support two coordinators to provide counselling and referrals and practical advice and assistance to growers, and to preserve the employment of cadets in the industry. In 1994, the total grant was $\$ 60,000$ while in 1996 , the cost was considerably less, due to the existing infrastructure and support from local sources (Horomia, 1996a). Similarly, in December 1997, the Community Employment Group was preparing to support communities affected by potential closures in the car assembly industry, with Thames and Nelson first on the list of communities to visit. Support in this case comprised needs analysis and support from Company Rebuilders (Horomia, 1997b). The reactivation of previous approaches indicated a growing number of ways in which the Community Employment Group engaged with communities to address local unemployment problems. 


\section{Exit management}

By 9 August 1996, Parekura Horomia had been asked by Bill Birch, the Minister of Employment to provide an update on progress on exit management, along with progress toward implementation of Focus on Employment measures. (Horomia, 1996b). Parekura Horomia noted that:

- the Business Grow National Trust had been dissolved and replaced by a charitable company, that the Ministry of Commerce would only pick up responsibility for Business Grow if a transfer of funding was made and that the Ministry of Labour and Commerce officials were unlikely to reach agreement on the future of Business Grow. Parekura Horomia asked the Minister of Employment to ask the Minister of Business Development to direct his officials to conclude an agreement on transferring responsibility

- the Mature Employment Service exit management group had met several times and no other government agency was able to ensure its continued existence

- discussions between the Community Employment Group, Education and Training Support Agency and the New Zealand Employment Service were continuing on how to continue to support the Be Your Own Boss programme

- work on exiting from Mainstreet had been deferred (Horomia, 1996b). These proposed transitions resulted in debate between Ministers not only about the ability of departments to 'pick up' programmes, but also the core purpose of the Community Employment Group. In particular, Roger Maxwell, the Minister of Business Development was unwilling to agree to the Business Grow programme being transferred without funding (Maxwell, 1996) and Katherine O'Regan, the Associate Minister of Social Welfare noting that 'seed funding' without ongoing funding 'inevitably creates... expectations which often strain the priority setting and resource allocation of the seed funders as well as the Departments which have to assume eventual funding responsibilities' (O'Regan, 1996). O'Regan (1996) 
also noted accountability problems for the Mature Employment Service, including:

- that the level of Community Employment Group funding was inconsistent, with each Mature Employment Service coordinator funded at a different rate (across 50 locations)

- that some Mature Employment Service centres had received further support from local authorities, corporate sponsorships or other business activities.

In late 1996, the National Government's focus turned to the upcoming October General Election. This marked the end of the period of growth for the Community Employment Group and the beginning of periods of structural change and uncertainty.

\section{The Parekura Horomia years}

Between 1991 and 1998, when Parekura Horomia was General Manager of the Community Employment Group, there was limited political or media criticism of the group. This was although 'it was politically vulnerable.... a difficult area' (Interviewee K). Most attributed this success to the personal leadership style of Parekura Horomia. 'He managed to keep a lid on every potential political disaster for ten years' (Interviewee A). He 'managed the dynamism and kept public and political criticism to a minimum. Through his team of head office lieutenants and regional managers, he managed to steer a course through what were often rough waters and allow his staff enough room to experiment and innovate on the ways they supported community organisations' (Gardner, 2014, p. 113).

The 2014 biography of Parekura Horomia; Kia Ora Chief, paints a picture of a man with deep roots in the rural East Cape of New Zealand. He was one of eight children brought up in a family with a strong Māori heritage. On leaving school, Parekura Horomia worked first as a manual labourer then later as a newspaper printer. Later again, Parekura Horomia became involved in the Department of Labour's work schemes, supporting unemployed people to gain skills. This background was to give Parekura 
Horomia a deep insight into both Māori communities and rural communities, one largely lacking in the Wellington-based public service. Gardner's biography is based on interviews with 65 of Parekura Horomia's family, friends and colleagues (Gardner, 2014), many of whom worked with him in the Community Employment Group. The following paragraphs draw significantly from the Gardner biography alongside the interviews held with (other) former Community Employment Group staff members. When the vacancy for the Community Employment Group arose, Gardner (2014, p. 111) described Parekura Horomia as 'a person who understood the community, who understood economic and regional development, who knew what was possible, where the resources were, who the movers and shakers were in the community and who had been there and done that.' Interviewee C was a little more succinct, noting that 'there was nobody on The Terrace ${ }^{11}$ who understood a guy with his arse hanging out of his trousers quite like Parekura Horomia.' Parekura Horomia was also able to work well with people of all kinds, including the imposing Bill Birch, Minister of Employment. 'I remember going into the committee room where he had to face Mr Birch... and then Birch looked at him and says "Well Parekura?" ... and Parekura said "You know me, Minister". And he got $\$ 2 \mathrm{~m}$ or $\$ 4 \mathrm{~m}$ to keep these groups going. So, then we get out the door and go down the lift onto Lambton Quay ${ }^{12}$ and we were just about 20 metres down the road and he suddenly dived next to a rubbish truck which is parked there, opens the door and "Kia ora", shake hands, blah de blah de blah, big chat with the rubbish man. Shut the door then we carried on down.' (Interviewee B).

Parekura Horomia's leadership style was unusual, or 'like no boss [Hone] had ever had before.... [he] recalled with great hilarity that Parekura looked as if he were conducting an orchestra of whiteboard pens. When they broached the matter with Parekura, he told them to shut up and that

\footnotetext{
11 'The Terrace' is a street in Wellington where many public-sector departments are based.

12 'Lambton Quay' is a street in Wellington.
} 
he had brought them to Wellington to see how a tight operation was run. You have to be really clear and make sure that, when everybody leaves, they know exactly what it is they are doing, OK?' (Gardner, 2014, p.119). Parekura Horomia 'had a habit of making everybody drop and gather round him on a regular basis and his attitude was, whatever you are doing, this is more important. And we would be subjected to anything from one hour to six hours, to a conversation which was largely him talking' (Interviewee B).

Parekura Horomia had the ability to win the support of his team, albeit with a reputation for having a temper. Parekura Horomia kept his regional managers very close 'we were up here a lot in Wellington and many, many, many nights in the Green Parrot ${ }^{13}$. And he trusted the judgement of his seniors, his managers' (Interviewee A). 'There were some serious dudes and tough characters in the CEG... yet Parekura was able to get the best out of them with his style of management.... [he] created an environment of trust amongst his staff... they felt safe with him. Even though at times he was annoying, staff knew that, as long as they were honest, he would back them' (Gardner, 2014, p. 297). '... he would yell a lot but more often than not, it was with anger and frustration at the situation rather than the individual' (Gardner, 2014, p. 300). 'He felt responsible for everything. So, the staff were trained up or admonished' (Interviewee A). 'He'd yell. But his bark was really worse than his bite. But he'd really put you on the spot... we were like naughty students and he was the principal' (Interviewee H). A story related by two interviewees related to a voice message left on one employee's phone. The employee recorded it and would play it at parties. 'I was there the day he left that message... and I thought, my God, if my General Manager... had just left a message like that on my phone, I would have been in the foetal position in the corner rocking back and forward...' (Interviewee $\mathrm{H}$ ).

\footnotetext{
${ }^{13}$ A local Wellington restaurant.
} 
Parekura Horomia also had a reputation for innovation in human resource management. 'He would talk to somebody in the lift going up to the work floor in the Wellington building and sometimes by the time they walked out that person had a job. And they could have previously been a cleaner but he'd put them into something else' (Interviewee B). In Gardner (2014, p. 118), Hone Harawira ${ }^{14}$ describes his recruitment 'the interview went okay, Parekura was just demonstrating who was the boss and taking the opportunity to take the piss out of me.' Parekura Horomia was also interested in young Māori. 'He took the unusual step of occasionally standing on The Terrace in Wellington and calling out to Māori students walking between the Kelburn university campus and downtown Wellington. He would talk to them and offer them work' (Gardner, 2014, p. 301). Another innovation was a holiday programme for the children of his staff. The children came into work with their parents and two staff were dedicated to looking after them. [He] 'made no attempt to hide the programme and justified it on the grounds of business continuity' (Gardner, 2014, p. 300). This willingness to work around existing rules and to create new ways of working was seen throughout the operations of the Community Employment Group.

Throughout his time as General Manager of the Community Employment Group, Parekura Horomia reported directly to the Chief Executive of the Department of Labour and was a member of the Senior Management Team for the department. He also had a direct link to the Ministers responsible for employment policy, signing out all correspondence to Ministers and meeting with them frequently. (Department of Labour, 1999); (Interviewee K). In this sense, Parekura Horomia took personal accountability for the operations of his Group. This link was strengthened by the placement of a former Community Employment Development Unit staff member into Roger Maxwell's office, the Minister Responsible for the Community Employment Group. Parekura Horomia had the support of his

\footnotetext{
${ }^{14}$ A prominent Māori activist and later Member of Parliament.
} 
Chief Executive, 'he had huge trust in Parekura... and they had the respect of Minister Birch and won the respect of Maurice McTigue and Roger Maxwell. It doesn't mean it was easy... boy did we have some fights' (Interviewee E).

Ministers took multiple opportunities to see the initiatives in action. They regularly and frequently toured the country visiting community groups to discuss progress. This level of engagement with communities enabled a deep understanding of who was involved in initiatives, who the clients were and how the initiatives operated. This deep understanding enabled Ministers to draw their own conclusions as to whether public money was being spent on the right things.

Parekura Horomia 'had an antenna for problems that might arise...[and] would not hesitate to rip up providers who were not delivering on their commitments' (Gardner, 2014, p. 115). 'I have no idea how many things Parekura saved before they exploded. I'm sure there were a few, but I never felt exposed. I felt CEG was at risk from different political philosophies... it was under risk in terms of being undermined by bureaucrats from other departments but no, I never felt it was risky in terms of its operations. Just because you had really good people who wouldn't have allowed that to happen. People who believed in public accountability' (Interviewee E).

Ministers supported the Community Employment Group, although were highly aware of the political risks. 'I believed in what they were trying to do so if something went wrong, l'd just have to handle it on the day... no one ever claimed they were going to change the world but we could make a little bit of difference in a lot of little places and in total it would add up to something significant over time' (Interviewee K). One interviewee attributed the support of Ministers to the context of the time. 'The risk was accommodated because the need was so high. It was a political risk high unemployment was a political risk... [politicians] needed to be able to say we are doing really innovative and amazing things, and to have a face 
in distressed communities. And that's what CEG provided. So, the political risk for a politician perceived to do nothing was seen to be higher than a risk of investing in CEG... there was a higher risk to doing nothing than there is to investing in this crazy bunch of people who every now and then turned out a gem. It was those gems that made a difference' (Interviewee E).

Monitoring and reporting systems were an important part of risk management. '... When Parekura came on board there were all these amazing things in place which drew on the government coffers... but accountability was just about non-existent. So, one of the things we had to do ... was supply masses amounts of information on where the different tranches of those projects were at. Because he came in knowing the dangers from the Group Employment Liaison Service and the risks they had to manage' (Interviewee B). 'He also had a number of tactics up his sleeve which was to review your own stuff before the others came in and did it for you' (Interviewee B).

Parekura Horomia 'knew... that Treasury always counted the outputs and Treasury counts. So, he had to be totally accountable about the outputs. And we all had to think of creative ways of demonstrating outcomes. And they had a system introduced... that resulted in weekly reporting... where every fieldworker documented significant encounters of work as interventions' (Interviewee B). Some fieldworkers did not appreciate the value of reporting 'every now and then he'd come up with these bloody... we had to do such and such and... we'd been filling in a log book or something for a week and I said to [my colleague], geez, I think this is going to kill us if we're not careful, because they'll know where we are and we don't always want to admit that. So, we stopped filling it in... in my case, weekly [report] was spelt with an "a"' (Interviewee C).

A reporting system, Prism, had been set up to collate reports for the Community Employment Group and throughout the life of the Community Employment Group, quarterly and annual reports to the Government were 
careful to identify the outputs resulting from the work of the Community Employment Group. These reports included commentary on the number of projects funded, how the projects fit within the strategic plan for the Community Employment Group and how many projects met contracted objectives. A final measure was of how many final reports were submitted on time.

Three interviewees noted the difficulty in evaluating community development programmes. 'Evaluation... is a real struggle in community development... there's no template except people's stories. And if you don't value people's stories because it could be skewed or... then it doesn't work. But if there is recognition of the value placed on the storyteller, about their journey and the consequences, then they can be very powerful. But they are very hard to sell politically' (Interviewee A). '... some of the work in facilitating responses in communities... that's hard to put a value on... It is like counselling for a grieving family or something and so everyone knows it is useful. What the ultimate reward is, who can tell?' (Interviewee K). 'Which is why this stuff is always easy pickings in terms of where are your outcomes? Where are your deliverables? What are you doing?' (Interviewee E). 'There were people who wanted to determine our success or failure depending on the number of jobs that were created... but... it wasn't actually about the number of jobs. It was about a whole economic transition... in many respects our work was about creating context and then jobs came from that... it was also about confidence in the community...' (Interviewee E).

There was tension too, between showcasing community success and attributing the success to the Community Employment Group. 'There were stories of groups that I worked with for a long time, but if they got an article in Employment Matters or the local rag... we stepped right back. We just loved them getting the glory for this project and we never really blew our trumpet about what's been done, and what we've done to enable that to happen and that was always the way we worked. But in the end, because we always did that, that kind of backfired in terms of us being 
seen as being valued, because we never promoted the value that we gave to things' (Interviewee $\mathrm{H}$ ).

In 1999, a Review of Community Employment carried out by the Department of Labour summarised its findings as follows:

'During the period CEG existed within DoL from 1991 to 1998, it developed a high level of maturity and effectiveness as an organisation. In the latter part of this period it was well in control of its processes and was achieving good outcomes for disadvantaged communities and successfully managing risk across a wide range of circumstances... Evaluations carried out on national projects illustrate that the CEG projects were holistic in their nature. They often address more than the employment needs of the people involved.... These evaluations have also demonstrated that the risk management tools used by CEG are effective, insofar as they allow groups to be flexible in their use of the money while still contributing to the government's desired outcomes' (Department of Labour, 1999).

The 1991-98 version of the Community Employment Group became known internationally for its approach and was seen as highly successful and innovative (Department of Labour, 1999). 'A strong relationship has been developed with Wisconsin in the United States, Australia... and South Africa' (Department of Labour, 1999). '... a Memorandum of Understanding with the State of Wisconsin... they would come and we would tour them around' (Interviewee A) 'We developed reciprocal relationships with people in Ireland and the Highlands of Scotland...' (Interviewee A). Representatives from the Community Employment Group also attended yearly meetings of the Organisation for Economic Cooperation and Development (OECD) Territorial Development Service as a member of the Local Economic and Employment Development Programme (Department of Labour, 1999).

In the Community Employment Group, Parekura Horomia had direct personal contact with each and every member of his staff, including his fieldworkers who were based in regions throughout New Zealand. The 
fieldworkers knew they had to personally stand behind every recommendation they made, and to defend this to Parekura Horomia who was not easily convinced. Parekura Horomia had extensive networks throughout New Zealand and with the organisations applying for funding. He was famed for his extensive travel around New Zealand and for regional hui (Gardner, 2014, p. 121) where he would personally demand answers from community individuals if there was a perception that funding was not being spent appropriately. Jas McKenzie, the Chief Executive of the Department of Labour, had no hesitation in paying for Parekura Horomia's travel expenses, a these were seen as vital to reaching into communities (Gardner, 2014, p. 115).

Parekura Horomia 'knew that his staff were out there doing all sorts of things that sometimes you couldn't imagine, he had good networks, he got feedback on who was naughty and who was nice. It was amazing how Wellington actually knew what was going on out there' (Interviewee B). This was in part attributed to the direct oversight that Parekura Horomia had. '... there was no person between you and the boss. Whereas if you were a person ten people down the line sitting in Kaitaia or Gore, where's your accountability? Whereas our accountability was to the top. Directly. Every day' (Interviewee E). '... we could circle the wagons pretty quickly. If Parekura didn't like what was going on, or what one of those regional people were doing, he would call them in. And there would be a free and frank discussion' (Interviewee E).

Parekura Horomia's management style was described as 'tight-loose-tight'. This included being 'as clear and accountable as possible with the money' (Interviewee B). 'Managers had to account for the funds they expended and they had to demonstrate they were creating jobs. This was the tight aspect of what Parekura coined tight loose strategy.... The loose aspect of the strategy was to give fieldworkers the leeway to be innovative' (Gardner, 2014, p. 299). This was 'to give initiative, organic development in work and the relationship of the fieldworker with the community and deciding whatever the project is and what stage it is... to be mobile and 
flexible... behind the scenes you have to have quite tight rules. Or expectations... you had to have tight accountabilities in order to give that carte blanche' (Interviewee A). Parekura Horomia's staff sometimes were frustrated with the time it took to make decisions. 'It took Parekura ages to make decisions.... often while waiting for more information or a different environment' (Gardner, 2014, p. 302). 'He would sit on applications and sometimes drive you to distraction because he just wasn't quite sure about it, there might be someone in there who was a bit dodgy...' (Interviewee A). Through this extensive networking and debate with staff, Parekura Horomia intimately knew the details of projects, and would have some that were closer to his heart than others. Mahi a Iwi was Parekura Horomia's 'baby and he was incredibly protective of it' (Interviewee B).

The fieldworkers in the Community Employment Group were seen as 'the right people'. They strongly believed in what they were doing and equally strongly identified with the communities they served. However, they knew they had to be accountable for what they did and that they needed to show success - otherwise, their efforts would be wasted. At times, the fieldworkers appeared to be working outside normal structures. Their passion for empowering communities meant that, if bureaucracy got in the way, they would go around it. This attitude was reflected in Parekura Horomia, as he was prepared to 'go out on a limb about an issue' and take risks.

Every decision to grant funding was discussed with all staff, so that everyone knew exactly what was planned. This allowed for robust discussion about risks or concerns, as well as mitigation strategies. As part of his risk management strategy, Parekura Horomia 'personally signed out every grant with the regional managers... [He] would have signing days when all the regional managers came in to meet with him and to sign off grant approvals. He would ask fieldworkers and managers about each application and then he would sign it and they all knew he was signing on trust' (Gardner, 2014); (Interviewee A). 'The system was tight - if you 
generated a proposal for funding it had to be tight' (Interviewee D). 'He was always on the lookout... he was quite intuitive... he signed out every application personally. He never let anyone else do that... he had the most extraordinary risk management. You couldn't put it in a textbook' (Interviewee A). Once an application was signed, a contract would be drafted. 'We had one person who managed all that... the levels of accountability weren't perhaps what they would be in today's public service... but we knew what we were investing in' (Interviewee E). The operating model reflected direct communication and integration with communities, enabling the Community Employment Group to build relationships that were unprecedented in New Zealand's history. This integration led to some misunderstandings. For example, with Parekura Horomia at its head and Māori being one of the target groups, the Community Employment Group was sometimes mistaken for an organisation that focused solely on Māori. '... it became a target, an easy political target, because its work was more concentrated with Māori' (Interviewee E). Indeed, the Community Employment Group was seen to be a leader in integrating a Māori perspective into their work, reflected in the Business Plan of 1997/98 and Te Puni Kōkiri audit of the Department of Labour. (Community Employment Group, 1997; Te Puni Kōkiri, 1999). A 1996 evaluation of Mahi a Iwi found that the success of initiatives were due to 'CEG's accessibility and low key approach; its sensitivity and commitment to the culture, style and pace of Māori groups, and its ability to work within and between Māori and Pakeha groups' (Byrne, 1999). This approach was not limited to Māori, with similar success factors found in the evaluation of the Pacific People's employment strategy (Byrne, 1999). Perhaps the approach is best summed up in the words of Wira Gardner and Parekura Horomia: 'CEG was not a Māori outfit; it was a mainstream agency. It just happened to have a few Māori in it and most unemployed people are Māori. Parekura... was focused on the mainstream. He used to say to us, never mind all that Māori shit. Get off and help everybody!' (Gardner, 2014, p. 123). The difference was that as the Community 
Employment Group people had a deep understanding of the communities they served, they were able to tailor and adapt programmes so as to meet the unique needs of the community. 


\section{Chapter 5: The Community Employment Group Case}

\section{Study - Part 2}

This chapter describes a downward trajectory of the Community Employment Group initiative.

The General Election on 12 October 1996 resulted in a 'close and indecisive result', leading to two months of negotiations before a coalition government was formed between the National and New Zealand First parties (Ministry for Culture and Heritage, 2016). The Coalition Agreement of December 2016 included:

'The integration of services delivered by the New Zealand Employment Service (NZES), Income Support (IS), Community Employment Group (CEG) and Education and Training Support Agency (ETSA) to job seeker beneficiaries (or communities) seeking access to employment assistance, income maintenance and education and training assistance, with the objective of delivering seamless education to all clients' (Hunn, 2000). This policy reflected the vision of Peter McCardle, Minister of Employment from 1996. Community Employment Group staff of the time expressed cynicism about the vision 'Peter McCardle ... decided that it would be better to put employment support... into one organisation with social welfare benefits people. And nothing could convince him otherwise and he picked up in his ruminations about Community Employment Group and said oh yes, that should go in there as well' (Interviewee B). 'Because it's got the word employment in it' (Interviewee H). There was no evidence of understanding that the Community Employment Group worked in a different way to other public services.

However, it was unclear for quite some time whether the integration would represent a structural or systems approach.

While the National/New Zealand First Coalition Government considered the future of the Community Employment Group, the Community Employment Group continued to operate. In January 1997, a quarterly 
report noted they were on target to fund 600 projects in 1997/98; that all projects were initiated to assist in either staircasing groups or individuals towards positive activity, work readiness, reemployment or expanding opportunities for employment, or a combination of these; that 94 per cent of funded projects had met contracted objectives. Eighty-four per cent of community respondents to a satisfaction survey were satisfied with the impact of projects and services delivered. However, only 15 per cent of final reports were submitted on time. (Horomia, 1997d).

Parekura Horomia's frustration with ongoing reviews was evident in a report to Peter McCardle, the Minister of Employment, in May 1997. He noted the 'fundamental review' of the Business Development Programme proposed by Max Bradford, the new Minister of Business Development (just one year after the previous Minister of Business Development had conducted a similar, although possibly smaller, review) and the potential for initiatives funded by the Community Employment Group to be drawn into this new review. Parekura Horomia had told the Ministry of Commerce officials that the Community Employment Group would not support its initiatives being drawn into 'yet another enterprise assistance review' (Horomia, 1997a).

In September 1997, Peter McCardle, the Minister of Employment announced $\$ 5.2$ million would fund new 'community broker organisations'. These organisations would be contracted by the Community Employment Group to 'broker community work opportunities for long-term job seekers'. In November 1997, the first five organisations were contracted, with the aim of around 50 organisations nationwide (McCardle, 1997). This represented a different way of working with communities, in effect moving from the community to the individual focus. In November 1997, a Dedicated Development Team of officials with responsibility for costs and benefits of different options for Work and Income New Zealand asked Ministers to make 'in principle' decisions between three options to deliver on the Coalition Agreement: 
- virtual (or non-structural) integration

- phased integration (moving from virtual to structural integration)

- full structural integration (Hunn, 2000) ${ }^{15}$.

On 15 December 1997, Cabinet agreed to a full structural integration of the New Zealand Employment Service, Income Support and the Community Employment Group into a single organisation. Integration was planned for 30 September 1998 (Hunn, 2000). On 19 December, the Minister of Employment's office received a fax from the Community Employment Group, outlining the risks and benefits of the General Manager reporting to the Chief Executive or a National Commissioner. Its recommendation was that 'initially, at least, a national CEG manager needs to be retained with a direct report to the [Chief Executive]. This will ensure that the very different CEG perspective is available across all regions, and that the senior management team has a more complete perspective of labour market activity' (Department of Labour, 1998). This was an attempt to ensure that accountability for the work of the Community Employment Group was held at a high level within the new organisation.

In May 1998, the Community Employment Group was asked to provide information on the employment outcomes of its work, albeit noting that 'the developmental nature of CEG's work makes it difficult to identify direct employment outcomes' (Horomia, 1998a). At the time, Horomia (1998a) noted that for 1996/97 there were 9,531 participants in Be Your Own Boss courses, resulting in 1,212 new businesses being established and

\footnotetext{
${ }^{15}$ At the time, the departments involved had different perceptions of the risks and benefits of integration (structural or virtual). The Department of Labour raised concerns about a 'takeover' of the New Zealand Employment Service under a structural integration. It also noted transitional risks, including the loss of staff, decreased productivity, industrial relations disruption and diversion of management attention. In contrast, the Department of Social Welfare supported full structural integration but was concerned that efficiency gains would be lost in a restructure. The Treasury considered a single organisation would be more effective, adaptable and flexible. Further, it considered the risks of change were manageable with strong leadership and a direct move to the creation of one organisation. The State Services Commission also supported structural integration and considered transitional risks could be minimized (Hunn, 2000).
} 
that between July 1997 and March 1998, Company Rebuilders created 40 new jobs. Also, the Community Employment Group had funded 704 community employment projects for $\$ 16.3 \mathrm{~m}$. During this time, the Community Employment Group was also working with communities affected by motor vehicle assembly plant closures in Thames, Porirua, Nelson and Manukau; and by the closure of Waitara and Taumarunui AFFCO meat processing plants and Sanfords Seafoods in Whanganui. Much of the work in these communities was in partnership with local Business Development Boards.

On 1 July 1998, State Services Commissioner Michael Wintringham announced the appointment of Christine Rankin as Chief Executive of the new Department of Work and Income. Christine Rankin had been the General Manager of Income Support (NZPA, 1998). Also in July 1998, the Lower North Island Regional Plan noted 'in the next six months Community Employment staff will be challenged by a new integrated organisational environment... although, over time clarity will emerge... there is nevertheless the inevitable climate of uncertainty as we explore new meanings and relationships in the emerging culture' (Bishara, 1998). This language was quite different to that used in interviews with the author and others, where there was a concern about the culture of the new organisation. 'Christine Rankin and [a senior member of staff] held a meeting where the CEG people were told that it was a jewel in the crown and they would love CEG to be a part of WINZ - they were pouring it on' (Interviewee D). Along with the concerns about the culture, a common theme through interviews was that the leadership in the new organisation did not understand how the Community Employment Group operated in partnership with communities.

The Department of Work and Income experiment

\section{Integration}

On 1 October 1998, the Department of Work and Income (WINZ) began operating with the Community Employment Group included as a business 
unit, with the manager reporting to the National Commissioner (a secondtier position) (McCardle, 1999).

When the Community Employment Group was moved to the Department of Work and Income, the accountability focus moved to Key Performance Indicators (KPIs). '... Work and Income was all about KPIs, you know, red, green, blue, yellow. You had your four. Red was you were not meeting, blue was you were on track, green was you were nearly there and yellow was you were behind.... He [the senior manager] was really clear that we still had to meet that... but how you did it and what you did to get there, he wasn't so caught up on that' (Interviewee G). Overall, though, the Department of Work and Income's culture retained a focus on income support rather than community development 'it was always about... KPIs... none around the community. It wasn't a driver... you got smacked on the hand if you were a red in something and what are you going to do to improve this... [the indicators were] the number of people who had gone off benefit into employment... the number of benefits you granted that were correct... I think the one about getting people off benefit into employment was the only thing they thought... that was the one that was related to employment in the community... so even though we were called Work and Income New Zealand... we never were. Where was the work side of things? Where did we invest in getting that better?' (Interviewee G). Parekura Horomia remained with the Community Employment Group to support the integration into the Department of Work and Income until February 1999, when he stood down to 'devote his time to campaigning' for the Ikaroa-Rāwhiti seat in the upcoming general election (Berry, 1999) and a review of the Community Employment Group commenced.

The proposed new structure to integrate Community Employment into the Department of Work and Income included:

- The National Manager Community Employment position was disestablished. 
- Contracting and monitoring went to the Regional Contract Management area.

- National contract management went to the National Contracts Unit.

- The evaluation function went to the mainstream evaluation unit.

- Fieldworkers would report to Regional Commissioners.

- Remaining in the national office were a team of four: a practice manager and three community employment advisors. This team would be responsible for: defining practice and guidelines, coordinating and providing a national overview of priority group strategies, monitoring trends and overall performance of Community Employment initiatives, providing input into Policy Advice and undertaking Ministerial servicing and providing a national troubleshooting resource.

- Three transitional grant management positions were proposed, with responsibility for assessing and approving grants. Regional Community Employment Manager positions were disestablished (Angus, 1999b). This proposal was met negatively by community groups. By 17 May 1999, 57 community groups had made submissions on the proposed changes to the Community Employment Group (Rankin, 1999). They noted that the relationship between Community Employment and communities would deteriorate, and were concerned about a potential loss of access to funding and services and a loss of the ability to resolve issues at initial contact (Angus, 1999a).

There was also growing criticism of the Department of Work and Income in the media, including about the Community Employment review. In June, the Evening Standard reported that the Palmerston North-based Open Learning Centre Te Whare Ākonga, had been left stranded while discussions about the Community Employment Group 'drag on' (Matthews, 1999). Also, in June 1999, a press release by the Labour Party announced that 'Mayors from around the country have joined in the chorus of disapproval at Work and Income New Zealand's plans to restructure the operations of the Community Employment Group' (New 
Zealand Labour Party, 1999). In August 1999, the Sunday Star Times reported that the Community Employment unit would be 'swallowed by Work and Income New Zealand, despite official advice not to axe it' (Sunday Star Times, 1999).

On 17 May 1999, the Department of Labour provided the Select Committee with a report on the 'objectives, nature and risk management strategies' adopted by the Community Employment Group from 1991 to October 1998 (Department of Labour, 1999). This paper noted that the Community Employment Group's effectiveness was based on an operating style that was quite distinct from mainstream government departments, including 'a fluid mix of local and regional responses, reliance on carefully developed local networks, a high level of trust from communities, direct communication between local communities and Wellington, involvement in policy and operational development by local and head office staff, work with very small local groups and emphasis on effective risk management of grants made outside the mainstream' (Department of Labour, 1999). This analysis indicates that the success of the group was due to its operating in a collaborative style.

However, in September 1999, the restructure of Community Employment was complete and fieldworkers commenced reporting through to Regional Commissioners. A Community Employment unit was retained at national level to provide support and advice to Regional Commissioners and fieldworkers (Maharey, 2000a). The most senior Community Employment officer in national office became a fourth-tier position (Hunn, 2000). The Regional Manager positions were disestablished, although John Bishara, a longstanding Community Employment Group manager accepted a position within Work and Income New Zealand in a regional capacity (Interviewee A; Interviewee B; Interviewee C; Interviewee D; Interviewee H). This removed leadership that had been largely in place since 1991, replacing it with a hierarchy of managers with a range of responsibilities outside the Community Employment Group. 
Leadership of fieldworkers, even at a regional level, was lacking. In September 1999, the move of Community Employment Group staff into the Christchurch office of the Department of Work and Income appeared to come as a surprise to the recently appointed Regional Commissioner. 'So, there were about six of us in Christchurch got moved into the office with the Work and Income people and we were kind of like the freaks. We just did not fit at all. And we were put under the Regional Commissioner... and he just didn't know how to cope with the six of us at all... he just didn't understand' (Interviewee H). '... just before I left I put together a whole lot of information and resources and then sat down together with [the regional commissioner] and he said "Oh, this is fascinating, so who looks after this now?" And we all looked at him and there was this look of shock came across his face' (Interviewee B). Although Regional Commissioners were now accountable for the work of the Community Employment Group fieldworkers, there was limited understanding of the role, no collaboration at a senior level, and no vision for the local area.

In contrast, in the Bay of Plenty where John Bishara was to work, staff appeared readier to manage the integration. A manager of a concept site described preparing for the integration of the New Zealand Employment Service and Community Employment Group into Income Support. '... we had to have an understanding of the Community Employment Group... it was mainly talking to colleagues... being really clear about what was the difference... why we were doing it, and what I didn't want to lose as a manager, that knowledge and that information and the reasons why it worked' (Interviewee G). This manager described being converted to a community focus ' I... became more passionate about the employment side and the community side and the advantages that could help towards our clients and putting people into employment... if we understood the community and understood people's needs, then it was easier about placing them. Because Work and Income, all I saw was we were placing people into employment [and] they weren't lasting... what I didn't want to see happen was that we put all this criteria around them... and we stopped 
people from being creative and innovative, and doing things differently' (Interviewee G). Although 'you didn't hear a lot about the CEG stuff... you heard a lot about the New Zealand Employment stuff but the CEG stuff was limited' (Interviewee G).

\section{Review}

On 27 November 1999, the nation turned to the polls, resulting in a Labour /Alliance Coalition Government. On 10 December 1999, Steve Maharey was appointed Minister of Social Services and Employment, with Parekura Horomia as Associate Minister. Included in the Labour Party manifesto was an intention to resolve the role and placement of the Community Employment Group. (Hunn, 2000). By early February 2000, Parekura Horomia had been given specific responsibility for policy in the community employment area and was 'working on future options for the... Community Employment Group' (Maharey, 2000a). Leadership and direction were being restored.

Shortly after the 1999 election, the Labour/Alliance Government commissioned a Ministerial review of the Department of Work and Income 'in light of the public controversy which has persisted, virtually from the inception of the organisation' (Hunn, 2000). Don Hunn, former State Services Commissioner, was to lead the review. The review commenced on 14 February 2000 and was completed on 8 May 2000, and relied on a wide range of documents, interviews with a range of groups and people including Ministers and former Ministers. The purpose of the review was to 'examine the reasons for the establishment of the Department of Work and Income, whether it has achieved the objectives set for it, what issues have arisen in the first 18 months of its existence and what adjustments may be necessary' (Hunn, 2000).

Hunn (2000) reported that he 'found a paradox'. On the one hand, the new Department had 'achieved a great deal in a short amount of time'. On the other hand, the Department of Work and Income was the subject of 'severe criticism and ridicule around the country. In twelve months, it has 
managed to alienate the public, parliamentarians, colleagues, clients and their advocates, tertiary students and university administrators, the media and members of its own staff.' When Don Hunn spoke with Community Employment Group staff, he found 'strong feelings that the community approach does not blend in well with the individualized focus of the Department of Work and Income' and was asked that an urgent review of Community Employment's place within the department take place. Further, Don Hunn concluded that the 'change to the organisational structure has prejudiced the delivery of community employment programmes, that the cohesion that previously existed between field workers and the programme overall has been dissipated, that the flexibility and innovative aspects of the work has been curtailed and there is no obvious interest in the work from DWI top management.' This indicates that, while the fieldworkers were continuing to work with communities, there was limited interest from leaders and very little collaboration at a senior or governance level.

By the time the 'Hunn Report' was finalised on 8 May 2000, the Minister of State Services had initiated work on the future placement of the Community Employment Group (Hunn, 2000). Parekura Horomia's involvement in the background was clear, with the Minister of Social Services and Employment, Steve Maharey responding to a Parliamentary Question in February 2000 with the fact that 'Parekura Horomia was working on options for the future of the CEG' (Maharey, 2000a). Former staff members also credited Parekura Horomia with the return of the Community Employment Group to the Department of Labour seeing him as their champion behind the scenes: 'when Parekura put the CEG back into DOL...' (Interviewee D); '... after a change in Government and a lot of behind the scenes work from Parekura and others, that it came back into the Department of Labour' (Interviewee B).

The paper tabled at Cabinet on 14 June 2000 defined the problem as 'a reduced focus on, and effectiveness of, community employment development... directly caused by the current structure and placement of 
Community Employment within the Department of Work and Income' and noted:

- the Government's intention to invest in community-based employment opportunities

- that the core capability to implement such initiatives was within the resource remaining from the Community Employment Group that now resided within the Department of Work and Income.

Maharey (2000a) noted an urgent requirement to re-establish Community Employment as a distinct entity and recommended the transfer back to the Department of Labour. Further,

The new objectives for the Community Employment Group were:

- a greater focus on community employment initiatives

- that the unique identity of Community Employment is preserved as a key mechanism to deliver on the Government's employment strategy

- that erosion of capability within Community Employment is halted.

This paper tabled at Cabinet on 14 June 2000 also noted that the Department of Work and Income was built around individualised assistance, whether this was of the provision of entitlements (benefits) or developing the capacity of individual job seekers and that the business of community employment is fundamentally different, working with collectives and taking a holistic view of the issues facing a community. It also noted the work of Community Employment was at the grass-roots level, below the business or established group level, and with people who are often not connected at all to the labour market. This led to a discounting of placement within the Ministry of Economic Development, as there would be a tendency to focus on the (established) private sector. Shifting Community Employment to the Department of Internal Affairs was also discounted, as it had a wider community development focus which would risk compromising the goals set for Community Employment in the Employment Strategy. The Department of Labour was seen to have the most aligned focus with the Community Employment Group and operated 
a devolved management structure, which would enable the Community Employment Group to retain its own management structure and distinct style. The intent was to return to a collaborative governance approach. An implementation plan was scheduled at the end of June 2000, with the aim to move the Community Employment Group 'as quickly as possible' back to the Department of Labour. All staff were to be transferred along with the budget the Community Employment Group had at the time of its transfer to the Department of Work and Income, and an additional appropriation of $\$ 1.2 \mathrm{~m}$ per year to rebuild and maintain the Community Employment Group's regional and head office structures that were removed by the Department of Work and Income in September 1999. Transition costs of $\$ 0.450 \mathrm{~m}$ were also planned for the $2000 / 01$ year. The State Services Commission did not support the proposal to move the Community Employment Group, commenting that there was no analysis of additional gains from a transfer and that the paper lacked a detailed assessment of the operational impacts and additional costs, including the scale of disruption to service delivery. The Treasury also did not support the transfer, based on a lack of evidence of better outcomes at equivalent cost and the risk of additional costs. These dissenting views were included in the paper tabled at Cabinet on 14 June 2000. These positions reflected a lack of understanding of the accountability needs for an initiative such as the Community Employment Group.

Despite the opposition from the Department of Internal Affairs, Department of Work and Income, State Services Commission and The Treasury; Cabinet agreed to transfer the Community Employment Group to the Department of Labour as a separate service group.

On the day of the Cabinet decision (14 June 2000), Steve Maharey, Minister of Social Services and Employment and, Parekura Horomia, Associate Minister of Social Services and Employment jointly announced the transfer of the Community Employment Group back to the Department of Labour. To facilitate the transition and to re-introduce the 
Community Employment Group way of working, at least two of the former regional managers in the Community Employment Group were hired. 'I was asked to go back as Operations Manager for a year... there were a team of us who went back to re-establish it, using people like me with some institutional history' (Interviewee A). '... I got brought back for the restart when it went back into Labour' (Interviewee B).

On 15 June 2000, the Evening Post reported that 'Community Employment Group workers are celebrating news they are to be moved back under the Labour Department's wing.' In that report, the General Secretary of the union that represented Community Employment Group workers was quoted as saying 'the culture shock of WINZ was too much for them... [they had] been fighting for more than a year to be allowed to do the work they were set up for and were glad to be going back' (Williams, 2000). In the Department of Labour, '... it was embraced... it was coming home... I can still remember the night the decision was made... going up to the Department of Labour offices... it wasn't an uproarious party but there were glasses of wine and a sense of accomplishment, the fact that... [the Community Employment Group]... had been returned to its rightful home' (Interviewee J).

However, there was concern that the ethos and institutional knowledge of the Community Employment Group had degraded and was no longer capable of achieving the successes of the past. One former employee, Garry Moore, was quoted in the New Zealand Herald of 23 October 2000 that the Community Employment Group 'had lost its way by becoming too tied to national programmes rather than keeping focused on the practical needs of the communities' (Dearnaley \& Collins, 2000). Further, the change in staffing over the period meant that 'the crew that were there didn't understand - it was a new crew - they were believers but they didn't necessarily have the skills' (Interviewee D). 'The damage was already done. We'd lost Parekura. MSD put a whole lot of social welfare thinking type people in there...' (Interviewee B). '... it was a Mark 2 version... because Parekura was gone, other key people like Garry were 
gone... it never quite got back on track and by that time... the number of people that had come in with social welfare were starting to outnumber the ones of us who were left' (Interviewee H). Hunn (2000) agreed that the 'skills of a number of the people... have now been lost.'

While the politics of the Department of Work and Income played out, the Department of Labour was working on a new framing for the labour market. March 2001 saw the publication of Workforce 2010, a document intended to show the complexity of the labour market and enable a systems approach to making change in the labour market system. This document represented a step-change in employment discussions: rather than groups of related priorities and initiatives as seen in the Prime Minister's Task Force on Employment in 1994, Workforce 2010 offered a simple framework to look at and address issues (New Zealand Government, 2001b). The framework was made up of three elements:

- Capacity: the ability to do something, or in the labour market: skills, knowledge and attitudes

- Opportunity: the options available for people to use their skills and knowledge (including labour market and non-labour market opportunities)

- Matching: the processes involved in connecting capacity to opportunities, including incentives or rewards, safety nets, rules and regulations, dispute resolution systems and information.

Workforce 2010 analysed each of these elements in turn, identifying the themes, risks and challenges in each. Although described as a strategy (Maharey, 2000b), Workforce 2010 was more of a basis for discussion than action. However, this marked a new way for New Zealand Government to look at unemployment problems and strongly influenced the thinking of the new Minister of Social Services and Employment.

\section{Back to the future}

On 31 July 2000, the Community Employment Group returned to the Department of Labour (The Treasury, 2001) and three months later, 
Charlie Moore was appointed General Manager of the Community Employment Group by the Department of Labour. Organisational design and planning took place between October and December 2000, with recruitment for positions commencing in February 2001 (Department of Labour, 2001). The pace of establishment was much slower than under Parekura Horomia, reflecting a quieter mode of leadership, perhaps influenced by the vision coming from above, rather than from the leader of the initiative.

In Budget 2000, published on 15 June 2000, the Community Employment Group was charged with administering three new types of initiatives: Capacity Building initiatives (by 1 October 2000); and Artworks and Community Employment Organisations (both by 1 November 2000) (The Treasury, 2000).

The aim was to see hapu, iwi and other Māori organisations producing community development plans that would eventually come to the Government for funding (Turia, 2000). At the Community Employment Group's national conference on 13 September 2000, staff were given information about administration of the Capacity Building initiatives, with a directive that the initiatives were to commence by 1 October 2000 - in just 18 days' time. Details about the initiatives were emailed to staff after the conference, along with written guidelines with detailed criteria to be applied to each application for grant funding. By 30 June 2001, 281 Capacity Building initiatives projects had been approved for funding by the Community Employment Group. (Department of Labour, 2002b). This hierarchical approach was to be replicated time and again over the following months for the Community Employment Group, creating challenges for the fieldworkers to partner with communities and co-design initiatives.

A later evaluation of the Capacity Building initiatives was damning. Information about the Capacity Building initiatives was considered by fieldworkers to be late, intermittent and inconsistent. Fieldworkers, 
regional managers and operations staff reported an uncertain understanding of the purpose of the initiatives and guidelines for grant funding. Further, policy, operations and field staff reported a perception that guidelines were relaxed at the end of the financial year, due to the amount of money unspent (Department of Labour, 2002b). The speed of implementation was the product of a very results-focused Minister, Steve Maharey: '... he was a Minister who thought it mattered an awful lot that he be seen to be delivering, and that meant the space between a department being... funded to do something and ... getting runs on the board... was very compressed' (Interviewee J).

The national conference on 13 September 2000 was also where Steve Maharey, the Minister of Social Services and Employment stressed the important role that the Community Employment Group had at grass-roots level and handed responsibility for the Government's Community Employment Organisations programme, which was to commence on 1 November 2000 (Maharey, 2000e). By 30 June 2001, the Community Employment Group had made 29 grants to Community Employment Organisations, committing 100 per cent of the Community Employment Organisations budget. Artworks, an initiative to support employment in the arts sector, was also scheduled to commence on 1 November 2000. By 30 June 2001, 11 Artworks applications had been approved, committing the full Artworks budget (Department of Labour, 2001).

In total, between 1 July 2000 and 30 June 2001, the Community Employment Group was responsible for 30,125 fieldwork interventions (not otherwise defined) and $\$ 18.8 \mathrm{~m}$ in grants. The transition back to the Department of Labour was considered complete by 30 June 2001 (Department of Labour, 2001). However, the focus of the Group was now on nationally-defined grant schemes and fieldworkers were unclear about their role and function. 


\section{Social entrepreneurs}

While the Community Employment Group staff were focused on implementing the three new initiatives in 2000/01, along with reestablishing themselves in the Department of Labour and continuing work with existing target groups; Steve Maharey, the Minister of Social Services and Employment was focusing on the Social Entrepreneur initiative, to be introduced in Budget 2001. Social entrepreneurs were people who 'take the same approach to opportunity and innovation as a business entrepreneur, but in support of social rather than commercial objectives' (Goff, 2001). This approach was 'an international movement... [with] a lot of activity in Australia...' (Interviewee J). '...[the Minister] had been over to the States and he'd seen this over there' (Interviewee H). '... the United Kingdom, USA and Canada... endorsed the role of social entrepreneurs as a means of providing solutions to entrenched social, economic, employment, environmental and cultural problems faced by disadvantaged individuals and communities' (Jeffs, 2006).

On 24 July 2000, the Department of Internal Affairs provided Steve Maharey, the Minister of Social Services and Employment, with a paper on social entrepreneurs. In December 2000, the Ministry of Social Policy followed this up with further work on the concept (Maharey, 2001b). While the Steve Maharey was keen to progress the initiative, Community Employment Group staff were reluctant '...and he said to us, I want to do this... I want to give money to our leaders and people that have been doing amazing things so that they can go and do some professional development or research on something that has some potential...' (Interviewee H). According to staff in the Community Employment Group, '...at the time we all went whoa, risk, risk, risk, risk and... put forward a lot of papers saying these are the reasons why we don't... think this is a good idea, it's not going to work...' (Interviewee H). '... all the signals coming from the top... were 'we want results' and it was either a benign attitude to risk or a denial of risk... they were only interested in the upside... which was wonderful programmes that were doing wonderful things' (Interviewee J). 
Grants for social entrepreneurs represented a change in the way the Community Employment Group operated. For example, rather than granting funds to organisations, social entrepreneur grants went to individuals. Decision-making on grants changed as well, with a panel comprising community representatives (sometimes former recipients of social entrepreneur grants) and public servants from the Community Employment Group, Department of Internal Affairs and Ministry of Social Development determining which individuals would receive grants ${ }^{16}$ (Maharey, 2003b). This approach to decision making was ill-defined and lacked transparency. Applications for grants were received at the local level and fieldworkers would determine whether or not the criteria for being a social entrepreneur was met. 'The yesses all went up to Wellington and that's when this joint panel... made the decision' (Interviewee H).

Staff were not convinced that the panel was the most appropriate way to allocate funding and had concerns that they had limited influence on decisions. '... this joint panel... all the policy people, they made the decision and that's when it turned to custard...' (Interviewee H). 'that was all we were allowed to do... we had to have a meeting... they had them all around the country... and [it] was like 'here's this person, this is what they want to do, this is their background. Do they meet the criteria? All we said was yes or no' (Interviewee H). 'It was the greatest let down, because we had spent years being so accountable for everything... it never saw the light of day that [a departmental representative] refused to finish the meeting until the person that was pilloried in the press for having a social enterprise grant, until that one was granted' (Interviewee B).

Gardner (2014, p. 301) reported a former staff member as observing 'after Para's departure, the grant process fell apart. Those who took over, didn't understand about nailing down and standing by clear deliverables and how

\footnotetext{
${ }^{16}$ The panel comprising three community representatives, two Community Employment Group representatives, one representative from the Department of Internal Affairs and one representative from the Ministry of Social Development selected the 51 potential social entrepreneurs (Maharey, 2003b).
} 
to manage risk.' The size of the group also raised concerns. 'It became too big.... If you are going to run something like a CEG which is high risk but high reward, it has to be tight... with size, comes profile. Bigger budget, more people, more to shoot at' (Interviewee E). 'It became more and more and more CEG people. Not that it didn't work. It just created more layers... you get more complicated' (Interviewee E).

On 24 May 2001, Steve Maharey, the Minister of Social Services and Employment, announced a $\$ 44.7 \mathrm{~m}$ budget package, including $\$ 3.6 \mathrm{~m}$ for social entrepreneurs, $\$ 1.6 \mathrm{~m}$ to support small business development for Pacific women and \$2m for an Ecoworks programme (Maharey, 2001a). On 16 November 2001, Katherine Rich, opposition spokesperson for employment asked Steve Maharey, the Minister of Social Services and Employment, 19 Parliamentary Questions relating to the Community Employment Group's administration of funding, including that for social entrepreneurs. Steve Maharey was unable to obtain the information by the due date to answer these questions.

On 22-23 November 2001, the Community Employment Group hosted a Social Entrepreneurship conference in Wellington, with over 200 delegates. At the conference, Steve Maharey, the Minister of Social Services and Employment, drew attention to a symbol - the Kea, noting that it had been selected because it was 'inquisitive and creative to the point at times of almost being annoying; it is intrepid; it is assertive, and it, at times, shows a breath-taking disregard for authority. One could argue that in these respects, as well there is some suggestion of the qualities of the social entrepreneur.' The aim was that the Kea would become a 'recognised brand, and a recognised badge marking out people who have a special commitment to social and economic development, and social justice' (Maharey, 2001a).

Funding and support for social entrepreneurs was not limited to the responsibility of the Community Employment Group. Steve Maharey, The Minister of Social Services and Employment noted that the Department of 
Internal Affairs had funded four social entrepreneurs under the Community Project Worker Scheme and the Department of Child, Youth and Family Services was involved with a number of social entrepreneurs. This was a new way of working, with the attendees at the national conference on 13 September 2000 attendees told that 'if social entrepreneurs are to realise their potential, there must be changes in the way that the public sector operates' (Maharey, 2001a).

Between November 2001 and 30 June 2002, the Community Employment Group provided grants to 24 social entrepreneurs for activities as diverse as 'taking on managerial studies and travelling overseas to research their area of interest' (Department of Labour, 2002a). Also, in June 2002, the Community Employment Group commenced leading Government's Connecting Communities Strategy, which would coordinate government assistance to communities for access to information and communications technology (Department of Labour, 2002b).

On 11 February 2003, the Community Employment Group invited 'leaders, innovators, movers and shakers in the community' to apply to the Social Entrepreneur Fund. The media release noted that the fund had been extended and was now available in 'not only economic and employment development, but also in the areas of youth, welfare, health and education community development' (Community Employment Group, 2003). On 16 June 2003, Steve Maharey, the Minister of Social Development and Employment announced grants to 51 community leaders from the Social Entrepreneur Fund (Maharey, 2003a).

By 2003, all decision-making about grants had been elevated to the head office in Wellington. The process for contract generation included assessment of an application by a fieldworker; review by the Regional Manager and then documentation forwarded to the grants management team for review and contract generation (Controller and Auditor-General, 2003). This was quite different to the processes described in the years 1991-1998, where fieldworkers were required to justify the basis of each 
grant to Parekura Horomia and staff were encouraged to question and debate the merits of each application.

\section{Under attack}

On 17 June 2002, the Evening Post reported that 'some critics don't like the [social entrepreneur] scheme and there is too little accountability.' In particular, ACT's Muriel Newman warned that money was 'being taken away from where it was needed and splashed around' and National 'declared the scheme well-meaning but superficial' (Hawkins, 2002). In June 2003, the Social Services Select Committee released its report on 2003/04 Estimates: Vote Employment. The report focused on Community Employment Organisations, recommending that the Department of Labour should 'increase scrutiny of the CEO programme.' This was to enable the Department to provide the committee with a clearer picture of outcomes and achievements. The committee also called for better coordination between government agencies delivering programmes at the local level (Social Services Select Committee, 2003).

In July 2003, Dr James Buwalda became the new Chief Executive of the Department of Labour. Shortly after, Steve Maharey, the Minister of Social Development and Employment, asked Dr James Buwalda to undertake a review of the Social Entrepreneur Fund, to 'focus it better on its intended purpose'. No further applications were to be sought beyond the current funding round. This was due to a perception that 'the CEG didn't understand the social entrepreneur concept... the range of initiatives were poorly run and there was no accountability' (Interviewee I).

That same month, the first newspaper report about the soon-to-be infamous hip hop grant to Fuarosa Tamati was published. The Dominion Post article noted that 'Tamati is the second youngest person to receive a social entrepreneur grant' and that the grant was to 'study hip hop culture in the United States.... The two month trip will take [Tamati and her mother] to New York, Los Angeles, Hawaii and American Samoa... together 
they will track the progress of Polynesians working in the American hiphop industry and study... elements of hip hop' (Fahy, 2003).

Also, in August 2003, Steve Maharey, the Minister of Social Development and Employment initiated work to 'review and clarify the strategic focus of CEG and its community employment funding' (Baxter, 2015). In October 2003, James Buwalda, Chief Executive of the Department of Labour initiated a review of grant funding processes (Baxter, 2015).

The report of the Controller and Auditor-General, released in November 2003, confirmed the previously released Evaluation into Capacity Building Grants, in that processes were lax. A particular issue was that in a number of cases, the Chairperson of the Trust signed a letter of agreement with the Community Employment Group, then was employed by the Trust to carry out the project work. Audited financial statements were not sought from recipients of grants and the assessment of applications lacked documentation. In 2003, the process for contract generation included assessment of an application by a fieldworker; review by the Regional Manager and then documentation forwarded to the grants management team for review and contract generation (Controller and Auditor-General, 2003). This was quite different to the processes described in the years 1991-1998, where fieldworkers were required to justify the basis of each grant to the General Manager of the Community Employment Group.

On 11 December 2003, the Social Services Select Committee received a briefing from the Community Employment Group on community employment programmes, the results of which were published on 24 February 2004 (Social Services Select Committee, 2004). Included in the information received by the committee was a table detailing the grants made in 2002/03 from the Social Entrepreneur Fund.

On 26 February 2004, Katherine Rich, National Party spokesperson for employment asked Steve Maharey, the Minister of Social Development and Employment 47 Parliamentary Questions in the form of 'which specific project objectives were not met by [group receiving funding] which in the 
last financial year received a Community Employment Group grant of [\$amount] for a project which had the stated purpose ["purpose"] and what are the reasons for the objectives of this project not being met?'. On the same date, Katherine Rich asked a further 19 questions about a range of Community Employment Group funds and funded projects, including 'Can the Minister explain why $\$ 26100$ of taxpayer funds has been used to support a Social Entrepreneur project which has a project purpose summarised as "for 2 people to do a whole lot of travelling for hip hop"?' On 27 February 2003, Katherine Rich asked a further 43 questions of the Minister of Social Development and Employment, Steve Maharey, in the same form as the first 47 questions (Rich, 2004a).

On 3 March 2004, Katherine Rich, National Party spokesperson for employment again questioned Steve Maharey, the Minister of Social Development and Employment, about the grant for ' 2 people to do a whole lot of travelling for hip hop', asking for itemised costs. Katherine Rich issued a press release on 17 March 2004 calling for the rules to be tightened around grants for social entrepreneurs. Drawing on the answers to her Parliamentary Questions, Katherine Rich quoted the project purpose in Labour Department papers as being for 'two people to do a whole lot of travelling for hip hop.' (Rich, 2004c).

Also, on 17 March 2004, the Christchurch Press published a front-page story on the funds used for the hip hop tour. The headline was 'Sour note for taxpayers over pair's hip-hop tour', and the story quoted Katherine Rich and the Minister of Social Development and Employment, Steve Maharey's Parliamentary Questions and Answers, detailing the expenditure on the 'two-month tour of the United States and Pacific Islands to investigate hip-hop' (Claridge, 2004c). A follow-up story on 18 March 2004 quoted Fuarosa Tamati as saying 'we went to Hawaii and Fiji, but that was basically to chill out.' Fuarosa Tamati also mentioned attending 'weddings and staying with family'. Fuarosa Tamati justified the expenditure by saying that 'I've been using what I saw in everyday work... 
we are here to raise the bar, create employment opportunities, and we are here for the long-haul' (Claridge, 2004d).

On 18 March 2004, Katherine Rich, National Party spokesperson for employment submitted four more questions about the objectives and funds granted from the Social Entrepreneur Fund. On that date, Muriel Newman of the ACT New Zealand Party sought a list of the contracts approved since June 2003 under the Social Entrepreneur Fund, including, for each project, the objectives, names of recipients and funds allocated. Katherine Rich also called for a 'full review of the Social Entrepreneur Fund' (Claridge, 2004b).

On 19 March 2004, the Press reported the General Manager of the Community Employment Group as saying 'public revelations had forced the agency... to initiate a review of the spending.' (Claridge, 2004b). Ruth Dyson, The acting Minister for Social Development and Employment had asked Dr James Buwalda, Chief Executive of the Department of Labour to review three Community Employment Group grants: a hip hop social entrepreneur grant; a community housing social entrepreneur grant and Te Hiku TV, a community employment organisation grant. The review was conducted by the Department of Labour chief internal auditor and two internal auditors, with Audit New Zealand providing quality assurance. A grants committee was established, chaired by the Chief Executive of the Department of Labour, Dr James Buwalda to oversee all CEG grant funding. (Baxter, 2015).

Between 19 and 26 March 2004, the Newztext Plus database of New Zealand newspapers identified that the hip hop tour grant was mentioned in at least 12 newspaper articles, most of them scathing of the tour. Also, starting on 19 March 2004 were a number of newspaper articles quoting Social Entrepreneur funding on a 'US trip to study lesbian sports.' On 21 March 2004, the Sunday Star Times reported that a 'boss of questionable

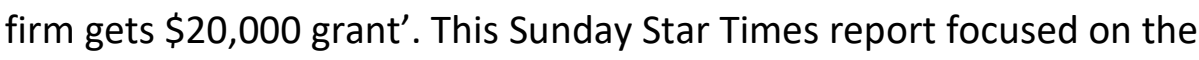
Cohousing NZ Ltd business, which had been 'partially blamed by 
liquidators for the demise of New Zealand's biggest rammed-earth homebuilding company' and included reference to the 'overseas travel grants for the study of hip-hop and gay and lesbian sports participation' (Milne, 2004). On 23 March 2004, the New Zealand Herald reported on the $\$ 115,000$ granted to a Far North Māori group to set up a regional television station. (Taylor, 2004).

On 27 March 2004, the Press reported that 'Prime Minister Helen Clark has personally ordered an inquiry into all funding grants handed out by the Community Employment Group.' Prime Minister Helen Clark was quoted as saying 'there has clearly been some quite inappropriate funding and we are concerned about that.' Steve Maharey, the Minister of Social Development and Trevor Mallard, Minister of State Services would work with the Chief Executive of the Department of Labour, Dr James Buwalda on the investigation (Claridge, 2004a).

In April 2004, the Department of Labour introduced new Community Employment Group grant guidelines and processes (Baxter, 2015). On 18 May 2004, Katherine Rich, National Party spokesperson for employment was again questioning Steve Maharey about the Community Employment Group. Katherine Rich's questions focused on the veracity of information provided by the Community Employment Group to the Minister for responses in Parliament, to which the Minister responded that he had previously been given inaccurate information. (Rich, 2004b).

The pressure from the media did not abate significantly over the following nine months. Between March and December 2004, at least 106 items referring to the hip hop grant appeared in New Zealand newspapers. From July 2004, the Community Employment Group was identified as 'the hip hop grant agency' or some close variation. Stories published in the media also referenced grants for: two women to travel to Jamaica to lobby for the inclusion of a Māori team in future netball world championship tournaments; a Buddhist group to conduct a feasibility study into meditation and education camps; twelve people to attend a hip hop 
summit in Auckland; development of teamwork in a darts and cultural society; a former Alliance Wellington Central candidate to study for a graduate diploma; a visit to art and craft outlets in Melbourne; attendance at a macadamia nut symposium in Australia; Māori to work on cruise ships in New Zealand; a strip performance; a family reunion; a hip hop hui in Hastings and a visit to Auckland to look at taro, hibiscus and citrus cultivation (Whimp, 2008).

In June 2004, the senior leadership team in the Department of Labour was restructured. Four senior managers lost their jobs, including Charlie Moore, the General Manager of the Community Employment Group. (James, 2004). Some attributed Charlie Moore's job loss to the media attention '... but the general manager at the time took the hit, and said, well, ultimately it was probably my responsibility...' (Interviewee B). The Department of Labour investigation into three grants commenced on 18 March 2004 and the report was released on 1 September 2004. The auditors concluded that most of the objectives and all reporting requirements had been met, and the level of expenditure was appropriate (Whimp, 2008). However, 'there were failures... the heart had gone. Flexibility of management and process had gone.... [there were] no reports, light proposals, different people approving' and a lack of clarity of who was in charge (Interviewee D).

In the words of Steve Maharey, the former Minister of Social Development and Employment,: 'the smallest of problems led to massive media coverage and an equal amount of political discomfort... in a programme involving forty-eight social entrepreneurs, one person famously decided to stop off in Hawaii on their way home... the resulting publicity led eventually to the closure of the programme... [and] the closure of the Community Employment Group' (Maharey, 2008). In contrast, the researcher finds that the closure of the Community Employment Group was due to poor decision making as result of a falling away of accountability mechanisms. 
The decision to close the Community Employment Group came from the Prime Minister, Helen Clark. 'It was a Cabinet decision but the Prime Minister was a very dominant actor in it, supported by her Chief of Staff and there was zero appetite for stories which would embarrass the government' (Interviewee J). 'Helen was very sensitive to problems and the CEG exposed government to problems.... Helen ... demanded to know what [the parties to the hip hop tour] were doing... she told the Minister to fix it and so it was closed' (Interviewee I).

On 20 September 2004, Cabinet agreed to 'dis-establish the CEG as a service of the Department of Labour and to establish a Transitional Management Unit (TMU) from 1 October 2004 (Maharey, 2004b). On the same date, Radio New Zealand announced to the general public that the Community Employment Group was to be disestablished. 'The Community Employment Group which was responsible for the controversial hip hop research grant, is to be disestablished. The group - which is part of the Department of Labour - funds community employment projects, and has been subjected to a lengthy review. The Government says the CEG's funding of $\$ 23$ million and its core functions will be now shared between the Department of Labour and the Ministry of Social Development. Social Development and Employment Minister Steve Maharey says CEG's grant approval processes were not as stringent as they should have been. One hundred and twenty staff will be affected by the changes' (Radio New Zealand, 2004).

All Community Employment Group staff transferred to the Transitional Management Unit and continued to manage existing and new grants and relationships with stakeholders. The Chief Executive of the Department of Labour, Dr James Buwalda continued to be responsible for personally approving any new grants (Maharey, 2004b). In contrast to the move to the Department of Work and Income in 1998 and back to the Department of Labour in 2000, Community Employment Group staff were not 
considered part and parcel of the transition of functions to the Ministry of Social Development and Te Puni Kōkiri. 'MSD will begin advertising the new positions as soon as possible... MSD and DOL will ensure that TMU staff are made aware of the opportunity for them to apply for the new positions...' (Maharey, 2004b). Cabinet also approved new grant funding guidelines for the programmes formerly administered by the Community Employment Group.

When the Community Employment Group had been transferred to the Department of Work and Income in 1998, there had been vocal disapproval from the staff (Hunn, 2000). Now, just six years later, the Community Employment Group was to disappear not with a bang, but a whimper. '... when it all went wrong the second time, I think there was too much rot. The quality had been undermined so much in that second version and people were tired and they didn't know which side to take...' (Interviewee B). The unemployment rates of the time were also much lower than in the early years of the Community Employment Group. '... unemployment wasn't the issue that it was when [the Community Employment Group] was created. It wasn't the desperate times'(Interviewee E). 'When unemployment reduced, the logic died away'(Interviewee I). Staff were denied an opportunity to celebrate the end of an era, as their planned farewell function was cancelled. On 10 May 2005, the front-page of the Dominion Post declared, 'As part of the handover [to the Ministry of Social Development and Te Puni Kōkiri], CEG was given approval to hold a conference... [but] the conference had grown in scope... [and] turned into a farewell party for CEG staff... It was too late to recoup $\$ 32,000$ of airfares, accommodation and venue hire already paid for' (Saunders, 2005).

\section{Legacy}

The legacy of the Community Employment Group is evident in the New Zealand public sector and Government today. This legacy is evident in the projects from that time that still exist, including some of the 'South Island 
rural revitalization projects', wildlife reserves and marae in the mid-North Island' (Gardner, 2014, p. 114) and the small businesses that began in Dunedin, that are still operating (Interviewee A). This legacy is also evident in the ability of communities to partner with government and to work at a much higher level of skill than previously (Interviewee A).

Perhaps the greatest legacy of the Community Employment Group, however, is the public servants who 'did their time' at the Community Employment Group and have gone on to serve at senior levels in the public service. Many of those who remain anonymous public servants 'have a touch of the Parekura philosophy embedded in their own psyche' (Gardner, 2014, p. 114).

It is not just the projects and programmes that form the legacy of the Community Employment Group, but the skills, knowledge, competencies, attitudes and philosophy of the people who were involved. One of those people, Garry Moore, a former employee of the Community Employment Group, went on to become the driving force behind the subject of the next case study, the Mayors Taskforce for Jobs.

\section{Lessons from the Community Employment Group}

We return now to the motivation for this thesis, and its question: what institutional arrangements enable iterative and ongoing community problem solving to address long-term unemployment? This case study has focused on the accountability arrangements, leadership behaviours and competencies and the participatory processes by which government and community agents collaborated in an initiative that spanned multiple governments, a shift in 'ownership' and an approach that went from exemplifying collaboration between government and communities, to a top-down more traditional approach, followed by an attempt to wind back the clock to the previous approach.

In this case study, the first seven years were led by a charismatic, revered leader who earned the trust of his superiors, yet behaved in ways that were unknown in the public service of the time, hiring people who were 
untested in the Wellington public sector, setting up childcare for workers and offering jobs to people on the basis of conversations. In many ways, the leadership of Parekura Horomia defined the Community Employment Group in its early years, and its success during this time was often credited to him, and the systems and processes he determined were necessary for the Group. His extensive, open, honest and sometimes brutal communication played a significant role in ensuring transparency and keeping the staff and stakeholders focused on the Group's goals and objectives. This communication also played a large role in accounting for the activities, expenses and achievements of the Group.

A particular focus of Parekura Horomia was on accountability, which was extensive and comprehensive, including frequent reporting, auditing, monitoring and evaluation. Formal and informal mechanisms existed side by side and reinforced each other, with personal accountability demanded of every fieldworker. People involved in the Community Employment Group during the transition and later when it returned to the Department of Labour, saw the loss of accountability mechanisms as a major factor in its demise.

A second contribution to the fall of the Community Employment Group was the removal of collaborative processes at grass-roots level. When decision making was lifted from fieldworkers to Wellington-based officials, the trust of staff and community partners that the right decisions were being made was lost. Exacerbating this was the public failure to account satisfactorily for funding spent on social entrepreneurs, resulting in the loss of trust at the highest level, resulting in from the call of Prime Minister Helen Clark to close the Community Employment Group. 


\section{Part 1}

This chapter and the next trace the Mayors Taskforce for Jobs from its origins as a deliberate collaborative initiative involving local and central government, to its status today, as a much weaker network of Mayors. The focus of these chapters is on:

- the leadership delivered by successive Chairs of the Mayors Taskforce for Jobs and its leadership teams, and the leadership of Government Ministers and Officials who engaged with the Mayors Taskforce for Jobs

- the accountability mechanisms set up for the Mayors Taskforce for Jobs and the ways different actors were held to account

- the participatory processes used by the Mayors Taskforce for Jobs to engage with Government and with each other.

\section{The origins of the Mayors Taskforce for Jobs}

\section{Inspiring leadership}

On 10 October 1998, Garry Moore: former accountant, Community Employment Group fieldworker, Area Health Board member and Christchurch City Councillor, was elected Mayor of Christchurch. Garry Moore brought with him a huge energy to make things happen and a wide knowledge of the challenges facing the people of New Zealand, especially in the employment arena. Garry Moore's first speech to the Council as Mayor promised 'business as unusual', as he prepared to make major reforms and to swim against the tide of privatisation. He saw the need for public entrepreneurship, including forging partnerships between the public and private sectors to achieve common goals (Christchurch City Council, 2006).

Garry Moore, Mayor of Christchurch impresses as someone who does not mince words, favouring a blunt approach that leaves the recipient clear about his vision (personal observation). His clarity of vision, charismatic 
energy and willingness to engage with anyone who could help paved the way for the Mayors Taskforce for Jobs. The Mayors Taskforce for Jobs started because Garry Moore didn't want a forum for Local Government leaders to be 'all egghead stuff' (Interviewee C).

On 2-3 June 1999, Garry Moore, Mayor of Christchurch hosted a forum at the Christchurch Convention Centre. Attended by Mayors and Local Government leaders from throughout New Zealand, the forum involved speakers from academia, bureaucracy and the community - although the community speaker nearly wasn't included. Garry Moore refused to agree to open the conference until a community perspective was included and he prevailed upon vivian ${ }^{17}$ Hutchinson, a Taranaki-based community activist and social entrepreneur (Hutchinson, 2017) to speak to attendees on the second day of the conference. vivian Hutchinson delivered an inspirational speech, noting the growth of technology to support communication, but the reduction in neighbourhood communication. He spoke of the structures that hold together community life being under severe stress, and the response through the recent Hikoi of Hope - a march from Cape Reinga to Parliament that protested against poverty. He described New Zealand's unemployment statistics as 'simply appalling' and challenged the attendees. 'It is perfectly feasible for us to... have a zerounemployment strategy in this country. It simply lacks the political will... and the leadership that can inspire national, local and community groups to work together in delivering the details... I believe that Mayors and Local Government will be important drivers of our employment strategies beyond the year $2000 . .$. we've tried to drive our jobs strategies from Wellington for far too long and it hasn't delivered the results. The leadership on this issue has to be local.' vivian Hutchinson went so far as to describe exactly what he wanted 'I would... like to see greater collaboration between Mayors throughout New Zealand in addressing employment issues and working for the zero-waste of your people. I would

\footnotetext{
${ }^{17}$ vivian prefers his first name spelt with a small ' $v$ '.
} 
like to see a 'Mayors for Jobs' network created that can operate in three main areas:

- firstly, to speak up and help put the 'jobs' issue back on the national agenda

- secondly, to share 'best practice' with one another on what can be effectively done at the local level

- and thirdly, to create national and local forums where we can really start to explore the challenges and opportunities arising from the changing future of work and income' (Hutchinson, 1999).

This challenge was taken up by Garry Moore, Mayor of Christchurch. Although a proposed meeting with the Chief Executive of the Department of Work and Income, Christine Rankin did not go ahead ('she was too busy to see me'), Garry Moore was able to convince six other Mayors from across the political spectrum to meet with vivian Hutchinson in February 2000 (Interviewee C). These early adopters of the vision were Mayors Sukhi Turner (Dunedin), Derek Fox (Wairoa), Jenny Brash (Porirua), John Chaffey (Hurunui), Tim Shadbolt (Invercargill) and Jill White (Palmerston North). The vision was one of governance, where Mayors could take political leadership of a serious immediate issue, and to consider the future of income and work in their communities. (The Jobs Research Trust, 2000b). This meeting set the platform for a wider meeting to take place in April 2000.

The meeting of 31 Mayors on 6 and 7 April 2000 was full of inspirational messages. Jim Anderton, the Deputy Prime Minister and Minister of Economic Development addressed the forum (Crean, 2000a) and Steve Maharey, the Minister of Social Services and Employment sent a letter of support. Steve Maharey's message was that the Mayors could 'expect the Government's full support' to tackle unemployment. Steve Maharey also issued a press release on 6 April 2000, noting his backing of the Mayors Taskforce for Jobs along with his desire to 're-examine the traditional roles of central and Local Government' and to partner around employment 
initiatives (Maharey, 2000f; Rasmussen \& Beer, 2000). The engagement of key Ministers at this early stage gave the Mayors Taskforce for Jobs credibility and set the scene for the partnership with the Labour/Alliance Government.

During the meeting in April 2000, Mayors outlined the challenges they faced in their communities and gave examples of initiatives in which they were involved. vivian Hutchinson again gave a keynote address, reminding the Mayors of the 1994 Prime Ministerial Task Force on Employment and its goal of no one out of employment for more than six months in the year 2000 - and the failure to achieve that goal. vivian Hutchinson challenged Mayors to think differently about work - not just about business development but about getting young people to contribute in a meaningful way to their communities (Hutchinson, 2000). vivian Hutchinson's talk was the catalyst for the tagline that was to last for at least the first five years: 'working towards the 'zero-waste' of New Zealanders.' This tagline captured and built on the slogan that many Local Government City, District and Regional Councils of the time were using in relation to environmental matters such as landfill.

\section{Quick agreement}

The meeting of 31 Mayors on 6 and 7 April 2000 resulted in agreement on the strategy. Two goals were set:

- by 2005 , no one under the age of 25 would be out of work or training in our communities

- by 2009 , all people in our communities will have the opportunity to be in work or training.

The use of the term 'our communities' gave Mayors a strong incentive to focus on their own areas of influence. It also provided for tangible goals focused on real people, with Mayors being keenly aware of the regional boundaries in which they operated and the local communities within them. 
Along with aspirational goals, the Mayors Taskforce for Jobs was quick to set up internal accountability mechanisms and eight Mayors were appointed to form a Core Group with Garry Moore, Mayor of Christchurch as Chair. Other Mayors on the Core Group were Yvonne Sharp (Far North); Basil Morrison (Hauraki); Graeme Ramsey (Kaipara); Frana Cardno (Southland); Sukhi Turner (Dunedin); Pat O’Dea (Buller); Tim Shadbolt (Invercargill); and Jenny Brash (Porirua) (Mayors Taskforce for Jobs, 2000). Of the 31 Mayors who attended the meeting on 6 and 7 April 2000, 22 went on to participate in the Mayors Taskforce for Jobs and a further two Mayors, who hadn't attended the forum, became involved shortly afterwards. Around that time, Jan Francis, a former Christchurch City Council employment manager and Local Employment Coordinator with the Department of Labour, was appointed Executive Officer of the Mayors Taskforce for Jobs (Interviewee L). Mayor Garry Moore, Jan Francis and vivian Hutchinson were to form a leadership team and work together on the Mayors Taskforce for Jobs for the next seven years.

While the goals and governance were clearly defined, accountability for funding was much less so, with Christchurch City Council taking on an administrative role and underwriting the Mayors Taskforce for Jobs due to Mayor Garry Moore's leadership. 'We didn't... want to set up a bureaucracy... it was Council money... why would we set up a... completely new system?' (Interviewee L). A membership fee of $\$ 0.05$ per ratepayer, to a maximum of $\$ 5,000$ was established (Dearnaley \& Collins, 2000). However, Jan Francis, Executive Officer, viewed accountability as critical to the success of the Mayors Taskforce for Jobs and began to set in systems and processes so that she could deliver 'in whatever form they wanted and ... within [a] time[frame]' (Interviewee L). The Core Group of Mayors met frequently and regularly and their meetings were recorded in comprehensive minutes. It was this Core Group of Mayors that would meet with the Labour/Alliance Government Ministers. The Core Group 
formed a decision-making body as well as a network for regular contact and discussions.

At this early stage, not all Mayors or City or District Councils supported the Mayors Taskforce for Jobs. In Invercargill, Mayor Tim Shadbolt was prevented from contributing the membership fee of $\$ 2,992$ from the Invercargill Mayoral Contingency Fund and had to take a proposal for funding to the full City Council. The proposal was passed only when Mayor Tim Shadbolt cast his own vote (Southland Times, 2000). At the other end of the country, Auckland City Councils were unwilling to participate, citing their own priorities ahead of joining the taskforce (Dearnaley, 2000). However, a critical mass had been formed with a vision that resonated throughout New Zealand and which would change the way Local and Central Government worked together.

\section{Early partnerships}

\section{Local engagement}

The work of the Mayors Taskforce for Jobs started in April 2000. At the local level, Christchurch City and Dunedin City Mayors met with the Buller District Mayor to help develop ideas that would create jobs (Crean, 2000b). Other local initiatives were pursued, with the first Mayors Taskforce for Jobs initiative announced in August 2000. Garry Moore, Chair of the Mayors Taskforce for Jobs brokered a partnership between the Department of Work and Income and Canterbury Development Corporation (partly funded by the Christchurch City Council), making case management compulsory for jobless youth aged under 20. The Department of Work and Income would provide staff and services to the value of $\$ 466,189$ a year and the Canterbury Development Corporation would provide $\$ 262,000$ a year (Crean, 2000c).

On 25 September 2000, a Memorandum of Partnership was signed between the Mayors Taskforce for Jobs and The Jobs Research Trust, a charitable trust based in New Plymouth. As part of this agreement, the 
Ministry of Economic Development provided funding to The Jobs Research Trust to enable The Jobs Letter, a two-three weekly newsletter that covered New Zealand employment issues, to be circulated free of charge to subscribers (The Jobs Research Trust, 2000a). This arrangement ensured the work of the Mayors Taskforce for Jobs was reported frequently and positively to a wide readership for the next six years. It also secured the services of vivian Hutchinson as an engaging and inspiring community leader.

\section{Labour/Alliance Government support}

Jim Anderton, the Deputy Prime Minister and Minister of Economic Development, and Steve Maharey, the Minister of Social Services and Employment remained strongly engaged with the Mayors Taskforce for Jobs, meeting with 14 Mayors in May 2000. They discussed the 'need for employment initiatives... to rebuild the not-for-profit sector in communities... Māori and Pacific employment issues and the need to retain young people in their communities' (The Press, 2000). The meeting resulted in agreement that a Memorandum of Understanding between the Labour/Alliance Government and the Mayors Taskforce for Jobs would be drafted (Appendix 1) (Anderton, 2000). The Memorandum of Understanding was 'vivian's idea... he said a MOU gives you a point of cooperation, if it does nothing else' (Interviewee L). Only four months later, on 12 September 2000, the first Memorandum of Understanding between Central Government and the Mayors Taskforce for Jobs was launched by Jim Anderton, the Deputy Prime Minister and Minister of Economic Development, and Steve Maharey, the Minister of Social Services and Employment. The Memorandum of Understanding stated that Ministers and officials would meet with the Mayors Taskforce for Jobs quarterly 'to discuss progress on this partnership' and that the Ministry of Economic Development would contribute $\$ 81,500$ to 'support the achievement of the objectives set out in the Memorandum of Understanding'. Government Officials found the Memorandum of Understanding concept difficult and suggested delaying any payment. 
'They tried to tie it down... they were told by their Minister [Jim Anderton], pay these people... they said to us initially... we could write them a letter and tell them we'll give it next budget year... Jim Anderton said to them don't write a [expletive] letter... give them the money. Write the check. So, they had to' (Interviewee L).

Just one month after the signing of the Memorandum of Understanding, on 19 October 2000, 12 Mayors from the Mayors Taskforce for Jobs met with seven Ministers and a representative from Deputy Prime Minister and Minister of Economic Development Jim Anderton's office. These Ministers represented a broad range of responsibilities, reflecting the importance placed on the relationship by Central Government and its willing to front up and participate. The Ministers were:

- Minister of Labour Margaret Wilson.

- Associate Minister of Social Services and Employment Tariana Turia.

- Associate Minister of Employment, Parekura Horomia.

- Minister of Youth Affairs Leila Harre.

- Minister of Consumer Affairs Phillida Bunkle.

- Minister of Social Services and Employment Steve Maharey.

- Associate Minister of Social Services and Employment Ruth Dyson.

The seven Ministers and a representative from Deputy Prime Minister and Minister of Economic Development Jim Anderton's office were invited to speak to the Mayors about:

- new policies that might impact employment, including their target groups

- how policies link with those of other ministries

- how these policies would support the taskforce goal of 'by 2005 , no young person under the age of 25 will be out of work or training in our communities' (Francis, 2000).

One result of the meeting was that Steve Maharey, Minister of Social Services and Employment agreed in principle to allocate five or six "hand- 
picked' workers from the Community Employment Group to the Mayors Taskforce for Jobs. This would provide the Mayors Taskforce for Jobs with people who could 'think strategically while working closely with communities' (Dearnaley \& Collins, 2000).

The Mayors Taskforce for Jobs was keen to get other government agencies on board, so that they had 'skin in the game. We were aware that at the local level... most things were...dependent on the government agencies being part of the plan' (Interviewee L). Central Government was seen as essential, as 'what tended to happen at the national level was, if there was any barrier at the local level, then if the Minister knew about it and said I didn't want this... [Officials would remove the barrier].' (Interviewee L). Two weeks later, nine Mayors met with Government Officials from the Department of Work and Income, Skill New Zealand, Ministries of Social Policy and Economic Development, and Department of Labour. Questions for the Officials included:

- What new initiatives have you put in place?

- What research are you doing, or have you done?

- Where do you get your data from?

- How broad is your consultation?

- What budget do you have for employment and training initiatives?

Engaging with Government Officials was critical to the Mayors Taskforce for Jobs but involved a different form of agreement. 'It was a deliberate strategy that government agencies would support the Mayors Taskforce for Jobs and it was a constant battle, certainly after the first few years, to make them see... that we didn't need a contract for service. There was none of this... contract for service and you are going to provide this or that... what we had to provide was a network of Mayors... it was a voice... it was a point of entry into every local authority in the country' (Interviewee L).

One form of agreement was a Principles of Partnership document, which set out an operating framework for the Community Employment Group 
working with the Mayors Taskforce for Jobs. This document, agreed on 5 March 2001, set out a formal structure for work carried out by the Community Employment Group and Mayors Taskforce for Jobs:

- Leadership, with the General Manager, Community Employment Group and Chair of the Mayors Taskforce for Jobs being responsible for national governance and management of the partnership.

- A National Planning and Coordination Group, comprising Community Employment Group senior management, a community operations advisor, regional representatives, the Taskforce Executive Officer (Jan Francis) and Taskforce Community Adviser (vivian Hutchinson).

- Regional Mayors Teams, including regional representatives and local community employment advisors.

- Community Employment Advisors, responsible for providing local employment development, advice, information and ideas to the Mayor; supporting strategic and specific planning and relationships; and contributing to the knowledge base.

While this may have felt like part of the new beginnings for the Community Employment Group with its recent return to the Department of Labour (as described in Chapter 5), neither group knew the Principles of Partnership agreement would not deliver on its promise and that the governance arrangements would fail to eventuate.

A further partnership was formed between the Mayors Taskforce for Jobs, Career Services and Skill New Zealand, with an announcement from Steve Maharey, Minister of Social Services and Employment on 28 June 2001 of a Destinations and Tracking project to collect data on school leavers and their destinations (New Zealand Government, 2001a). Also, in 2001, the Mayors Taskforce for Jobs announced its support of the Araroa project, series of local walks that would join to become a nationwide walkway while providing employment in rural areas. These initiatives were to be collectively governed by Central Government and the Mayors Taskforce for Jobs. The engagement with community organisations in this situation, was 
through traditional contracts for service, held between Central Government and the community-based providers.

\section{Consolidation}

\section{Structure and strategies}

With Central Government agreements in place and funding secured, it was time for the Mayors Taskforce for Jobs to determine a Strategic Plan. On 27-29 March 2001, the Core Group of Mayors defined six goals:

- hold two public forums to which all Mayors and media are invited

- take leadership locally on employment issues

- provide advocacy on nationwide policies and programmes

- build strong relationships with Central Government agencies

- promote leadership on employment goals as an issue for Local Government elections

- further develop the Mayors Taskforce for Jobs structure, administration and partnerships (Mayors Taskforce for Jobs, 2001).

This strategy noted that the Mayors Taskforce for Jobs had 31 participating Mayors at March 2001. New members were from Waitakere, Manukau, Tauranga, Ōpōtiki, Tararua, Lower Hutt and Westland. However, a majority of Mayors had still not joined as many City and District Councils did not see the value in the initiative. In one reported example, the Marlborough District Council was not in favour, citing a 'waste of time and money' as the reason to not be involved (The Press, 2001).

In late 2001 and early 2002, the Mayors Taskforce for Jobs sought to strengthen relationships and ensure funding for the Mayors Taskforce for Jobs was secure (Francis, 2003b). Government and business were key targets. The Mayors Taskforce for Jobs also faced its first real membership challenge, with local body elections in October 2001. However, they had achieved real momentum with a programme that Mayors were starting to want to join, and by the end of October 2001, 42 Mayors were a part of the Mayors Taskforce for Jobs. 
In February 2002, the Mayors Taskforce for Jobs held its second Annual Meeting. Steve Maharey, Minister of Social Services and Employment continued to visibly support the Mayors Taskforce for Jobs, addressing the meeting and urging the Mayors to continue addressing the challenge of employment for all, especially youth (Maharey, 2002). At the meeting, a partnership between the Mayors Taskforce for Jobs and the New Zealand Business Council for Sustainability was launched. The New Zealand Business Council for Sustainability was an incorporated society with 40 businesses including Fonterra, Telecom and The Warehouse. The purpose of the agreement was to identify promising youth employment initiatives and to lobby Government to develop the initiatives. Under the partnership, a project officer was appointed to coordinate initial research into the state of youth employment in New Zealand and to promote the business case for youth employment initiatives (The Jobs Research Trust, 2002).

Around that time, a firmly-worded 'Election Employment Policy' was suggested to the Labour Party for its 2002 election campaign. The policy suggested that 'the entire community... [should] make a cultural shift to value our young people, treat them as assets not costs'.... This same policy highlighted that 'we have a popular government, the smartest employment Minister for a long time and a growing economy' (Mayors Taskforce for Jobs, 2002). This approach highlights the strong relationship the Mayors Taskforce for Jobs held with members of the Labour Party. At the time, Local Government New Zealand was seen as 'hostile' toward the Mayors Taskforce for Jobs, as they 'didn't really want this bunch of Mayors going off... [they] were very nervous [about Mayors talking with politicians]... they could talk freely and frankly' (Interviewee L). Without the bureaucracy however, Christchurch City Council staff 'started to get nervous... [they didn't] want to be liable... if it goes belly-up'. (Interviewee L). Eventually, arrangements were made with Local Government New Zealand to take on an administrative role for the Mayors Taskforce for Jobs, including being the legal entity for contracts. This was achieved in 
2002 (Local Government New Zealand, 2003). '[They] became the umbrella group, but we were very clear that that was all they were... they would not control anything, they had no control over the finances...' (Interviewee L). While initially the relationship was poor, once Local Government New Zealand became the umbrella group, they were accommodating of the Mayors Taskforce for Jobs, going so far as to allow Mayors to 'use their board room... they would provide refreshments for those quarterly meetings... they could come to the meeting with the politicians if they wanted to, to sit in on it' (Interviewee L). Local Government New Zealand described the Mayors Taskforce for Jobs as 'a business unit of Local Government New Zealand' (Local Government New Zealand, 2004). The more formal relationship between Local Government New Zealand and the Mayors Taskforce for Jobs was reflected in the July 2002 Mayors Taskforce for Jobs meeting held in conjunction with the Local Government New Zealand conference (Mayors Taskforce for Jobs, 2003b).

On 3 and 4 February 2003, Mayors met for a strategy meeting where a new structure was proposed, then taken to the Annual Meeting on 6 and 7 March 2003. The aim of the proposal was to strengthen the structure and address the process for participation in decision-making roles. These new accountability arrangements were careful to specify decision and relationship management responsibilities. In the new structure, Local Government New Zealand was responsible for the funding contracts and payment of accounts. Partnership portfolios were created and Mayors were assigned as relationship leads for: Central Government, the Community Employment Group, Ministry of Social Development, Ministry of Economic Development, Te Puni Kōkiri, Tertiary Education Commission, Labour Market Policy Group, Ministry of Youth Affairs, Ministry of Education the Department of Conservation, Local Government New Zealand, the Council of Trade Unions, New Zealand Business Council for Sustainable Development, Career Services and Economic Development Agency of New Zealand. Mayors also took responsibility for The Jobs Research Trust and Employment Catalyst, Te Araroa (the New Zealand 
walkway), Project Management and Media/Public Relations (Francis, 2003b).

The third Annual Meeting, held on 6-7 March 2003, focused on how the Mayors Taskforce for Jobs was working at a national and local level, and included panels with government and non-government partners. The end of the first day was marked by the signing of a Memorandum of Understanding between the Mayors Taskforce for Jobs and the Council of Trade Unions. This Memorandum of Understanding restated the original goals along with their timeframes (2005 and 2009) and set out a commitment for the New Zealand Council of Trade Unions to meet annually with the Mayors Taskforce for Jobs to review the Memorandum of Understanding and seek additional areas of cooperation (Appendix 3). The second day involved a wide range of people from local and national partnerships and culminated in a speech from Jim Anderton, Deputy Prime Minister. Jim Anderton's speech noted the youth unemployment rate was 'around 11 per cent' and that the 'challenge is to ensure we are giving young Māori and Pacific Island people the opportunity to make a contribution to our economy.' He reinforced the partnership between Government and the Mayors Taskforce for Jobs in the final words of his speech 'I am here to work with you to create jobs. Our communities expect nothing less.' (Anderton, 2003).

Supporting the Annual Meeting, a summary of the projects supporting the Mayors Taskforce for Jobs goal had been completed by participating Mayors. This 32-page document described, for each region, what youth employment projects were underway, how the projects address the Mayors Taskforce for Jobs goal, what progress is being made, key partners, funding sources and costs. The projects were highly practical, with many resulting in permanent job opportunities for the involved youth (Mayors Taskforce for Jobs, 2003i). The document provided opportunities to showcase successful initiatives, and confirm that funding was being used to good effect. 
In June 2003, Mayors met to discuss how to take the Mayors Taskforce for Jobs to the next level. The structure developed earlier in the year was confirmed (Figure 16) and the budget increased by 30 per cent to allow for increased administrative support, travel and ability to contract for services. The Core Group acknowledged the urgent need to seek increased funding to ensure the Mayors Taskforce for Jobs was adequately resourced (Mayors Taskforce for Jobs, 2003h).

Figure 15: Structure for the Mayors Taskforce for Jobs: 2003

\section{Mayors Taskforce for Jobs}

(Administrative Support - Local Government New Zealand)

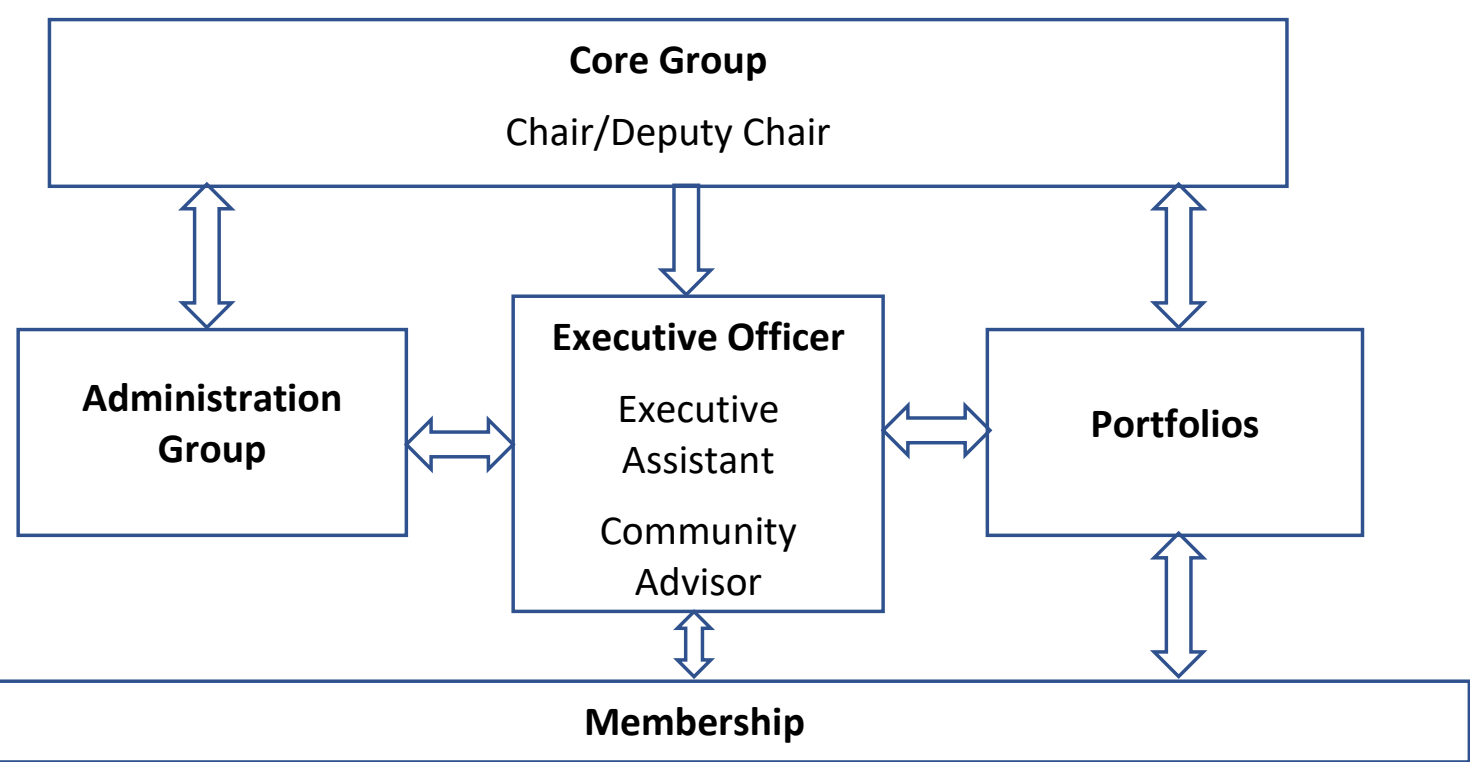


Seven strategies were developed for implementation in the $2003 / 04$ year. These strategies were to:

- engage all members in the goals and actions to achieve local leadership

- share best practice widely

- drive the relationships with government agencies

- work with imaginative private sector initiatives

- establish a parallel youth employment network

- establish a monitoring framework

- advocate privately with government.

Each strategy was allocated a 'champion' Mayor, with support from the administrative team (Mayors Taskforce for Jobs, 2003c).

During this period, the Mayors Taskforce for Jobs focused on building public understanding of its work through a targeted media strategy. In early 2003, North and South and the Listener - both nationwide magazines with a wide readership - carried stories about the Mayors Taskforce for Jobs. Radio New Zealand also interviewed Garry Moore, Chair of the Mayors Taskforce for Jobs, on the popular 'Nine to Noon' show. Jan Francis, Executive Officer of the Mayors Taskforce for Jobs, published a progress review in 2003, which highlighted a range of factors that had contributed to the success achieved in the first three years. This media strategy was intended to showcase the work of the Mayors Taskforce for Job, to encourage participation by Mayors and to provide a form of accountability to the general public.

The factors that contributed to the success of the initiative at that point were considered to be:

- sharing information, ideas, advice and examples across regions to give impetus to local areas and projects 
- maintaining relationships with Ministers and public-sector Officials so that the Mayors Taskforce for Jobs could have input into policy development, resource allocation and information dissemination

- project funding and paid staff to drive work at a local, rather than national level (Francis, 2003b).

\section{Business partnerships}

In 2002, vivian Hutchinson negotiated a major coup for the Mayors Taskforce for Jobs. The Tindall Foundation established the Employment Catalyst Fund to support Mayors Taskforce for Jobs projects. In its first year, the Employment Catalyst Fund supported 14 projects which also attracted local support from the Ministry of Social Development, Community Employment Group, Tertiary Education Commission and local community trusts. The combined value of the projects was $\$ 2.9 \mathrm{~m}-\mathrm{a}$ considerable increase on the $\$ 500,000$ per annum previously provided by the Tindall Foundation and allocated for Mayors Taskforce for Jobs projects (Mayors Taskforce for Jobs, 2003b). By September 2003, the Employment Catalyst Fund had the seven projects complete a Year One report and have funding allocated for a second year: Launchpad (Nationwide), 4Trades (Dunedin), Te Araroa, Youthworks (Taranaki), Buller, Kaikōura and Whangārei. Completed projects were in Porirua, Waimakariri and Westland. A new project was funded for Patea, where an early Māori Pa would be created (Francis, 2003a).

In 2004, the Mayors Taskforce for Jobs took over responsibility for management of the Employment Catalyst Fund and February 2005 saw the release of a further progress report on the Employment Catalyst Fund. At that stage, seven projects had been approved, four continued to be supported and there were 'a number of other projects in the pipeline'. The four existing projects were the Ōtara Work Creation Project, Te Araroa Trust, Innovative Waste Kaikōura and Whangārei Walkway. The new projects were the Ōtorohanga Trade Centre $(\$ 50,000)$, Tauranga Priority One Instep Programme $(\$ 50,000)$, Central Otago Horticultural and Careers 
Project (amount to be determined), Nelson Tasman Connections

$(\$ 50,000)$, Waitaki Heritage Alive $(\$ 24,000)$, Manawatu Tools for Schools mentoring project $(\$ 45,000)$ and the Mayors Taskforce for Jobs Guarantee Project (amount to be determined). Issues identified for the fund was that there were not a large number of funding requests or new ideas, resulting in work with Mayors, particularly in small areas, to develop ideas that could attract funding (Elphick, 2005).

Accountability for the Employment Catalyst Fund included the establishment of three groups within the Mayors Taskforce for Jobs and a clear distinction between the roles and responsibilities of the different groups, management team and project advisers. The roles and responsibilities were:

- the Governance Group, responsible for setting policy and agreeing guidelines, and monitoring the progress of projects funded by the Employment Catalyst Fund

- the Approval Group, responsible for supporting project advisers and recommending projects for funding based on funding applications.

- the Advisory Group, comprising young people and others who were 'in a position to give enlightened feedback to the Taskforce'. This group would offer advice on youth employment issues in New Zealand, advise on innovative youth employment actions and solutions, give feedback on the Employment Catalyst Fund and comment on and contribute to evaluation and monitoring activities.

- the Mayors Taskforce for Jobs management team would receive and screen proposals, ensure compliance with the Tindall Foundation contract, ensure payments are made to projects and liaise with Local Government New Zealand regarding management of the fund.

- project advisors would visit provisionally approved projects to make final decisions on funding, ensure all documentation and reports required by projects are completed and filed, maintain oversight on the progress of projects, visit all assigned projects before the end of 
their year's funding and gather information and documentation to support future funding applications.

- Local Government New Zealand would be the receipting agent for funds from the Tindall Foundation, ensure payments were made, provide an annual financial report and invest funds and distribute the interest to the Employment Catalyst Fund. (Mayors Taskforce for Jobs, 2004c).

As such, accountability for the Employment Catalyst Fund had many levels and layers, ranging from strong oversight and monitoring of individual projects to a national view and advice on the outcomes sought. Where there was doubt as to a project's feasibility, face-to-face meetings with the project team would determine whether the Mayors Taskforce for Jobs would support the project. The multiple layers were supported by a central coordination point, ensuring that all reports were of the required quality and timeliness. Release of funds was through a third party, although Local Government New Zealand appeared to have an accounting, rather than oversight, function.

\section{Central Government partnership}

While Central Government was focusing on new ways to stimulate community engagement and action, changes were coming to the Local Government sector. On 1 July 2003, the Local Government Act 2002 came into force. This Act heralded a new way of working for local bodies and an explicit acknowledgement of their role in achieving community outcomes, beyond their remit of 'roads, rates and rubbish' (McKinlay, 2006). While employment was not explicitly mentioned as a role of Local Government, it was seen as 'a legitimate role of Councils'. (Interviewee L). Local Government New Zealand, in seminars on the new Local Government Act, showed how the Mayors Taskforce for Jobs could be a valuable contributor to the Long-Term Council Community Plans (Mayors Taskforce for Jobs, 2003b). 
On 2 October 2002, the Mayors Taskforce for Jobs met with Ministers to sign a second Memorandum of Understanding. The meeting to sign the Memorandum of Understanding was held in the New Zealand Government Cabinet Room - a symbol of the high regard in which the relationship was held. The Prime Minister of the time, Helen Clark was known to apply the 'sniff test' to any such agreements or arrangements. If there had been any risk associated with such an historic agreement, the Cabinet Office signing of the Memorandum of Understanding would never have happened (Personal communication, 2018). A photo taken at the time was subsequently used widely by the Mayors Taskforce for Jobs to show the good relationship it had with Government (Figure 17).

Figure 16: Local Government at the Cabinet Table

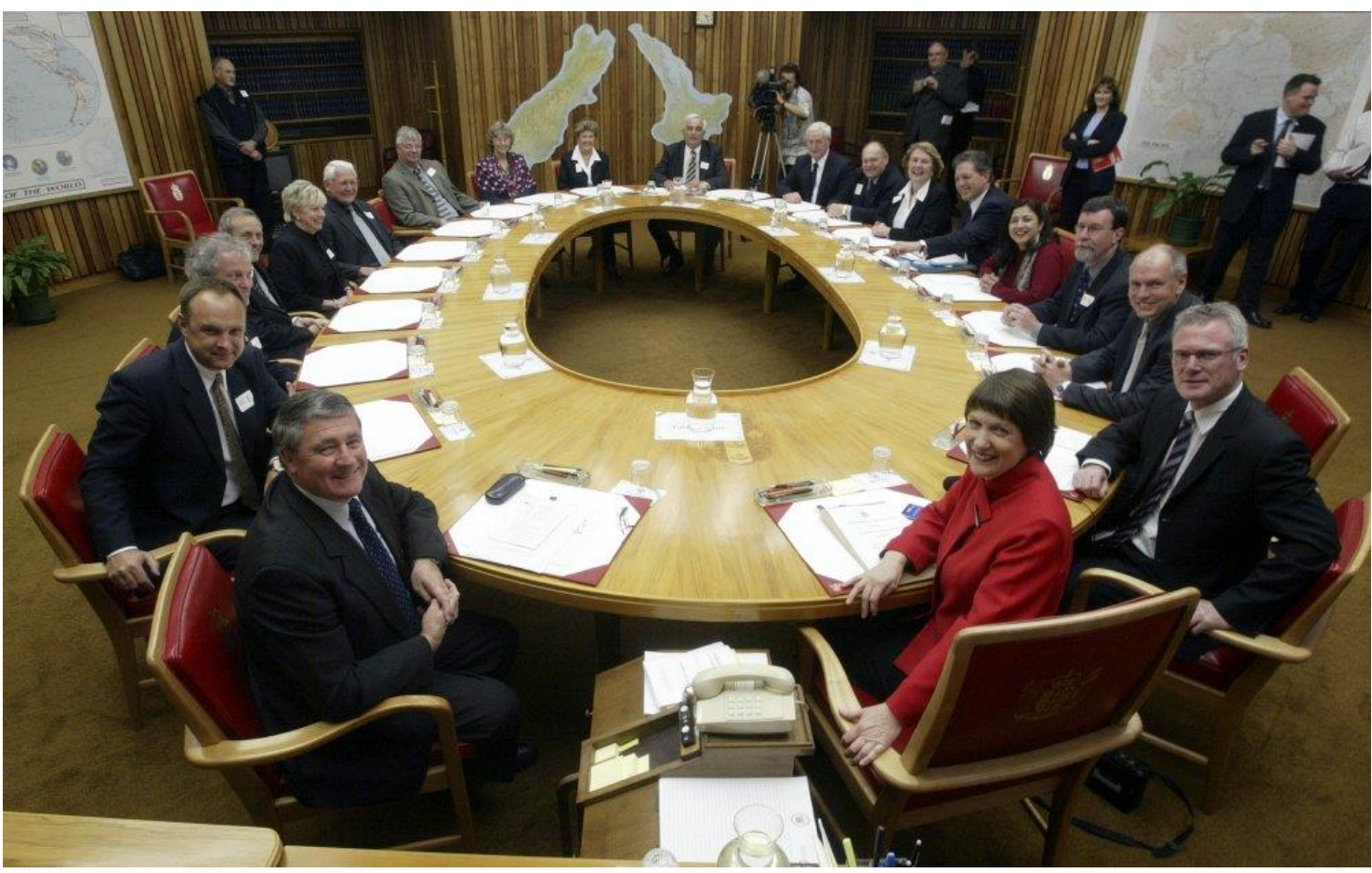

(clockwise from bottom) Jim Anderton (Minister of Economic Development), Graeme Ramsey (Mayor of Kaipara), Chris Lux (Mayor of Thames-Coromandel), David Braithwaite (Mayor of Hamilton), Sue Morris (Mayor of Ruapehu), Gordon Blake (Mayor of South Waikato), Eric Tait (Mayor of Ōtorohanga), Jenny Brash (Mayor of Porirua), Yvonne Sharp (Mayor of Far North), Paul Matheson (Mayor of Nelson), Pat O'Dea (Mayor of Buller), Kevin Brown (Mayor of Grey), Frana Cardno (Mayor of Southland), Tim Shadbolt (Mayor of Invercargill), Sukhi Turner (Deputy Chair of Taskforce, Mayor of Dunedin), Garry Moore (Chair of Taskforce, Mayor of Christchurch), Chris Carter (Minister of Local Government), Steve Maharey (Minister of Social Services and Employment), and Helen Clark (Prime Minister of New Zealand).

Source: The Jobs Letter 21 October 2002. 
This new Memorandum of Understanding included a new goal: By 2007, all 15-19-year-olds will be engaged in appropriate education, training, work, or other options which will lead to long term economic independence and well-being. When Steve Maharey, Minister of Economic Development and the Associate Minister of Education (Tertiary Education) was questioned in Parliament about the meaning of the 'other options' on 10 February 2004, he responded with examples: 'community or voluntary work, gap year travel, drug or alcohol rehabilitation or caring for a family member... the goal is intended to support the[ir] aspirations... leading to long term economic independence and well-being, not to coerce them into prescribed activities' (Maharey, 2004a).

The Memorandum of Understanding also re-stated the original Mayors Taskforce for Jobs goals all young people up to age 25 being in employment or education and training; and all people in our communities having the opportunity to be in work or training, although the dates for achievement (2005 and 2009) were omitted. Also, new in the second Memorandum of Understanding was a principle that recognised the value of information sharing and importance of information held by local authorities. These subtle wording changes reflected the ability of the Mayors Taskforce for Jobs to flex and adapt to the environment.

The commitment to meet quarterly to discuss progress was retained in the Memorandum of Understanding between Government and the Mayors Taskforce for Jobs. Other partners were also acknowledged in the Memorandum of Understanding, including the New Zealand Business Council for Sustainable Development, The Jobs Research Trust, Local Government New Zealand and the Tindall Foundation (Employment Catalyst Fund).

By mid-2003, Central Government Officials were taking the Mayors Taskforce for Jobs more seriously. The Ministry of Social Development had taken on the 'lead agency' role for government agencies' relationships with the Mayors Taskforce for Jobs and Bruce Ash, the Regional 
Commissioner in Christchurch was in the role 'National Programme Manager for the Mayors Taskforce for Jobs' (Ministry of Social Development, 2003b). Bruce Ash's main role was to manage the relationship between the Mayors Taskforce for Jobs and the Community Employment Group (Interviewee L).

June 2003 also saw the launch of the first joint Ministry of Social Development and Mayors Taskforce for Jobs Newsletter. This newsletter was intended as a two-monthly newsletter 'specifically designed to enhance information sharing between Mayors and the Ministry of Social Development' (Ministry of Social Development, 2003b). These newsletters 'became more professional as they went along'. The newsletters were designed to 'showcase opportunities' and publication would alternate between the Mayors Taskforce for Jobs and Ministry of Social Development. 'But the forewords came from both'. (Personal Communication, 2017). One of the functions of the newsletter was to provide data and statistics that measured progress towards goals (Ministry of Social Development, 2003b). This newsletter provided a way to hold each partner to account for producing the newsletter, and to account to the public more generally on the progress made by the Mayors Taskforce for Jobs.

May 2003 marked another major coup for the Mayors Taskforce for Jobs, this time with Central Government. Budget 2003 included a $\$ 56.6 \mathrm{~m}$ package 'to ensure all 15- to 19-year-olds are involved in education, work, training or other options by 2007.' A press release from Helen Clark, Prime Minister, noted that the manifestos of both coalition partners, Labour and the Progressives, included a commitment to this group of people as a priority. Included in the package was an expansion of the Gateway and Modern Apprenticeships programmes, reintroduction of student allowances for those aged 16-17 years and other specialist programmes (Clark, 2003). 
Garry Moore, Chair of the Mayors Taskforce for Jobs took credit for the Youth Transitions package as 'a direct result' of the agreement between Government and the Mayors Taskforce for Jobs (Mayors Taskforce for Jobs, 2003b).

Budget 2003 also delivered a package titled 'Jobs Jolt', which included the Mayors Taskforce - Flexible Employment Fund of $\$ 1.5 \mathrm{~m}$ over three years, to be used for one-year initiatives. This fund replaced the previous Mayors Taskforce allocation in the Transition to Work Contestable Fund, which ended on 30 June 2003 (New Zealand Government, 2003). The Flexible Employment Fund was to commence in October 2003 and provide funds for 'collaboration between central and Local Government aimed at providing 1-year projects that will have outcomes for youth such as training, education and work.' The fund of $\$ 0.462 \mathrm{~m}$ each year was to be supplemented by Mayors funds. The forecast net cost in $2007 / 08$ was $\$ 1.318 m$ (Ministry of Social Development, 2003a).

Meetings in September 2003 saw Mayors raise concerns about decisions with Officials and Ministers. The first meeting was when the Core Group met with Steve Maharey, Minister for Social Development and Employment and Jim Anderton, Minister for Economic Development to discuss the goals of the Mayors Taskforce for Jobs and how Government agencies could participate at a local level. The Mayors Taskforce for Jobs was keen to reinforce the importance of information sharing and agreement on the shared goals. In response, the Ministers agreed that the Mayors Taskforce for Jobs would be involved in policy decisions and that a process was needed to expedite this (Mayors Taskforce for Jobs, 2003j). The Mayors Taskforce for Jobs expressed its concern at the ending of the Destinations and Tracking pilots, programmes aimed at tracking school leavers through to employment. Steve Maharey 'reassured them that the work was going on through the youth transitions policy and that it would be continued in some form.' While Career Services had sought funding to continue the pilots, this was declined, and the Ministry of Social 
Development agreed to 'pick up the funding for the current year' (Mayors Taskforce for Jobs, 2003e).

These decisions to stop initiatives indicated that the Mayors Taskforce for Jobs and Central Government had different perceptions of what it meant to work in partnership. With officials, the relationship was one of consultation rather than collaboration, and even consultation processes were lacking. Subsequently, at an Officials meeting, Peter Hughes, Chief Executive of the Ministry of Social Development 'acknowledged the announcement [about the Jobs Jolt package] could have been handled better, and in future he will ensure the Taskforce is consulted prior to major changes' (Mayors Taskforce for Jobs, 2003d).

The reassurances from Ministers and Officials were not sufficient for the Mayors Taskforce for Jobs, with concerns being raised about the shortterm nature of Government strategies and the Budget process which was 'cloaked in secrecy'. Mayors felt that many of the discussions with Ministers and Officials were for show, with not a lot happening around the assigned portfolios, except just prior to meetings (Mayors Taskforce for Jobs, 2003g).

Concerns remained later in October 2003, when a meeting was held between the Mayors Taskforce for Jobs and Policy Officials to discuss the Youth Transitions policy. When Officials admitted they might meet 60 per cent of their target group, the Mayors Taskforce for Jobs made 'strong recommendations regarding accountability and the universality of the proposed service' (Mayors Taskforce for Jobs, 2003f). There was also concern that the funding would be gradually scaled back over time. While Officials may have listened to the recommendations of the Mayors Taskforce for Jobs, these were not actioned.

In March 2004, Steve Maharey, Minister of Social Development and Employment, who had been a consistent supporter of the Taskforce, was on leave from Parliament creating a void where an active relationship had been. However, the importance of the Mayors Taskforce for Jobs' 
relationship with Central Government was affirmed through the quarterly meeting which included Jim Anderton, the Minister of Economic Development; Ruth Dyson, Acting Minister of Social Development and Employment; Rick Barker, Associate Minister of Social Development and John Tamihere, Employment and Minister of Youth Affairs. The value of the partnership and its achievements were confirmed by Ministers and discussion commenced on the nature of unemployment. Although unemployment had reduced, pockets of very high unemployment remained in some communities (Mayors Taskforce for Jobs, 2004d). Mayors had come with an agenda to discuss the Government's 'commitment to ongoing funding' and were able to raise the need for a more sustainable funding mechanism for projects. They noted that under the current funding mechanisms, many pilot projects were vulnerable (Mayors Taskforce for Jobs, 2004a). Rather than committing to ongoing funding, Officials drew in other Government Agencies to partner with the Mayors Taskforce for Jobs,-including the Community Employment Group, Te Puni Kōkiri and the Tertiary Education Commission. Each of these agencies had a regional presence and actively sought ways to engage with the Mayors Taskforce for Jobs at a local level (Mayors Taskforce for Jobs, 2003d).

Support from the Community Employment Group was solid. Along with funding going to the Mayors Taskforce for Jobs, each Mayor was to have a designated fieldworker in an account manager role, with face-to-face meetings scheduled quarterly. Quarterly reports were required from each fieldworker, to be tabled at Council meetings and analysed for themes and good practice ideas. The Community Employment Group was also to review the Memorandum of Understanding and report within two months how it would strengthen its role within the organisation (Mayors Taskforce for Jobs, 2003d). However, by November 2003, the Mayors Taskforce for Jobs was questioning the effectiveness of the Community Employment Group (Mayors Taskforce for Jobs, 2003f) - unsurprisingly in light of its imminent fall from grace, as described in Chapter 5. 
Officials from 'education and training' appeared '[willing] to work together' and the meetings were 'all very productive resulting in positive outcomes and future action.' A meeting with Leith Comer, Chief Executive of Te Puni Kōkiri resulted in his request that all regional managers met with Mayors to discuss the achievement of Mayors Taskforce for Jobs goals at the local level (Mayors Taskforce for Jobs, 2003j).

After meeting with the Mayors Taskforce for Jobs, the Tertiary Education Commission undertook a survey of Mayors to determine the extent to which each district was engaging with the Tertiary Education Commission. The survey found that 13 Councils had engaged with the Tertiary Education Commission on specific projects; and there was a need to foster a better understanding of roles and responsibilities of the different groups as well as remove barriers to funding (Tertiary Education Commission, 2004).

Funding woes continued to be a topic for discussion throughout 2004 and into 2005. At the 28 October 2004 Officials meeting, there was discussion about the Government's contribution to the Mayors Taskforce for Jobs. The Ministry of Economic Development was 'unsure how the Ministry could continue to contribute but was concerned that there should be a move to a three-year sustainable model rather than... a one-year focus.' The Mayors Taskforce for Jobs noted that this was not how they saw funding - they had seen it as 'part of the partnership which would continue unless there were reasons to review the Mayors Taskforce for Jobs participation in the achievement of joint government goals.' Officials agreed to review how the Mayors Taskforce for Jobs would be funded at the current level for the financial year 2004/05 and beyond that to 'at least 2007' (Mayors Taskforce for Jobs, 2004e). In February 2005, the Ministry of Social Development and Department of Labour appeared to commit to three-year funding for the Mayors Taskforce for Jobs. Alison Dalziel, a 'strong supporter' of the Mayors Taskforce for Jobs had moved from the Ministry of Economic Development to the Department of Labour and was developing the three-year contract. Alison Dalziel's support extended to 
advocating within the Officials' group to strengthen ties between government Officials and the Mayors Taskforce for Jobs (Interviewee L).

Uncertainty around ongoing funding was not the only problem, with Government at times finding it difficult to pay existing bills. The Executive Officer had to repeatedly call to remind Government to pay on invoices (Francis, 2004b).

Despite the challenges around obtaining funding for the operations of the Mayors Taskforce for Jobs, significant funding was being put into youth employment services, albeit not without controversy. On 28 October 2004, Officials reported at the Mayors Taskforce for Jobs meeting that the Youth Transitions policy had secured a further $\$ 56 \mathrm{~m}$ over four years. The Youth Transition Service would be implemented successively over three years, with an allocation of \$3m in 2005; \$5m in 2006 and \$7m in 2007. The expectation was that Mayors would assist with 'time, expertise, facilitation, information and statistics... mostly around the engagement in the planning process' (Mayors Taskforce for Jobs, 2004e). However, Mayors considered the new Youth Transition Services were off to a rocky start. Varying information had been given to Council staff by Regional Commissioners and it was felt there was little consistency between regions. The role of Council officers had not been negotiated well and there was no budget allocation to support the work. Jan Francis, as Executive Officer of the Mayors Taskforce for Jobs was on the National Advisory Group, but in November 2004, the Group had not yet met (Mayors Taskforce for Jobs, 2004b).

These concerns had not yet been addressed by February 2005, when Jan Francis met with Mike Smith of the Ministry of Social Development and pointed out that issues to be addressed included: Terms of Reference being discussed before sign off; nationwide oversight of services; ensuring other strategies are included in strategic planning; acknowledging the conflict between a collaborative planning process and then a competitive tender; involvement of the Ministries of Youth Development and 
Education, and the role of Councils after the planning process. In the same meeting, Jan Francis, Executive Officer of the Mayors Taskforce for Jobs raised the difficulty of contracting for community organisations when renewal of contracts was left almost up to the expiry date of the previous one. Sustainable funding for employment projects was also raised, with a concern that the Ministry of Social Development was providing one-year funding with a requirement that the community organisation would become self-sustaining in the subsequent year (Francis, 2005).

The General Elections posed a challenge for the Mayors Taskforce for Jobs. Relationships with Ministers had taken time to build and relied on a degree of personal commitment from these busy people and by early 2004, the Mayors Taskforce for Jobs was discussing the need to build working relationships with National Party representatives. However, early overtures were not taken up (Mayors Taskforce for Jobs, 2004a). A more formal Political Parties Employment Meeting was scheduled for 19 August 2004, with invitations going to representatives from New Zealand First, Act, Greens, United Future and the Labour Party. It is not clear whether this meeting eventuated, although on 21 April 2005, the Mayors Taskforce for Jobs met with representatives of National, New Zealand First, United Future, the Māori Party, Green Party, ACT and Labour. Mayors Taskforce for Jobs Chair Garry Moore's aim was that the Mayors Taskforce for Jobs objectives would be 'embraced by all political parties and seen as an apolitical cultural goal for all New Zealanders' (The Jobs Research Trust, 2005a). This wasn't to be realised, with the National, New Zealand First and ACT New Zealand political parties later refusing to make a public statement of support.

The value of the Mayors Taskforce for Jobs to Central Government was highlighted by requests for Mayors Taskforce for Jobs input into other areas, with November 2004 bringing an invitation to write a 'think-piece' for Hui Taumata 2005. Hui Taumata was a meeting bringing together a 'wide range of perspectives across Māoridom, to look at ways to accelerate Māori economic growth', supported by Helen Clark, Prime 
Minister and with a budget of $\$ 1 \mathrm{~m}$ (Clark, 2004). Sir Paul Reeves, convenor of the Steering Group organising Hui Taumata, asked that the Mayors Taskforce for Jobs vision for cultural change be included in the think-piece, along with 'concrete ideas' of possible ways forward, drawing on examples of where Māori and the Mayors Taskforce for Jobs were working toward common goals (Reeves, 2004)

\section{Local engagement}

In October 2002, at the time of the second Memorandum of Understanding, 50 Mayors were members of the Mayors Taskforce for Jobs. Of these, 20 had been with the Mayors Taskforce for Jobs since at least March 2001 and 30 were new to the Mayors Taskforce for Jobs. This was due in part to the local body elections that were held on 13 October 2001 and the efforts of Jan Francis, Executive Officer of the Mayors Taskforce for Jobs to meet with every new Mayor and extend an invitation to join the Mayors Taskforce for Jobs. After the Memorandum of Understanding was signed, Mayors continued to join the Mayors Taskforce for Jobs. Timaru Mayor Wynne Raymond joined after discovering that joining the Taskforce would give access to funds for local initiatives. Previously, he 'didn't believe that Mayors could do anything that was not already being done by other agencies' (The Timaru Herald, 2002). However, the partnership with Government enabled Mayors to hold community organisations in their regions to account for government funding, and to raise issues with Ministers and Officials.

In Ōtorohanga, Mayor Dale Williams found that many of the services funded by the Government were not visible in the community. 'That people were being paid and funded to deliver a service that had never been to Oto, that we'd just uncovered... and we just said... you either deliver, or we'll go back and tell Wellington that you are absent without leave' (Interviewee M).

Increased recognition brought with it new members of the Mayors Taskforce for Jobs. On 7 July 2003, Marlborough District Mayor Tom 
Harrison joined the Taskforce, bringing the total number of Mayors to 58, and 100 per cent participation by South Island Mayors (Mayors Taskforce for Jobs, 2003a). 2003 also marked the decision for the Taskforce Administration group to report the names of the Mayors not involved in the Mayors Taskforce for Jobs, rather than those who were. By the Core Group meeting in September 2003, 59 Mayors had joined the Mayors Taskforce for Jobs. Just 15 Mayors had not joined (Francis, 2003a).

The frequency of local body elections was a constant challenge for the Mayors Taskforce for Jobs and in 2004, another election loomed. With the Mayors Taskforce for Jobs now seen as a viable part of the landscape, it was important to maintain momentum, especially where there were changes in Mayors. One tactic used by the Mayors Taskforce for Jobs was to request membership fees six months after a local body election. This gave Jan Francis, Executive Officer of the Mayors Taskforce for Jobs time to educate new Mayors about the Mayors Taskforce for Jobs and to confirm their continued support. Another tactic used by Jan Francis was to engage with Council staff so that if the Mayor sought advice from their team, Council staff could talk knowledgeably to the Mayor about the benefits of membership of the Mayors Taskforce for Jobs. (Interviewee L).

While the majority of Mayors were now members of the Mayors Taskforce for Jobs, there remained a focus on growing membership. An overarching theme from the April 2004 forum was agreement of the 'need to have the Mayors Taskforce for Jobs philosophy embedded in the culture of Councils throughout the country' (West, 2004). In March 2004, the Mayors Taskforce for Jobs comprised 60 Mayors (81 per cent of all Mayors). Only 14 Mayors remained outside the Mayors Taskforce for Jobs (Francis, 2004a). September 2004 saw challenges from Auckland Mayoral candidates as to why the incumbent, John Banks, had not joined the Mayors Taskforce for Jobs. Banks' response was that unemployment had halved over the last three years, and that his focus was not on the job creation programmes that typified the work of the Mayors Taskforce for Jobs, but rather was on commercial and infrastructural development, that 
'creates real sustainable employment through investment and growth' (New Zealand Herald, 2004).

\section{Summary of the early years}

From 2000 to 2004, the Mayors Taskforce for Jobs forged relationships with a wide range of partners, gaining support for the stated goals to address unemployment and obtaining a significant amount of funding both to run its operations and, in the Employment Catalyst Fund, to distribute to local initiatives. These years were characterised by tenacious and energetic leadership, a clear vision and an ability to bring people on board. While accountability mechanisms took time to fully implement, roles and responsibilities were clear and risks were managed. Participation included frequent telephone contact as well as an emphasis on face-toface contact with Government Ministers and Officials. While regular meetings took place, there were misunderstandings between Ministers, Officials and the Mayors Taskforce for Jobs about the extent of the partnership. Where policy and setting budgets were involved, Central Government appeared to want to, at the most, consult with the Mayors Taskforce for Jobs, even on initiatives that had been set up under their joint umbrella. At the local level however, Officials strongly encouraged local relationships and provided resources to support these.

In-person and electronic forums provided for a wide dissemination of information, ensuring those who were interested, could easily find out about the Mayors Taskforce for Jobs and join or otherwise support it. The following ten years are described in the next chapter. 
Part 2

From 2004 to 2014, the Mayors Taskforce for Jobs underwent multiple changes in its leadership, in the ways it interacted with Central Government and in how it held actors to account. This chapter sees the membership rise to all Mayors throughout New Zealand, but a collapse of collaboration with the arrival of the new Government in 2008.

\section{Change upon change}

\section{From goals to guarantees}

The end of 2004 saw the first of the Mayors Taskforce for Jobs' deadlines loom into view. The goal 'by 2005 , no young person under 25 years will be out of work or training in our communities' had not been met. Luckily, the Memorandum of Understanding with the Government had allowed for a longer timeframe, stating that 'by 2007 , all 15-19-year-olds will be engaged in appropriate education, training, work or other options which will lead to long term economic independence and well-being.'

Despite time running ahead of goals, the Mayors Taskforce for Jobs was not ready to concede defeat. The end of 2004 saw vivian ${ }^{18}$ Hutchinson providing advice to Garry Moore, Chair of the Mayors Taskforce for Jobs on 'how the Mayors Taskforce for Jobs can re-state its intentions [as] we [are] only weeks away from the beginning of 2005 , the date we set ourselves as our main goal for getting all young people into work or education.' vivian Hutchinson recommended a celebration of the 'fact that this Taskforce has gained much more traction on employment issues, and has sparked more practical initiatives on the ground, than was achieved by earlier efforts such as the Prime Ministers Employment Task Force in 1994.' vivian Hutchinson attributed the success of the Mayors Taskforce for Jobs to 'the model of cooperation and collaboration between local and

\footnotetext{
${ }^{18}$ vivian Hutchinson prefers his name spelt with a small ' $v$ '
} 
Central Government... collaboration with business interests... [and] a fundamental revolution in the way Mayors see themselves and the role they are seen to take in their communities.' vivian Hutchinson recommended that the Mayors Taskforce for Jobs should focus on 'an ongoing and living guarantee that there will be decent work and good training opportunities for all young people in this country.' Specific dates or goals to be achieved had been 'an excellent strategy to put the stretch on ourselves' but that it was time to focus on delivering the vision of the Mayors Taskforce for Jobs 'now'. This would also remove the confusion between the different dates and age ranges of the Mayors Taskforce for Jobs and its Central Government partners. (Hutchinson, 2004).

The Mayors Taskforce for Jobs subsequently adapted its mission statement to include the concept of 'job guarantees for all young people under 25 years' (The Jobs Research Trust, 2005b).

A youth guarantee - that all young people under 25 years be in paid work, in training or education, or in useful activities in our communities A job guarantee - that all adults who are long-term unemployed (registered for more than 12 months) have the opportunity and be encouraged to be in paid work, in training or education, or in useful activities in our communities.

New Mayors

On 9 and 10 October 2004, the Local Government elections saw a change in the membership of the Mayors Taskforce for Jobs. Welcome letters were sent to new Mayors, where the previous Mayor was a member. Signup letters and information packs were sent to Mayors who were not members. After the Local Government New Zealand New Mayors workshop, Adrienne Staples, Mayor of South Wairarapa joined the Mayors Taskforce for Jobs, bringing the total membership to 64 , or 86 percent of all Mayors (Mayors Taskforce for Jobs, 2004b). 
By December 2004, Jan Francis, Executive Officer of the Mayors Taskforce for Jobs had visited 22 new Mayors, with three visits remaining, to be completed in January 2005. Jan Francis reported that Mayors were 'happy to be briefed' and that most requested staff attend the meeting as well. As a result of those meetings, Francis noted key points that came up 'repeatedly' in discussions. These included the need for:

- capacity in Councils, including project managers or coordinators, expertise and resources to develop proposals, and staff fully supportive of the Mayor

- information for Councils, including local-level labour-market information, stocktakes of the local situation; and who can assist at the local level, including when government agencies are not located within the local area

- early successes to capitalise on the Mayor's enthusiasm and innovative approaches for small towns dealing with growth

- support from management of the Mayors Taskforce for Jobs, especially for new Mayors (Francis, 2004c).

Not all new Mayors supported the Mayors Taskforce for Jobs, with new Dunedin Mayor Peter Chin questioning whether there remained a reason for the Mayors Taskforce for Jobs' existence, and if there was, what it might be. The comments came in response to a reported $3.9 \%$ unemployment rate, the lowest in almost 19 years (Gorman, 2004). Early 2005 saw the final Mayors Taskforce for Jobs Annual Meeting that Garry Moore would chair. On 28 February and 1 March 2005, 36 Mayors and representatives of District and City Councils attended, along with representatives from the Ministry of Social Development and Steve Maharey, the Minister of Social Development and Employment. At the meeting Garry Moore, Chair of the Mayors Taskforce for Jobs acknowledged the low unemployment figures but noted that this 'is a Taskforce on jobs... not unemployment.' Dick Hubbard, Mayor of Auckland noted that 'it is during the good times that we need to put in the 
infrastructure...' (The Jobs Research Trust, 2005b). Dick Hubbard was one of three new Mayors who had recently joined the Mayors Taskforce for Jobs, taking numbers to 68 Mayors, or 92 per cent of all Mayors in New Zealand. In contrast to the previous Auckland Mayor, Hubbard was vocal in his support for the Mayors Taskforce for Jobs (Auckland City Council, 2005).

In July 2005, Garry Moore stepped down from the Chair, although remained on the Core Group of the Mayors Taskforce for Jobs. Paul Matheson, the Deputy Chair of the Mayors Taskforce for Jobs and Mayor of Nelson City, stepped into the Chair position. Yvonne Sharp, Mayor of the Far North District took on the Deputy Chair of the Mayors Taskforce for Jobs position at the Annual General Meeting (Hutchinson, 2005). Succession planning had been considered by the Mayors Taskforce for Jobs, with the aim that Deputy Chairs would move into the Chair position. (Interviewee L, Interviewee M).

\section{A new Chair}

The new Mayors Taskforce for Jobs Chair Paul Matheson's style was quite different to Garry Moore's, with less direct engagement in the business of the Mayors Taskforce for Jobs. 'Garry... called Ministers to account... was very direct... ran annual meetings... was very good at getting Mayors to support, passionate about it.' Garry Moore was also focused at the national level, with few Christchurch-based initiatives. Whereas 'Paul was completely different. He... called a spade a spade... ran quite a few events... but he basically just left it all to [Jan Francis].' Paul Matheson's focus tended to be on his own district, although he did 'meet with the politicians' (Interviewee L).

This leadership change also saw a change in support and partnerships for the Mayors Taskforce for Jobs. vivian Hutchinson, an inspirational and instrumental force behind the Mayors Taskforce for Jobs, resigned. (Mayors Taskforce for Jobs, 2006a). vivian Hutchinson's resignation marked a 'falling out about accountability' between Jan Francis, Executive 
Officer of the Mayors Taskforce for Jobs and vivian Hutchinson. While Jan Francis was under pressure to deliver to government agencies 'in whatever form they wanted and... within [a] time[frame]', vivian Hutchinson was more focused on relationships with the Chairs and politicians (Interviewee L).

The Jobs Research Trust (of which vivian Hutchinson was a trustee) also indicated their partnership with the Mayors Taskforce for Jobs would come to an end in 2006. This was also to be the end of The Jobs Letter, a publication the Mayors Taskforce for Jobs had funded since its inception and one which published regular updates on the activities of the Mayors Taskforce for Jobs. The Jobs Research Trust had also maintained an Internet presence on behalf of the Mayors Taskforce for Jobs, which meant the development of a new website was needed (Mayors Taskforce for Jobs, 2006a).

September 2005 saw the Labour Party re-elected and after 30 days, a government formed comprising Labour, New Zealand First and the United Future Party (the Labour/Progressive Coalition).

The Mayors Taskforce for Jobs retained partnerships with Local Government New Zealand, the Coca-Cola Careers Expo Trust, The Tindall Foundation and the Ministry of Social Development. An Officials Group; comprising Officials from the Department of Labour, Ministry of Economic Development, Ministry of Social Development, Te Puni Kōkiri, Tertiary Education Commission, Ministry of Youth Development, Department of Internal Affairs and Career Services, met regularly with the Mayors Taskforce for Jobs, actively working towards the Government and Mayors Taskforce for Jobs shared goals. A key output of the Officials Group in 2006 was the toolkit, intended to 'provide Mayors with practical tools' (Mayors Taskforce for Jobs, 2006a). This toolkit was 'based on three pillars... [it] took a lot of effort... [and] was a good way of getting messaging out there' (Personal Communication, 2017). The three pillars were the stated priorities of the Officials Group, which were to: 
- improve information about education and work choices for Māori youth based on the key messages the Māori community want to signal to their young people

- raise employer awareness, and invite participation from business and union representatives, of the opportunities to improve productivity by training staff in the foundation skills of literacy and numeracy

- raise the employability profile of young people with disabilities, using a whole-of-community approach (Mayors Taskforce for Jobs, 2006a).

Of critical importance to the Mayors Taskforce for Jobs were the relationships with the Department of Labour and Ministry of Social Development, as these organisations were signatories on the Government's funding contract with the Mayors Taskforce for Jobs. Further regional forums were held during 2005. The aim of these forums was to showcase best practice and support Mayors to achieve the youth goal. These forums were hosted by local Mayors, facilitated by Celia Lashlie $^{19}$ and included presentations from government Officials and Jan Francis, Executive Officers of Mayors Taskforce for Jobs. These regional forums were 'about motivating communities... they would see they could pool resources and strengths...sometimes it was about finding youth leaders and on the back of it, creating opportunities' (Personal Communication, 2017).

On 15 and 16 November 2005, Paul Matheson, Chair of the Mayors Taskforce for Jobs hosted a Mayors Taskforce for Jobs forum in Nelson. This forum was to be one Mayor's first memorable experience of the Mayors Taskforce for Jobs. 'I went because I was on a junket... our previous Mayor was a member and I had never heard that organisation referred to... the (Nelson) Mayor took us on a bus tour around Nelson, and he showed us a trade training centre... a youth hub, Nelson Tasman

\footnotetext{
${ }^{19} \mathrm{~A}$ leading advocate for youth
} 
Connections... I'm sort of absorbing it, but I wouldn't say I was totally focused' (Interviewee M).

By the time the November 2005 forum was held, Professor lan Shirley of the Institute of Public Policy (Auckland University of Technology) had been commissioned to lead a working group of economists to inform the Mayors Taskforce for Jobs' schedule of work and priorities for the future (The Jobs Research Trust, 2005b). The resulting report, Transition Assistance for Young People delivered in May 2006, argued in favour of a jobs 'guarantee' and noted that many of the measures 'central to positive transitions for young people' could be implemented without offering a guarantee. It also noted the importance of government understanding that transition from education to employment was a process and the need to intervene at various points in the process, taking into account the diverse nature of the youth population and local conditions (Lange, 2007).

In December 2005, the Mayors Taskforce for Jobs joined its voice to others calling for an increase in the minimum wage from $\$ 9.50$ an hour to $\$ 12.00$ an hour. The rationale given was to encourage 'greater investment in skill training leading to increases in productivity' (New Zealand Herald, 2005b). The release was in support of Member of Parliament Sue Bradford's 'Minimum Wage (Abolition of Age Discrimination) Amendment Bill', which was launched on 8 December 2005 (Green Party, 2005). This type of lobbying was unusual for the Mayors Taskforce for Jobs, both in content and in nature.

In March 2006, David Benson-Pope, the new Minister of Social Development and Employment, confirmed continuing support for the Mayors Taskforce for Jobs, including a statement in a press release that indicated a strong intention to continue to work together. '[The Mayors Taskforce for Jobs has] been a very successful initiative... we'll be resigning the Memorandum of Understanding... soon. (Benson-Pope, 2006). Nine months later, on 5 December 2006, a new Memorandum of Understanding was signed between the New Zealand Government and the 
Mayors Taskforce for Jobs. This signing of the new Memorandum of Understanding coincided with the launch of a new campaign from the Mayors Taskforce for Jobs 'Our Youth, Our Future' and the Toolkit developed by the Officials Group.

The Toolkit included cards with key points about employment, a task-sheet and contact list along with a series of guides:

- investing in youth

- Māori youth and enterprise

- young people with disabilities as employees.

The Toolkit launch and signing of the Memorandum of Understanding took place at the Beehive (home of New Zealand's Parliament), with five Government Ministers in attendance along with 'many other local members of Parliament, plus Chief Executives and representatives from... many government departments' (Mayors Taskforce for Jobs, 2007b). At that time, only two Mayors were not a part of the Mayors Taskforce for Jobs, including the Mayor of Wanganui (Benson-Pope, 2007).

The long-awaited 2006 Memorandum of Understanding reflected small but significant differences from the Memorandum of Understanding signed in 2002 . While some changes merely reflected updated strategies and priorities, other changes (mainly through the removal of particular phrases) signalled a need for a document that was both palatable and achievable for both parties. Additions included an objective for the Mayors Taskforce for Jobs to 'positively influence Central Government policy to achieve the Mayors Taskforce for Jobs vision'. References to the 'importance of sustainability' and 'no justification for the waste of New Zealanders through unemployment' were removed, while the commitment to 'reducing long term unemployment' was changed to 'reducing barriers to employment.' One final change was that the Government was no longer to 'ensure Government expenditure contributes to improved outcomes', but rather, Mayors Taskforce for Jobs 
Mayors were to 'consider how Government expenditure in the regions contributes to outcomes' (Appendix 2).

Along with the Memorandum of Understanding, a new website made clear Mayors obligations to the Mayors Taskforce for Jobs. These were to:

- give support and advocacy to the goals of the Taskforce

- contribute financially to the running of the Taskforce (calculated on a population basis and invoiced annually)

- attend as many of the Taskforce meetings as able

- share local examples of 'best practice' initiatives with other Mayors from around the country (Mayors Taskforce for Jobs, 2007a).

The Strategic Plan for 2006-2007 reconfirmed the thrust of the Mayors Taskforce for Jobs and its focus on young people. Rather than two goals or guarantees, the vision was that:

All young people under 25 years be in paid work, in training or education, or in productive activities in our communities and that all people over 25 have the opportunity and be encouraged to be in paid work, in training or education or in productive activities in our communities.

The strategies to achieve the vision were to:

- engage all members in the goals and actions to achieve local leadership

- share best practice widely

- advocate privately with central and Local Government on issues that impact on youth employment

- work with education providers and employers to ensure effective transition programmes for school leavers

- drive relationships with government agencies

- work with imaginative private sector initiatives

- develop mechanisms to encourage participation of young people with the Taskforce (Mayors Taskforce for Jobs, 2006b).

These strategies differed from the previous year, in which two additional strategies were noted: 
- advocate for youth and job guarantees

- establish a monitoring framework that measures progress towards the goals (including establishing a scoreboard to be reported annually in The Jobs Letter) (Mayors Taskforce for Jobs, 2005).

Early in 2007, Paul Matheson, Chair of the Mayors Taskforce for Jobs was quoted on two occasions with messaging that did not reflect that of the Strategic Plan. On 23 April 2007, the New Zealand Herald wrote that the Mayors Taskforce for Jobs had given up on their target date to 'end teen joblessness'. Paul Matheson, Chair of the Mayors Taskforce for Jobs was quoted saying that Mayors, the Social Development Minister and Ministry of Social Development had all accepted they would 'not quite' reach the target this year. However, in the same article, David Benson-Pope, Minister of Social Development was quoted as saying 'my goal is very much to deliver on that commitment by the end of this year and I'm very focused on it' (New Zealand Herald, 2007). A subsequent article in the Nelson Mail had Mayors Taskforce for Jobs Chair Paul Matheson clarifying that he was still committed to eliminating youth unemployment by the end of the year (Nelson Mail, 2007a).

On 8 May 2007, Paul Matheson, Chair of the Mayors Taskforce for Jobs called for a meeting of the Mayors Taskforce for Jobs to discuss the 'tragic deaths of two teenage girls outside an out-of-control party in Christchurch.' He described the 'sole purpose of the taskforce' as 'looking after young people' (Nelson Mail, 2007b). A meeting was subsequently held on 21 May 2007, in Christchurch. 'Around 20 members of the Mayors Taskforce met... to identify the problems and come up with solutions to make their communities safer' (Christchurch City Council, 2007). Most solutions focused on restricting young people's access to alcohol, which the Government of the day reported it was 'already reviewing' (Radio New Zealand, 2007).

Despite Paul Matheson, Chair of the Mayors Taskforce for Jobs appearing draw the focus away from employment, support for the Mayors Taskforce 
for Jobs from Central Government continued (at least in the media), with announcements made on 28 May 2007 of the recipients of the Ministry of Youth Development's Youth Development Partnership Fund. The Minister of Youth Affairs noted in the press release that 'the Fund's theme of education, training and employment aligned with the priorities set by the Mayors Taskforce for Jobs' (New Zealand Government, 2007).

On 26 June 2007, the Mayors Taskforce for Jobs hosted a two-day forum on youth employment. Eighteen of the 72 Mayors attended, along with youth workers, educators and career advisors. The workshop was addressed by David Benson-Pope, the Minister of Social Development and Employment, highlighting the region's falling youth unemployment levels. In the same article, Ōtorohanga Mayor Dale Williams was quoted as saying 'the real challenge for the Mayors Taskforce is to stay relevant' (Leaman, 2007). The following month, Dale Williams was elected new Deputy Chair of the Mayors Taskforce for Jobs.

New initiatives continued to be announced throughout 2007. For example, on 12 July 2007, Auckland City Council announced plans to develop a cadetship and graduate programme for under 25 -year-olds, as part of the Council's commitment to the Mayors Taskforce for Jobs (Auckland City Council, 2007). In a further example, on 25 September 2007, the Business Development Centre announced a national rollout of a small business development scheme. The scheme allowed small businesses to obtain an overdraft of up to $\$ 10,000$ for 12 months. Along with $\$ 150,000$ from the Mayors Taskforce for Jobs, the Ministry of Social Development invested $\$ 200,000$ and WEL Energy Trust invested $\$ 50,000$ (Business Development Centre, 2007).

On 13 October 2007, the local body elections resulted in 12 new Mayors and a new round of education for the Mayors Taskforce for Jobs team. Paul Matheson, Chair of the Mayors Taskforce for Jobs was one of the Mayors replaced in the local body elections when he chose to not contest the election. 


\section{Challenging relationships}

From February 2008, relationships between the Mayors Taskforce for Jobs and Central Government became more and more distant. Although an intention to work together was signed, the parties were moving steadily away from a partnership or even consultation.

\section{Local solutions for local issues}

By 1 February 2008, Dale Williams was Chair of the Mayors Taskforce for Jobs. Dale Williams' focus for the Mayors Taskforce for Jobs was 'local solutions for local issues' because 'if it's not local, even if it's regional, it just doesn't work for communities' (Interviewee M). This approach saw a change in emphasis to 'Youth in Transition', with the concept covering transition to education, training, work or the community. The focus was practical, including career advice, school leaving qualifications, transition into training and into work, lifelong learning and further transitions into better work. Dale Williams, Chair of the Mayors Taskforce for Jobs noted that 'remaining actively involved with our young people... will reap huge rewards for all of us. (Mayors Taskforce for Jobs, 2008). At the time, there was discussion about the focus of the Mayors Taskforce for Jobs, whether it was too wide or too narrow and whether it aligned with the Ministry of Social Development cohorts. One person interviewed noted that the real problem was in the people aged 16-18. This was the group for which neither the Ministry of Education nor the Ministry of Social Development were responsible - they were too old to go to school but too young to get a benefit (Interviewee M).

During the week of 15 February 2008, the New Plymouth District Council celebrated the success of the Mayors Taskforce for Jobs. The Council credited a move from 981 under-20s on unemployment benefits in 1997, to just 55, to the Mayors Taskforce for Jobs (Evans, 2008).

The change in Mayors also brought changes to engagement in the Mayors Taskforce for Jobs. On 28 February 2008, City Vision-Labour Councillors made a statement that John Banks, the new Auckland City Mayor, was set 
to exit the Mayors Taskforce for Jobs and cancel all the 'positive employment initiatives' which arose from it. At that stage, cadetships in Council organisations and graduation ceremonies for apprentices had been cancelled and the plans for an additional Youth Transition Service in Tamaki 'look(ed) grim’ (City Vision-Labour Councillors, 2008b). By 6 March 2008, John Banks had exited the Mayors Taskforce for Jobs, becoming the first Mayor to leave the initiative. Questioning at a Council meeting failed to elicit a reason why John Banks decided to leave the Mayors Taskforce for Jobs (City Vision-Labour Councillors, 2008a). However, the exit was not unexpected, given John Banks resisted joining while previously Mayor of Auckland. On 2 April 2008, local newspaper the Clutha Leader headlined with 'Banks slams youth taskforce'. A quote from the article attributed to John Banks stated, 'I'm not going to waste ratepayers' money navel-gazing with other Mayors when the responsibility falls with Central Government.' Not all councillors agreed with this summation, with a vote to remain in the Mayors Taskforce for Jobs narrowly being lost by two votes (McCracken, 2008).

Despite the challenges to the Mayors Taskforce for Jobs, Mayors continued to join. On 6 April 2013, Manawatu Mayor Margaret Kouvelis was recorded as having joined the Mayors Taskforce for Jobs to 'drive economic development in Manawatu as well as maximising skills, employment, innovation and retaining youth in the district' (Manawatu Standard, 2013).

Finally, on 7 May 2013, the Mayors Taskforce for Jobs was able to claim 100 per cent membership: all Mayors throughout New Zealand were a member of the Mayors Taskforce for Jobs. The last to join were the Mayors of Tauranga and the Chatham Islands. With the recent amalgamation of Auckland Councils, the total number of Mayors (and of Councils) was 67 (Mayors Taskforce for Jobs, 2013a).

While Dale Williams as Chair of the Mayors Taskforce for Jobs had made it his mission to get all Mayors involved, he didn't expect that all would be 
whole-heartedly committed to the cause. 'It was important to us to be able to say to Ministers at the time every single Mayor is backing this... [we needed] strength in numbers, solidarity... we were speaking on behalf of every single Mayor, which by default was every single community, which was by default every single voter' (Interviewee M). The aim was to ensure the Mayors Taskforce for Jobs was relevant, and had some leverage in the partnership with Central Government.

\section{New relationships with Central Government}

On 8 November 2008, the New Zealand General Election resulted in a change of government, from Labour to National. One of the new Government's first actions was to hold a jobs summit in Auckland, inviting sector leaders and including Dale Williams, Chair of the Mayors Taskforce for Jobs (Gardner, 2009). At the summit, Stephen Tindall (founder of The Warehouse) surprised the Tindall Foundation Manager and other delegates at the conference, by announcing a $\$ 1$ million boost to funding for 'bottom-up' training. This announcement also marked the beginning of the end of the Tindall Foundation's financial support for the Mayors Taskforce for Jobs, with the Tindall Foundation Manager commenting that the foundation 'preferred to be a catalyst for new projects rather than giving ongoing funding, and had stopped supporting the Mayors Taskforce for Jobs' (Collins, 2009). Although the financial support ceased, the Tindall Foundation remained a strong supporter of Mayors and funded Auckland Connections (a Taskforce project) until at least 2016 (Interviewee L).

The regular meetings between the Mayors Taskforce for Jobs and Ministers were also starting to slide. On 5 March 2009, Annette King (in opposition) asked Paula Bennett, the Minister for Social Development, how many times she had met with the Mayors Taskforce for Jobs since November 2008. The response was that the Minister had met once with the Mayors Taskforce for Jobs in November 2008 and that future meetings were to be confirmed (Bennett, 2009). When asked, Dale Williams, Chair of the Mayors Taskforce for Jobs noted that he was 'not at all concerned' 
about the relationship between the Mayors Taskforce for Jobs and Government, and that 'Paula Bennett, Rodney Hide and John Key are extremely supportive of (the) Mayors Taskforce for Jobs, and the negotiations (on the Memorandum of Understanding) will be a formality' (Houlahan, 2009).

On 23 March 2009, the Press (a Christchurch newspaper) reported that the Mayors Taskforce for Jobs had had to scale back on its ambition of 'eliminating youth unemployment this year.' In 2007, youth unemployment reached 250 from about 14,000 in 2000 but in 2009 the effects of the worldwide recession were beginning to be felt (Houlahan, 2009).

On 28 April 2009, the Government and the Mayors Taskforce for Jobs signed a new Memorandum of Understanding. This document was fundamentally different to those that had been in place before, highlighting an intention to work together, rather than to achieve goals. The new Memorandum of Understanding stressed the opportunity for local communities to have an input into the policy-making process; for a two-way communication channel; for interaction in a structured way; for local decision makers and communities to advise on how to make policy relevant at the local level, and a 'quick and effective way' for Government to consult with local communities. The Memorandum of Understanding noted that an 'area of common interest... is... maximising local employment opportunities for young people and ensuring their successful transitions to education, training or employment.' This contrasted strongly with the previous Memoranda of Understanding, where agreement was made to 'work together to facilitate community development initiatives... promote close cooperation between Central Government and local economic and employment development organisations... 'work together to promote new solutions to sustainable employment... and... provide opportunities for policy input by local communities.' Funding and initiatives were not mentioned in the 2009 Memorandum of 
Understanding. This Memorandum of Understanding marked the end of a collaborative relationship between Central and Local Government.

\section{Central Government support}

The new Government and its unwillingness to collaborate with the Mayors Taskforce for Jobs marked a sharp decline in the fortunes of the Mayors. The Mayors Taskforce for Jobs was no longer supported by the Ministry of Social Development or by the newly-established Ministry of Business, Innovation and Employment. Described by one Parliamentarian as a lost cause, suitable only to shut itself down (ACT New Zealand, 2011), the Mayors Taskforce for Jobs continued to exist, albeit accepting greater oversight by Local Government New Zealand.

Support from the Beehive also started to slide, with one indicator being the number of media releases made by Ministers that mentioned the Mayors Taskforce for Jobs. Between 2000 and 2018, the New Zealand Government made 101 press releases that included reference to the Mayors Taskforce for Jobs. Ninety-four of these press releases were made before the change of Government in 2008. In the first term of the National Government, seven press releases mentioned the Mayors Taskforce for Jobs. Between 2011 and 2018, Ministers did not mention the Mayors Taskforce for Jobs in any press releases. Figure 19 sets out the number of press releases that mention the Mayors Taskforce for Jobs between 2000 and 19 May 2018. 
Figure 17: NZ Government press releases: Mayors Taskforce for Jobs

\begin{tabular}{|l|c|}
\hline Government & $\begin{array}{l}\text { Number of press releases by New } \\
\text { Zealand Government that } \\
\text { mentioned the Mayors Taskforce } \\
\text { for Jobs }\end{array}$ \\
\hline Labour/Alliance 1999-2002 & 19 \\
\hline Labour/Progressive 2002-2005 & 43 \\
\hline Labour/Progressive 2005-2008 & 32 \\
\hline National 2008-2011 & 7 \\
\hline National 2011-2014 & 0 \\
\hline National 2014-2017 & 0 \\
\hline Labour 2017-19 May 2018 & 0 \\
\hline
\end{tabular}

Note: also includes where the 'Mayors Taskforce' was mentioned.

On 2 August 2009, the Government announced a new package of funding titled 'Youth Opportunities'. This package was aimed at supporting young people during the economic recession and included Job Ops; a financial incentive for business owners to offer six-month's employment to young people and Community Max, a financial boost for community projects that employed young people. Other policies included a Youth Guarantee, enabling 16-17-year-old students to attend tertiary institutions at no cost; service academies for Year 11 and 12 students aiming to enter the New Zealand Defence Force; and an expansion of the Limited Service Volunteers programme, a six-week military training course for unemployed youth (Key, 2009). None of these policies aligned with the Ōtorohanga approach of creating a system to prevent youth unemployment. However, Dale Williams, as Chair of the Mayors Taskforce for Jobs strongly encouraged Mayors to make the most of the opportunities for the young people in their communities (Mayors Taskforce for Jobs, 2009) - while advocating fiercely for a continuation of funding for the Ōtorohanga initiatives (Boyes, 2009).

In this environment, it was 'hard to get stuff done' (Personal communication, 2018). However, on 11 February 2010, the Mayors Taskforce for Jobs released a damning review into Modern Apprenticeships. The review found completion rates of 33 per cent on average, with the best results when the provider was based in a particular geographic region and prepared to go the extra mile with the apprentices 
(Mayors Taskforce for Jobs, 2010a). The release of this report led to a meeting scheduled between Steven Joyce, the Tertiary Education Minister and Mayors, with the Minister stating a preference for 'performancebased funding'. (Collins, 2010a). This approach didn't talk to the Mayors' call for local systems to address local problems.

March 2010 saw the announcement of a new strategy to improve education, employment and training outcomes for young Māori. The Mayors Taskforce for Jobs partnered with Marcus Akuhata-Brown to develop the Rangatahi Leadership Programme (later known as Tuia). This programme enabled a young Māori person to be selected by their local Mayor. The Mayor would provide mentoring to the young person and enable them to attend regular Wānanga with other people in the programme (Mayors Taskforce for Jobs, 2010c). The Tuia programme was still live in 2020.

In June 2010, a new Memorandum of Understanding was agreed. This Memorandum of Understanding stated that the 'core area of common interest for the Government and the Mayors Taskforce for Jobs is maximising local employment opportunities for young people and ensuring their successful transition to education, training or employment.' The Mayors Taskforce for Jobs further agreed to assist communities to respond to the Whānau Ora programme and to be involved with Community Response Panels.

While showing disappointment with the apprenticeship system, the main focus for the Mayors Taskforce for Jobs in 2010/11 was to work with Central Government to create a National Youth Transitions Service (Mayors Taskforce for Jobs, 2010b). In October 2010, the Mayors Taskforce for Jobs released a proposal that would ensure that every 16 or 17-year-old is in work or further training after leaving school. A national call centre was to be sent all school-leavers' details so that contact could be made. Those who needed support would be referred to local Youth Transition Services. The Minister of Social Development, Paula Bennett 
was reported as being 'very interested' in the proposal (Collins, 2010b). The total cost of the Mayors' proposed youth transitions service was $\$ 13$ million (Interviewee L).

In November 2010, the Core Group of the Mayors Taskforce for Jobs met with Officials and agreed that the Core Group would meet annually to discuss strategic direction. It was also envisaged that a strategic meeting with Ministers would take place on an annual basis (Mayors Taskforce for Jobs, 2011). While positive, this represented a relationship in which parties met in person less than one quarter of the times per year they had previously.

However, over the next six months, relations between the National Government and the Mayors Taskforce for Jobs appeared to sour. In a Parliamentary Question on 22 March 2011, Jacinda Ardern, the Labour Party Spokesperson for Social Development asked Paula Bennett, the Minister of Social Development to describe her relationship with the Mayors Taskforce for Jobs. While the Minister described it as 'very good', the minutes of the last meeting between Paula Bennett and the Mayors Taskforce for Jobs, held on 10 March 2011, noted the Mayors were 'extremely disappointed in the response from the Minister and the disrespect with which they had been treated.' Further questioning elicited a statement Paula Bennett that she and the Mayors Taskforce for Jobs members had 'hotly debated' how best to join forces to tackle youth unemployment (Bennett, 2011). This 'hot debate' was described by one interviewee as 'we got offside with [Minister] Bennett... I got offside...she was the worst... ... she was terrible' (Interviewee L).

On 28 March 2011, the New Zealand Herald reported further on Minister of Social Development Paula Bennett's meeting with the Mayors Taskforce for Jobs and subsequent questions in the House. Paula Bennett 'dismissed criticisms... blaming the inaccuracy of the minute taker.' However, the Herald reported that 'Mayors who were present... confirmed the ill-feeling from the March 10 meeting...' The 'hot debate' appears to have been in 
relation to the Minister's intention to cease funding youth transitions, noting that other priorities took precedence. The meeting minutes noted that the Minister also 'challenged the Mayors as to what they brought to the table and what she obtained for the grant provided, adding that the taskforce appeared to be a lobby group for pet projects' (Cheng, 2011). Debate over the future of the Youth Transition Service continued via the media, with Dale Williams, Chair of the Mayors Taskforce for Jobs noting in an article in the New Zealand Herald on 20 April 2011 that he had met again with Paula Bennett, the Minister of Social Development to discuss the project, where they agreed that 'tackling youth unemployment was the most important issue to stay focused on'. While government was paying $\$ 13 m$ per year to cover 65 per cent of the country and selected school leavers judged at most risk of dropping out, Dale Williams said a targeted system created resentment. By rationalising the existing services, a national service could connect with every individual, although Officials disagreed (Collins, 2011).

In June 2011, the attack on the Mayors Taskforce for Jobs continued, with Sir Roger Douglas, the ACT Party's Finance Spokesperson telling the Mayors Taskforce for Jobs to 'abolish yourself.' Sir Roger Douglas noted that if the Mayors Taskforce for Jobs was serious about tackling youth unemployment, it would 'disband immediately', as the money spent on the Mayors Taskforce for Jobs ('diverted from the taxpayer') had 'undoubtedly... cost many potential jobs for youngsters' (ACT New Zealand, 2011). Dale Williams, Chair of the Mayors Taskforce for Jobs quickly responded, letting readers know that he had been forced to 'ask Sir Roger to leave the meeting... he came across as a belligerent old dinosaur... he banged the table and swore...' (Twentyman, 2011). On 9 August 2011, during the Estimates Debate on Vote Employment, Nanaia Mahuta, Member of Parliament called out that the Government was 'silent about the Mayors Taskforce for Jobs'. The challenge from Nanaia Mahuta was that the Mayors had identified commitment to 
reducing youth unemployment, had partnered with the business community to do so, and was calling on Central Government for the final piece of the puzzle. However, 'we are hearing that the Limited Service Volunteer programme ${ }^{20}$ is the solution to youth unemployment' (Bennett, 2011).

In February 2012, Paula Bennett, the Minister of Social Development released the National Government plans for youth. Under the banner of a comprehensive welfare reform, Paula Bennett announced a system that focused strongly on targeted individuals considered at most risk of unemployment. This included 'a managed system of payments... with an allowance and payment card for living costs... sharing information between ministries to target school leavers most at risk...' (Bennett, 2012). The focus was to move to only the 16- and 17-year olds that the Ministry of Social Development classified as 'high risk'. Rather than continue existing contracts, the new youth services providers were selected through a national tender process.

Along with the changes to youth services, the Government was keen to define the role of local Councils with the Local Government Act 2002 Amendment Bill. This Bill proposed removing Local Government responsibility for 'the four well-beings' - being economic, social, cultural and environmental well-being. On 20 March 2012, Nick Smith, Local Government Minister was quoted as saying that 'Councils would be steered away from spending on social and cultural activities in favour of core activities such as key infrastructure, regulations and public services... many things Councils did were not core services... that included the Mayors Taskforce for Jobs' (Chapman, 2012). In response, Dale Williams, Chair of the Mayors Taskforce for Jobs stated that 'the great work done in communities... could be destroyed if the purpose of Local Government is narrowed to services determined by Central Government...' (The Timaru

\footnotetext{
${ }^{20} \mathrm{~A}$ six-week, military-style training programme, where young unemployed people live and train on an army base.
} 
Herald, 2012). On 30 November 2012, changes to the Local Government Act were confirmed, removing the four well-beings, despite the 'concerns and criticisms of provincial Mayors and Councils' (New Zealand Labour Party, 2012).

By this time, the Mayors Taskforce for Jobs had a budget of around $\$ 500,000$ per year, of which approximately $\$ 250,000$ came from membership fees, $\$ 25,000$ from Local Government New Zealand and $\$ 250,000$ from Central Government. The agreement was re-signed every year, with a set of agreed actions. The actions would reflect the priorities of the day from the National Government and funding would match the membership fees (Interviewee M).

\section{Dissolution of the partnership}

\section{From partner to contractor}

By June 2013, the form of the relationship between Central Government and the Mayors Taskforce for Jobs had changed. 'They kept putting in front of us a document that was completely different from a high-level partnership agreement... it was more a service delivery contract as though we were a contractor. We kept sending it back, modified' (Interviewee M). 'We were providing a network... intelligence at the local level... a whole group of Mayors. We didn't need a contract for service' (Interviewee L). By October 2013, Dale Williams, Chair of the Mayors Taskforce for Jobs had announced his intention to not stand in the local body elections and prepared to hand over the reins of the Mayors Taskforce for Jobs Chair to Jenny Rowan, Mayor of Kāpiti. However, Jenny Rowan was not elected, and the succession plan was 'blown out of the water'. (Interviewee M). Dale Williams was asked to continue to chair the Mayors Taskforce for Jobs for the remainder of the year. In his last meeting with Stephen Joyce, the Minister of Tertiary Education, Skills and Employment; Dale Williams understood that a new agreement would be drafted immediately. However, it wasn't until February 2014 that a new agreement was supplied to the Mayors Taskforce for Jobs for review (Interviewee M). 
On 27 February 2014, a Mayors Taskforce for Jobs workshop was held in Rotorua. Although by this stage all Mayors were members of the Mayors Taskforce for Jobs, only nine were in attendance for the workshop. During the workshop, Mayoral engagement was discussed as a concern with one (attending) Mayor admitting a level of cynicism about the Mayors Taskforce for Jobs. Other Mayors cited high workloads as a reason to not be engaged, especially for those in metropolitan areas. A further concern was the 'looseness' of the structure, which resulted in agreement to apply to become an incorporated society. At this workshop, the proposed Memorandum of Understanding was discussed, with members noting the delays in signing the agreement. The offer was a contract for $\$ 170,000$ but further discussion was needed with Stephen Joyce, the Minister of Tertiary Education, Skills and Employment; and Tariana Turia, Associate Minister of Tertiary Education, Skills and Employment about 'skills development' and 'Māori issues'. Concerns were raised that the Mayors Taskforce for Jobs was being required to fall in line with the Government's requirements, rather than build on the strengths and successes achieved to date (Cranston, 2014).

At this stage, the pressure was on for the Core Group, many of which were new Mayors. The Core Group thought that without Government funding, the Mayors Taskforce for Jobs was technically insolvent. Further, with the obligations of Directors under the Companies Act 1993, the Core Group members were individually and severally liable for the insolvency of the Mayors Taskforce for Jobs. This was despite the ongoing membership fees and, if a contract with Central Government didn't materialise, then the Mayors Taskforce for Jobs was not required to deliver additional services. In short order, a new agreement between the Government and the Mayors Taskforce for Jobs was signed. This new agreement focused more on service delivery and included a clause that the Mayors Taskforce for Jobs could not criticise the Government of the day (Interviewee M). This agreement was no longer a partnership document, rather, it was a contract for services. 
Key departures

Along with the departure of Dale Williams, Chair of the Mayors Taskforce for Jobs, the Annual General Meeting of 21 July 2013 saw thanks to Jan Francis, Executive Officer of the Mayors Taskforce for Jobs and Mo Pettit, Administrator for their service and contribution to the Mayors Taskforce for Jobs (Mayors Taskforce for Jobs, 2013b) Jan Francis had been with the Mayors Taskforce for Jobs since its beginning in 2000 and had been a key force behind the scenes. However, the three-yearly turnover of Mayors through local body elections and the challenges involved in reaching all new Mayors was tiring. 'When Dale went, [Jan Francis] thought, I don't want another Chair... because after every election I went around every new Mayor and on average there were about 20, 25 new Mayors. It was a huge, huge job to do, to go around and talk to all the new Mayors...' (Interviewee L).

In 2014, the Mayors Taskforce for Jobs looked very different from its origins. Jan Francis, Executive Officer of the Mayors Taskforce for Jobs had been with it since the beginning, maintaining relationships behind the scenes with Mayors, Council Chief Executives, Mayor's Executive Assistants, Central Government Officials and other key stakeholders. Jan Francis was instrumental in inducting new Mayors into the Mayors Taskforce for Jobs, after each local body election travelling the length and breadth of the country to meet the 20 or 30 new Mayors and to explain the benefits of joining the Mayors Taskforce for Jobs. Jan Francis also managed the accountability side, from contracts with Government and agreements with stakeholders, to setting budgets and sourcing contractors for smaller jobs (Interviewee L).

While Jan Francis had organised for a transition to a new contractor, the position did not work out. 'The CEO of Local Government New Zealand stepped in... first they changed the whole role to a coordinator' (Interviewee L). This changed the nature of the relationship between Local Government New Zealand and the Mayors Taskforce for Jobs, with the 
coordinator sitting in Local Government New Zealand's offices. A major part of the role of the Mayors Taskforce for Jobs coordinator was to 'rejuvenate the taskforce' (Personal Communication, 2018), a significant change from the early days of the Mayors Taskforce for Jobs where the Chair played a major role in gathering support from other Mayors.

\section{Legacy}

The Mayor's Taskforce for Jobs remains in place, but 'it is quite - although not entirely - different today.' The current focus is on 'creating partnerships and demonstrating value' (Personal Communication, 2017). 'How it is put together and the driver behind it is different. It hasn't entirely lost touch with its origins' (Personal Communication, 2017). Each Council still pays a membership fee and this appears to be seen as merely one aspect of Council business. The fee remains low.

The coordinator sits within Local Government New Zealand and carries out tasks such as supporting Mayors with Industry Training graduations, making applications for grant funding and coordinating a Rangatahi Leadership Programme (Personal Communication, 2017). Seventeen Mayors now form the Core Group, meeting quarterly in Wellington, although it is not clear if they meet with Ministers.

The change of Government in October 2017 may signal a new era for the Mayors Taskforce for Jobs. In July 2018, a new Memorandum of Understanding was signed, representing an agreement between:

- Nanaia Mahuta, the Minister of Local Government

- Jenny Salesa, the Minister for Building and Construction

- Willie Jackson, the Minister of Employment

- Peeni Henare, the Minister for Youth

- Max Baxter, Chair of the Mayors Taskforce for Jobs and Ōtorohanga District Council Mayor

- Malcolm Alexander, Chief Executive, New Zealand Local Government Association Inc. 
Of note is the positioning within that statement - the first Minister is the Minister of Local Government. Also worthy of note is that alongside the Chair's signature (Max Baxter, Ōtorohanga District Council Mayor) is the signature of the Chief Executive of Local Government New Zealand. It appears that the Mayors Taskforce for Jobs is no longer fully controlled by the Mayors.

Further, the role of the Mayors Taskforce for Jobs was summarised in the Memorandum of Understanding as 'advocating, maximising opportunities for young people, building knowledge, skills and relationships... and as a channel for providing employment-related information to stakeholders.' Funding is not attached to the Memorandum of Understanding, although it notes that 'in some cases it will be appropriate to discuss the potential for Parties to provide funding, while recognising that each party will need to make a determination of their own ability to fund initiatives...' (2018 MOU).

As in 2002, a photograph was taken to commemorate the signing of the Memorandum of Understanding, showing Government Ministers alongside Mayors and the Chief Executive of Local Government New Zealand. However, there is a stark contrast between the 2018 photograph, with its plain background and the photograph of 2002, where the Prime Minister Helen Clark was front and centre, and the setting was the Cabinet Room in Parliament (Figure 19). 


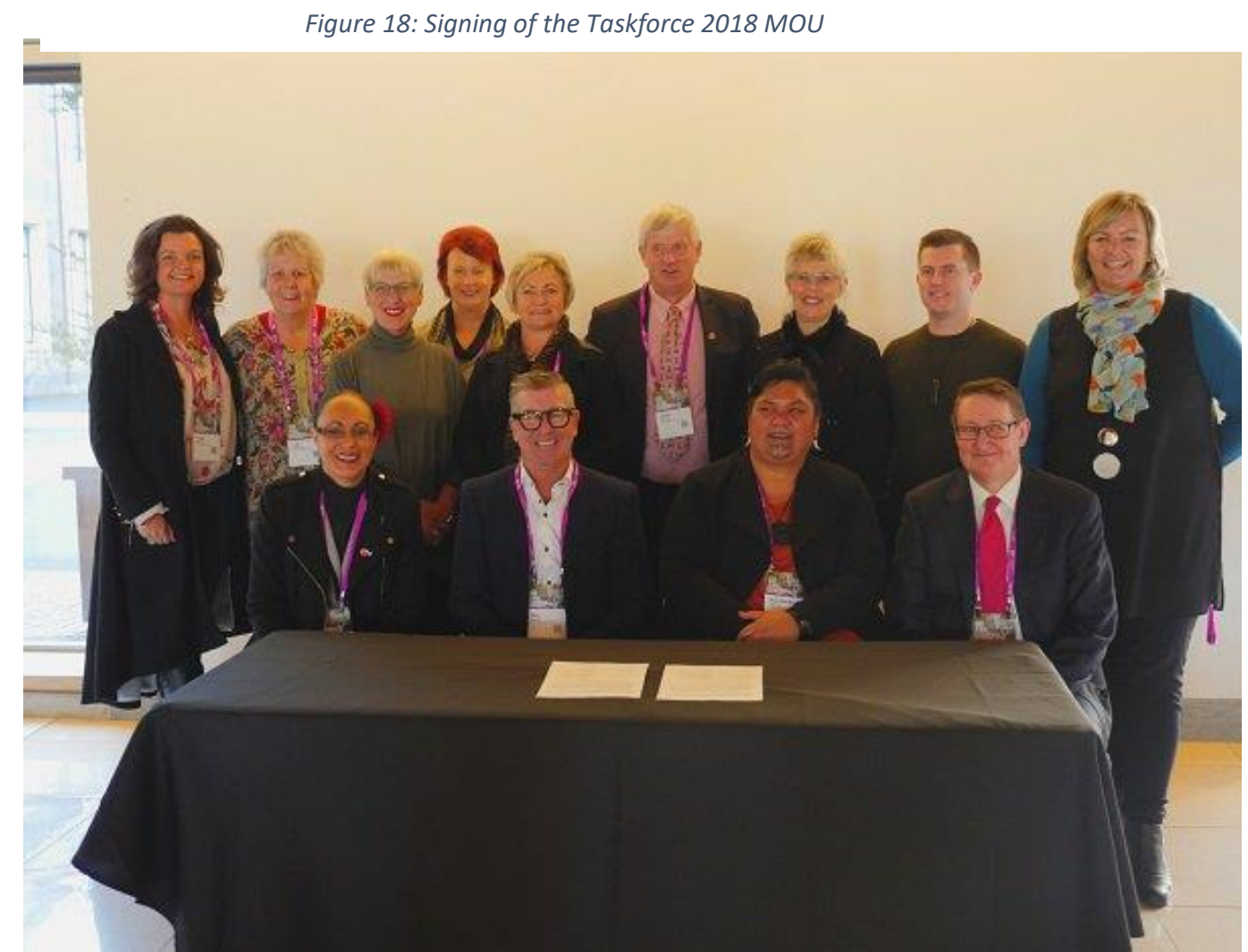

Mayors, Ministers and the Chief Executive of Local Government New Zealand at the signing of the $2018 \mathrm{MOU}$.

The real legacy of the Mayors Taskforce for Jobs can be seen in a multitude of programmes and services that found their origins in the original Mayors Taskforce for Jobs. Programmes such as 'Auckland Youth Connections', Tuia and some trades graduations continue today. However, these are not actively promoted by the Mayors Taskforce for Jobs coordinator, but rather, 'if one pops up, then we'll support it'. (Personal Communication). The evidence-based approach to programmes has also become a legacy for the future. Former Mayors Taskforce for Jobs Chair Dale Williams has developed 'COAL' - a 'very tidy, tight set of steps that when communities follow, they get results' (Interviewee M). This is a tool that Dale Williams was seeking when he became Mayor of Ōtorohanga in 2003.

Youth unemployment rates have remained stubbornly high over the last 30 years. It seems government missed an opportunity to partner with the Mayors Taskforce for Jobs to develop a national youth transitions programme that could build on the successes of local programmes. The benefits could have been an increased number of youth transitioning from 
compulsory education to their next phase and therefore decreased unemployment and disengagement. Perhaps the best result might be that the Government learns from the lessons of yesterday. In this case, evaluation reports on youth transition programmes should provide a core piece of evidence for decisions, as we grapple with the same problems of youth unemployment today.

\section{Summary of the later years}

From 2004 to 2014, the Mayors Taskforce for Jobs struggled to maintain relationships with Government Ministers and Officials. While successive Memorandum of Understanding indicated a commitment of Government to work in collaboration with the Mayors Taskforce for Jobs, this was not enough to ensure a positive working relationship, let alone a collaborative partnership.

Changes in leadership throughout this time also had an impact on the Mayors Taskforce for Jobs. When the messaging was diluted and the purpose unclear, it was difficult to see progress in the initiative. However, the appointment of a visionary new leader with a strong direction resulted in the commitment of all Mayors to the initiative. While in many cases, this commitment on paper was not followed through with action, the tactic of having all Mayors, with reach into every community in New Zealand, offered a strong incentive for Government to participate.

One aspect that remained constant throughout the case study was the formal accountability mechanisms set in place early in the operation of the Mayors Taskforce for Jobs. The 'core group' of Mayors, initially responsible for strategic direction, decision making and relationship management still exists, although with a lesser remit than before. Operations are coordinated from a central point, but without the status of an Executive Officer to carry out activities on behalf of the core group. Other mechanisms set up to support the distribution of grants disappeared when the funding pool disappeared. 
Finally, and similarly to the experience of the Community Employment Group, when the initiative lost the ability to engage at a senior level with Government, it was no longer able to account directly for its activities or to have a say in policy design.

\section{Lessons from the Mayors Taskforce for Jobs}

Once more, returning to the seminal question of this thesis: what institutional arrangements enable iterative and ongoing community problem solving to address long-term unemployment? this case study has focused on the accountability arrangements, leadership behaviours and competencies and participatory processes by which government and community agents collaborated in an initiative that started from the demands of an unusual and challenging new Mayor to build a nationwide collaboration that moved beyond local bodies' traditional rebate of roads, rubbish and rates and to focus on the social wellbeing of communities.

In this case study, the mantle of leadership was transferred between Mayors, and the fortunes of the initiative were very much at the whim of central government. While the case study traverses a time where there were three different Mayors leading the initiative, the emphasis in this thesis is on the two who were passionate about the Mayors Taskforce for Jobs, each focused on long term unemployment but with different approaches to achieve the goal. Both these leaders are inspirational speakers, capable of generating excitement and support for their cause. This communication was backed by a clarity of vision in each and the tenacity to hold on to that vision even in times of challenge. Of note for both of these leaders was the support of Jan Francis and vivian Hutchinson, who contributed significantly to the leadership of the initiative through their contribution to accountability - one focused on the formal systems and processes, and the other focused on informal mechanisms, and keeping the initiative in view of stakeholders.

This case is an unusual example of a collaborative initiative, in that it was local government partnering with central government for a common goal. 
The relationships built were with people at all levels, from Ministers of the Crown, to public officials, with businesses, between Mayors and with local government staff. This engagement was ongoing, comprehensive and exhausting, with face-to-face meetings undertaken throughout New Zealand, in large and small towns, from the Far North to Southland. Added to this was the firstly quarterly, then annual meetings with Ministers and officials in Wellington, and the corresponding record keeping they entailed. All in all, the participation could be described as frequent and purposeful, with agendas reflecting strategic discussions as well as holding Ministers and officials to account for delivery on their commitments. 


\section{Chapter 8: Analysis}

This chapter is structured around the overall research question and three sub-questions generated from the literature, with each being addressed in turn by a short reprise on the literature, a within-case comparison and a cross-case comparison.

The overall research question is:

- What institutional arrangements enable iterative and ongoing community problem solving to address long-term unemployment? More specifically, the three sub-questions that have been explored empirically are:

- What accountability arrangements, tools or methods can allow the Government to partner meaningfully and well with New Zealand communities to address long-term unemployment?

- What types of participatory processes might enable communities and government organisations to engage in partnerships that address longterm unemployment?

- What leadership behaviours and competencies might facilitate partnerships between government agencies and communities to address long-term unemployment?

\section{Accountability}

\section{A recap of findings thus far}

The literature on accountability or 'the means by which individuals and organisations report to a recognised authority (or authorities) and are held responsible for their actions' (Edwards \& Hulme, 1996) defines different types of accountability:

- short-term functional accountability for resource use and strategic accountability for results (Avina, 1993)

- the problem of 'accountability to whom' (Stone \& Ostrower, 2007). 
Ebrahim (2003) helpfully combines the notions of functional and strategic accountability with 'accountability to whom'. The result is a framework that places accountability mechanisms on three different dimensions: strategic - functional, upward - downward and internal - external. Added to these dimensions is the notion of accountability along a formality continuum (Masdar, 2015). This enables accountability mechanisms to be understood according to their placement on each of the dimensions (Figure 21).

Figure 19: Four Dimensions of Accountability

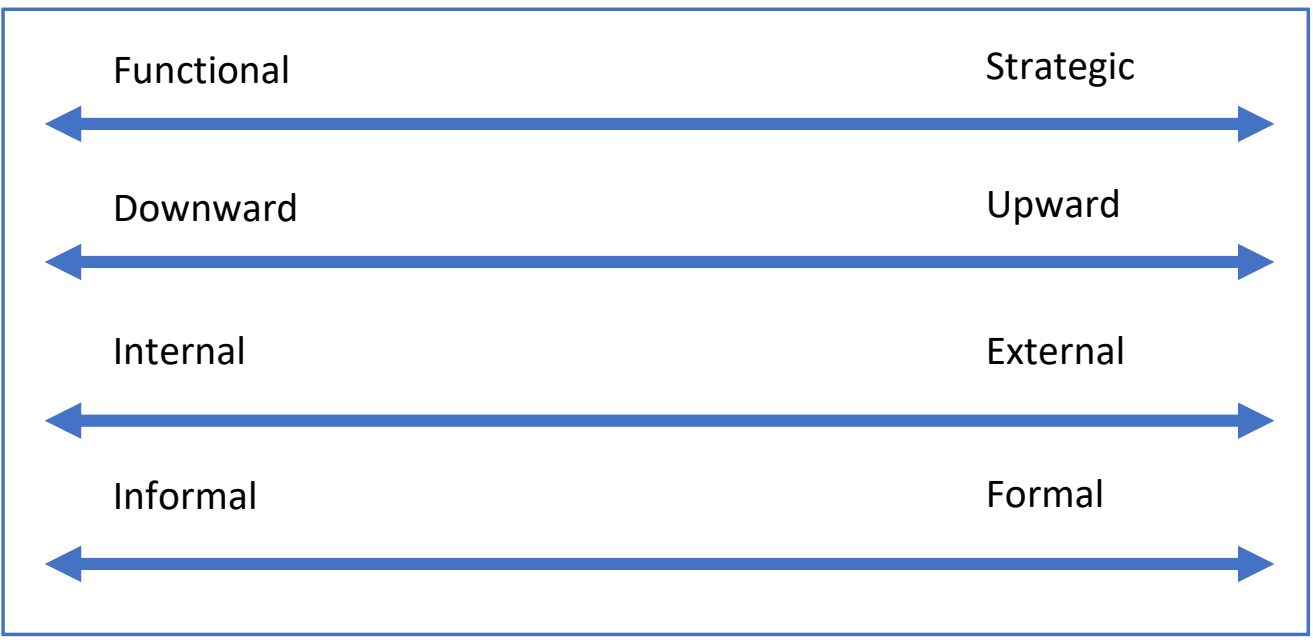

Decision-making processes are highlighted in the collaborative governance literature as an accountability mechanism worthy of consideration (Booher \& Innes, 2006; Henton et al., 2005). Added to this is the monitoring by government when community actors are involved (Donahue et al., 2011). Smith et al. (2006) focus on individual board member reporting as the mechanism for accountability and the forum in which the member reports (public meeting, own organisation, funding organisation). These mechanisms are at the formal end of the dimension, with little information available on informal mechanisms.

\section{Accountability in the Community Employment Group}

Accountability in the Community Employment Group was extensive and comprehensive, especially in the first seven years of its existence. 
Accountability mechanisms covered the full spectrum of the functional strategic continuum, with:

- frequent reporting on outputs

- a dedicated monitoring and evaluation team

- an audit programme

- consistent efforts to address the need for strategic accountability, through evaluation reports and individual reports on successful initiatives.

Through extensive and frequent reporting, Ministers responsible for the Community Employment Group were kept appraised of activities and outputs. Similarly, fieldworkers kept their community contacts appraised of progress towards formal partnering on initiatives, including when an application for funding was declined. The robust discussion at the national level meant the fieldworker had a strong basis on which to communicate; and could continue to engage in the partnership.

Later, when the Community Employment Group became a part of Work and Income New Zealand, the monitoring and evaluation teams were disestablished, and the monitoring focus shifted to the more restricted but visible 'traffic light reporting' on key performance indicators. However, such indicators were inadequate as they could not account for the complexity involved in delivering Group programmes. At this time, decision-making processes did not have the same level of transparency, meaning a greater risk of disconnect between the Group and their community partners.

Informal accountability mechanisms played a large role in the Community Employment Group under Parekura Horomia and included the personal accountability that Parekura Horomia demanded from community members as well as his own staff:

- the regular and frequent visits by Ministers to visit community groups and discuss progress, enabling Ministers to see for themselves how funding had been used 
- the use of newsletters and other funded publications to share stories about projects with the wider public. Press releases by the Group or the Minister responsible with similar, positive stories were often picked up by the national media and included in newspapers of the time.

\section{Accountability in the Mayors Taskforce for Jobs}

Accountability in the Mayors Taskforce for Jobs was also comprehensive, with a range of accountability mechanisms, primarily internal and external. The establishment of the 'Core Group' of Mayors created a legitimate decision-making body for the Mayors Taskforce for Jobs, enabling internal accountability between members. Regular meetings were held and comprehensive minutes taken, providing a clear record of meetings, actions agreed and timeframes for follow up. Individuals in the Core Group were publicly tasked with responsibilities and detailed reporting ensured they were kept on task.

Names of the members of the Mayors Taskforce for Jobs were published in each Annual Report, ensuring transparency about who was involved. In the Annual Report of 2003, the names of Mayors who were not involved were published.

The Employment Catalyst Fund was a significant responsibility for the Mayors Taskforce for Jobs, requiring a project team and accountability mechanisms to be set in place. Accountability for the Employment Catalyst Fund had many levels and layers, ranging from strong oversight and monitoring of individual projects to a national view and advice on the outcomes sought. Where there was doubt as to a project's feasibility, faceto-face meetings with the project team would determine whether the Mayors Taskforce for Jobs would support the project. The multiple layers were supported by a central coordination point, ensuring that all reports were of the required quality and timeliness.

External accountability arrangements were also reflected in a range of Memoranda, creating partnerships between the Mayors Taskforce for Jobs 
and The Jobs Research Trust; the Department of Work and Income and Canterbury Development Corporation; the Government; the Community Employment Group; the New Zealand Council for Business Sustainability and the Council of Trade Unions. These Memoranda set out the purpose of the partnership, relative responsibilities and how often the Memoranda would be reviewed.

While the focus was on formal, functional accountability, a range of informal mechanisms were at play in the Mayors Taskforce for Jobs. One of the most noteworthy mechanisms was the direct access Mayors had to Ministers, giving Mayors the ability to informally hold Ministers to account for the actions of public servants within their portfolios.

Another example of informal accountability was found in the Mayors Taskforce for Jobs relationship with the Jobs Research Trust. A major output of the Jobs Research Trust was the Jobs Letter, a newsletter targeted to a wide audience. This newsletter enabled the Mayors Taskforce for Jobs to have its activities reported, offering a form of accountability to the communities of the taskforce.

Regular publications by the Mayors Taskforce for Jobs also highlighted successful projects from throughout New Zealand, showing how funding had been used to transform lives. The mainstream media also played a role in reporting on the performance of the Mayors Taskforce for Jobs, with a sustained and targeted media campaign by Mayors Taskforce for Jobs Chair Garry Moore. And finally, Ministers showed support for the Mayors Taskforce for Jobs by frequently mentioning it in media releases, invariably in a positive light.

Accountability arrangements, tools and methods that enable partnership

At their best, the Community Employment Group and Mayors Taskforce for Jobs used a wide range of formal and informal accountability arrangements for functional and strategic purposes, and to ensure accountability upward and downward. The transparency these 
accountability arrangements brought to these initiatives were a key factor in their ongoing survival.

Effectiveness of the Community Employment Group and Mayors Taskforce for Jobs initiatives was questioned when the informal accountability arrangements fell away, and the focus turned to functional accountability. Ebrahim (2003) notes that when one aspect only of accountability is prioritised, the entire initiative will be at risk. This theory has been borne out by the experience in the Community Employment Group and Mayors Taskforce for Jobs. In particular, when informal mechanisms were dispensed with, the initiatives were no longer able to prove their worth to their partners.

It is worth noting too, that transparency in the Community Employment Group not only enhanced accountability but enabled all members of the Group to understand the rationale for decisions and provided a strong basis on which they could communicate decisions - favourable or unfavourable - to their community partners. This transparency engendered trust between communities and the Government (or at least the fieldworkers), enabling iterative and ongoing problem solving in these communities.

While the literature on collaborative governance does not provide many examples of informal accountability mechanisms, this thesis provides examples of three types of informal accountability mechanisms:

- 'show and tell', where Ministers visited initiatives and were able to see for themselves how the initiatives were working

- 'using the narrative', by publishing accounts of successful initiatives in newsletters and reports that were widely available to the public

- 'personal accountability', where face-to-face discussions with the manager responsible enabled a comprehensive understanding of how initiatives were working, or supposed to work, leaving little room for obfuscation. 


\section{Leadership}

\section{A recap of findings thus far}

The collaborative governance literature found a need for facilitative leadership in collaborative governance (Ansell \& Gash, 2008). The 'facilitative' leader is known for bringing together stakeholders and getting them to engage with each other in a collaborative spirit. When facilitation does not work, Susskind \& Cruikshank (1987) suggested two stages of escalation for the leader, from facilitator, to mediator then mediator to arbitrator. In this literature, the focus of the leader is on ensuring that collaboration takes place or on day-to-day management of the collaborative process (Crosby \& Bryson, 2010; Emerson et al., 2012).

Crosby \& Bryson (2010) suggest nomenclature of the 'champion' (manager of the collaborative process) and 'sponsor' (responsible for securing authority and resources). Huxham (2000) noted that 'thuggery', or singleminded persistence was perhaps the role of the collaborative governance leader, particularly when sponsorship or securing resources was needed.

\section{Leadership in the Community Employment Group}

The most visible leader in the Community Employment Group was Parekura Horomia and his focus was on setting the environment in which collaboration could take place. To do this, Parekura Horomia, acted as the sponsor by ensuring the vision for the Group aligned with Government priorities; securing the resources, including staff and delivering at pace. The result of aligning the vision with the Government priorities was that the Group was entrusted with more funding and a steady increase in resources and programmes over the next five years.

Parekura Horomia took the fact of collaboration for granted by hiring the people for whom this was second nature. He did not need to mediate between his fieldworkers and community representatives or require it to happen - collaboration was simply expected as a core part of the role. Parekura Horomia also furnished his staff with detailed information, 
ensuring they fully understood the reasons why a proposal would or would not be funded. In return, he expected transparency and accountability about their activities.

A deep understanding of the public sector by Parekura Horomia was also evident. Knowing the rules meant that he was able to bend, break or make up rules, as evidenced by his approach to human resource management and childcare for staff.

A significant part of the role Parekura Horomia played was 'communicator'. He communicated frequently with Ministers, stakeholders, community representatives and with his staff. The purpose of most of the communication was to give direction, manage risk or discharge accountability. This extensive communication was critical to transparency and accountability. Parekura Horomia's ability to manage up, out with stakeholders and down with staff so that all were working toward the same goals must also be identified as key to the success of the initiative.

\section{Leadership in the Mayors Taskforce for Jobs}

The Mayors Taskforce for Jobs was set up under the triumvirate of Garry Moore, vivian ${ }^{21}$ Hutchinson and Jan Francis.

Mayors Taskforce for Jobs Chair Garry Moore was able to create close working relationships with Ministers and had a direct communication style. He was passionate about the Mayors Taskforce for Jobs and able to engage other Mayors in the vision.

vivian Hutchinson was able to support Garry Moore with his inspirational keynote speeches, such as the speech that started the Mayors Taskforce for Jobs; and championing the Mayors Taskforce for Jobs through a nationwide newsletter. Garry Moore and vivian Hutchinson focused on the national, rather than local level.

\footnotetext{
${ }^{21}$ vivian prefers his name written with a small ' $v$ '.
} 
Jan Francis was the steady influence in the Mayors Taskforce for Jobs, highly aware of accountability arrangements and maintaining the personal connection with Officials, Mayors and Mayoral staff that would turn the ideas into practical reality.

In this case, there was no clear-cut 'sponsor' or 'champion' of the collaborative governance process, with all three leaders involved in securing agreements for funding and ensuring conditions were met for payment.

By 1 February 2008, Dale Williams was elected Chair of the Mayors Taskforce for Jobs. Dale Williams brought the focus of the Mayors Taskforce for Jobs back to employment and local solutions for local issues. While the mantra was local, Dale Williams was able to work on the national stage, bringing together ideas for a nationwide and inclusive youth transition service. Dale Williams had a tough job with the National Party in Government, having to work with an administration that was at times openly hostile to the Mayors Taskforce for Jobs and reluctant to engage at a partnership level. In response, Dale Williams focused on getting every Mayor in New Zealand to join the Mayors Taskforce for Jobs. This tactic was to give the Mayors Taskforce for Jobs strength in numbers and solidarity, to show the Government that the Mayors Taskforce for Jobs was able to speak on behalf of every Mayor, every community and every voter in New Zealand. During this period, Jan Francis continued to ensure a structured and safe approach to governance by engaging with all members, creating robust systems and processes, and ensuring all decisions were fully documented.

\section{Leadership that facilitates collaboration}

Analysis of these case studies indicates that a wider conceptualisation of leader is needed in the collaborative governance literature, and that facilitative leadership is only one tool in the toolkit of leaders involved in collaborative partnerships. While a single-minded determination is also present, the leaders involved had to have: 
- a robust grasp of the operating environment, including being able to design bespoke accountability mechanisms and tools, and to deploy informal accountability tools

- an ability to conceptualise a vision and to operationalise this through practical ways of working in a space where there is no template

- an ability to pivot according to the needs and desires of the Government - whether as Ministers with oversight of the collaborative process or as partners, in both the Community Employment Group and Mayors Taskforce for Jobs cases, the Government dictated the success or failure of the initiative

- exemplary communication abilities, beyond facilitation/mediation and arbitration; to sharing and getting buy-in to a vision from people of all types, including peers, staff and Ministers.

Leadership capabilities can be shared among a few people responsible for the initiative, as in both the Community Employment Group and Mayors Taskforce for Jobs cases, leadership extended beyond the nominated manager or chair.

\section{Participation}

\section{A recap of findings thus far}

The Ansell \& Gash (2008) definition 'a governing arrangement where one or more public agencies directly engage non-state stakeholders in a collective decision-making process that is formal, consensus-oriented, and deliberative and that aims to make or implement public policy or manage public programmes or assets' indicates a formal arrangement, where stakeholders are carefully selected and who participate in a strongly scripted decision-making process.

This raises the question of how stakeholders are selected and highlights the challenges that might be had in participating in a formally scripted process that is dictated by government. Huxham (2000) notes that challenges of participation include the need for working relationships at different levels of the organisation as well as the degree to which the 
whole organisation is involved and any history of past conflict. Motivation and ability are also seen as challenges to participating in collaborative endeavours (Lawrence \& Deagen, 2001).

However, the collaborative governance literature indicates that the participation of stakeholders is critical to collaborative governance and that ensuring the right people are engaged is a fundamental design issue. Weak or non-inclusive participation can threaten the legitimacy of outcomes and the capacity to participate depends on the motivation and ability of stakeholders. Power imbalances and a past history of conflict can reduce motivation to engage, especially if there is mistrust between stakeholders.

\section{Participation in the Community Employment Group}

The original mission of the Community Employment Group was to 'encourage and assist communities and organisations in the development and establishment of new employment initiatives through information dissemination, brokerage, facilitation, networking and transferring the benefits of previous successful initiatives to other communities and organisations.' This mission reflected a grass-roots level engagement with communities, rather than with a more formally selected representative group of stakeholders who participate in a formal decision-making process.

The operating model reflected direct communication and integration with communities, enabling the Community Employment Group to build relationships that were unprecedented in New Zealand's history. The workforce was mobile, spending more time with communities than with their colleagues or managers; and the fieldworkers were drawn from the communities they served - Māori communities, rural communities, women, gang affiliates, activists and others.

Of note from this case study was the community's requirement that fieldworkers had the mandate to deal with issues on the ground and the ability to contribute significantly to decisions made at the national level. 
This reflected a level of trust in those fieldworkers and support from the community, that the subsequent decisions were legitimate.

\section{Participation in the Mayors Taskforce for Jobs}

The Mayors Taskforce for Jobs was a new and untested approach to an unemployment problem. In this case, the Government did not select a group of stakeholders to confer with on problems of policy or practice. Instead, the Mayors Taskforce for Jobs created itself as a new entity who then lobbied the Government to become involved as partners in decisionmaking. This new entity represented a double layer of collaboration, with the Mayors of New Zealand coming together as one organisation, which then collaborated with numerous other entities, including Central Government.

Partnership between the Government and the Mayors Taskforce for Jobs was represented by a Memorandum of Understanding, setting out common goals and enabling funding to be passed from the Government to the new entity. Formal meetings were held between Mayors and Ministers, Mayors and Officials, Mayors and other Mayors, and Mayors and the Executive Officer. The Executive Officer also kept in close contact with Officials. While it is not possible to confirm the exact timing and dates of all of these meetings, it is clear that there was regular face-to-face and teleconference engagement between Mayors and key stakeholders, especially during the first five years.

While challenges of collaborative governance include power imbalances, analysis of this case indicates that at times, the direct access of the Mayors to the Ministers had a material effect on the relationship between Mayors and public servants. This was borne out in meetings between Mayors and Officials, where the Officials were held to account for decisions made in their areas of responsibility, or where funding was released due to Ministerial intervention. This unusual power came from the direct relationship Mayors had with Ministers and was probably behind the 2002 'Election Employment Policy' the Mayors provided to the Labour Party: a 
bold move when the government actor traditionally holds the power to dictate what topics are put to their partners. This bold move appears to have fallen on unusually fertile ground however, as the newly elected Labour Government included a significant package for unemployed youth in their May 2003 budget, which Mayors perceived as a direct result of the agreement between the Government and the Mayors Taskforce for Jobs.

One challenge for the Mayors Taskforce for Jobs was the constant turnover of Mayors due to local body elections. On average, about 20 new Mayors were inducted into the Mayors Taskforce for Jobs every three years.

This case is highly unusual, in that collaborative governance was not selected by the Government; instead, Ministers responded to calls to form a partnership with a new entity - the Mayors Taskforce for Jobs. Frequent and regular communication between parties on shared goals ensured the community represented by the Mayors had a strong voice in policy and programmes, at least in the beginning stages of the partnership. As time passed and new Ministers stepped in, that close working relationship began to fail, until it was played out - acrimoniously - in the media.

\section{Processes that enable participation}

Participation in collaborative governance does not need to be with a formally selected, representative group of stakeholders. In one case, the stakeholders selected themselves and in the other case, fieldworkers who were entrenched in communities worked organically with the communities and organisations at grass-roots level.

The notion of formal, consensus-oriented and deliberative decision-making practices is also challenged by these case studies. In the Community Employment Group, fieldworkers had the mandate to make low-level decisions as guided by the needs of the communities they were working with; and a number of smaller decisions would result in an application for funding, which was then submitted to Government Officials and represented by the fieldworker. In the Mayors Taskforce for Jobs, 
decisions about funding remained the responsibility of Ministers, and a standard budget process. However, Mayors were able to see a direct line between the goals they set with, and advice they gave to, the Government; and the funding subsequently allocated - at least, in the early years.

Finally, a comment on the notion that weak or non-inclusive participation by stakeholders can reduce the legitimacy of outcomes. In the Mayors Taskforce for Jobs, the number of Mayors involved gradually increased over time. However, their most potent stage was when few Mayors were involved, as this was the point at which Ministers were most involved. This indicates that there can be weak participation (in terms of numbers) on the side of the community, but that this does not need to detract from the quality of outcomes as long as those stakeholders involved remain committed and active. However, when participation by the Government was at face value only, there was a clear steer away from the advice of the Mayors Taskforce for Jobs - despite there being a much larger number of Mayors involved. 


\section{Chapter 9: Conclusion}

\section{The problem, research questions and approach}

The wicked problem of long-term unemployment is both an economic and social challenge, and one that demands innovative and agile policy responses. Economists have focused on the problem of unemployment for at least the last 30 years, citing the redistributionist policies of a welfare state or job availability and job quality as part of the problem, and solutions such as pruning the welfare state or subsidising employment. However, these solutions do not consider the social challenges inherent in long-term unemployment. Where, as in New Zealand, unemployment and long-term unemployment affects people differently, the solutions need to work for individuals and communities and include a focus on psychological concerns such as the motivation of potential employees and the attitudes of employers.

In New Zealand, a strong design feature of the public sector is agency theory, which draws on economic principles. This approach leads to a focus on markets and results in predominantly macro-economic solutions to address the problem of long-term unemployment. A further challenge of this approach is that the hierarchical structures, systems and processes create a barrier to the collaboration with communities. Reducing this barrier could enable government and communities to design and deliver innovative solutions to long-term unemployment that draw on the skills and resources of local communities.

This thesis, therefore, focused on the over-arching question:

- What institutional arrangements enable iterative and ongoing community problem-solving to address long-term unemployment?

An answer to this question was sought by applying a collaborative governance lens on two initiatives designed to address unemployment in New Zealand communities, the Community Employment Group and Mayors Taskforce for Jobs. Collaborative governance has arisen as an 
alternative to hierarchical and adversarial approaches; and has at its heart the notion of government and non-government actors working together on public policy problems.

In determining the components of collaborative governance on which to concentrate, I drew on the Pierre \& Peters (2005) definition of governance, where it is represented as the combination of four activities:

- $\quad$ articulating a common set of priorities for society;

- achieving coherence, where the goals are consistent and coordinated;

- steering, where society is steered to achieve the goals; and

- establishing accountability, or finding some means of holding actors accountable for their actions.

This definition highlights that inherent within governance are the leadership behaviours and competencies that will articulate priorities, ensure coherence and steer towards goals with multiple parties, and the accountability arrangements when parties are not arranged in hierarchical order. A third component reflects the fact that collaborative governance involves actors from different organisations participating collectively in decision-making. These three considerations led to the refinement of three research sub-questions:

- What accountability arrangements, tools or methods can allow the Government to partner meaningfully and well with New Zealand communities to address long-term unemployment?

- What public sector leadership behaviours and competencies will facilitate collaboration between government and communities to address long-term unemployment?

- What types of participatory processes will enable communities and government organisations to engage in partnerships that address longterm unemployment?

Two initiatives based on collaboration, the Community Employment Group and Mayors Taskforce for Jobs have been used by the New Zealand Government to address unemployment in New Zealand communities. 
- The Community Employment Group was established in 1991 with the aim 'to encourage and assist communities and organisations in the development and establishment of new employment initiatives through information dissemination, brokerage, facilitation, networking and transferring the benefits of previous successful initiatives to other communities and organisations.' This initiative relied on an extensive network of fieldworkers who would work for the Government, within communities and engage in ongoing problem-solving to address unemployment. The fieldworkers were supported by a Wellingtonbased, national office team, which created and enforced the accountability mechanisms that gave the initiative legitimacy and enabled its sustained focus through multiple changes in government.

- In 2000, the Mayors Taskforce for Jobs was formed to achieve 'zero waste of New Zealanders'. This initiative was a collaboration within a collaboration - Mayors of New Zealand came together with this common goal and they partnered with the Government and a range of other organisations to achieve it. Similar to the Community Employment Group, this initiative promoted local solutions to local problems, enabling a sharing of ideas throughout New Zealand and access to resources to turn ideas into reality.

These two initiatives appear to be quite different from each other. However, they were both seen as world-leading in their time by the international delegations who came to New Zealand to observe, and to promote proposals for similar approaches in other jurisdictions. Both initiatives enjoyed times of high support and engagement from the Government, and both suffered when that support was withdrawn. Both initiatives traversed the challenging line of collaboration between the Government and communities and both enjoyed success in addressing long-term unemployment, in communities as diverse as Kaikoura ${ }^{22}$ and

\footnotetext{
${ }^{22}$ A town of around 2,000 people on the East Coast of the South Island, now famous for its whale watching tourism activities which were set up under a forerunner to the Community Employment Group.
} 
Ōtorohanga ${ }^{23}$. This indicated the presence of two case studies that could provide a richness, a depth of data and insights into the challenges of collaboration in the New Zealand public sector.

Analysis of the case studies centred on the topics of accountability, leadership and participatory processes. For each research sub-question, the case studies were mined for relevant information, drawing from the rich detail to provide focused data for analysis. These findings were then compared with the literature. Key findings from the analysis follow.

\section{Findings}

Collaborative governance has provided a useful lens through which to consider the rise and fall of the Community Employment Group and the Mayors Taskforce for Jobs. These initiatives were used by the New Zealand Government over the years 1991 to 2013 . Both initiatives lasted for over a decade, incorporated a form of collaborative governance and reflected iterative and ongoing community problem-solving to address the risk of long-term unemployment.

While the sub-research questions identified accountability, leadership and participatory processes as separate components of collaborative governance, I found that overall, these components are inextricably intertwined in a collaborative governance initiative. A collaboration can enable its participants to design its own rules and ways of working, depending on its resources, skills and above all, its leadership. Accountability mechanisms and participatory processes should be a key focus of the leaders, as they need to ensure these mechanisms and processes are designed in a way to meet the needs of the initiative and the partners. Equally, the leader's abilities will determine how well accountability mechanisms (especially informal ones) will work and will empower the participation needed at each level of the initiative.

\footnotetext{
${ }^{23} \mathrm{~A}$ town of around 2,500 people in the heart of the King Country in the North Island, with an economy based mainly on agriculture.
} 
The following section addresses each of the research sub-questions in order and the final section brings together the findings in relation to the overall research problem: what institutional arrangements enable iterative and ongoing community problem-solving to address long-term unemployment?

\section{Accountability}

The research sub-question was:

- What accountability arrangements, tools or methods can allow government to partner meaningfully and well with New Zealand communities to address long-term unemployment?

The literature on collaborative governance provided indications of the accountability arrangements, tools and methods that might be useful, but there was no minimum requirement or exhaustive list to guide the practitioner. This research has identified a minimum list of seven types of accountability arrangements that are necessary to the success of collaborative governance initiatives. This research also challenges the existing literature which describes accountability arrangements as sitting in the 'shadow' of existing institutions and underestimates the role of the narrative.

Accountability arrangements in a collaborative governance initiative do not need to sit within the shadow of existing institutions. Instead, accountability arrangements should be seen as critical to the survival of the initiative and as such, subject to the most intense scrutiny. In both case studies, a key focus of the leaders was to determine what accountability arrangements were necessary. The leaders drew on their knowledge of the public sector and how it operated, ensuring that key stakeholders would be satisfied with the information delivered - both formally and informally. Formal accountability mechanisms such as quarterly reports were used with care to deliver functional accountability, ensuring the inputs and activities completed were documented and understood. Less formal mechanisms such as 'show and tell' used the 
media and public relations to deliver success stories to Ministers and communities, ensuring hearts were engaged as well as minds.

The role of the narrative in collaborative governance initiatives has been underestimated in the literature. From the outside, collaborative governance can appear murky. It deals with wicked problems and there is little evidence to guide where and when investment should be made. Progress is often seen best in outcomes, which can take years to emerge. While traditional accountability tools and mechanisms are unable to deliver this narrative in a meaningful way, a public narrative was used as a tool in both case studies. Early in the lives of the Community Employment Group and Mayors Taskforce for Jobs, the leaders were able to highlight successful initiatives through publications they funded or published. These stories were used to account for progress to external stakeholders, as well as to celebrate milestones achieved by participants.

The accountability arrangements, tools and methods recommended as a result of this research are:

- agreed mandates and responsibilities for each of the agents involved

- formal reporting that details inputs and activities, and provides transparency about expenditure

- clear decision-making processes that involve the perspective of the community partner or the people working directly with the community

- detailed records of decisions, along with their rationale, that can be shared transparently between the partners

- 'show and tell', to enable partners to see for themselves how initiatives are working, and to personally discuss the initiative with those people directly involved

- 'using the narrative', by publishing accounts of initiatives so that the wider community can understand what is happening in their area

- 'personal accountability', where individuals involved in decisionmaking or making recommendations personally account for their actions. 
The above list should be considered a minimum requirement for collaborative governance initiatives, as without any one of these, the initiative will lack transparency and compromise its legitimacy. Further, the informal accountability mechanisms (show and tell, using the narrative and personal accountability) are at least as important as formal mechanisms in collaborative governance. In both case studies, when informal mechanisms fell away, the initiatives failed to thrive.

\section{Leadership}

The sub-research question was:

- What public sector leadership behaviours and competencies will facilitate collaboration between government and communities to address long-term unemployment?

The collaborative governance literature focused on the role of the leader in facilitating collaboration. However, this research has found that leadership is inextricably intertwined with accountability and participatory mechanisms and that a range of other behaviours and competencies are required.

In collaborative governance initiatives, leaders create the rulebook with the written and unwritten rules by which the game is played. When the focus is a wicked problem, such as long-term unemployment, it can be assumed no prior path to success has been laid. Indeed, it is the absence of a successful institution that allows the collaborative governance initiative to be formed - it provides an untried option for the Government, which is particularly valuable when no other option is evident and the evidence calls for something - anything - to be done.

The public sector leadership behaviours and competencies recommended as a result of this research are:

- Vision creation: Being able to conceptualise a vision, to communicate it and to operationalise it in practical ways where there is no template. 
- Subject matter expertise: Extensive knowledge of the operating environment, including being able to design and deliver bespoke accountability mechanisms and deploy informal accountability tools.

- Flexibility and adaptability: Being able to pivot according to the needs and desires of government, while remaining true to the vision and continuing to deliver on agreements.

- Communication skills: Convincing others to buy-in to the vision and to support the initiative.

- Tenacity and resilience: Wicked problems do not lend themselves to simple and fast solutions. In a democratic system, there will always be politicians looking to score points and an initiative that does not appear to be delivering results will be an easy target. The proactive collection of data and deployment of accountability mechanisms, both formal and informal, will form an important line of defence in these cases, but the ability to retain self-motivation and the tenacity to ensure resilience in other members of the team is critical.

Perhaps the most challenging aspect of leadership was that those leaders who were successful had an unwavering belief in the value of their initiative and used every opportunity to promote its existence, maintenance and sustenance. Without that passion, I doubt that the initiatives could have continued for as long as they did. However, it must be noted that for a significant period of time, these successful leaders had fertile ground in their audiences and that when those holding the power over resources were disinclined to believe the narrative, passion alone could not sustain the initiatives. Indeed, for the Community Employment Group, even where there was strong evidence of success at a functional level, the absence of support from the Government meant that the initiative was closed.

\section{Participatory processes}

The sub-research question was: 
- What types of participatory processes will enable communities and government organisations to engage in partnerships that address longterm unemployment?

The literature on participatory processes in collaborative governance indicates a formal arrangement, with stakeholders who are carefully selected and participate in a scripted decision-making process. This research found that participation can be a much looser arrangement, with decisions delegated to a grass-roots level, held at governance levels or a mixture of both. The important factor found in the research was that sustained engagement and communication were critical to the success of initiatives, and that while decision-making is important, it does not stand alone as the most important process.

The nature of participatory processes, or how government agents and community representatives can work together requires frequent, regular, open and honest communication. This communication does not have to be with formally selected, representative groups of stakeholders. Instead, as the case studies show, the community participants can be self-selected or identified under a more organic process. However, the risks inherent in the self-selection approach must be offset by fully transparent and visible accountability mechanisms.

The participatory processes recommended as a result of this research are:

- frequent and regular face-to-face meetings between representatives of the community and government partners, to ensure ongoing communication and personal accountability for decisions and responsibilities

- sustained personal engagement at the local level, to ensure local knowledge is relevant and up-to-date, and that communication is frequent and ongoing

- formal reporting and documentation of decisions so that all parties understand requirements, activities and outcomes 
- genuine, open and honest communication between all parties, internal and external, to assist with understanding and to quickly identify and address issues and risks.

In contrast to the definition of collaborative governance, where decisionmaking is formal, consensus-oriented and deliberative, decision-making can be iterative and delegated down or up as appropriate. For example, in the Community Employment Group, a number of decisions were made at the grass-roots level by the fieldworkers; however, decisions that required more transparency were escalated within the hierarchy. These findings indicate that the type of collaborative governance that would facilitate ongoing community problem-solving might benefit from a definition that more closely matches its reality. I propose the following definition for this nature of initiative:

'A formal arrangement where government agents and community representatives work together over time to identify and implement solutions to wicked problems in local communities.'

\section{Implications for practice}

Unemployment is a problem in many communities throughout New Zealand and is likely to get worse in light of the global pandemic. This provides an opportunity for government to again try new paths, that draw on the strengths and resources of communities, alongside the necessary macro-economic shifts aimed at addressing the wide-ranging nature of the problem.

This thesis provides guidance that might help government work more closely with communities over the following years to address the coming wave of unemployment. In addition to the specific recommendations for accountability mechanisms, leadership behaviours and competencies and participatory processes above, the wider implications for practice across government and in the public sector include: 
- the selection of leaders who are able to manage collaborative initiatives with a depth of knowledge and expertise, to engage and empower staff and stakeholders, and to commit to the initiative over long periods of time

- the development of performance frameworks that encompass formal and informal, functional and strategic, and upward and downward accountability mechanisms, and are bespoke for the initiative at hand

- a greater emphasis on the ability to assess and support initiatives that are developed by communities, rather than directed top-down by government

- greater ability of officials to understand the motivations of the narrator, to test and critique the narrative and to seek to understand the narratives as an integral part of accountability stories

- a commitment to support collaborative initiatives for longer periods of time, so that iterative and ongoing problem-solving can be achieved.

Each one of these implications requires a commitment and focus from government and public sector leaders, and an understanding that collaborative governance initiatives require thinking differently about policy solutions to wicked problems and the internal arrangements that will facilitate them.

\section{Implications for further research}

While the collaborative governance literature is light on the specifics of areas in which this research is interested - accountability, leadership and participatory processes, the literature has provided a sufficient guide to analyse these aspects of the case studies and to enable additions to this literature at the detailed and nuanced level. The research has also highlighted some areas where there is space to add to the literature on collaborative governance and to build on the conclusions. These areas are:

- the potential for a definition of collaborative governance that more fully reflects the situation of ongoing engagement and is not centred around the decision-making process. I propose the following: 'A formal 
arrangement where government agents and community

representatives work together over time to identify and implement solutions to wicked problems in local communities.' This definition could be tested against a wide range of collaborative governance initiatives of this type

- to further explore and understand the use of the narrative in accountability, especially for initiatives that aim to address wicked problems using collaborative governance. Areas of focus might include the components necessary in a narrative to discharge accountability; narrative devices (considering the ability of technology to create and shape a narrative, or the role of Parliamentary Questions or the media); and how the narrative can interact with more formal reporting mechanisms to provide a well-rounded and complete performance story

- whether there is a relationship between the scale and scope of a collaborative governance initiative and its longevity.

Iterative and ongoing problem-solving, especially when considered in the light of wicked problems, indicates that the longevity of collaborative governance initiatives is an area of worthy of focus. It is likely that the challenges of time, scope and scale of collaborative governance initiatives will have bearing on the ability to deliver iterative and ongoing problemsolving with communities.

Both of the case studies in this thesis had a life of close to 14 years, or nearly five terms in the New Zealand electoral cycle. Both had a narrative that described a clear upward trajectory, followed by a downward trajectory. While the Community Employment Group has clearly disappeared, the Mayors Taskforce for Jobs has recently been rejuvenated, although the extent of this rejuvenation is unclear without more detailed research.

These case studies indicated that there is little room for complacency in collaborative governance. Active management of relationships, strong and 
continuing leadership, formal and informal accountability mechanisms that hold the initiative together, and frequent participation all intertwine as key factors to ensure the longevity of an initiative. When any one of these factors fall away, the initiative is at risk.

However, these factors are difficult to scale. When dozens of relationships are required as a part of the initiative, these can be confusing and difficult to manage. Strong leaders struggle to interact with all team members when teams grow; informal accountability mechanisms - shown to be so important in the Community Employment Group, grow difficult with multiple stakeholders. And finally, frequent and meaningful participation becomes more difficult, as more stakeholders are added.

Added to the complexity is the dynamic environment of government, the ever-changing face of Ministers and the need to be focused on initiatives that are palatable to the public, especially in election year. These all result in weighty challenges to initiatives where collaborative governance is at play.

\section{Last words}

This thesis contributes to knowledge in three ways: through the richly detailed descriptions of two case studies of collaborative governance used in New Zealand over the last 25 years; by adding nuance to the collaborative governance literature where it is light and by providing guidance to help the New Zealand Government address wicked problems by working together with communities at a local level.

The two case studies presented in this research deliver a chronological account of each initiative. On the surface, this enables a greater understanding of what these initiatives were and how they worked - a contribution in itself that will be valuable for students of public policy or public management. Digging deeper into the specific sub-research questions enabled a contribution to the collaborative governance literature, which was the focus of this thesis. Given the richness of the narratives, it is likely that the application of a different set of sub-research 
questions is possible and could be used to elicit answers to other questions of interest to public policy or public management academics.

By using collaborative governance as a lens on these two initiatives and generating answers to the sub-research questions that focused on accountability, leadership and participatory processes, this thesis adds nuance to the literature where it is light, specifically by identifying a range of mechanisms, tools and arrangements; behaviours and competencies that appear necessary to the effective collaborative governance initiative. By expanding on the literature in this way, a further contribution is possible. The contribution to practice is a series of considerations for public sector leaders when considering how they might work more closely with communities in the coming years. This is especially relevant in the time of the global pandemic, where unemployment is likely to get worse in many New Zealand communities; and the need to reform our economy, with less reliance on tourism in the short term.

A final contribution is the proposed definition for collaborative governance initiatives that are ongoing and aim to address wicked problems. This is: 'A formal arrangement where government agents and community representatives work together over time to identify and implement solutions to wicked problems in local communities.'

This thesis has shone a light on the conditions that might help governments work more closely with communities over the following years to address the coming waves of unemployment and has added materially to scholarship in this field. 
Appendix 1: Mayors Taskforce for Jobs / Central

Government MOU

The Mayors Taskforce for Jobs entered into five key Memoranda of Understanding with Central Government, starting with the first in August 2000. These are replicated in full below. 


\section{Memorandum of Understanding (2000)}

29 August 2000

\section{BACKGROUND}

1. In February 2000, a group of Mayors from throughout New Zealand met in Christchurch to establish a MAYORS TASKFORCE for JOBS which would be a national focus for Mayors concerned about the future of work and livelihood in our communities.

2. Following the February meeting 31 Mayors joined with the initial group at a forum in Christchurch in April, to advance the concept further. The majority of Mayors throughout the country are supportive but were unable to attend due to prior commitments. The forum endorsed the objectives and the two goals of the Taskforce.

\section{OBJECTIVES OF THE MAYORS TASKFORCE FOR JOBS}

3. The objectives of the MAYORS TASKFORCE for JOBS are:

- to provide a national focus of leadership on the jobs issue through co-operation between Mayors concerned about employment issues in their communities,

- to share best practice on what we can achieve on employment at the local level,

- to create local and national forums which address the big picture' of trends on the issues of income and work,

- to link with imaginative private sector initiatives that are addressing unemployment.

4. The Mayors Taskforce for Jobs is committed to two goals:

- Goal one: By 2005, no young person under 25 years will be out of work or training in our communities.

- Goal two: By 2009, all people in our communities will have the opportunity to be in work or training. 


\section{OBJECTIVES OF THE LABOUR-ALLIANCE GOVERNMENT}

5. The Government has established Key Government goals to guide public sector policy and performance. These goals include:

- Strengthen national identity and uphold the principles of the Treaty of Waitangi

- Grow an inclusive, innovative economy for the benefit of all

- Restore trust in Government and provide strong social services

- Improve New Zealanders' skills

- Close the gaps for Maori and Pacific people in health, education, employment and housing.

6. The Government is committed to the following employment goals:

- Ensuring macroeconomic policies enable sustained economic growth and its accompanying job creation

- Promoting an employment rich economy by removing barriers to employment growth

- Developing a flexible, highly skilled workforce

- Developing strong communities

- Improving participation in employment for Maori and Pacific people

- Improving participation in employment for people with disability and other groups at risk of long term and persistent unemployment.

7. The key principles of Government involvement in regional development are:

- Making the most of what a region has to offer rather than solely making transfers from prosperous regions to less prosperous regions

- Partnering with the local community to facilitate the development of local strategies that respond to local opportunities and that integrate social, environmental and economic concerns 
- A 'whole of government' response where the activities of central government are integrated into regional strategies together with local stakeholders.

\section{THE DIMENSIONS OF THE CHALLENGE}

8. Nearly 200,000 people are jobless in our communities. The parties to this Memorandum of Understanding are renewing their public commitment to addressing these issues and pledging to co-operate on future initiatives. We recognise that we need to act strategically and effectively and to think long-term.

9. What we are most concerned about are the long-term trends on work and income in our communities. The parties to this memorandum affirm that there is no continuing justification for the 'waste of New Zealanders' through unemployment. There needs to be a concerted leadership effort at both local and central government level about the future of work and livelihood and the creation of more opportunities for our children's children.

10. The jobs of the future will certainly still come from new business opportunities. However, future employment will also be driven by our collective choices to value the new work that needs to be done and ensure Maori and Pacific Island people also have access to these new work opportunities. This will require a shift in thinking about what we value and the parties can play an important governance role in leading these choices on behalf of our communities.

\section{PRINCIPLES OF APPROACH}

11. Central government and the Mayors Taskforce for Jobs are committed to zero waste of people.

12. Central government and the Mayors Taskforce for Jobs are committed to closing the divisive and debilitating gaps that have opened up throughout New Zealand society. There are gaps between the skilled and the unskilled, between employment rich and employment poor 
communities and between the cities and the provinces. The most urgent and visible gaps exist between Maori and Pacific communities and others.

13. Central government and the Mayors Taskforce for Jobs are committed to reducing long term unemployment.

14. Central government and the Mayors Taskforce for Jobs are committed to building a working partnership to address unemployment at the local level, through fostering co-operative relationships across all sectors.

15. The Mayors Taskforce for Jobs and central government recognise the importance of co-ordination and collaboration to addressing complex social problems.

16. The Mayors Taskforce for Jobs and central government recognise that local solutions have the greatest chance of success where local leadership and community ownership are key ingredients.

\section{OBJECTIVES OF THE PARTIES}

17. The Mayors Taskforce for Jobs and central government will assemble a package of programmes from which communities can draw to assist community development initiatives, and develop and support community entrepreneurs. This package is likely to include support for:

- Building the capacity of local people and community development agencies

- Obtaining advice or expertise to assist in regional/community strategic planning initiatives

- Re-thinking government expenditure in the regions to improve outcomes

- Funding for specific community/regional development initiatives.

18. Mayors will participate in the development of regional/local action groups, which will develop clearly articulated long term strategies to work on whole of government solutions in their areas. Wherever possible these groups will build on existing mechanisms for central and local government, community and business partnership around employment creation and 
community development. Central government will ensure that barriers are removed where possible so that appropriate, innovative and flexible decisions can be made at the local level.

19. The Mayors Taskforce for Jobs will promote close co-operation between the Ministry of Economic Development and local economic and employment development organisations to minimise duplication and build on successful structures.

20. The Mayors Taskforce for Jobs and central government will work together to promote new solutions to unemployment which reflect the changing nature of work in our country.

21. The Mayors Taskforce for Jobs and central government will develop mechanisms for policy input by local communities. Wherever possible these will build on existing mechanisms for central and local government, community and business partnerships around employment creation and community development.

22. The Mayors Taskforce for Jobs, the Ministers of Economic Development and Employment and appropriate officials will meet quarterly to discuss progress on this partnership.

23. This Memorandum will also act as a working document between central government, the Mayors Taskforce for Jobs and any Working Parties and Technical Groups that Local Government New Zealand establishes for employment and economic development.

24. Central and local government will work as partners on employment and economic development building on the issues identified at the inaugural central/local government forum in March 2000. 


\section{Memorandum of Understanding (2002)}

Beehive, Wellington 2 October 2002

MEMORANDUM OF UNDERSTANDING

between the GOVERNMENT of NEW ZEALAND and the MAYORS

TASKFORCE FOR JOBS

1. This Memorandum of Understanding outlines the process by which Central Government and the Mayors Taskforce for Jobs will cooperate towards the achievement of the shared goal, that:

- By 2007, all 15-19 year olds will be engaged in appropriate education, training, work, or other options which will lead to long term economic independence and well-being.

2. This agreement also acknowledges the contribution that this common goal makes to the Mayors Taskforce for Jobs commitment to working towards:

- all young people up to age 25 being in employment or education and training; and ultimately

- all people in our communities having the opportunity to be in work or training;

- and to the wider employment, education, social and economic development goals of the New Zealand Government.

3. The parties to this Memorandum of Understanding are renewing their public commitment to addressing these issues and pledging to co-operate on future initiatives. We recognise that we need to act strategically and effectively and to think long-term.

4. This Memorandum also signals the intentions of both parties to cooperate in the development and achievement of employment goals which will contribute to improved opportunities for all New Zealanders. 


\section{BACKGROUND}

5. In February 2000, a group of Mayors from throughout New Zealand met in Christchurch to establish a MAYORS TASKFORCE for JOBS, which would be a national focus for Mayors concerned about the future of work and livelihood in our communities.

6. Since the launch the Taskforce has gained increasing support and Mayors from around the country have seen the Taskforce as a way to provide leadership on the crucial issue of employment and livelihood in their communities, to support local initiatives and to work together to share successful projects and solutions. This is the first time in New Zealand that Mayors have joined together on a social issue. By September 200250 Mayors (67\% of all Mayors) have joined the Taskforce.

7. The objectives of the MAYORS TASKFORCE for JOBS are:

- to provide a national focus of leadership on the jobs issue through co-operation between Mayors concerned about employment issues in their communities,

- to share best practice on what we can achieve on employment at the local level,

- to create local and national forums which address the big picture' of trends on the issues of income and work,

- to link with imaginative private sector initiatives that are addressing unemployment.

8. The Government's vision is that New Zealand is:

- a land where diversity is valued and reflected in our national identity

- a great place to live, learn, work and do business;

- a birthplace of world-changing people and ideas;

- a place where people invest in the future. 
9. In helping to achieve this vision, Government will be proactive in supporting growth, will work co-operatively with other sectors to achieve that, and will emphasise the importance of sustainability.

10. The Government is committed to developing the skills and talents of New Zealanders, and to promoting increased opportunities for participation through social and economic development.

11. The Government's Employment Strategy framework seeks to minimise persistent disadvantage in the labour market and maximise the number of jobs and level of earnings for all.

12. The Tertiary Education Strategy will also contribute to raising the skills and capabilities of New Zealanders, so that they are able to participate in the knowledge economy. The Government is seeking to foster a tertiary education system that contributes to economic and social development through the development of skilled and adaptable people and through research and scholarship that create new ideas.

13. The Government also has a vision of New Zealand as a country where young people are vibrant and optimistic through being supported and encouraged to take up challenges. The Youth Development Strategy Aotearoa provides a policy platform for developing policy advice and initiatives which will contribute to this goal.

14. The key principles of Government involvement in regional development are:

- Making the most of what a region has to offer rather than making transfers from prosperous regions to less prosperous regions

- Partnering with the local community to facilitate the development of local strategies that respond to local opportunities and that integrate social, environmental and economic concerns.

- A 'whole of government' response where the activities of Central Government are integrated into regional strategies together with local stakeholders. 


\section{THE DIMENSIONS OF THE CHALLENGE}

15. Household Labour Force data indicate that as at June 2002 100,000 people were unemployed and more than 170,000 jobless in our communities. Of particular concern is that $11.1 \%$ of young people aged 15 to 24 years are currently unemployed.

16. What we are most concerned about are the long-term trends for work and income in our communities. The parties to this Memorandum affirm that there is no continuing justification for the 'waste of New Zealanders' through unemployment. There needs to be a concerted leadership effort at both local and central government levels about the quality of work and the creation of more opportunities for our children and our children's children.

17. The jobs of the future will certainly still come from new business opportunities. However, we also need to be concerned about the quality of people's working lives. We also need to ensure that all people, including Mäori and Pacific Island people, have access to existing and new work opportunities. The parties to this agreement can play an important governance role in leading and facilitating the future direction on behalf of our communities.

PRINCIPLES OF APPROACH

18. Central Government and the Mayors Taskforce for Jobs are committed to building a working partnership to work towards this goal at the local level, through fostering co-operative relationships across all sectors.

19. Central Government and the Mayors Taskforce for Jobs recognise the need for sustainable development to provide long-term solutions for communities.

20. Central Government and the Mayors Taskforce for Jobs are committed to working together to address the issues that have caused disparities between different groups in society, including between ethnic groups and 
between regions. This includes a specific commitment to addressing the disparities that exist between Maori and Pacific communities and others.

21. Central Government and the Mayors Taskforce for Jobs are committed to reducing long term unemployment.

22. The Mayors Taskforce for Jobs and Central Government recognise the importance of co-ordination and collaboration to address complex social problems.

23. The Mayors Taskforce for Jobs and Central Government recognise that local solutions have the greatest chance of success where there is local leadership and community ownership.

24. The Mayors Taskforce for Jobs and Central Government recognise the value of sharing information on labour market trends and future needs, and recognise the importance of information held by local authorities.

\section{UNDERTAKINGS OF THE PARTIES}

25. The Mayors Taskforce for Jobs and Central Government will work together to facilitate community development initiatives, and develop and support community entrepreneurs. This package is likely to include:

- Building the capacity of local people and community development agencies

- Obtaining advice or expertise to assist in regional/community strategic planning initiatives

- ensuring Government expenditure in the regions contributes to improved outcomes

- Funding for specific community/regional development initiatives.

26. Mayors will participate in the development of regional/local action groups, which will develop clearly articulated long term strategies to work on whole of government solutions in their areas. Wherever possible these groups will build on existing mechanisms for central and local government, community and business partnership around employment creation and community development. The parties will work together to ensure that, 
where appropriate, innovative and flexible decisions can be made at the local level.

27. The Mayors Taskforce for Jobs will promote close co-operation between the Central Government and local economic and employment development organisations to minimise duplication and build on successful structures.

28. The Mayors Taskforce for Jobs and Central Government will work together to promote new solutions to unemployment which reflect the changing nature of work in our country.

29. The Mayors Taskforce for Jobs and Central Government will provide opportunities for policy input by local communities. Wherever possible these will build on existing mechanisms for central and local government, community and business partnerships around employment creation and community development.

30. This Memorandum will also act as a working document between Central Government, the Mayors Taskforce for Jobs and any working parties and technical groups that Local Government New Zealand establishes for employment and economic development.

31. The Mayors Taskforce for Jobs and Central Government will work together on the further development of common goals.

\section{PARTNERSHIP PROCESS}

32. Central Government and the Mayors Taskforce for Jobs are committed to working in partnership and agree to ensure processes are in place to facilitate this positive working relationship.

33. This process will include quarterly meetings, or as necessary, with the Ministers of Social Services and Employment, Economic Development, Local Government, and other Ministers as appropriate.

34. The Mayors Taskforce for Jobs and Central Government agree that progress towards agreed common goals will be reviewed annually. 
35. The Mayors Taskforce for Jobs core group will meet quarterly with officials of the Employment Senior Officials Group (and other officials as necessary) to discuss progress on the Taskforce goals, and to ensure the effective transfer of information and learnings between the two parties.

36. The Mayors Taskforce for Jobs will continue to build on the relationships with their other partners

- New Zealand Business Council for Sustainable Development

- Jobs Research Trust - The Jobs Letter

- Local Government New Zealand

- Tindall Foundation (Employment Catalyst Fund)

37. In order to facilitate this partnership, officials of relevant government agencies and the Mayors Taskforce for Jobs may develop specific agreements to support this Memorandum. 


\section{SIGNATORIES}

On behalf of the Mayors Taskforce For Jobs

Mayor Garry Moore

Chair, Mayors Taskforce for Jobs

Signature:

Date:

Mayor Sukhi Turner

Deputy Chair, Mayors Taskforce for Jobs

Signature:

Date:

On behalf of Central Government

Hon Steve Maharey

Minister of Social Services and Employment

Signature:

Date:

Hon Jim Anderton

Minister for Economic Development

Signature:

Date:

Hon Chris Carter

Minister of Local Government

Signature:

Date: 


\section{SCHEDULE: PARTIES TO THIS MEMORANDUM}

\section{As at 2 October 2002}

\section{Members of the Mayors Taskforce for Jobs \\ Murray Anderson, Mayor of Ashburton \\ Bob Parker Mayor, of Banks Peninsula \\ Pat O'Dea Mayor, of Buller}

Malcolm Macpherson, Mayor of Central Otago

Garry Moore, Mayor of Christchurch

Juno Hayes, Mayor of Clutha

Sukhi Turner, Mayor of Dunedin

Yvonne Sharp, Mayor of Far North

Owen O'Connor, Mayor of Gore

Kevin Brown, Mayor of Grey

David Braithwaite, Mayor of Hamilton

Basil Morrison, Mayor of Hauraki

Tom Robinson, Mayor of Horowhenua

Tony Arps, Mayor of Hurunui

John Terris, Mayor of Hutt

Tim Shadbolt, Mayor of Invercargill

Alan Milne, Mayor of Kapiti

James Abernethy, Mayor of Kaikoura

Graeme Ramsey, Mayor of Kaipara

Sir Barry Curtis, Mayor of Manukau

Bob Francis, Mayor of Masterton

Stan Scorringe, Mayor of Mackenzie

Paul Matheson, Mayor of Nelson

Peter Tennent, Mayor of New Plymouth

John Forbes, Mayor of Opotiki

Mark Bell-Booth, Mayor of Palmerston North

David Buist, Mayor of Papkura

Jenny Brash, Mayor of Porirua

Clive Geddes, Mayor of Queenstown Lakes

Grahame, Hall Mayor of Rotorua

Sue Morris, Mayor of Ruapehu
Michael McEvedy, Mayor of Selwyn

Mary Bourke, Mayor of South Taranaki

Gordon Blake, Mayor of South Waikato

Frana Cardno, Mayor of Southland

Brian Jeffares, Mayor of Stratford

Maureen Reynolds, Mayor of Tararua

Jan Beange, Mayor of Tauranga

Chris Lux, Mayor of Thames / Coromandel

Wynne Raymond, Mayor of Timaru

Jim Gerard, Mayor of Waimakariri

David Owen, Mayor of Waimate

Les Probert, Mayor of Wairoa

Bob Harvey, Mayor of Waitakere

Alan McLay, Mayor of Waitaki

Chas Poynter, Mayor of Wanganui

Kerry Prendergast, Mayor of Wellington

John Drylie, Mayor of Westland

Colin Hammond, Mayor of Whakatane

Craig Brown, Mayor of Whangarei

Government Ministers:

Hon Steve Maharey

Minister of Social Services and Employment

Associate Minister of Education (Tertiary

Education)

Hon Jim Anderton

Minister for Economic Development

Minister for Industry and Regional

Development

Hon Chris Carter

Minister of Local Government 
Between

the Government of New Zealand

and the Mayors Taskforce for Jobs

5 December 2006

1. This Memorandum of Understanding acknowledges the Mayors

Taskforce for Jobs vision:

- that all young people under 25 be in paid work, in training or education, or in productive activities in our communities; and

- that all people over 25 have the opportunity and be encouraged to be in paid work, in training or education, or in productive activities in our communities.

2. Contributing to this vision, this Memorandum of Understanding outlines the process by which Central Government and the Mayors Taskforce for Jobs will cooperate towards the achievement of the shared priority goal, that:

- By 2007, all 15-19 year olds will be engaged in appropriate education, training, work, or other activities that contribute to their long-term economic independence and wellbeing.

These options are likely to include, although are not restricted to:

- Career information and advice

- Youth Transition Services

- Industry-based skills training

- Enterprise education

- Tertiary education and training.

3. The Parties to this Memorandum of Understanding are renewing their public commitment to achieving this common goal. We recognise that we need to act strategically and effectively and to think long-term. 
4. This Memorandum also signals the intentions of both Parties to cooperate in the development and achievement of employment goals that will contribute to improved opportunities for all New Zealanders.

\section{BACKGROUND}

5. In February 2000, a group of Mayors from throughout New Zealand met in Christchurch to establish a MAYORS TASKFORCE for JOBS, which would be a national focus for Mayors concerned about the future of work and livelihood in our communities.

6. Since the launch the Taskforce has gained increasing support and Mayors from around the country have seen the Taskforce as a way to provide leadership on the crucial issue of employment and livelihood in their communities, to support local initiatives, and to work together to share successful projects and solutions. By 2006, 71 Mayors (97\% of all Mayors) had joined the Taskforce.

7. The objectives of the Mayors Taskforce for Jobs are:

- to provide a national focus of leadership on the jobs issue through cooperation between Mayors concerned about employment issues in their communities

- to share best practice on what we can achieve on employment at the local level

- to create local and national forums which address the "big picture" of trends on the issues of income and work

- to link with imaginative private sector initiatives that are addressing local employment issues

- to positively influence Central Government policy to achieve the Taskforce vision.

8. The Government's vision is that New Zealand is:

- a land where diversity is valued and reflected in our national identity

- a great place to live, learn, work and do business 
- a birthplace of world-changing people and ideas

- a place where people invest in the future.

9. In helping to achieve this vision, Government will be proactive in supporting growth, will work co-operatively with other sectors to achieve that, and recognises the importance of the roles and responsibilities of Local Government.

10. This Memorandum of Understanding recognises Central Government's strategic priorities and the role of Local Government in achieving them. These priorities can be summarised as:

- Economic transformation: working to progress our economic transformation to a high income, knowledge-based market economy, which is both innovative and creative and provides a unique quality of life to all New Zealanders

- Families - young and old: all families, young and old, have the support and choices they need to be secure and be able to reach their full potential within our knowledge-based economy

- National identity: all New Zealanders to be able to take pride in who and what we are, through our arts, culture, film, sports and music, our appreciation of our natural environment, our understanding of our history and our stance on international issues.

11. Specific strategies and programmes such as Better Work-Working Better, the Workplace Productivity Agenda, the Tertiary Education Strategy, and Healthy Eating-Healthy Action seek to address labour market issues associated with improving participation in the workforce, productivity levels and skills. These drive the policy and programme agenda and provide specific opportunities for the Mayors Taskforce for Jobs and Central Government to progress their shared visions.

12. The key principles of Government involvement in regional development are: 
- making the most of what a region has to offer, rather than making transfers from prosperous regions to less prosperous regions,

- partnering with the local community to facilitate the development of local strategies that respond to local opportunities and that integrate social, environmental and economic concerns, and

- a 'whole of government' response where the activities of Central Government are integrated into regional strategies together with local stakeholders.

\section{THE DIMENSIONS OF THE CHALLENGE}

12. Household Labour Force Survey (HLFS) data indicate that as at June 2006 , a total of 79,000 people were unemployed, a decrease from 100,000 as at June 2002 . Our concern is that $13.6 \%$ of our shared target group of 15 to 19 year-olds are unemployed. Although this is a decrease from $15.1 \%$ in June 2002 , the lower total unemployment rate means that the 15-19 year-olds now comprise almost $30 \%$ of all those unemployed.

13. What we are most concerned about are the long-term trends for work and income in our communities. There needs to be a concerted leadership effort at both local and central government levels about the quality of work and the creation of more and diverse opportunities for our young people and our young people's children.

14. The jobs of the future will certainly still come from new business opportunities. However, we also need to be concerned about the quality of people's working lives and the level of income to sustain families and communities. We also need to ensure that all people, including Mäori and Pasifika peoples, have access to existing and new work opportunities. The Parties to this agreement can play an important governance role in leading and facilitating the future direction on behalf of our communities.

PRINCIPLES OF APPROACH 
15. Central Government and the Mayors Taskforce for Jobs are committed to building an effective partnership to work towards this goal at the local level, through fostering co-operative relationships across all sectors.

16. Central Government and the Mayors Taskforce for Jobs recognise the need for sustainable development to provide long-term solutions for communities.

17. Central Government and the Mayors Taskforce for Jobs are committed to working together to address the issues that have caused disparities between different groups in society, including between ethnic groups and between regions. This includes a specific commitment to addressing the disparities that exist between Mäori and Pasifika communities and others.

18. Central Government and the Mayors Taskforce for Jobs are committed to reducing barriers to employment.

19. The Mayors Taskforce for Jobs and Central Government recognise the importance of co-ordination and collaboration to address complex social problems.

20. The Mayors Taskforce for Jobs and Central Government recognise that local solutions have the greatest chance of success where there is local leadership and community ownership.

21. The Mayors Taskforce for Jobs and Central Government recognise the value of sharing information on labour market trends and future needs, and recognise the importance of information held by local authorities.

\section{UNDERTAKINGS OF THE PARTIES}

22. The Mayors Taskforce for Jobs and Central Government will work together to facilitate community development initiatives, and to develop and support enterprise and entrepreneurs. These initiatives are likely to include, though are not restricted to:

- building the capacity of local people and local, community, and economic development agencies to facilitate the provision of a wide range of opportunities, 
- provision of information, advice and facilitation to assist in national, regional, local, and community strategic planning initiatives,

- considering how Government expenditure in the regions contributes to the community outcomes expressed in long-term council community plans (LTCCPS) and to having a co-ordinated approach by Local and Central Government and the community in the planning and implementing of these outcomes, and

- funding for specific community/regional development initiatives.

23. The Mayors Taskforce for Jobs will continue to promote close cooperation between Central Government and local economic and employment development organisations to minimise duplication and build on successful structures.

24. The Mayors Taskforce for Jobs and Central Government will work together to promote new solutions to sustainable employment, skill development and workplace learning that reflects the changing nature of work in our country.

25. The Mayors Taskforce for Jobs and Central Government will provide opportunities for policy input by local communities. Wherever possible these will build on existing mechanisms for central and local government, and for community and business partnerships around employment creation and community development.

26. This Memorandum will also act as a working document between Central Government, the Mayors Taskforce for Jobs, and any working parties and technical groups that inform Local Government New Zealand (LGNZ) on employment and economic development.

27. The Mayors Taskforce for Jobs and Central Government will work together on the further development of common goals.

28. This Memorandum of Understanding will be reviewed by June 2008 .

PARTNERSHIP PROCESS 
29. Central Government and the Mayors Taskforce for Jobs are committed to working in partnership and agree to ensure processes are in place to facilitate this positive working relationship.

30. This process will include meetings held at least quarterly, with the Ministers of Social Development and Employment, Economic Development, Local Government, and other Ministers and ministerial bodies as appropriate.

31. The Mayors Taskforce for Jobs and Central Government agree that progress towards agreed common goals will be reviewed annually.

32. The Mayors Taskforce for Jobs core group will meet quarterly with officials of the Mayors Taskforce for Jobs officials group to discuss progress on the Taskforce goals, and to ensure the effective transfer of information and learnings between the two Parties.

33. The Mayors Taskforce for Jobs will continue to build on the relationships with their other partners in the business, community and Local Government sectors.

34. In order to facilitate this partnership, officials of relevant government agencies and the Mayors Taskforce for Jobs may develop specific agreements to support this Memorandum. 
SIGNATORIES

On behalf of the Mayors Taskforce for Jobs

Mayor Paul Matheson

Chair, Mayors Taskforce for Jobs

Signature:

Date: ...... / ...... / ......

Mayor Yvonne Sharp

Deputy Chair, Mayors Taskforce for Jobs

Signature:

Date: ...... / ...... / ......

On behalf of Central Government

Hon Trevor Mallard

Minister for Economic Development

Signature:

Date: ...... / ...... / ......

Hon Mark Burton

Minister of Local Government

Signature:

Date: $\ldots \ldots /$....... / ......

Hon David Benson-Pope

Minister for Social Development and Employment

Signature:

Date: ...... / ...... / ...... 


\section{SCHEDULE: PARTIES TO THIS MEMORANDUM}

\section{As at 5 December 2006}

Members of the Mayors Taskforce for Jobs

Mark Ammon, Mayor of Waitomo District Janie Annear, Mayor of Timaru Barbara Arnott, Mayor of Napier Mark Ball, Mayor of Franklin Phillipa Barriball, Mayor of ThamesCoromandel

Mary Bourke, Mayor of South Taranaki Jenny Brash, Mayor of Porirua Bob Buchanan, Mayor of Rangitikei Malcolm Campbell, Mayor of Kawerau District Frana Cardno, Mayor of Southland Peter Chin, Mayor of Dunedin John Coles, Mayor of Waimate Stuart Crosby, Mayor of Tauranga Sir Barry Curtis, Mayor of Manukau Brendan Duffy, Mayor of Horowhenua District Meng Foon, Mayor of Gisborne John Forbes, Mayor of Opotiki Bob Francis, Mayor of Masterton Clive Geddes, Mayor of Queenstown Lakes Jim Gerard, Mayor of Waimakariri District Tim Gilbertson, Mayor of Central Hawke's Bay Wayne Guppy, Mayor of Upper Hutt Peter Harris, Mayor of Waikato District Bob Harvey, Mayor of Waitakere Juno Hayes, Mayor of Clutha Kevin Heays, Mayor of Kaikoura Tracy Hicks, Mayor of Gore Colin Holmes, Mayor of Whakatane District Dick Hubbard, Mayor of Auckland John Hurley, Mayor of Tasman District Garry Jackson, Mayor of Hurunui Brian Jeffares, Mayor of Stratford Peter King, Mayor of Kaipara Tony Kokshoorn, Mayor of Grey District John Law, Mayor of Rodney Alan Livingston, Mayor of Waipa Michael McEvedy, Mayor of Selwyn Ian McKelvie, Mayor of Manawatu Alan McLay, Mayor of Waitaki District Gary McPhee, Mayor of Carterton Malcolm Macpherson, Mayor of Central Otago Paul Matheson, Mayor of Nelson Alan Milne, Mayor of Kapiti Coast District Gary Moore, Mayor of Christchurch Sue Morris, Mayor of Ruapehu David Ogden, Mayor of Hutt Bede O'Malley, Mayor of Ashburton John O'Neill, Mayor of Mackenzie District Pamela Peters, Mayor of Whangarei Kerry Prendergast, Mayor of Wellington Les Probert, Mayor of Wairoa
Mary Pugh, Mayor of Westland Michael Redman, Mayor of Hamilton Maureen Reynolds, Mayor of Tararua John Robertson, Mayor of Papakura Martin Sawyers, Mayor of Buller Tim Shadbolt, Mayor of Invercargill Yvonne Sharp, Mayor of Far North Neil Sinclair, Mayor of South Waikato Alistair Sowman, Mayor of Marlborough Adrienne Staples, Mayor of South Wairarapa Clayton Stent, Mayor of Taupo District Heather Tanguay, Mayor of Palmerston North Peter Tennent, Mayor of New Plymouth John Tregidga, Mayor of Hauraki Hugh Vercoe, Mayor of Matamata-Piako District

Graeme Weld, Mayor of Western Bay of Plenty Dale Williams, Mayor of Otorohanga District Kevin Winters, Mayor of Rotorua George Wood, Mayor of North Shore Lawrence Yule, Mayor of Hastings

\section{Government Ministers:}

Hon Trevor Mallard

Minister for Economic Development

Minister for Industry and Regional

Development

Minister for State Owned Enterprises

Minister for Sport and Recreation

Hon Mark Burton

Minister of Local Government

Minister of Justice

Minister in Charge of Treaty of Waitangi

Negotiations

Hon David Benson-Pope

Minister for Social Development and

Employment

Minister for the Environment 
Memorandum of Understanding (2009)

BETWEEN THE GOVERNMENT OF NEW ZEALAND AND

THE MAYORS TASKFORCE FOR JOBS

This Memorandum of Understanding clarifies the relationship between the Government of New Zealand (the Government) and the Mayors Taskforce for Jobs (the Taskforce).

Background

The Taskforce was formally established in April 2000, following a community conference in Christchurch that recognised employment and livelihood as fundamental to stability in communities. By 2009, 69 Mayors (95\% of all Mayors) had joined the Taskforce.

Objective

The objective of this Memorandum of Understanding is to affirm the commitment of the Government and the Taskforce to building an effective partnership to work on areas of common interest.

Benefits of the Partnership

The partnership between the Government and the Taskforce will provide the following mutual benefits:

- the opportunity for local communities to have input into the policymaking process at the highest level

- a strong two-way communication channel between central government and local communities

- the opportunity for Ministers and key local and regional decisionmakers from across New Zealand to interact in a structured way about issues of common concern

- the opportunity for local decision-makers and communities to advise the Government on how to make key Government policy relevant at the local level 
- a quick and effective way for the Government to consult with local communities on proposed major policy changes.

Areas of Common Interest

The core area of common interest for the Government and the Taskforce is maximising local employment opportunities for young people and ensuring their successful transitions to education, training or employment. From time to time the Government and the Taskforce may agree on other areas of common interest as outlined in Annex A. The Minister for Social Development and Employment and the Chair of the Taskforce have the authority to vary the areas of common interest outlined in Annex A by agreement in writing (but may consult other relevant Ministers where the Minister considers it appropriate).

The Government mandates government officials to work with the Taskforce to develop priorities, actions and initiatives relating to the areas of common interest.

Undertakings of the Parties

The Government and the Taskforce will:

- affirm the commitment to work in partnership on areas of common interest meet at least quarterly each year work together to determine areas of common interest annually review areas of common interest

- annually review the priorities, actions, initiatives and results relating to areas of common interest

- annually review the level of funding for the Taskforce.

Review of Memorandum of Understanding This Memorandum of Understanding will be reviewed by June 2010. 
Annex A - Other Areas of Common Interest

The Government and the Taskforce agree to work together to respond to the impact of the recession by focusing on the following in the short term:

- assisting communities that are disproportionately affected by the recession

- responding to local employment shocks as a result of the recession. 


\section{Memorandum of Understanding (2018)}

The Mayors Taskforce for Jobs and Government Partnership for Jobs

Purpose

This Memorandum of Understanding (MOU) sets out the nature of the relationship by which Central Government and the Mayors Taskforce for Jobs (MTFJ) will cooperate to achieve better employment outcomes for young New Zealanders.

The Parties to the MOU will collaborate with the ambition to see all young people under the age of 25 engaged in education, training, work or other positive activity that will support their growth and development.

The Parties recognise that barriers to employment are often best addressed at a local level. They also believe that cooperation can make a significant difference to the lives and prospects of young people through the leadership of Mayors working closely alongside Central Government. The Parties

This MOU is an agreement between the Minister of Local Government, the Minister of Employment, the Minister for Building and Construction, the Minister for Youth and the Mayors Taskforce for Jobs (the Parties), supported by officials from other Government agencies that include but is not limited to:

- the Department of Internal Affairs

- the Ministry of Business, Innovation and Employment

- the Ministry of Social Development

- the Ministry of Youth Development

- Te Puni Kōkiri

- The Tertiary Education Commission.

The MTFJ is a nationwide network of most of New Zealand's Mayors governed by a core group of 17 Mayors. This MOU recognises the importance of the role Mayors play in driving local change. The role of the MTFJ, and Mayors, is that of holistic place shapers. 
The MTFJ will endeavour to create a supportive environment for officials to achieve our common goals. The Parties acknowledge that there are other parties such as NGOs, iwi and businesses who play a key role in the employment of young people.

The Parties recognise that the work done by the MTFJ, and its knowledge of these areas, in particular, should be utilised by Government. Additional areas of work are possible, if the relationship between the Parties uncovers the need for increased scope.

Areas of focus

The MTFJ has identified four key areas of work on employment issues that it wishes to focus on:

- Education, including:

- Educational and training pathways

- Skill gaps

- Employer engagement

- Health, including

- The impact of Mental Health on employment

- The impact of drug testing on employment and user behaviour

- Driver Licensing, including:

- Review of progress on driver licensing initiative

- Advocacy by MTFJ; and

- Rangatahi Mentoring, including:

- Importance of mentoring and support for young people to succeed socioeconomically

- The role Mayors can play in mentoring or enabling mentors / mentees.

The initial focus of the work with the Parties will be on supporting local initiative to increase employment including implementation of $\mathrm{He}$ Poutama Rangatahi and the Provincial Growth Fund. Other agencies will be invited to contribute to the key areas of work, where they have 
responsibilities and expertise, such as the Ministry of Health and Ministry of Education.

Context

The Government is committed to ensuring that New Zealand has a highly skilled and innovative economy that provides well-paid, meaningful and sustainable jobs. We want a high-performing economy that will deliver good jobs, decent work conditions and fair wages.

Current labour market objective to guide policy and implementation include:

- Improvement of aggregate labour market productivity

- Creation of decent jobs

- Reduction of unemployment and under-employment across all regions, ages, ethnic and disability groups

- Higher wages across the wage distribution

- Opportunities for people to have access to lifelong learning

- Ensuring that people and workplaces are adaptive in the face of economic transitions.

The MTFJ runs advocacy projects and sets out to partner with bestpractice organisations to promote the economic well-being of young people. The MTFJ mission is to:

- Advocate for the importance of education, training, employment, economic and community development

- Maximise opportunities for our young people that are future-focused and aligned with economic development

- Build knowledge, skills and relationships with on-going benefits to young people, employers, communities and the New Zealand economy.

The MTFJ is also a channel for providing employment-related information to local stakeholders, as well as providing ways to facilitate access to the right people and groups locally. 
Agreement

The Parties support an integrated approach to ensure that all young people have the opportunity to grow and develop skills, including in work places, which enables them to participate fully in society. The Parties will operate in accordance with the following key assumptions:

- Young people are a key focus of this MOU especially those currently not in education, employment, or training (NEET). Particular attention will be paid to Māori, Pasifika and young people with disabilities

- Employment initiatives should form an integrated part of wider regional economic development, skill formation and labour market policies

- Central and Local Government will collaborate through productive partnerships. The partnership approach will focus on the respective strengths of Central and Local Government in pursuit of improved employment outcomes for young people

- The Parties will operate through open information exchange and identify areas for collaboration that add value and avoid duplication of effort

- Given the diversity of New Zealand's regions, flexible and adaptive approaches will be explored to meet the differing needs of young people.

Engagement

The Parties commit to establish and maintain an effective relationship based on trust, respect and openness.

The relationship will be underpinned by clear and regular information flows between the Parties. Feedback loops will be created to ensure that there are insights and lessons learnt to inform Central Government policy development as well as dissemination of best practice across the different regions. 
The Parties will support the piloting of new approaches including bringing together local parties to develop innovative approaches to employment of young people. The involvement of Mayors will be sought in developing, supporting and implementing local initiatives as appropriate.

The MTFJ will assist in advising on the local knowledge or parties needed for successful stakeholder groups where possible.

The MTFJ will promote and celebrate successful collaboration, where appropriate highlighting the role that Central Government has played. The Parties commit to regular meetings and discussions, including providing updates on the four key work areas at quarterly meetings. The Parties will identify initial priorities and discuss key performance measures for joint initiatives, reporting on these as appropriate in the quarterly meetings.

The Parties recognise that these quarterly meetings are a valuable means to share knowledge of their respective areas at governance and operational levels.

Where relevant, updates on employment initiatives of the Parties will be summarised and jointly presented on websites to ensure there is clear and well aligned information available to a wide range of audiences.

Opportunities for joint branding will be explored where possible.

Comments made by the Mayors on any operational reports that agencies provide will be acknowledged, and where appropriate, utilised to inform future operational outcomes.

The Parties acknowledge that the role of Mayors may vary in different areas but there is a commitment to working for maximum impact and consulting as appropriate with all the relevant parties.

The Parties acknowledge that commitment to work together on employment in this MOU does not preclude participation and input to wider related work led by Central Government. 
Issues outside the scope of this MOU, such as wider issues of funding of local government, will be dealt with in the appropriate forums.

Progress of the MOU will also be reported in the annual Central - Local Government Forum.

Funding

This MOU recognises that there will be opportunities to work together on joint initiatives and that in some cases it will be appropriate to discuss the potential for Parties to provide funding, while recognising that each party will need to make a determination of their own ability to fund initiatives based on policy and financial considerations.

Information and measures

The Parties agree to monitor and report on initiatives jointly undertaken under this MOU.

Officials will work with the MTFJ Secretariat to ensure regional NEET rates (or numbers) are made available to the Parties after the release of the quarterly Household Labour Force survey results.

Officials and the MTFJ Secretariat will also discuss monitoring data and information needed to ensure that Mayors are well equipped to analyse employment dynamics in their areas. Central Government officials will also work with the MTFJ secretariat to ensure well aligned and consistent information and messaging on employment initiatives.

The Parties will share information in accordance with their obligations under the Privacy Act 1993. The Parties may share:

- Statistical information that supports initiatives under this MOU

- Personal information can be disclosed tot eh other party if the disclosure fits into one of the exceptions under Principle 11 of the Privacy Act 1993.

Signatories

Hon Nanaia Mahuta, Minister of Local Government 
Hon Jenny Salesa, Minister for Building and Construction

Hon Willie Jackson, Minister of Employment

Max Baxter, Chair, Mayors Taskforce for Jobs, Mayor, Otorohanga District Council

Malcolm Alexander, Chief Executive, New Zealand Local Government Association Inc

Hon Peeni Henare, Minister for Youth 
Appendix 2: Mayors Taskforce for Jobs - Other Agreements

The Mayors Taskforce for Jobs also entered into agreements with key stakeholders outside Central Government. Two of these agreements are replicated in full below. 


\section{Memorandum of Understanding: NZ Council of Trade Unions}

6 March 2003

\section{INTRODUCTION}

1. This Memorandum of Understanding outlines the process by which the New Zealand Council of Trade Unions and the Mayors Taskforce for Jobs will cooperate towards the achievement of the shared government goals, that:

- By 2007, all 15-19 year olds will be engaged in appropriate education, training, work, or other options which will lead to long term economic independence and well-being

- all young people up to age 25 being in employment or education and training; and ultimately

- all people in our communities having the opportunity to be in work or training;

And the Mayors Taskforce for Jobs goals :

- By 2005 , no young person under 25 years will be out of work or training in our communities

- By 2009 , all people in our communities will have the opportunity to be in work or training

2. The parties to this Memorandum of Understanding are renewing their public commitment to addressing these issues and pledging to co-operate on future initiatives. We recognise that we need to act strategically and effectively and to think long-term.

3. This Memorandum also signals the intentions of both parties to cooperate in the development and achievement of employment goals which will contribute to improved opportunities for all New Zealanders to have a decent quality job.

4. The Mayors Taskforce for Jobs and the NZCTU are committed to working in partnership and agree to ensure processes are in place to facilitate this positive working relationship. 


\section{PARTNERSHIP PROPOSALS}

5. The NZCTU and Mayors Taskforce for Jobs will establish as appropriate website links.

6. The Mayors Taskforce for Jobs and the NZCTU will discuss the promotion of a set of minimum employment rights as a guide for young people and will co-operate with Government on this proposal.

7. The Mayors Taskforce for Jobs and NZCTU will promote regional employment plans.

8. The NZCTU and Mayors Taskforce for Jobs will work co-operatively on several pilot regional forums on economic development that can involve unions, government agencies, local employers and other relevant organisations.

9. The NZCTU and Mayors Taskforce for Jobs will promote employment policies which are inclusive in respect of Maori, Pacific peoples, those with disabilities and others who have been disadvantaged in the labour market.

10. The Mayors Taskforce for Jobs will co-operate with NZCTU and as agreed with Business NZ on a campaign to lift the participation of employers and workers in industry training.

11. The NZCTU will work with Mayors Taskforce for Jobs on initiatives involving schools and promoting employment opportunities for school leavers.

12. The Mayors Taskforce for Jobs will work with CTU Regional constituent bodies (Local Affiliate Councils) on the promotion of quality employment and training opportunities.

13. The Mayors Taskforce for Jobs and NZCTU will, as appropriate, discuss any submissions or proposals to Government in the area of employment, work-life balance, labour market issues, and training. 
14. The Mayors Taskforce for Jobs and NZCTU will work together on the further development of common goals.

PARTNERSHIP PROCESS

15. The NZCTU and Mayors Taskforce for Jobs will meet annually to review this Memorandum and seek additional areas of co-operation.

16. Regular contact shall be maintained between CTU staff and Mayors Taskforce for Jobs staff and the Mayors Taskforce for Jobs core group.

Signed on 6th March 2003 in Christchurch.

Garry Moore, Chair Mayors Taskforce for Jobs

Paul Goulter, Secretary Council of Trade Unions 
Principles of Partnership between Community Employment Group

and Mayors Taskforce for Jobs

5 March 2001

An Operating Framework for Community Employment Group working with the Mayors Taskforce for Jobs

Background

In September 2000 the Ministers of Economic Development and Employment, along with Taskforce Mayors launched a partnership between central government and the Mayors Taskforce for Jobs. The basis for this partnership is set out in the document agreed to by both parties: Mayors Taskforce for Jobs Memorandum of Understanding.

The Community Employment Group, as the key government agency concerned with local employment development has committed support to the Taskforce towards the achievement of its two strategic goals. These goals are:

"By 2005, no young person under 25 years will be out of work or training in our communities"

"By 2009, all people in our communities will have the opportunity to be in work or training"

Support from CEG will be in the nature of community employment and development services through field staff, assisted by a national planning and co-ordination group. The partnership will seek to strengthen and rebuild local community economic and employment development structures and strategies.

Key Principles

- Mutual effort between the Taskforce and CEG will operate at local to national levels

- The two strategic goals are "cultural" or visionary goals 
- CEG work in support of the MFJTF strategy applies only to TLAs of Taskforce members

- Mayors and Community Employment Advisers will establish clear expectations at the beginning of the relationship

- The focus of mutual effort will be on identifying local employment needs and opportunities and designing or reinforcing strategies to meet these

- Strategies will build on existing infrastructure, networks and projects wherever possible

- Each party will acknowledge the other in any publicity associated with jointly supported strategies

Working Structure

1. Leadership

The General Manager of CEG, and the Chairman of Mayors Taskforce for Jobs will be responsible for national governance and management of the partnership.

2. National Planning and Co-ordination Group

A national work group comprising CEG senior management, a CEG Community Operations Adviser, CEG regional Mayors Taskforce for Jobs representatives, the MTFJ Executive officer, and the Taskforce Community Adviser.

Responsibilities

- Undertake the initial planning and guide subsequent implementation of the CEG/Mayors Taskforce for Jobs initiative

- Maintain a national perspective of the CEG/Mayors Taskforce for Jobs initiative and inform respective local participants

- Prepare and disseminate resource information

- Jointly agree on communications about the CEG/Mayors Taskforce for Jobs initiative to external stakeholders

- Meet quarterly to report on progress 


\section{CEG Regional Mayors Teams}

Regional team representative to the national planning and co-ordination group, and Community Employment Advisers working with Taskforce member Mayors within the region

Responsibilities

- Build and maintain a regional perspective of the CEG/Mayors Taskforce for Jobs initiative

- Provide peer support to each other in building effective relationships with Mayors, and in problem solving

- Collate information and feedback to the national work group, and identify successful working models

\section{Community Employment Advisers}

Local Community Employment Advisers working with local Mayors who are members of the Mayors Taskforce for Jobs.

Responsibilities

- Provide local employment development advice, information, and ideas to the Mayor in relation to the two strategic goals

- Support the Mayor with strategic and specific planning of employment strategies

- Support effective relationships between the Mayor and all stakeholders, including communities at disadvantage in the labour market

- Contribute to the CEG/Mayors Taskforce for Jobs knowledge base, and assist with the dissemination of good practice information

\section{Guiding Parameters}

- The CEA and Mayor should base their relationship on the government/Mayors Taskforce for Jobs joint interest objectives of the MOU

- CEG recognises the Mayors Taskforce for Jobs as a national strategy 
- CEG does not recruit Mayors into the Taskforce

- The Mayor is the strategy champion, the field worker provides advisory, planning and liaison support directly to the Mayor

- Work with a Mayors Taskforce for Jobs Mayor is to be recorded as a non-funded project in weekly reports e.g." MTFJ Christchurch".

March 2001 


\section{References}

ACT New Zealand. (2011). Abolish Yourself, ACT Tells Mayors Taskforce [Press release]

Al-Ayouty, I., \& Hassaballa, H. Regional unemployment in Egypt: Spatial panel data analysis. African Development Review, $n / a(\mathrm{n} / \mathrm{a})$.

doi:https://doi.org/10.1111/1467-8268.12461

Anderton, J. (2000). Mayors Memorandum of Understanding. (14 September 2000). Wellington, NZ: Hansard.

Angus, F. (1999a). Additional information requested on the CE review. (28 May 1999).

Angus, F. (1999b). Consultation Document: Review of Work and Income NZ Communtiy Employment. (3 May 1999).

Ansell, C., \& Gash, A. (2008). Collaborative Governance in Theory and Practice. Journal of Public Administration Research \& Theory, 18(4), 543571.

Auckland City Council. (2005). Auckland City helps address skill shortages [Press release]

Auckland City Council. (2007). Youth ambitions supported by council [Press release]

Avina, J. (1993). The evolutionary life cycles of non-governmental development organizations: SUMMARY. Public Administration \& Development (1986-1998), 13(5), 453.

Baker, S. (2009). In pursuit of sustainable development: A governance perspective. Paper presented at the 8th International Conference of the European Society for Ecological Economics, Ljubljana, Slovenia.

Barrett, P., \& Spoonley, P. (2001). Transitions: Experiencing employment change in a regional labour market. New Zealand Journal of Industrial Relations, 26(2), 171-183.

Batory, A., \& Svensson, S. (2019). The fuzzy concept of collaborative governance: A systematic review of the state of the art. Central European Journal of Public Policy, 13(2).

Baxter, J. (2015, 24 February 2015). [Response to Official Information Act request on Community Employment Group].

Bennett, P. (2009). 870 (2009). Hon Annette King to the Minister for Social Development and Employment. Hansard.

Bennett, P. (2011). Unemployment - Ministers Statement.

Bennett, P. (2012). Welfare reform legislation to be introduced [Press release]

Benson-Pope, D. (2006, 20 March 2006) David Benson-Pope Interview - The Next Three Years/Interviewer: D. Owens. 
Benson-Pope, D. (2007). Mayors' Taskforce Annual Conference [Press release]

Berry, R. (1999, 31 August 1999). TVNZ decision on Fox awaited. The Evening Post, p. 17.

Best, R., \& Burke, P. (2019). Is there regional lock-in of unemployment rates in Australia? Australian Journal of Labour Economics (AJLE), 22(2), 93115.

Bingham, L. (2011). Collaborative governance. In M. Bevir (Ed.), The Sage book of governance. Thousand Oaks: Sage.

Blaikie, N. (2007). Approaches to social enquiry: advancing knowledge. Cambridge: Polity Press.

Bond, L., et al. (2012). Exploring the relationships between housing, neighbourhoods and mental wellbeing for residents of deprived areas. BioMed Central Public Health, 12, 48.

Booher, D., \& Innes, J. (2006). Complexity and adaptive policy systems: CALFED as an emergent form of governance for sustainable management of contested resources.

Boyes, N. (2009, 28 September 2009). Fighting to get them work. Waikato Times.

Bray, M., \& Strang, J. (1996). Tackling Unemployment: The Government's response to the recommendations of the Employment Task Force. Social Policy Journal of New Zealand(6 July 1996).

Bryan, T. (2004). Tragedy Averted: The Promise of Collaboration. Society and Natural Resources, 17, 881-896.

Business Development Centre. (2007). Waikato Business Development Scheme Goes National [Press release]

Byrne, J. (1999). Literature Review on Community Development. Wellington: Department of Labour.

Cameron, A. (2015). Experience with the UK New Enterprise Allowance scheme. Local Economy, 30(5), 479-483. doi:10.1177/0269094215589145

Cedefop. (2018). From long-term unemployment to a matching job: the role of vocational training in sustainable return to work. Luxembourg: Publications Office

Chan, W., et al. (2011). A multidisciplinary primary care team consultation in a socio-economically deprived community: An exploratory randomised controlled trial. BMC Health Services Research, 11(15).

Chapman, B. (1993). Long term unemployment: the case for policy reform. The Economic and Labour Relations Review, 4(2), 218.

Chapman, K. (2012, 20 March 2012). Mergers easier to undertake - Smith. The Press. 
Cheng, D. (2011, 28 March 2011). Bennett blames minute-taker. NZ Herald.

Christchurch City Council. (2006). Chch Mayor Garry Moore will not seek fourth term [Press release]

Christchurch City Council. (2007, 21 May 2007). Mayors' unite for teen safety. Scoop Independent News.

City Vision-Labour Councillors. (2008a). Banks Alone in Exiting Mayors' Taskforce For Jobs [Press release]

City Vision-Labour Councillors. (2008b). Banks to exit Mayors' Taskforce for Jobs? [Press release]

Claridge, A. (2004a, 27 March 2004). Hip-hop timeline. The Press, p. 3.

Claridge, A. (2004b, 19 March 2004). Probe into 'hip-hop tour' funds. The Press.

Claridge, A. (2004c). Sour note for taxpayers over pair's hip-hop tour. The Press.

Claridge, A. (2004d, 18 March 2004). Trip hop for hip-hop defended. The Press.

Clark, H. (2003). Budget 2003: \$56m plan to get all young people into education, training or work announced [Press release]

Collins, S. (2009, 2 March 2009). Tindall calls up the reserves. New Zealand Herald.

Collins, S. (2010a, 27 February 2010). Major shakeup ahead for apprenticeship system. New Zealand Herald.

Collins, S. (2010b, 16 Oct 2010). Plan to chase leavers as school ends. NZ Herald.

Collins, S. (2011, 20 April 2011). Scheme to track school-leavers hits a hurdle. NZ Herald.

Community Employment Group. (1997). Te Ahu Tangata: 1997/98 Business Plan. Wellington, NZ: Department of Labour

Community Employment Group. (2003). Searching for community champions [Press release]

Controller and Auditor-General. (2003). Inquiry into Public Funding of Organisations Associated with Donna Awatere Huata MP. Wellington, NZ.

Cranston, A. (2014). Workshop: Mayors' Taskforce for Jobs - Rotorua.

Crean, M. (2000a, 8 April 2000). Mayors aim for 'zero' NZ jobless. The Press, p. 1.

Crean, M. (2000b, 10 April 2000). Mayors to talk jobs on Coast. The Press, p. 2.

Crean, M. (2000c, 14 August 2000). No dole for nothing plan. The Press. 
Creech, W. (1996). Exit Management from selected CEG national initiatives: Mature Employment Service. (15 August 1996).

Creswell, J. (2009). Research design: Qualitative, quantitative and mixed methods approaches. Los Angeles: Sage.

Crosby, B., \& Bryson, J. (2010). Integrative leadership and the creation and maintenance of cross-sector collaborations. The Leadership Quarterly, 21(2).

Cullen, M. (2017). A Social Democratic Critique. In J. Boston \& D. Gill (Eds.), Social Investment: A New Zealand Policy Experiment. Wellington: Bridget Williams Books Ltd.

Darling, J. (1992). New strategies to combat long-term unemployment in the UK. International Journal of Manpower, 13(9), 38.

Dean, A. (2013). Tackling Long-Term Unemployment Amongst Vulnerable Groups. doi:doi:https://doi.org/10.1787/5k43jct8n2nv-en

Dearnaley, M. (2000, 19 September 2000). Auckland mayors lukewarm on job creation taskforce. The New Zealand Herald.

Dearnaley, M., \& Collins, S. (2000, 23 October 2000). Maharey agrees to mayoral plan for community workers. New Zealand Herald.

Department of Labour. (1992). Community Employment Group Activity Summary 1991/92. Wellington.

Department of Labour. (1998). Community Employment Group (CEG)

Position in Integrated Structure. (19 December 1998).

Department of Labour. (1999). Review of Community Employment. Wellington: Department of Labour.

Department of Labour. (2001). Department of Labour Annual Report 2000/01. Wellington, NZ.

Department of Labour. (2002a). Department of Labour Annual Report 2001/02.

Department of Labour. (2002b). Evaluation of the Community Employment Group's Capacity Building Initiatives. Wellington, NZ: Department of Labour.

Donahue, J. D., et al. (2011). Tasks and Tools Collaborative Governance (pp. 207-239): Princeton University Press.

Douglas, S., et al. (2020). Understanding Collaboration: Introducing the Collaborative Governance Case Databank. Policy and Society, 39(4), 495509. doi:10.1080/14494035.2020.1794425

Dovey, L. (2003). Achieving Better Social Outcomes in New Zealand Through Collaboration: Perspectives from the United States. Wellington:

Ebrahim, A. (2003). Accountability in Practice: Mechanisms for NGOs. World Development, 31(5), 813-829. 
Edwards, M., \& Hulme, D. (1996). Too Close for Comfort? The Impact of Official Aid on Nongovernmental Organizations. World Development, 24(6), 961-973.

Eisenhardt, K. M. (1989). Agency Theory: An Assessment and Review. The Academy of Management Review, 14(1), 57-74.

Eisenhardt, K. M., \& Graebner, M. E. (2007). Theory Building from Cases: Opportunities and Challenges. The Academy of Management Journal, 50(1), 25-32. doi:10.2307/20159839

Elphick, C. (2005). Employment Catalyst Fund 2004-2005

Emerson, K., et al. (2012). An Integrative Framework for Collaborative Governance. Journal of Public Administration Research \& Theory, 22(1), 129.

English, M. R., et al. (2002). Building communities while building plans: a review of techniques for participatory planning processes. Public Administration Quarterly, 26(3), 503-539.

Evans, R. (2008, 15 Feb 2008). Agency busy cutting youth unemployment. Taranaki Daily News.

Fahy, B. (2003, 10 July 2003). Following the hip hop trail. The Dominion Post.

Flyvbjerg, B. (2006). Five misunderstandings about case-study research. Qualitative Inquiry, 12(2), 219-245. doi:10.1177/1077800405284363

Francis, J. (2000). Meeting with Government Ministers at Wellington City Council 19 October 2000. Retrieved 7 April 2017 from http://www.jobsletter.org.nz/mtfjobs/mtfjobs21.htm

Francis, J. (2003a). Core Group Meeting Report - 17th and 18th September 2003.

Francis, J. (2003b). Progress Review.

Francis, J. (2004a). Core Group Meeting Report 9 March 2004.

Francis, J. (2004b). Mayors Taskforce for Jobs Administration Report November 2004.

Francis, J. (2004c). New Mayors Visits - December 2004

Francis, J. (2005). Administration Report

Freeman, J. (1997). Collaborative governance in the administrative state. UCLA Law Review, 45(1).

Gardner, C. (2009, 25 Feb 2009). Region snubbed in job summit. Waikato Times.

Gardner, W. (2014). Kia Ora Chief. Wellington: Huia Publishers.

Glasbergen, P., \& Driessen, P. (2005). Interactive planning of infrastructure: the changing role of Dutch project management. Environment and Planning C: Government and Policy, 23, 263-277. 
Goff, P. (2001). Key defining elements of a social entrepreneur. Hansard. Gorman, P. (2004, 13 November 2004). Dunedin Mayor queries need for jobs taskforce. The Press.

Groenewold, N., \& Hagger, A. J. (2008). Regional unemployment disparities: an evaluation of policy measures. Australian Economic Papers, 47(4), 355-375. doi:https://doi.org/10.1111/j.1467-8454.2008.00354.x

Green Party. (2005). Young workers' raw pay deal must end - Bradford [Press release]

Hawkins, B. (2002). Govt gives $\$ 1.3 \mathrm{~m}$ to movers and shakers. The Evening Post.

Henton, D., et al. (2005). Collaborative governance: A guide for grantmakers The William and Flora Hewlett Foundation

Holden, M., \& Lynch, P. (2004). Choosing the Appropriate Methdology: Understanding Research Philosophy. The Marketing Review, 4, 397-409.

Horomia, P. (1991a). Community Employment Group: Policy Issues.

Wellington.

Horomia, P. (1991b). Progress report - setting up of Community

Employment Group. (1 November 1991).

Horomia, P. (1992a). Community Employment Group (CEG) Outputs: 1992/93 Executive Summary. (19 February 1992).

Horomia, P. (1996a). Hawkes Bay Hailstorm Response. (23 December 1996). Wellington.

Horomia, P. (1996b). Progress on exit management from selected CEG national strategies. (9 August 1996). Wellington.

Horomia, P. (1996c). Progress on implementation of Focus on Employment measures. (9 August 1996). Wellington.

Horomia, P. (1997a). Business Development Programme Review. (7 May 1997). Wellington.

Horomia, P. (1997b). Car assembly industry closures. (19 December 1997).

Horomia, P. (1997c). CEG's exit management plan: background to meeting on Tuesday 15 April. (14 April 1997). Wellington.

Horomia, P. (1997d). Quarterly report on non-departmental output class: Community Employment Projects. (28 January 1997). Wellington.

Horomia, P. (1998a). Employment outcomes of Community Employment Group supported projects. (5 May 1998). Wellington.

Houlahan, M. (2009, 23 March 2009). Youth Unemployment. The Press.

Hunn, D. (2000). Ministerial Inquiry into the Department of Work and Income (WINZ). Wellington.

Hutchinson, V. (1999, 2-3 June 1999). It is the local that learns. Paper presented at the Community Governance Forum, Christchurch, NZ. 
Hutchinson, V. (2000, 6-7 April 2000). Making hope possible. Paper presented at the Mayors Taskforce for Jobs, Christchurch, NZ.

Hutchinson, V. (2004). Restating our intentions for 2005 - from goals to guarantees.

Hutchinson, V. (2005, 20 October 2005). Mayors Taskforce Changes. The Jobs Letter.

Hutchinson, V. (2017). Vivian Hutchinson. Retrieved 3 April 2017 from http://www.vivianhutchinson.org.nz/aboutext

Huxham, C. (1996). Collaboration and Collaborative Advantage. In C. Huxham (Ed.), Creating Collaborative Advantage. London: SAGE Publications Ltd.

Huxham, C. (2000). The challenge of collaborative governance. Public Management (1461667X), 2(3), 337-357.

doi:10.1080/14616670050123260

Irvin, R. A., \& Stansbury, J. (2004). Citizen Participation in Decision Making: Is It Worth the Effort? Public Administration Review, 64(1), 55-65. doi:10.2307/3542626

Jacoby, J., \& Terpstra, M. (1990). Collaborative Governance: Model for Professional Autonomy. Nursing Management, 21(2), 42.

James, C. (2004, 28 June 2004). Colin James: Innovation - with a hatchet. New Zealand Herald.

Jeffs, L. (2006, June 2006). Social Entrepreneurs and Social Enterprises - Do they have a future in New Zealand? Paper presented at the 51st ICSB World Conference, Melbourne, Australia.

Jones, C., et al. (1997). A general theory of network governance: Exchange conditions and social mechanisms. Academy of Management. The Academy of Management Review, 22(4), 911-945.

Kapucu, N., et al. (2009). Collaborative Public Management and Collaborative Governance: Conceptual Similarities and Differences. European Journal of Economic and Political Studies, 2(1), 39-60.

Key, J. (2009). Youth Opportunities: Speech to National Conference [Press release]

Kia Piki Ake Welfare Expert Advisory Group. (2019). Whakamana Tangata: Restoring dignity to social security in New Zealand. Wellington: NZ Government.

Kieselbach, T. (2003). Long-Term Unemployment Among Young People: The Risk of Social Exclusion. American Journal of Community Psychology, 32(1/2), 69.

Klijn, E.-H. (2008). Governance and Governance Networks in Europe. Public Management Review, 10(4), 505-525. doi:10.1080/14719030802263954 
Krugman, P. (1994). Past and prospective causes of high unemployment. Economic Review - Federal Reserve Bank of Kansas City, Fourth Quarter 1994(79), 4.

Lambert, T. E., et al. (2017). The impact of growth and innovation clusters on unemployment in US metro regions. Regional Science Policy \& Practice, 9(1), 25-37. doi:https://doi.org/10.1111/rsp3.12087

Lange, T. (2007). Revisiting the Job Guarantee: Ten Propositions towards a Model for New Zealand. New Zealand Journal of Employment Relations (Online), 32(3), 69-82.

Lawrence, L., \& Deagen, D. (2001). Choosing Public Participation Methods for Natural Resources: A Context-Specific Guide. Society \& Natural Resources, 14(10), 857-872. doi:10.1080/089419201753242779 Leaman, A. (2007, 26 June 2007). Mayors talk jobs for youth. Waikato Times.

Lindsay, C. (2009). In a Lonely Place? Social Networks, Job Seeking and the Experience of Long-Term Unemployment. Social Policy and Society, 9(1), 25.

Local Government New Zealand. (2003). Annual Report 2002/2003. Wellington: Local Government New Zealand.

Local Government New Zealand. (2004). Annual Report 2003/04. Wellington: Local Government New Zealand.

Loomer, A. H., et al. (1993). The nurse advocate and care for the caregivers. Nursing Management, 24(2), 64.

Lowndes, V., \& Skelcher, C. (1998). The Dynamics of Multi-Organisational Partnerships: An Analysis of Changing Modes of Governance. Public Administration, 76(Summer 1998), 313-333.

Maharey, S. (2000a). Community Employment. (7 June 2000).

Maharey, S. (2000b). Government releases employment strategy document [Press release]

Maharey, S. (2000e). Maharey announces plans for Community Employment Organisations [Press release]

Maharey, S. (2000f). Maharey backs Mayors Taskforce for Jobs [Press release]

Maharey, S. (2001a). Enabling social entrepreneurs - a partnership between government and community [Press release]

Maharey, S. (2001b). Social entrepreneurs. Hansard, 9 March 2001, 1983.

Maharey, S. (2002, 14 February 2002). Growth, innovation and partnership between central and local government. Paper presented at the Mayors Taskforce for Jobs Annual Meeting, Christchurch, NZ.

Maharey, S. (2003a). Social Entrepreneur Fund. Hansard, 609, 6259. 
Maharey, S. (2003b). Social entrepreneur panel. Hansard.

Maharey, S. (2004a). Answers to Written Questions. Hansard.

Maharey, S. (2004b). Repositioning of community employment activities.

Maharey, S. (2008, 15-16 October 2008). Building a good society:

Partnerships, inclusion and the New Zealand experience. Paper presented at the Partnerships for social inclusion conference, Melbourne, Australia.

Manawatu Standard. (2013, 6 April 2013). Taskforce aiding young into work. Manawatu Standard.

Mann, S. (1986). Introspective Methods: The Social Construction of Mental Processes. Lenguas Modernas, 13, 115-127.

Masdar, N. (2015). The practices of upward accountability in the Malaysian NGO. Economics and Finance, 31(2015), 152-160.

Matthews, L. (1999, 19 June 1999). CEG works, so why change it? The Evening Standard, p. 2.

Maxwell, R. (1991a). Achievement of Employment Objectives. (4 December 1991). Wellington.

Maxwell, R. (1991b, 13 March 1991) Enterprise Assistance Programme Review/Interviewer: H. Hancock. Parliamentary Questions (Vol 6), Hansard.

Maxwell, R. (1991c). Establishment of Community Employment Group within the Department of Labour: Progress Report. Wellington.

Maxwell, R. (1991d). Report of Progress. (20 December 1991).

Maxwell, R. (1992a). Monthly Report: January. (4 February 1992).

Maxwell, R. (1992b). Possibilities for rationalisation of business development and community employment and development schemes. (4 May 1992).

Maxwell, R. (1992c). Report of the Employment Taskforce Visit to Eastern Bay of Plenty - April 1992. (4 May 1992).

Maxwell, R. (1996). Exit management from selected CEG national initiatives: Business Grow. (23 August 1996).

Mayors Taskforce for Jobs. (2000, 6-7 April 2000). Mayors Taskforce for Jobs Christchurch Launch 6-7 April 2000 Summary. Paper presented the Mayors Taskforce for Jobs, Christchurch, NZ.

Mayors Taskforce for Jobs. (2001). Strategy 2001-2002.

Mayors Taskforce for Jobs. (2002). Election Employment Policy.

Mayors Taskforce for Jobs. (2003a). Administration Group Conference Call Minutes 7 July 2003.

Mayors Taskforce for Jobs. (2003b). Annual Report July 2002 to June 2003. Mayors Taskforce for Jobs. (2003c). Creating Employment for Young People in Your Community: Ideas and Solutions. 
Mayors Taskforce for Jobs. (2003d). Meeting Notes: Wellington Meetings 17/18th September 2003.

Mayors Taskforce for Jobs. (2003e). Ministers Meeting 17th September 2003.

Mayors Taskforce for Jobs. (2003f). Minutes - Administration Group Conference Call 3rd November 2003.

Mayors Taskforce for Jobs. (2003g). Minutes - Administration Group Conference Call 6th October 2003.

Mayors Taskforce for Jobs. (2003h). Notes: Core Group Meeting 17th June 2003.

Mayors Taskforce for Jobs. (2003i). Youth Employment Projects: March 2003.

Mayors Taskforce for Jobs. (2003j). Zone Report.

Mayors Taskforce for Jobs. (2004a). Administration Group Conference Call 16th February 2004 - Minutes.

Mayors Taskforce for Jobs. (2004b). Administration Report November 2004.

Mayors Taskforce for Jobs. (2004c). Employment Catalyst Fund: Management Team and Governance Group Roles and Responsibilities.

Mayors Taskforce for Jobs. (2004d). Ministers Meeting.

Mayors Taskforce for Jobs. (2004e). Officials Meeting.

Mayors Taskforce for Jobs. (2005). Mayors Taskforce for Jobs Strategy 2005-2006

Mayors Taskforce for Jobs. (2006a). Annual Report - June 2006

Mayors Taskforce for Jobs. (2006b). Strategic Plan 2006-07.

Mayors Taskforce for Jobs. (2007a, 14 Oct 2007). Mayors Taskforce for Jobs - Obligations. Retrieved 29 Jul 2018 from https://web.archive.org/web/20071014180726/http://www.mayorstaskfo rceforjobs.co.nz/who/obligations.html

Mayors Taskforce for Jobs. (2007b). Toolkit Luanch and Signing of Memorandum of Understanding. Retrieved 9 March 2007 from https://web.archive.org/web/20070309231710/http://www.mayorstaskfo rceforjobs.co.nz:80/activities/5Dec.html

Mayors Taskforce for Jobs. (2008). Annual Report to 30 June 2008.

Mayors Taskforce for Jobs. (2009). Newsletter May 2009.

Mayors Taskforce for Jobs. (2010a). Mayors release report into modern apprenticeships [Press release]

Mayors Taskforce for Jobs. (2010b). Newsletter March 2010. 
Mayors Taskforce for Jobs. (2010c, March 2010). Rangatahi Leadership Programme - Marcus Akuhata-Brown. Mayors Taskforce for Jobs Newsletter March 2010.

Mayors Taskforce for Jobs. (2011). 2011 Annual Report

Mayors Taskforce for Jobs. (2013a). Every NZ Mayor now a Mayors Taskforce for Jobs Member [Press release]

Mayors Taskforce for Jobs. (2013b). Mayors Taskforce for Jobs. from https://web.archive.org/web/20131103014338/http://www.mayorstaskfo rceforjobs.co.nz/

McCardle, P. (1997). Community Broker Organisations Up and Running [Press release]

McCardle, P. (1999, 28 April 1999). [Representation of the Community Employment Group].

McCracken, H. (2008, 2 April 2008). Banks slams youth taskforce. Clutha Leader.

McGuire, M. (2006a). Collaborative Public Management: Assessing What We Know and How We Know It. Public Administration Review, 66, 33-43.

McKegg, K., et al. (2013). He Oranga Poutama: What we have learned. Wellington, NZ: Sport New Zealand

McKenzie, A. (2016). Social Assistance Chronology. Wellington: Ministry of Social Development.

McKinlay, P. (2006). The challenge of Democratic participation in the community development process. Community Development Journal, 41(4), 492.

Merriam, S. (1998). Qualitative Research and Case Study Applications in Education: Revised and Expanded from Case Study Research in Education.

Meyer, C. (2001). A case in case study methodology. Field Methods, 13(4), 329-352.

Milne, J. (2004, 21 March 2004). Boss of questionable firm gets $\$ 20,000$ grant. Sunday Star Times.

Ministry for Culture and Heritage. (2016, 12 July 2016). 1996 and beyond the road to MMP. Retrieved 16 March 2017 from https://nzhistory.govt.nz/politics/fpp-to-mmp/1996-and-beyond Ministry of Justice. (2010). The New Zealand crime and safety survey: 2009: Main Findings Report. Wellington.

Ministry of Social Development. (2003a). Mayors' Task Force - Initiative Details.

Ministry of Social Development. (2003b). Newsletter June 2003.

Nelson Mail. (2007a, 24 April 2007). Mayor hits out at claims. The Nelson Mayor. 
Nelson Mail. (2007b, 8 May 2007). Mayor seeks meeting to discuss party deaths. The Nelson Mail.

New Zealand Government. (1995). Focus on Employment. Wellington, NZ.

New Zealand Government. (2001a). Tracking secondary school leavers career options [Press release]

New Zealand Government. (2001b). Workforce 2010. Wellington, NZ.

New Zealand Government. (2003). Jobs Jolt will get more New Zealanders into work [Press release]

New Zealand Government. (2007). Funding boost for innovative council youth project [Press release]

New Zealand Herald. (2004, 30 September 2004). Banks, Hubbard, Fletcher debate the issues. New Zealand Herald.

New Zealand Herald. (2005b, 3 December 2005). Mayors back $\$ 12$ minimum wage. New Zealand Herald.

New Zealand Herald. (2007, 23 April 2007). Mayors give up target date to end teen joblessness. New Zealand Herald.

New Zealand Labour Party. (1999). Mayors express concerns about fate of CEG [Press release]

New Zealand Labour Party. (2012). Local Government changes ignore needs of provincial NZ [Press release]

NZPA. (1998). CEO for new dept named [Press release]

O'Brien, M. (2010). Review of Collaborative Governance: Factors crucial to the internal workings of the collaborative process. Ministry for the Environment.

O'Leary, R., \& Vij, N. (2012). Collaborative Public Management: Where have we been and where are we going? American Review of Public Administration, $X X(X), 1-16$

O'Regan, K. (1996). [Exit management from selected CEG national initiatives: Mature Employment Service].

O'Toole, L. (1997). Treating Networks Seriously: Practical and ResearchBased Agendas in Public Administration. Public Administration Review, 59(3), 187-197.

Office of the Chief Executive Department of Labour (1991). [Community Employment Group].

Ostrom, E. (1990). Governing the commons. New York: Cambridge University Press.

Ostrom, E. (1996). Crossing the great divide: Coproduction, synergy, and development. World Development, 24(6), 1073-1087. doi:10.1016/0305750X(96)00023-X 
Ouchi, W. G. (1980). Markets, Bureaucracies, and Clans. Administrative Science Quarterly, 25(1), 129-141. doi:10.2307/2392231

Pfeffer, J. (1982). Organizations and Organization Theory. Marshfield, MA: Pitman.

Pierre, J., \& Peters, B. (2005). Governing complex socienties: trajectories and scenarios. Hampshire: Palgrave MacMillan.

Radio New Zealand (Writer). (2004). Community Employment Group to be disestablished.

Radio New Zealand. (2007, 21 May 2007). Mayors Reax. Radio NZ.

Rankin, C. (1999). Work and Income NZ: Report on the nature and purpose of the review of community employment. (17 May 1999).

Rasmussen, E., \& Beer, J. (2000). Chronicle. New Zealand Journal of Industrial Relations, 25(2), 215-231.

Reeves, P. (2004, 21 December 2004). [Hui Taumata 2005].

Rich, K. (2004a). Community Employment Group and Hip Hop. Hansard, 616, 11920.

Rich, K. (2004b). Further information on the Community Employment Group. Hansard, 617, 12973.

Rich, K. (2004c). Let's have hip-ops, not hip-hop [Press release]

Robinson, M. (1992, 26 February 1992). [OHTs for submission to Minister of Employment].

Ronk, L. L. (1993). Gender gaps within management. Nursing Management, 24(5), 65.

Rowe, G., \& Frewer, L. J. (2000). Public Participation Methods: A Framework for Evaluation. Science, Technology, \& Human Values, 25(1), 329. doi:10.2307/690198

Saunders, A. (2005, 10 May 2005). Hip-hop agency's last hurrah. The Dominion Post, p. 1.

Schick, A. (1998). Why most developing countries should not try New Zealand reforms. The World Bank Research Observer, 13(1), 123-131.

Scoppetta, A., \& Buckenleib, A. (2018). Tackling Long-Term Unemployment through Risk Profiling and Outreach.

Scott, G. (1995). Place Struggles: A critical analysis of changing patterns of work, unemployment and local development in New Zealand and the West Coast of the South Island. (Doctor of Philosophy in Geography), Canterbury University, Christchurch.

Scott, T. A., \& Thomas, C. W. (2017). Unpacking the Collaborative Toolbox: Why and When Do Public Managers Choose Collaborative Governance Strategies? Policy Studies Journal, 45(1), 191-214.

doi:http://dx.doi.org/10.1111/psj.12162 
Smith, M., et al. (2006). Corporate Governance in a Collaborative Environment: what happens when government, business and civil society work together? Corporate Governance: An International Review, 14(3), 159-171. doi:10.1111/j.1467-8683.2006.00496.x

Social Services Select Committee. (2003). 2003/04 Estimates Vote Employment Report of the Social Services Committee.

Social Services Select Committee. (2004). Briefing from the Department of Labour Communtiy Employment Group on community employment programmes.

Southland Times. (2000, 6 July 2000). Casting vote. The Southland Times. Spoonley, P. (2008). Utilising a Demand-led Approach in a Local Labour Market. Local Economy, 23(1), 19-30. doi:10.1080/19401490801906536

Steurer, R. (2009). Sustainable development as governance reform agenda: an aggregation of distinguished challenges for policy-making. Vienna.

Stone, M., \& Ostrower, F. (2007). Acting in the Public Interest? Another Look at Research on Nonprofit Governance. Nonprofit and Voluntary Sector Quarterly, 36(3), 416-438.

Sunday Star Times. (1999, 1 August 1999). Jobs lost. Sunday Star Times.

Susskind, L., \& Cruikshank, J. (1987). Breaking the Impasse: Consensual approaches to resolving public disputes: Basic Books.

Taylor, K. (2004, 23 March 2004). \$115,000 for a second Maori TV station. New Zealand Herald.

Te Puni Kokiri. (1999). Follow up review of the Department of Labour's service delivery to Maori. Wellington, NZ: Te Puni Kokiri.

Te Uepu Hapai i te Ora. (2019). He Waka Roimata: Transforming our criminal justice system. Wellington: NZ Government.

Tertiary Education Commission. (2004). The Tertiary Education Commission (TEC) Interaction Survey

The Jobs Research Trust. (2000a, 26 September 2000). Mayors sign up partnership with the Jobs Research Trust. Retrieved 7 April 2017 from http://www.jobsletter.org.nz/mtfjobs/mtfjobs18.htm

The Jobs Research Trust. (2000b). Mayors Taskforce for Jobs Goals and Objectives. Mayors Taskforce for Jobs. Retrieved 6 April 2017 from http://www.jobsletter.org.nz/mtfjobs/mtfjobs00.htm

The Jobs Research Trust. (2002, 31 January 2002). New Zealand Business Council Youth Employment Project. The Jobs Letter. Retrieved 11 April 2017 from http://www.jobsletter.org.nz/jbl16000.htm

The Jobs Research Trust. (2005a, 4 May 2005). Mayors meet with political parties. The Jobs Letter.

The Jobs Research Trust. (2005b, 3 March 2005). Mayors Taskforce meets. The Jobs Letter. 
The Press. (2000, 6 May 2000). Mayors pursue job talks. The Press, p. 4. The Press. (2001, 11 May 2001). Mayors' jobs taskforce questioned. The Press, p. 6.

The Timaru Herald. (2002, 5 October 2002). Signing up gives access to funds. The Timaru Herald, p. 6.

The Timaru Herald. (2012, 8 August 2012). Fears for jobs taskforce. The Timaru Herald.

The Treasury. (2000). Vote Employment. Wellington, NZ.

The Treasury. (2001). Vote Employment. Wellington, NZ.

Theodore, N. (2007). New Labour at work: long-term unemployment and the geography of opportunity. Cambridge Journal of Economics, 31(6), 927.

Troup, H. (1995). Employment Task Force: Community Employment Group role. (26 September 1995).

Turia, T. (2000). Closing the gaps [Press release]

Twentyman, M. (2011, 21 June 2011). Mayor defends MPs ejection.

Waikato Times.

Walker, A. (2006). Child Protection and Interagency Collaboration. Policy Quarterly, 2(4), 29-37.

Walker, P., \& Shannon, P. (2011). Participatory governance: towards a strategic model. Community Development Journal, 46(S2), ii63-ii82.

Weber, E. P., \& Khademian, A. M. (2008). Wicked Problems, Knowledge Challenges, and Collaborative Capacity Builders in Network Settings. Public Administration Review, 68(2), 334-349.

West, R. (2004, 23 April 2004). PM thanks mayors for efforts on youth jobs. The Daily News.

Whimp, G. (2008). The Great Hip Hop Scandal. The Journal of New Zealand Studies, 6(7).

Williams, S. (2000, 15 June 2000). Workers' group applauds switch. The Evening Post, p. 11.

Yin, R. K. (1989). Case study research: Design and methods. London: Sage Publications. 